University of Louisville

ThinkIR: The University of Louisville's Institutional Repository

Electronic Theses and Dissertations

$12-2020$

\title{
Mitigating black claustrophobia: space, trauma, and healing modalities in the postcolonial narrative.
}

\author{
Saleema Mustafa Campbell \\ University of Louisville
}

Follow this and additional works at: https://ir.library.louisville.edu/etd

Part of the Africana Studies Commons, Literature in English, North America, Ethnic and Cultural Minority Commons, and the Race, Ethnicity and Post-Colonial Studies Commons

\section{Recommended Citation}

Campbell, Saleema Mustafa, "Mitigating black claustrophobia: space, trauma, and healing modalities in the postcolonial narrative." (2020). Electronic Theses and Dissertations. Paper 3541.

https://doi.org/10.18297/etd/3541

This Doctoral Dissertation is brought to you for free and open access by ThinkIR: The University of Louisville's Institutional Repository. It has been accepted for inclusion in Electronic Theses and Dissertations by an authorized administrator of ThinkIR: The University of Louisville's Institutional Repository. This title appears here courtesy of the author, who has retained all other copyrights. For more information, please contact thinkir@louisville.edu. 
MITIGATING BLACK CLAUSTROPHOBIA: SPACE, TRAUMA, AND HEALING MODALITIES IN THE POSTCOLONIAL NARRATIVE

\author{
By \\ Saleema Mustafa Campbell \\ B.A., Emory University, 2003 \\ M.A.T., Agnes Scott College, 2007 \\ M.A., Kentucky State University, 2011 \\ A Dissertation \\ Submitted to the Faculty of the \\ College of Arts and Sciences of the University of Louisville \\ in Partial Fulfillment of the Requirements \\ for the Degree of \\ Doctor of Philosophy \\ in Pan-African Studies
Department of Pan-African Studies
University of Louisville
Louisville, Kentucky

December 2020 
Copyright 2020 by Saleema Mustafa Campbell

All rights reserved 

MITIGATING BLACK CLAUSTROPHOBIA: SPACE, TRAUMA, AND HEALING MODALITIES IN THE POSTCOLONIAL NARRATIVE

\author{
By
}

Saleema Mustafa Campbell

B.A., Emory University, 2003

M.A.T., Agnes Scott College, 2007

M.A., Kentucky State University, 2011

A Dissertation Approved on

November 17, 2020

by the following Dissertation Committee:

Mawuena Kossi Logan, Ph.D., Chair

Theresa Rajack-Talley, Ph.D.

Tyler Fleming, Ph.D.

Karen Chandler, Ph.D.

Ann Elizabeth Willey, Ph.D. 


\section{DEDICATION}

This dissertation is dedicated to Mildred Hill McGriff, Rahkiya Mustafa Armstrong (née Milgene McGriff), Amir Note Mustafa Campbell, Khamisi Kenyatta Campbell, and to those who view their blackness as a self-inflicted wound. May you one day understand the slave ship origins of this trauma. 


\section{ACKNOWLEDGEMENTS}

I would like to thank my extraordinary chair, Dr. Mawuena Kossi Logan, for his expertise, dedication, guidance, and supreme patience. It has been my pleasure to learn from you. I would also like to thank my other committee members, Dr. Rajack-Talley, Dr. Fleming, Dr. Chandler, and Dr. Willey for their assistance, kindness, and consideration. With my entire heart, I must also acknowledge my husband, Khamisi, and son, Amir, for their endless love and support. There have been no greater sources of strength for me than you two. Many thanks to my family in Atlanta, Georgia, Tobago, and my adopted family here in Kentucky, especially my Sunday school class at Immanuel Baptist Church and my wonderful colleagues at Kentucky State University. Special thanks to Keymia Morrow, Jasmine Karlowski Gomez, Pepi Lovell, Kristine Hodges, Catrice Barrett (for the lifetime inspiration), Thuvia P. Jones, Susan Taylor, Danyelle Kincaid, Shannon Brogan, Dantrea Hampton, Doris Hampton-Young, and Erin Gillesmy ladies of light and intellect. I would also like to express gratitude to my graduate cohort brothers, Dr. JC Campbell and Dr. Antron Mahoney. Through every obstacle, we have had each other, and I am forever indebted to you both. We made it! Finally, I

celebrate the teachers and professors who will remain in my heart forever: Mrs. Albrecht, Tamela Yeargin, Joanne Carey, Rudolph Byrd, Deloris P. Aldridge, Leroy Davis, Nathan McCall, Catherine Manegold, Leslie Harris, Wole Soyinka, Willie Tolliver, and Joy 
Gleason Carew. Legends extend beyond all spatial configurations and limits of time, and it is a gift to progress your legacies! 


\title{
ABSTRACT \\ MITIGATING BLACK CLAUSTROPHOBIA: SPACE, TRAUMA, AND HEALING MODALITIES IN THE POSTCOLONIAL NARRATIVE
}

\author{
Saleema Mustafa Campbell
}

December 10, 2020

This dissertation examines the space or spaces of blackness and the black body in the United States. This nation was shaped by the institution of slavery, and its greatest legacy is the trauma that still resonates in social structures and spaces complicating the lived experiences of many. The various responses to these traumas are documented in literary form by authors who serve as cultural witnesses. The narratives featured in this research project, collectively and individually, offer a voice to the traumatic plight of individuals in the U.S. who struggle to contemplate and rectify the traumas of this nation's past. This research demonstrates the relationship between lived space and behavior and also how space can reinforce power and hegemony. This particular form of analysis can offer new perspectives to the field of postcolonial theory and criticism. From slave narratives to Afro-futuristic literature, this project, therefore, endeavors to examine the motif of space in these various texts as an investigation of the postcolonial dilemmas of race as a social construction, racialization, inequality, and oppression. Additionally, this research aims to emphasize the power of literature to effect change and healing. Chris Tiffin and Alan Lawson adumbrate this power of literature when they argue that “[i]mperial relations may have been established initially by guns, guile and disease, but 
they were maintained in their interpellative phase largely by textuality..." (3). The relationship between space and postcolonial theory is not new, but the changing global landscape creates new opportunities to expand this platform. In conclusion, this project considers the profound possibilities for spatial and postcolonial theory to stimulate agency and greater cultural awareness in other societies and other global spaces. 


\section{TABLE OF CONENTS}

Page

ACKNOWLEDGEMENTS iv

ABSTRACT vi

CHAPTER I: Introduction. 1

Theoretical Approaches and Literature Review 5

New Theoretical Frontiers and Postcolonial Space: Contributions to Scholarship..30

CHAPTER II: Antebellum Spatial Analysis: Locating Traumatic Space in the Slave

Narrative

The Production of Space .............................................................................. 43

The Implications of Space in the Narrative of the Life of Frederick Douglass.....49

Exposing Spatial Networks in the American Institution of Slavery in Twelve Years a Slave: Narrative of Solomon Northup .....................................57

Traumatic Space and Loopholes in Incidents in the Life of a Slave Girl

CHAPTER III: Passing through Traumatic Spaces of Blackness and the Black Body in

Literature of the New Negro Era and Harlem Renaissance Movement .73

New Racialized Spatial Arrangements in the Postbellum Period..........................76

Hegemonic Persistence in the Coding of Blackness and the Black Body .80

Black Identity and the Exploration of Passing as a Mediating Force in the

Literature of the New Negro Era and Harlem Renaissance Movement.

Transcending Black Spatial Boundaries in Chesnutt's The House behind the

Cedars

Negotiating Racialized Space in Nella Larsen's Passing

Transcending the Space of the Black Body in George Schuyler's Black No More

The Danger of the White Gaze and Social Perception 129 
CHAPTER IV: "Rememory" and the Ghosts of the Past: The Signification of Enslavement in Postbellum Social Spaces and Inherited Trauma in the Neo-slave Narrative 133

"Rememory" and Spatial Disruption in Toni Morrison's Beloved 135

Beloved and the Hallowed Spaces of the Postbellum South 143

Beloved's Theme of Community Recognition and Healing 157

Kindred and the Tenuous Space of Blackness in an Amerikkkan Homeland .....158

Kindred and Safe Passage in the Sweet Land of Liberty.... .162

Antebellum Racialized Power Dynamics and Psychophysical Entrapment 167

A Homeland of Slave Relics and Inherited Traumas..... .171

A Lesson before Dying and the Black Prisoners of their Environments 175

Indicators of Post-Traumatic Slave Syndrome in Jefferson and Grant 178

Black Person versus Environment in A Lesson before Dying. 184

Traumatic Space, Loopholes, and New Pathways

CHAPTER V: Reimagining Contested Space, Articulating Liberation, and Projecting Healing in Afro-futuristic Literature

Societal Collapse, $21^{\text {st }}$ Century Spatial Entrapment, and Reimagining Contested Space in Octavia Butler's Parable of the Sower. .204

Cultural Loss, Black Identity, Black Body as Hero's Shield, and the Repurposing Plantation Space as Homeland in Octavia Butler's Fledgling. .213

Repurposing Plantation Notions with Black Caricatures in Fledgling..... .219

Fledgling's Ina Society as Homeland Model. .230

CHAPTER VI: Conclusion .234

REFERENCES .247

APPENDIX .258

CURRICULUM VITA .271 


\section{CHAPTER I}

\section{INTRODUCTION}

"We live in a space which is radically in question for us, that makes our barest speaking a problem to itself. For voice does issue in part from civil space. And alienation in that space will enter and undercut our writing, make it recoil upon itself, become a problem to itself"

-Dennis Lee, postcolonial theorist, 1974

\section{Mitigating Black Claustrophobia: Space, Trauma, and Healing Modalities in the}

Postcolonial Narrative is a research project that began as a response to an intellectual challenge, which was essentially to expand the social responsibility of this work-to find the "Black in the green (environmental studies)" or a perspective of ecocriticism and theory that would intrigue and rouse Black communities. Initially, I wanted to investigate environments and physical spaces involved in colonial conflicts and write about their need for agency as an ecological campaign. For example, I wanted to hear from and speak for the "jungles" in the "Heart of Darkness". I was inspired by the work of the environmentalist and writer Ken Saro-Wiwa, who spoke out against the environmental degradation that the multinational petroleum industry was causing in his homeland of Ogoniland, Nigeria, a cause for which he would lose his life.

To be clear, I did not translate this intellectual challenge as a promotion of environmentalism and/or conservation because, historically, Black people throughout the diaspora have demonstrated long-standing concerns for the environment. I translated the goals of this new research focus to include, demonstrating the socio-spatial expanse of 
oppression, increasing spatial studies aligned with decolonization campaigns, and using postcolonial narratives to show physical space as a tool of oppression.

Additionally, this academic leap felt reasonable to me because at the time that I was moved in this new research direction, I had been transfixed by Tambu, the protagonist in Tsitsi Dangarembga's novel, Nervous Conditions, and the persistent anxiety that accompanied her in every space, new and familiar, that she entered. That anxiety was familiar, as was the freedom that Harriet Jacobs claimed by hiding in the crawl space of her grandmother's attic for seven years in Incidents of the Life of a Slave Girl. As a Black woman, the pleasure of hiding was well-known to me too; it is at the root of code-switching. There is control and protection in hiding. Eventually, what I realized was that these characters were speaking directly to this notion of space as a tool of the empire or a ruling authority. They were both speaking to a Black narrative that spanned age, geographical location, time, class, and social condition.

Then my grandmother, Mildred Hill McGriff, entered the conversation and appeared to me in a dream and solidified my research focus and my path forward. In this dream, my grandmother was sitting at our dining room table where she was always fixed when she visited. That was the entire dream. Her appearance, as I have interpreted it, directed me to the main investigation of this project. She did not utter a single word, but I recalled immediately in seeing her at our kitchen table that she rarely left our home when she was in town. She suffered from what I refer to in this project as Black claustrophobia or an anxiety triggered by close proximity to a historical site of racial conflict or pain, which results in an irrational fear of, cautiousness towards, and/or reclusiveness from public spaces. 
Dream interpretation has a long history in human society. In ancient times, many cultural groups believed that dreams were prophetic (long before Freud published his dream analysis studies). Dreams have meaning and value for me as well. What was hidden in this particular dream of my grandmother was her perspective then, which she never discussed with her grandchildren. She believed the white world was not to be trusted and only cautiously approached, so she frequently confined herself. That was what she was doing in that moment at the kitchen table. Furthermore, I specifically remember her demonstrative resistance to our holiday and weekend celebrations at Stone Mountain Park, the symbolic birthplace of the Ku Klux Klan and home to a half milewide carving of the Confederate leaders, Jefferson Davis, Robert E. Lee, and Stonewall Jackson.

Mildred Hill McGriff provided no answers, but I was left with the following research questions: how do I tell her story and explain her Black trauma? And how do I use narratives to show the range of Black experiences, our humanity, and avoid framing us by our suffering and our lack? How do I continue to rail against the economic and ideological forces that control the dominant narrative and constrain Black voices while showing the construction of hegemonic and racialized social spaces - the kinds of spaces that my grandmother perceived and regularly avoided because she felt Tambu's nervous anxiety and like Harriet Jacobs found solace in hiding? Engaging these questions would require a collaboration of several methodological approaches.

In consideration of these ambitions, this dissertation essays to create a bridge between spatial theory, trauma theory, and postcolonial theory and literature. Trauma and 
displacement have been key themes in postcolonial literature, but how trauma is transposed to actual space as a result of colonialism and its numerous enterprises offers a new frontier to explore in literary criticism. Postcolonial literature in confrontation with colonialism and other related forms of subjugation historically has promoted new perspectives related to spaces and sites of conflict, but those perspectives tend to address the human to human (and institution to human) actions related to the continued exploitation of people.

This research uses the concept of spatiality in the imagined space (the text), explored through the scope of causal analysis, and applies it to real/physical space. Space is "the physical setting in which everything occurs", which is uniquely different from place (Meskell and Preucel 215). Place is "a social outcome of valuing space" [which involves] "transform [-ing] it into a humanized landscape" (215). This research will help to demonstrate and evaluate the shared bond of lived space, behavior, and experience with the intent of explaining how space can reinforce power relations and dominance. Space is not an abstract concept void of significance; it is very much a construction of societal design. For this reason, the work of Henri Lefebvre, a ground-breaking sociologist and theorist of the twentieth century especially on the subject of social space, is central to this research.

In The Production of Space Lefebvre, argues that space is a product of people and "subsumes things produced and encompasses their interrelationships in their coexistence and simultaneity" (73). Space is fundamentally social, and Lefebvre questions the implications of what has been inscribed in actual space. For the enslaved and colonized, many spaces have been coded in trauma, and it is these spaces, which are at focus in this 
research. This particular form of analysis offers new perspectives in the field of postcolonial theory, expanding its relevancy, by accounting for the impact of colonization on space and its evolving dynamic with marginalization in postcolonial settings. Additionally, postcolonial literature explored in this mode unveils modern traumatic cultural formations by recognizing trauma in various configurations, and it could potentially inspire healing among those affected. Fundamentally, slavery/colonization inflicts and manifests many wounds, and this research endeavors to excavate the lingering traumas in various spaces of colonial conflict.

\section{Theoretical Approaches and Literature Review}

One of my most beloved places to go exploring nature, as a child, was Stone Mountain Park: it sits just outside of the city of Atlanta in Georgia. There exists the largest exposed quartz monzonite rock dome in the world. Surrounded by acres of the greenest trees and the most pristine lakes and streams, the mountain gave my eight-yearold imagination all of the inspiration it had ever required. I would run on the park's many trails and dig up rocks to scream at and run from the infinite multiplicities of insects that I would find hiding underneath them. Stone Mountain was also one of my favorite places to visit on a holiday. Sadly, my grandmother, who often lived with us during our summer breaks, would never join us there; she would remain at home whenever we planned to visit the park. For her, the park only conjured up memories of a not-so-distant, traumatic past. She perceived the park as a memorial to a deep-rooted history of racial bigotry and violence in the American South. Where I saw branches on trees ripe for climbing, she recalled bodies swinging surrounded by crowds of gawking onlookers. Where I saw 
rolling hills perfectly sculpted for sliding and tumbling, she remembered crosses burning in honor of the Confederacy and the Mount Rushmore-resembling memorial of Confederate leaders carved on the mountain's side; to her this place was a celebration of the white south. Those trips to Stone Mountain Park would never bring her joy, for they caused an overwhelmingly dark and alienating experience in and away from that space; there could be no comfort where the persecution of so many had been celebrated. As stated earlier, my grandmother was suffering, as so many other Black Americans, from a form of black claustrophobia.

My dissertation pulls from theories that ultimately work to therapeutically excavate these historical sites, compelling truths about them into the mainstream and altering the public recognition of these spaces as a means of healing. My research is concerned with mending wounds; my grandmother's recurring trauma triggered by the intrusion of remembrances of past racial violence into her present circumstances provides for an important occasion for activism among those working towards the cause of restorative justice, a cause that is essentially a war with society for greater reconciliation and comfort. Additionally, this kind of study of lived experience or how human beings investigate and structure the world engages a phenomenological research approach - - the core of the inquiry of this research. It is at the core of the inquiry of this research. Experience is a sensory response to phenomena, and these responses must be interpreted and explained. What we experience shapes what we know, and, according to Michael Quinn Patton, phenomenological study is "the focus on meaning making as the essence of human experience" (115-116). The lived experiences of the human being provide a wide map of pains, joys, and mysteries for exploration. 
In his 1962 essay entitled "The Creative Process," James Baldwin argued that the artist "cannot allow any consideration to supersede his responsibility to reveal all that he [or she] can possibly discover concerning the mystery of the human being" (670). He would suggest that the role of the artist (through his or her art) is to expose all of the instability in the world in order to procure stability. This brand of social responsibility that Baldwin describes is precisely what distinguishes, to a large extent, the postcolonial author from his/her other literary and creative counterparts, the responsibility of maintaining a "never ceas[-ing] war" with society for "its sake and his [or her] own" (670).

Within the scope of this responsibility, postcolonial authors, in opposition to socio-cultural and ideological-political hegemonic constructions and formations, have the opportunity and duty to affect ways for their readers to understand spaces and recognize sites of conflict. It is a goal of my research to demonstrate how the work that they produce influences what the readers remember of their societies and of themselves. One perspective of Stone Mountain Park is that it is an amazing holiday escape; another is that it is an enclave of painful, brutal memories. Both perspectives are equally valid, but unfortunately both are not equally validated in the public sphere. This important work belongs to postcolonial authors, for they give their texts agency or the ability to modify this imbalance. These texts have the power to assert cultural integrity, revise history, and reclaim cultural spaces and places. There is a capacity for healing imbedded in the postcolonial authors' work; they are often conscious of the text's power to define, affirm, exclude, and/or include, and they wield this consciousness tactfully. In this dissertation, I explore the postcolonial author's long history of empowering texts; the destination of the 
message is at focus for the postcolonial author, and it holds equal value to the message's origin, in contrast to literary critic Roland Barthes' argument in his classic essay "Death of the Author" (148). Although I acknowledge the danger involved in not privileging the origin of the message as Barthes suggests, the important work of the postcolonial author necessitates that the origin, message, and destination be held in equal regard.

One of the destinations at focus in this research is the postcolonial setting: specifically how authors use literature to explore issues related to spatiality in these settings, or sites of encounter, while simultaneously empowering the written word as a form of activism in order to expose some of the important postcolonial dilemmas pertaining to race, racialization, oppression, trauma, and social alienation. Postcolonial texts have always worked to make public the range of colonial and neocolonial issues that covertly and overtly fuel postcolonial sites of contestation, and spatiality studies reveal both postcolonial and poststructuralist concerns. One of the forefathers of postcolonial theory, Edward Said, explores the relationship between empire and geography in Orientalism and paved the way for an analytical approach in postcolonial literature that more specifically engages the role of language, the imagination, and geography in systems of domination. He argues that "some distinctive objects are made of the mind, and that these objects, while appearing to exist objectively, have only a fictional reality" (54-55). He suggests that objective space is far less important than the "imaginative or figurative value" that gives it an emotional meaning (54-55). Social theorist and geoepistemologist, Michel Foucault, suggested that "a whole history remains to be written of spaces - which at the same time would be the history of powers" (45). 
Relatedly, spatial theory is the study of space and place. It involves, but is not limited to, geography, material objects, the built environment, social institutions, the body, imaginary sites, and ideological positions (Meskell and Preucel 215). It provides this research with the definitions for investigation as well as the ability to view space and place as social constructions. In 1974, when Henri Lefebvre pioneered the study of space in The Production of Space, he influenced theorists towards a "spatial turn" and compelled them to consider space in new ways. No longer was space an abstract concept, but it reflected lived experiences and held significance. Those who are victims of oppressive spaces today may be the conductors of oppression tomorrow, and social spaces are a new frontier for excavation and reclamation in this battle against neocolonialism.

It is the global landscape that creates this new frontier. As literary critic, Simon Gikandi, explains, many of the once clearly defined boundaries between the center and the periphery in the new global landscape are now ambiguous (627-33). For this reason, globalization and postcoloniality have an unreconciled relationship. The theme of spatiality and related spatial theories participate in the conversation about the evolving globalized landscape as well as the interactions between nature and human beings. Space is essential to the postcolonial experience, and it offers a means of exploring postcolonial dilemmas, especially around the subject of land conflicts. The notion that space and location are so closely linked to identity formation and how identity is defined by others presents an additional opportunity for postcolonial literature to challenge and redefine existing and taken-for-granted epistemologies. Discussions related to the theme of space provide greater attention to the implications of actual geographical space. Postmodern 
political geographer, Edward William Soja, introduced the theory of thirdspace in 1996, as a means of helping to bridge the discussion between real and imagined spaces (57). He explains "thirdspace as an-Other way of understanding and acting to change the spatiality of human life, [or] a distinct mode of critical spatial awareness that is appropriate to the new scope and significance...of spatiality-historicality-sociality" (57). Again, this mode of thinking establishes a link between geographical constructions of space and social, psychological constructions of space. As postcolonial theorist Bill Ashcroft explains, history is embedded in locations and through this process empty space becomes a place, and in the colonial 1 experience, place is in "a continual process of being written" (346). It should be the urgent work of postcolonial authors and the literature that they yield to explore, analyze, and acknowledge the trauma present in the various spaces of lived experience. This research will use the subject of spatiality in literature to highlight the profound possibilities of current and future postcolonial studies to promote greater social awareness and upliftment.

It should be noted that this form of postcolonial study involves cross-cultural criticism or the study of all cultures affected by the imperial process "from the moment of colonization to the present" (Ashcroft et al. 2). This research will consider literature from different geographical spaces in the United States as well as real, fictional, and Afrofuturistic spaces at the intersection of culture and technology. There is a "continuity of preoccupations throughout the historical process initiated by European imperial aggression" in all of these spaces (2). Literature of the United States is at the center of

\footnotetext{
${ }^{1}$ For the purposes of this dissertation, the terms colonial and colonialism involve the forcible subjugation and domination of many. It begins with the trans-Atlantic slave trade and includes those who have been displaced by this process as well.
} 
this discussion, irrespective of the nation's current power and hegemonic, global influences, because its "post-colonial nature has not been generally recognized"(Ashcroft 2). There are communities of people, African Americans for example, who are still developing national traditions in the United States and consequently rejecting essentialist ideologies and rebuffing the Centre's promotion of exclusivity while working to establish themselves as a "self-constituting entity" (18). As Hazel Carby asserts regarding the alienation that Black citizens of the British Commonwealth feel within the British national discourse:

Citizens who are imagined as being without a history other than that granted by the limited terms of existence defined as 'subject peoples' but whom I regard as modern and modernising people, people who through their conscious and deliberate efforts to liberate themselves from colonialism through migration can be described as postcolonial residents in the metropolitan heart of empire (226229).

Carby ponders: how can they explain their "existence and fix [their] racialized meaning in [their] historical moment?" (230).

African Americans, similarly to Blacks throughout the diaspora, represent the postcolonial "Third World" fighting against oppressive forces inside (but truly outside) of the so-called first-world landscape that they occupy. They are kindred to those in search of a space of belonging; therefore, they also suffer the consequences of the imperial process. These literatures are united and distinctively post-colonial because they elevate marginalized voices and identities from various sites of conflict. Deborah Madsen elucidates the significance of recognizing the common struggle highlighted by these marginalized voices:

The definition of American literature as synonymous with the literature of the American invader-settler culture seems to me to represent a triumph of the 'universalising impetus of imperialism' and the 'homogenising drive of 
[American] nationalism' as well. Only in a comparative framework can the colonial and post-colonial condition of ethnic communities within the borders of the United States, communities such as the Native American tribes, Chicano/as, Afro-Hispanic and African American communities, be recognized for precisely what they are. In comparison with the post-colonial expression of Australian Aboriginal writers, Canadian First Nations writers, New Zealand Maori writers, indigenous African writers, the work of American Indian writers assumes a new set of significances that is derived from a matrix of indigenous experience, and not from the stifling paradigm of sophisticated metropolitan centre versus primitive post-colonial margin. This is important, because the values assigned to literary expression in native cultures may share more in common with each other than with the values of Western literary representation. This is even more important than the shared experiences of imperial domination, cultural catastrophe, genocide, and erasure. That the voices should speak is more important, ultimately, than that of which they speak (10-11).

Although postcolonial literature attempts to do the important work of elevating these marginalized voices by addressing the issues and consequences of colonization, it is critical to remember that this literature is its own metanarrative and is also subjective. These voices do need an empowering influence, but no written account is truly independent of partiality because embedded in it is someone's perspective. However, achieving the impossible standard of objectivity is not a major aim of postcolonial resistance in literature; rather, this literature's aspirations are aligned with a desire to increase a diversity of perspectives. Authors in postcolonial societies or writers who have been shaped by the imperial process can offer new representations and challenges to Euro-American "universal" and/or normative epistemologies/knowledge systems in order to promote the inclusion of diverse voices - voices that could potentially alter our perspectives on lived experiences. Although writers should have the freedom to write with or without a sense of social responsibility, for many of them who respond to their postcolonial landscapes, words can become the invisible bullets in a struggle against oppressive forces. Words captured in various forms of literature can articulate new 
perspectives that reflect unique and diverse cultural experiences. Especially with regard to autobiographical and fictional texts, with their literature, these authors transcend the limitations of other forms of narration to reveal often hidden aspects of the post/colonial experience; their literature can confront very important social issues that have contemporary relevance and historical significance. Their texts help remove wellestablished and/or newly-formed social veils.

The limitless potential of these works to confront significant social issues is grounded in the advent of postcolonial theory. From the formation of this field of study, there have been debates in and outside of the field of literary theory surrounding the meaning of the term 'postcolonial', so it has various definitions depending on the context and the nature of the discussion. Its least complicated denotation is existing or occurring after the end of colonial rule. As a feature of theory, its meaning has become so broad that it can sustain its own academic field of study. This field of study began to grow in importance during the 1970s and continued to rise in the West after the publication of Edward Said's cogent critique of Eurocentric constructions of the Orient in his groundbreaking book, Orientalism.

In this work, Said explores artificial or stereotypical boundaries between the Orient and the Occident. He argues that generalizations lead to misconceptions, and misconceptions create perspectives that extend to the practice of viewing/subjugating 'others.' It is this view of 'others' or outsiders that drives the necessity of postcolonial theory and other forms of analysis. Since the publication and success of Orientalism, and as a reaction to much discourse, debate, and advancement in the realm of theory 
following its publication, the term and the study have grown in greater significance and meaning.

In The Empire Writes Back, Bill Ashcroft, Gareth Griffiths, and Helen Tiffin argue that "literature is one of the most important ways in which new perceptions [and] the day-to-day realities experienced by colonized people have been most powerfully encoded and so profoundly influential" (1). Literature helps to articulate the tensions between the colonized and imperial powers; in this process, it takes on a uniquely political and cultural preoccupation that derives from its desire to assert a clear separation from the influence of that imperial power (2). According to Ashcroft et al, this separation is achieved by postcolonial authors when their literature, which emerged from colonization, "foreground[s] [its] tension with the imperial power" and highlights differences "from the assumptions of the imperial centre" (2). This postcolonial literature speaks to the experiences of people from the cultures along the metaphorical peripheries and margins of Empire. Ashcroft et al suggest that postcolonial literatures developed in corresponding stages of national and regional consciousness (4). As countries and communities attempted to free themselves of their imperial and colonial restraints, the literature of these communities responded to the needs of the people, who desired to assert their cultural differences and values. As Ashcroft et al elucidate, "Language becomes the medium through which a hierarchical structure of power is perpetuated" (7). In order to truly reject this power, they argue, one must develop an effective postcolonial voice. Another noted postcolonial scholar, Ngũgĩ Wa Thiong’o, explains in his book Barrel of a Pen that the postcolonial author must "expose the European audience to the naked reality of the relationship between Europe and the third 
world" (74). It is this same voice of excavation and revelation that is utilized in postcolonial literatures to expose the emotional value of spaces, both literal and figurative, in various communities, for colonialism often displaces people and their memories.

As the literary scholar and critic, Jonathan Culler notes in Literary Theory: A Short Introduction, "literature is the vehicle of ideology...and an instrument for its undoing" (38). Literature, especially prose fiction, historically has been the "activity of the cultural elite", but as Culler suggests, it has also been "the noise of culture as well as its information... and engages readers in the problems of meaning" (40). There are no limits to the awareness that storytelling can promote, for literary representations are never just purely aesthetic because they are always wedded to political and ideological questions and realities. What is important for postcolonial authors is sharing and inclusion. Their perspectives can be revealing and therapeutic, and because the literature comes from the margins, they promote diversity as well. For this reason, it is also vital that postcolonial authors in their writing honor the notion that language belongs to the people; all classifications of people must be included in this designation.

Thus, postcolonial literature's “inclusion” promotes cultural well-being. Theorist Robert J.C. Young states that the field of postcolonialism affirms the rights of human beings to have access to the same cultural and material circumstances (2-4). He argues that anthropological theories legitimized colonial and imperial rule, which enabled the West to define the universal. Postcolonial textual analysis is thus consumed with initiatives that engage an elaboration of the theoretical structures that contest the dominant western ways of viewing things (2-4). Young argues that postcolonial theory is 
a reorientation of this universal experience in terms of its concepts towards perspectives of knowledge conceived outside of the West. Postcolonial theory maintains the goals of validating subaltern knowledge because it attacks the epistemological underpinnings of Western traditions.

In an attempt to minimize the influence of Western traditions and articulate the tensions related to space in postcolonial societies, this research endeavors to examine spatial structures and demonstrate how they can be codified in conflict and trauma. Postcolonial theory informs this type of investigation because it involves a contestation of the dominant ways of seeing things and aspires to reclaim the power to define. In “Writing against Neo-colonialism”, Ngũgĩ said it best: “A people united for democracy can never be defeated and the writer must be part and parcel of that revolutionary unity for democracy, socialism, and liberation of the human spirit to become even more human" (164). Postcolonial literature helps readers understand that colonialism and its various enterprises have not died, but the struggle against these institutions has simply transformed. This research recognizes that spatial structures can participate in these transformed domination systems.

These real world domination systems are indelibly bound to language, so postcolonial theorists must empower language in order to articulate the claims of the traumatized. History/historical writing - the stories that explain the past events of the world and literary texts inform and interrogate each other (Barry 166). The two have a cyclical relationship in which subversive power flows back and forth between them. Accordingly, the literary theory, New Historicism, is vitally important to this research because it forces readers of historical writing or fiction to ask questions about how events 
have been interpreted and what these interpretations might reveal about the interpreter.

New Historicism recognizes and refuses to ignore human complicity in historical writing.

It is a "method based on the parallel reading of literary and non-literary texts" (166).

Peter Barry argues:

New historicists focus attention on issues of state power and how it is maintained, on patriarchal structures and their perpetuation, and on the process of colonization, with its accompanying 'mind-set'...[thus demonstrating] that every facet of reality is texualized... [including] social structures, [which they suggest] are determined by dominant 'discursive practices' (173).

Correspondingly, spaces are among these social structures that are charged in a similar

manner with oppressive agency. As Stephen Greenblatt states:

If there is any inevitability in new historicism's vision of history, it is this insistence on agency, for even inaction or extreme marginality is understood to possess meaning and therefore to imply intention. Every form of behavior, in this view, is a strategy: taking up arms or taking flight are significant social actions, but so is staying put, minding one's business, turning one's face to the wall. Agency is virtually inescapable (15).

Theorists of New Historicism are aware of the subjective investment or the "historicity" in historical writing and recognize that history is not immune to the interplay of power and subversion (166). Old historicism embraced a broad, universal understanding of historical writing and failed to recognize the suppression and/or exclusion of minority literature into the canon, but New Historicism helps to demonstrate the ways that culture and society affect each other, and it acknowledges that the historical narrative is not to be excluded (Veeser XII). "With the advent of New Historicism, the pendulum of criticism swung from form to context," writes Joseph North (141). Combating hegemonic historicism speaks to the activism at the center of this research; it acknowledges that history written in deference to Eurocentric views aided colonialism and slavery. 
In this form, the literature is also undertaking the work of postmodernist theory in re-inscribing history or showcasing its subjectivity in order to contradict the historical representation and memories in master narratives. Where modernists viewed history through the lens of rational thinking and objectivity, the postmodern perspective assumes that there is no coherence in history. Thus, there is no place for master historical narratives because they do not reflect reality, but instead they construct a version of reality and the past (Iggers 122-3). As a result, postcolonial theorists are presented with an additional responsibility of engaging these historical works in order to challenge their accuracy and offer new, diverse representations, which involve people and the spaces that they occupy. This research necessitates an engagement with intellectuals of the postcolonial world who endeavor to pursue this important challenge and participate in the very restorative and uplifting work of writing fiction that contests beliefs about historical story-telling in general.

Correspondingly, poststructuralism, in general, is a theoretical field of ample significance to this investigation for this reason because it emphasizes open interpretation of the text and suggests that meanings are "multiple and deferred rather than fixed" (Nicol 6). It offers a theoretical rationalization for separating the text from the author. As a form of literary criticism it was developed in late twentieth century in opposition to the structuralism movement, which was an earlier form of criticism of the 1950s and 1960s. One of poststructuralism's many assumptions is that the author's intended meaning is secondary (and sometimes insignificant) to what the reader perceives. The reader has the right to interpret the author's work without restriction or without paying consideration to 
authorial intent ${ }^{2}$. In this particular research study, assumptions will be made about the themes, meanings, and significance of various works of literature, and these assumptions may operate outside of the author's original intentions. This does not mean that the postcolonial author and his or her writing cannot be aligned jointly with a campaign of resistance and/or decolonization. Authors are born of and are products of the communities in which they write; they do not reside in vacuums. The author is a mandated witness who does not simply tell the stories of "imagined communities," but he or she tells the stories of people with as much honesty as humanly possible, even if there may be gaps between the intention and result (Anderson XI-9). Literature is quite often a representation of life, some form of it. It is merely a copy, but one that can potentially explore its range of social and subjective complexities. That is the power and the cost of literary representation, and it is vital to allow literature the opportunity to broaden the scope on cultural experiences: the traumas, tensions, and the hegemonic influences. The spaces that will be examined in this research offer opportunities to expose these crypts. As Dennis Lee explained in the opening epigraph, for the postcolonial writer, space is radically in question and his or her voice emanates from it. Without consideration to it, circumstances for the writer can become problematic (348).

One problematic aspect of the postcolonial experience that the writer may influence is the resulting mental trauma born of this experience. Telling these stories can potentially change lives, and it is literature's preoccupation with making meaning that provides the impetus for a growing trend among postcolonial critics and theorists of recognizing and substantiating the close ties between postcolonialism and post-traumatic

\footnotetext{
2 Theorists of New Criticism coined the term 'intentional fallacy' to refer to this inherently problematic pursuit of determining an author's purpose or intent.
} 
cultural formation. Postcolonial literature in a mode of resistance has the potential to help contradict master narratives that have been selectively constructed to serve domination systems, promote heteronomy, and help to maintain various forms of cultural trauma (an event(s) that leaves scars deep enough to define one's identity) giving them the potential for generational impact (Eyerman 74).

In Cultural Trauma: Slavery and the Formation of African American Identity, Ron Eyerman explains that cultural trauma causes a social crisis in terms of meaning and identity, and it is the intellectuals who become "carrier groups" who are central in articulating claims of the traumatized as a kind of social movement (63). These movements of intellectuals help to build and influence notions of collective identity, which are products of collective memory. They do this by challenging aspects of the collective memory that have been recognized as historical facts but are often inaccurate or misrepresentations. He suggests that this collective memory is a result of "interaction, a conversational process within which individuals [and collectives] locate themselves... within [social] narratives" (67). Collective memory is essential to group identity and must be consistently reformulated to remain appropriate for new historical contexts. It functions like a map uniting a nation or community through space and time (66). Collective memory and collective identity are interlinked much like remembrances and representations.

Eyerman argues that cultural trauma is experienced as a time-delayed, negotiated memory, and it is this specific process that places representation in a key role, especially when it involves a group's position in a political or public arena (71-2). Representation in this case becomes multi-dimensional and broadly impactful in terms of its political, 
moral, and aesthetic value; with limited representation minority articulations are often silenced. Resolving issues related to representation essentially involve solving issues related to how collective memories of a defining cultural trauma are used to establish historical facts. This is an issue pertaining to whose "truth" is adopted, or becomes mainstream.

Social spaces participate in this conversation about representation as well, for they are products and "tools of thoughts and actions" (Lefebvre 26-27). Though spaces are often perceived as abstract, they have value in the same sense that digital commodities do. They are often projections of social relationships (27). They can also inflict trauma and trigger traumatic memories for specific cultural members and can be used to maintain power relations in systems of control. In the realm of postcolonial theory, distinctive collective cultural memories that have been shaped by the traumatic events of slavery, colonization, and their various, multidimensional consequences and repercussions are given focus and consideration, and collective cultural memories pertaining to spaces provide a new and important sector of analysis within postcolonial theory. It is a goal of this research to explore the links between social space and historical trauma, and race and racialization are clear manifestations of trauma related to colonial conflict. Thus, it is crucial to understand how race and space are uniquely linked.

Although race is appreciated as a socio-cultural phenomenon and construction, one that is not biologically determined, in most societies, racial identity is still a very significant and complicated means of signifying difference. In Racial Formation in the United States, Michael Omi and Howard Winant explain the race-making process as one of creating "others" through classification. They deem classifying to be a universal 
phenomenon, but they argue that racial categories themselves create a much more complicated narrative and reflect cultural meaning, specific practices, social structures, and power dynamics (105-6). It is with this understanding that Melissa Weiner argues in "Towards a Critical Global Race Theory" that globalization and nationalist resurgences have racializing practices. "Racial" groups can be formed even in circumstances where race is not traditionally recognized, for power allows dominant groups to shape "racial" identities in order to uphold their privilege through inequality in social practices, law, etc. (333).

As other critical race scholars have suggested before her, race is deeply entrenched in social structures and institutions. Weiner also posits that in the new globalized landscape race takes on a mutable nature and actors in a racialized social system may not even be aware of their participation (333). Often ethnicity can function as race in some national contexts. Race may be a surface-level manifestation of difference, but it involves deep implications and ramifications in regard to how some groups are treated. Weiner participates in important cultural work that examines the impact of race and race-making on various cultural experiences in the global community.

Notions of white nationalism and racism show similar links in construction and design because they both can involve the perpetuation of racial and social hierarchies. The goal of racialization in the modern world, Weiner would suggest, is that it helps to standardize "perceptions of inferiority and superiority based on perceived biological and/or cultural differences" (334). These racial and social hierarchies become one and the same. The same racial signification and identification process that were rooted in histories of colonialism, imperialism, and empire expansion is simply reconstituted, and 
the dominance of the powerful is only consolidated (335). To break centuries of this kind of exploitation and domination, scholars must challenge global, national, and local practices and mechanisms that uphold homogeneity and enforce exclusion and oppression on the basis of real or imagined differences. It is paramount to examine cultural space for manifestations of racialization. Race may be a social construction, but the experiences and consequences of this construction are real and devastating. Without addressing conception, and lingering manifestations of race, this current research would be immaterial, for the historical events of slavery and colonization are contingent upon the reality/manifestations of the concept of race. These traumatic events are interconnected, and the perception of race as a valid tool of demarcation is one of their unifying factors.

In addition to being used as a tool of demarcation, race has also been a tool of subjugation, and many scholars have previously established the relationship between this form of subjugation and trauma. Frantz Fanon and W.E.B. Du Bois, among other scholars of the African Diaspora, have both dissected the psychological impact of slavery, colonization, and neocolonial institutions on the Black psyche. However, this trend towards a psychological study recognizes that what may be apparently clear within the community of those who have been victimized by colonization is not so clear in terms of the larger public discourse; for example, my grandmother's painful associations with Stone Mountain Park seemed to stand outside of the larger public perspective. Although a story is meaningful, that meaning is not always universally accepted or complete. When cultural groups and historical experiences are limited to singular, definitive stories, selective "truths" are recognized, especially with regard to colonialism and its numerous enterprises. This struggle for expanded recognition has now become the domain of 
resistance for postcolonial critics and theorists. These critics and theorists understand the significance and potential in trauma theory to shape the public narrative related to colonization and its corresponding cultural trauma. They recognize that as a result of their efforts the public narrative can become more inclusive and less hegemonic.

Yet again, this focus on the public narrative is tied to postcolonial literature's poststructuralist origins. It is a literary-focused consciousness-building campaign related to identity formation, and postcolonial literature, in this role, functions as a tool of mediation in the campaign to articulate the cultural traumas associated with colonization, their impacts on collective memory, and the process of healing en route to cultural reformation. As Ngũgĩ explains in Something Torn and New, "Postcolonial Africa never properly mourned the deaths that occurred in the two [most] traumatic events in its history: slavery and colonization" (59). He refers to this lack of mourning as a "denial of loss" that at the group level, given the absence of healing, can become a "collective crypt" of trauma that can be passed on from one generation to the next (58). For this reason, cultural trauma, postcolonial literature, and healing are all entwined. The colonial subject's memory was dismembered through language, and it will require reconceptualization by means of a creative imagination realized in language to promote the healing and consciousness-development needed to thrive. This ability to heal and thrive inspired potentially by the reconceptualization occurring within the text helps the text to serve additionally as "a bench by the road"3 or a recognition of this dismemberment that promotes a renewal of spirit (Morrison 4).

\footnotetext{
${ }^{3}$ In 1988, Toni Morrison gave a lecture while accepting the Melcher Book Award. During her remarks, she shared that Beloved was a necessary work of fiction because there were few memorials or "bench[-es] by the road" to recognize the survivors and victims of enslavement. In this way, literature can serve as a
} 
In terms of memory reformation, postcolonial scholars have concerned themselves with a range of cultural traumas beyond slavery, including Apartheid, racism, classism, gender-discrimination, the American system of segregation, and other cultural/social disturbances that have triggered the loss of a common history or cultural memory. History can be both ethnocentric and subjective, but postcolonial literature acts on notions of a public and uniform collective memory as a social movement working to force broader perspectives into this reality. Postcolonial literature resists by "necessitat [ing] a radical rewriting of the historiographical version of the past which gives prominence of place to a western calendar of events" (Harlow 86). Through the vehicle of literary representation, postcolonial literature attacks cultural trauma at its roots, in its embedded and attached memories, that can be translated differently depending on the historical context that is applied, which is contingent upon one's cultural experience. Literary representation provides the forum for fantasy to confront serious reality through semiotics.

American chattel slavery offers an example of how this contradiction in terms of memory develops. For the enslaved, the experience was undoubtedly traumatic, but this Black collective memory, as argued earlier, born of real suffering and degradation, was not in tune with the public memory of slavery, or the dominant culture's perspective which tends to exclude indigenous, ethnic, vernacular histories, etc. For example, the late nineteenth and early twentieth century black caricatures such as the Uncle Tom and mammy figures littered films, books, and minstrel show stages in order to showcase plantation life and African American participation in it as harmonious and tranquil—two plaques as historical markers throughout the country to honor African American legacies and histories. 
very different memory-related projections of this experience. As a result of these conflicting memories of slavery, Blacks' hopes for full citizenship and integration would diminish. Generations of Blacks would reconstruct slavery as the "primal scene of black identity" or the birthplace of their identity (Eyerman 76). Thus, slavery would define "group membership and a membership group" (76-77).

The cultural identification marker of 'African American' as a term represents conflict and trauma, for it is indicative of the chasm ${ }^{4}$ between Black collective memories and public memories. It reflects a lack of complete integration of former slaves into American society. The terms of this identification marker speak directly to the conflict of slavery, the process by which the African became an American, so it is a "historicallyformed collective memory" of slavery that defines this cultural group (76). This representation preserves a memory of the experience of slavery and simultaneously serves as a demarcation from white American culture. In this regard, the memory of slavery, a very specific cultural trauma, serves as the key characteristic of African American cultural representation and experience. The term locates a specific cultural identity that also signals a division or exclusion from a collective notion of American culture. This is not to suggest that the historical significance of slavery should be minimized, which realistically cannot even be achieved. As the earlier references to black caricatures should illustrate, this issue is about whose perspective of slavery is selected, adopted, and/or popularized.

\footnotetext{
${ }^{4}$ The identification marker, African American, represents this conflict and trauma more directly than other markers that have been utilized to characterize this group of people, e.g. Black, Colored, and Negro. Regardless, they all reflect this chasm.
} 
Unfortunately, the African American collective memory of slavery remained outside of the scope of the public memory because the public memory actively worked to diminish the traumatic nature of slavery via various sanitizing forms of Western historiography. Slavery is often one-dimensionally remembered and characterized as an economic development of capitalism; this version is a common feature in many American public school curricular plans (Ghansah 15). This progresses a public forgetting of the trauma associated with this institution, regardless of its clear salience in the Black collective memory.

These separate memories are progressed through the generations, and the divisions are maintained in distinctive social representations. Like most cultural identities, African American cultural identity is socially and historically constructed, and this community becomes tied to a trauma whose significance defines its cultural experience, while the steadfast representation of this trauma decreases the community's full inclusion into the larger American landscape. This is no argument for full social inclusion, the reality of which for Black people sounds almost fantastical, because their corporeal distinctions would still exist and function as a signifier of difference and otherness. As Omi and et al. argue, race, while not a "transcendent category" in the United States, is a "master category," in that "it is not possible to understand the (il)logic of any form of social stratification, any practice of cultural marginalization, or any type of inequality or human variation, without appreciating the deep, complex... interpretation of race..." (106). The point is that there are unique challenges that are triggered by the existence of an identity that has been constructed and continues to be recognized as 'other', and the enforcement of the designation of 'other' maintains the social trauma and 
alienation. This research contributes to the existing social movement to recognize, understand, and mitigate these challenges, not eliminate them, as such. Reimagining ourselves and reclaiming our culture is key.

Correspondingly, in Something Torn and New, Ngũgĩ suggests that "black consciousness [is] the right of black peoples to draw an image of themselves that negates and transcends the images of themselves that were drawn by those who would weaken them in their fight for, and assertion of, their humanity [or] the right to call [their] souls [their] own" (111). Postcolonial literature in the mode of post-traumatic cultural formation aims to promote the development of this reconceptualized black consciousness by demonstrating the relationship between historical events and mental processes on the colonized psyche. With colonization and slavery, interactions and integrations of people occurred in atypical and destabilizing ways. Worldviews collided, and cultural practices were replaced throughout the world, especially among people of African descent. Postcolonial literature examines the gaps where cultural bridges failed or were never intended to develop.

In colonial societies, celebrations of heterogeneous groupings failed along with the social acceptance and inclusivity that they can inspire. A small world order developed and the notions of the West were elevated along with Western cultural collective identity norms. The psychological effects of being taken over and controlled in this process of colonization and occupation are significant and wide-ranging, and symptoms of distress are inevitable. Postcolonial literature attempts to recognize trauma in its various forms, especially with regard to the individual and collective sense of identity and culture. This represents a healthy mode of mourning by remembering. The symptoms of this trauma, 
especially in a repetitive, unending, trans-generational cycle, are stagnating. In order to allow the psyche a space of healing and help to promote greater conscious-awareness of this kind of trauma, post-traumatic cultural formation literature works to acknowledge some of the multi-faceted features of psychological duress while promoting new experiences and insights that could encourage healing.

Admittedly, promoting these new insights does not guarantee healing. This is not a work aimed at retrieving some unaffected experience to which to return, but the goal is to remember the significance of events. For some, this will offer healing; for others the memories will remain as fresh as new wounds. This does not negate the reality that remembrance is an aspect of healing. In the case of the enslaved and/or the colonized, it involves a recognition of the extent to which the trauma occurred. Sam Durrant writes: "the postcolonial narrative enables us to work through our relation to history; it is not a communal act so much as an act of creating community" (11). This community is formed by recognizing variations in the human experience. There are valid explanations as to why "The Star-Spangled Banner" receives mixed reactions, or why some would never refer admiringly to crop lands as "amber waves of grain." Some collective and individual memories are difficult to deconstruct, and awareness of trauma may, for some, cause the opposite feeling of recovery. Some wounds may be irreversible, but the postcolonial narrative presents us with an opportunity to simply bear witness.

In spite of the potential for inconsistent results, postcolonial scholars and authors persist in progressing the earlier successes of the Civil Rights era and African

\footnotetext{
${ }^{5}$ This statement is a reference to recently renewed debates related to Colin Kaepernick and "patriotic" songs that promote white supremacy and/or a myopic, romantic depiction of American history, especially the slave era. The "Star-Spangled Banner" and "America the Beautiful" have both been accused of falling into this category.
} 
Independence movements that pushed more perspectives of colonialism, slavery, and other forms of colonial trauma into the national collective memory on all platformslocal, national, and international. In order to achieve any measure of reconciliation, representations as products of memory must become more inclusive. It is the literature and its ineradicable relationship with meaning that helps to articulate trauma, forge new public memories as a result, and alter the representation of cultural experiences in order to promote healing. With this power and influence, the collective crypts of trauma can be decimated and spaces can be reclaimed and/or transformed.

\section{New Theoretical Frontiers and Postcolonial Space: Contributions to Scholarship}

There are many cultural wars yet to fight, and the landscapes or spaces of these battles are constantly changing. As mentioned previously, globalization has a significance to this investigation because it changes the colonial landscape, expanding or creating new traumatic spaces. What is nation today may not be nation tomorrow. Spatial studies within the postcolonial framework, which is paramount in this research project, allow the opportunity to transcend the increasing complication of globalization by exploring the implications of space and the conflicts that particular spaces present to wide-ranging communities of people as well as forms of nature. These spaces include old, precolonial spaces of conflict; current, emerging spaces of conflict (the nature of this conflict may be in fluctuation due to globalization); and future, imagined spaces of conflict.

Postcolonialism's preoccupation with social responsibility and cultural connectedness in postcolonial literature is essentially a response to urgent societal issues. Postcolonial writers act as a medium for social change, as they contest new forms of 
hegemony that exist in their respective fields of production. Considering its history, the literature and related literary analysis add new elements to the public discourse on these subjects by articulating the claims of the traumatized and strengthening formerly silenced voices on subjects too infrequently discussed. By refusing to imitate the colonizer's rules about literature and language and refusing to capitulate to hegemonic norms, these authors initiate healing and progress. Postcolonial space is simply an important, new frontier for this kind of exploration and analysis.

Postcolonial literature and scholarship must continue to develop in ways that promote decolonization and the undoing of neocolonial discourses and modes. These works must involve a reimagining of postcolonial worlds that highlight trauma and tensions that challenge the potential for citizens of colonized spaces to achieve productive lived experiences. It is true that Eurocentric colonial histories will remain, but through literature and an exploration of specific themes, postcolonial theorists help to rewrite these records. Those who would have you believe in a singular version of an event are merely trying to apply objectionable standards by which to exclude.

With regard to inclusion, this project does not focus on gender per se, although the majority of the texts and protagonists featured in this research are women and girls. As a consequence, some might consider this work as feminist criticism because it exposes the "mechanisms of patriarchy," and an exploration of the female world is taking place in some regards (Barry 117). Personally, I appreciate feminist criticism that is more overtly theoretical and very intentional in its analysis of femininity as a social construction (120). It is important to acknowledge these achievements, but I must stress that the central focus of this research is space, social and racialized. Obviously, feminist criticism is necessary 
work, but as Peter Barry asserts "not all literary criticism written by women is feminist" (134). I am speaking to a constant dilemma of the Black woman/female scholar. She shoulders the tensions of her race, class, and gender, and all must be addressed simultaneously.

Notwithstanding, feminist and postcolonial discourses can both include gender criticism, for both according to Ashcroft et al "seek to reinstate the marginalized in the face of the dominant... [and are] concerned with inverting the structures of domination" and the substitution of their traditions (233). These discourses exist on converging paths, for they are unavoidably invested in the subaltern. Black female bodies occupy a majority of the focus in this study and reflect the double colonization of imperialism and patriarchy (233). For this reason, gender will often intersect conversations about race and postcolonial theory. Female voices deserve the same privileges and considerations, and some of these intersections will be noted at various stages of this research.

The exploration of space at work in this research operates with the simple understanding that changing views can improve lives by including marginalized voices. In the context of my grandmother's relationship with Stone Mountain Park, a simple informative placard acknowledging — merely to help end a practice of ethnic cultural erasure - the history of hatred and violence that once enveloped the park's identity may have made it a little easier for her to cope with her remembrances. If confederate monuments are to remain throughout this country progressing a celebration of and codification of white supremacy, then these commemorations of Black suffering must loom as brightly. 
It should also be noted that many of the literary texts selected in this research project are canonical, which for other researchers would make them less appealing for a dissertation study. Yes, many of these texts have been thoroughly considered from other analytical perspectives, but these texts and the collective range that they offer were selected because they have considerable appeal and great potential to capture the considerations and interests of my students at Kentucky State University, a historically Black institution in Frankfort, Kentucky. I partially dedicate this work to my students because often they feel the weight of but cannot explain the impact of their blackness. They grapple with the unknown roots of their trauma, and I hope one day they will recognize and benefit from the kind of study that I have put forth in this research. One day, the slave roots of their trauma will be clear to them as a result of these histories finding their way into the dominant narrative.

In this introductory chapter, we discuss approaches, theories, and literature that rationalize my objective in this dissertation of using narratives to probe postcolonial spaces, which Stone Mountain Park is. This is a gap that exists currently in the field of postcolonial literary criticism and theory. Often the colonial trauma in space, a crucial dimension in the lived experience, is inadequately explored. Space is regarded as empty or valueless. It is a goal of this research to unite the spatial and postcolonial theories considered in this first chapter more cohesively in order to progress the scholarship in the direction of magnifying the lingering traumas related to exploitation and subjugation so that more members of the world community will embrace the truth that we are all complicit in some form of oppression or another. Social spaces are no exception in this 
consideration. We all must play a role in our healing as well; thus, this dissertation is my contribution to this healing process.

In continuation of this theme, the second chapter of this study will explore the slave narratives of Harriet Jacobs, Frederick Douglass, and Solomon Northup. The authors of these autobiographical texts helped to give birth to the work of analyzing colonial space as a site of trauma, specifically the United States. Henry Louis Gates Jr. explains that these narratives were written to "rail against... a perverse fiction of the natural order of things" (Andrews and Gates ix). These authors engage in and deconstruct the American antebellum space exposing the horrors and traumas of their lived experiences. As abolitionists, they make early connections between social relations and the production of space. They offer various demonstrations of how public spaces, or space which the public claim a stake in, are policed and used to construct antisocial environments that ultimately function as mechanisms of hegemonic control. Additionally, this chapter will provide a historical context for the lingering legacy of slave-era trauma in American postbellum social structures and spaces.

The third chapter will engage the genre of historical fiction in the postbellum/post-Reconstruction era and explore the theme of passing as a way to circumvent racialization and "othering" that resonate with spatiality. The works of the New Negro era and Harlem Renaissance authors, Charles Chesnutt, Nella Larson, and George Schuyler will be examined. These authors assumed the mantle of spatial and trauma studies from their antebellum predecessors by examining the lived experiences of those who escaped the traumas of public space by transmuting their racial identities. With their focus on race and the complexity of color, these authors advance the discussion and 
analysis of postcolonial space and resistance in the form of conformity and codeswitching, and offer the black body for consideration as a traumatic space. Paradoxically, this resistance has its own traumatic effects.

Chapter four will explore the writings of contemporary authors, Octavia Butler, Toni Morrison, and Ernest Gaines; their works of fiction offer retrospectives on the subjects of the pre-Civil Rights era, American rural and urban spaces, and inherited traumas in the form of lingering societal ghosts. Their works will particularly be discussed as neo-slave narratives in an attempt to reveal the ways in which the ghosts of the past (slavery) continue to haunt people of African descent in the U.S. These writers create fictional case studies that analyze the sustained production of trauma in modern spaces of conflict. In addition to exposing the ghosts of slave-era trauma, they help to underscore the impact of the traumas in public and social spaces; from them, we learn as time has progressed so has the advancement of constructs intended to increase antisocial environments and mechanisms of hegemonic control over some communities of people. These traumas are real and oppressive, and these authors work to detail how uniquely evolved they become in the post-Civil Rights era.

Chapter five will continue to explore the imaginings of Octavia Butler, as a postcolonial science-fiction writer and Afrofuturist author, and her imminent projections related to issues involving spatiality, globalization, and postcolonial theory and their confluence on spaces and space-related conflicts. Butler provides imagined transformations of contested spaces into spaces of healing. Her work addresses the rise of spatial inequalities by adopting the Lefebvre concept of 'the right to the city'; she 
endeavors to change her societal space by changing perspectives of them. She produces fictional spaces that can serve as models in an effort to inspire real societal change.

Finally, the conclusion will highlight opportunities for future research related to identifying other manifestations of spatial trauma and validating as well as identifying other forms of black claustrophobia. This research was limited to the American landscape in very specific historical time periods. As noted earlier, racialization on the global landscape can occur in varying forms, so there are spaces that have been racialized as 'Black' or 'other' that warrant investigation in various spaces of time. Thus, spaces in different historical contexts should be considered as well. Relatedly, this spatial analysis has many implications for the burgeoning theoretical field of ecocriticism. This form of spatial theory can be applied to advocate for environmental causes. Unfortunately, there are endless possibilities when considering the traumatic influences of colonialism and its various enterprises on spaces of encounter-past, current, and future. 


\section{CHAPTER II}

\section{ANTEBELLUM SPATIAL ANALYSIS: LOCATING TRAUMATIC SPACE IN THE SLAVE NARRATIVE}

"She fixes her eyes to the horizon, and the hope she will never catch. Carrying her seeds. The clanking of metal on her feet. Remembering the fruit that will be born of strife."

-Amir Campbell, "Mother on a Plantation"

Slave narratives have always been the subjects of great critical attention; they provide, as William L. Andrews suggests, "some of the most graphic and damning documentary evidence of the horrors" of the institution (Andrews and Gates 1). These offerings of painful truths from the Africans who survived the middle passage and wrote to substantiate its terrors stand in defiance of a historical pattern of denial associated with the role of the institution in shaping their lives and the lives of their descendants; these stories are their legacies (VII-1). Additionally, they confirm their humanity, grit, and determination to survive.

These narratives first emerged in the 1700s with the publication of A Narrative of the Most Remarkable Particulars in the Life of James Albert Ukawsaw Gronniosaw, An African Prince, in London in 1772. This was followed by the publication of the Interesting Narrative of the Life of Olaudah Equiano, or Gustavus Vassa, the African in London in 1789. The first female slave narrative, The History of Mary Prince, was also published there in 1831. Frequent lecture tours from American fugitive slaves, such as Frederick Douglass, William Wells Brown, and others, stimulated a healthy market and appetite in Great Britain for these stories (Andrews and Gates 2). In America, these 
eyewitness testimonials were driven by a range of ambitions in addition to the primary objective of activating a campaign of resistance through exposé reporting. Essentially, they were petitions for freedom in autobiographical form and revealed very exacting characterizations of the institution. Sexual exploitation, family separation, inhumane living/working conditions, food shortages, and abuse were some of the many themes incorporated in these works, and because these narratives would blend "personal memory and rhetorical attack, [they stood] as both powerful tools of literature and propaganda" (3-4). These authors were advocates of human equality and wrote to change ignorant or indifferent minds while acknowledging their own selfhood. With their attempts to address the moral and social complexities of slavery, these accounts endeavored to function as a civilizing influence on the United States and Europe, and by means of their visceral substantiation for the immediate emancipation of the enslaved, which could also be translated as a call for rebellion (especially in the case of The Confessions of Nat Turner, 1831), they served as tools in militant anti-slavery activism campaigns.

It should be noted that many scholars, including John Sekora, James Olney, and Robert Stepto, and others, have suggested that slave narratives were compromised and challenge the legitimacy of their autobiographical status since in many cases their narrators were instructed/encouraged by abolitionists to follow a formula that would appeal to the interests and sympathies of their readership. ${ }^{6}$ Despite these restrictions and limitations, there is an adequate amount of scholarship that reaffirms these Black

\footnotetext{
${ }^{6}$ See Sekora, John. "Black Message/White Envelope: Genre, Authenticity, and Authority in the Antebellum Slave Narrative.” Callaloo, vol. 32, no. 32, 1987, pp. 482-515; Olney, James. “i Was Born': Slave Narratives, Their Status As Autobiography and As Literature." Callaloo, vol. 20, no. 20, 1984, pp. 46-73; Stepto, Robert B. "Storytelling in Early Afro-American Fiction: Frederick Douglass' 'the Heroic Slave."” The Georgia Review, vol. 36, no. 2, 1982, pp. 355-368.
} 
narrators'/writers' agency irrespective of the amanuensis' influence, in some cases. ${ }^{7}$

Robert Levin suggests that "mediating forces" are often present for narrators writing from within a cultural space (100). He argues:

There are similar rhetorical constraints on virtually all of the slave narratives...but also similar signs of agency and rhetorical resourcefulness on the part of black authors, who did what they could to maintain authority over the narratives that bore their names...these writers called attention to the lack of freedom in the "free" North and in this way suggested that the challenge that continued to face the nation was to live up to its revolutionary ideals. In post-Civil War autobiographical narratives and in the neo-slave narratives of twentieth-century US fiction, African American writers... would re-voice that challenge while honoring the agency and vision of the slave narrators who came before them (112-114).

For the purposes of this research, what these activist writings divulge about freedom, bondage, space, class and social structure are of the greatest import, and they provide the spatial context through which spatial and trauma theory can be employed. By virtue of their authorship, the enslaved and formerly enslaved are theorizing about space, for they are writing from a space outside of the master's realm of control, defying the white man's gaze, another space of opposition. More importantly, these narratives challenge the belief that the enslaved lacked a motive for life and liberty (Andrews and Gates 11). Frederick Douglass, Solomon Northup, and Harriet Jacobs clearly signal (for themselves and as representatives of the enslaved members of their societies) that freedom is attained by achieving some combination of reaching the "Free states,"

\footnotetext{
${ }^{7}$ See Andrews, William L, and Eric J Sundquist. "To Wake the Nations: Race in the Making of American Literature.” American Literature, vol. 66, no. 1, 1994, pp. 174-174., doi:10.2307/2927456; Andrews, William L. To Tell a Free Story: The First Century of Afro-American Autobiography, 1760-1865. University of Illinois Press, 1986.
} 
renaming one's self, and/or participating in anti-slavery activism (8). These freedom fighters are affirming a desire for space, place, and a secure homeland.

From the Narrative of the Life of Frederick Douglass (1845), Andrews argues that Douglass shows that "freedom [has] a more idealized dimension" and is more inclusive of just a physical locale, for he "uses language to change the minds of others... [a] most compelling sign of that individual's freedom" (12-13). His work is "highly selfconscious", and he is keenly aware that he is not only exploring the conditions of the enslaved and the oppressiveness of bondage, but also highlighting the dimensions in a class struggle for power and authority (14), therein opening the door for spatial studies to unshroud some of the physical boundaries and structures allied with this struggle.

In Twelve Years a Slave: Narrative of Solomon Northup (1855), Northup addresses "the moral and social complexities of the American caste and class system" as well, and he showcases a beautiful life "compromised by [America's] complicity with slave power" (Andrews and Gates 17, 20). One day he is a free man traveling the countryside to pursue his musical ambitions, and the next he is the victim of slave catchers, reduced to the limited reality of being regarded as chattel. Northup's unwavering emphasis on the secret, structural network that enables his kidnapping unveils the anxieties in life for freemen and women. As a result, his work underscores the idea that freedom for African Americans of this time period is about realizing both a physical space "as well as an emotional space where [they] could exercise social and economic self-sufficiency and independence"; more broadly, Northrup contributes to the reconceptualization of "the idea of home" [as a space as well as a concept] and asserts a clear ambition for one that is safe for the members of his community (Andrews and Gates 
20). Much like Douglass, he is asserting claims about the spatial structures among other barriers that impede the attainment of this goal.

Similarly to her literary predecessors, Harriet Jacobs, wrote Incidents in the Life of a Slave Girl (1861), to stake a claim for "a room of [her] own" (Andrews and Gates 20). As the first former slave woman in America to compose a full-length narrative, her account reads, according to Nellie McKay and Frances Foster, as though it were a "public confession in her ongoing search for self-esteem" (XVII). Jacobs writes with great vulnerability in a form that her male counterparts did not, as she is most certainly aware of the susceptibility of her feminine virtue and the shame that her revelations of sexual exploitation and violations could cause. It is with this constrained voice that she highlights how, according to Orloff Miller, living conditions in antebellum America involved a "systematic ordering of law, custom, landscape, and material culture to reinforce social rank [and structure]" (Miller 67). More directly than her counterparts, she challenges this systematic ordering and emphasizes its traumatizing consequences on her lived experiences. McKay and Foster contend that in finding her voice Jacobs' writings "exploit the reality of the small spaces she was forced to occupy... [and] her final escape from slavery was achieved through a progression of movements from one [of these] small space[s] to another [affording her] incremental degrees of control" (XVII). Undeniably, Jacobs is a foremother in spatial theory; as McKay and Foster observe "our understanding of her as a black woman...comes through our ability to read the ironies, silences, and spaces" in her work (XVII).

The social structures of varying configurations that these narratives work to categorize as tools of reinforcement and allies of this American caste system are what are 
of interest to this research. I argue that their acknowledgment in these narratives proffer a means by which these authors participate in spatial theory concomitantly with abolitionism. Antebellum properties were designed to create clear distinctions between formal and working spaces, and slaves equated their living conditions to the character of their masters (Miller 67-8). With this understanding in mind, important questions can be asked about these settings. What spaces seemed to cause the enslaved and others to have the greatest sense of alertness or fear? How did the authors emphasize tension, conflict, and trauma in their social spaces as they endeavor to publicize the physical and psychological cruelties of slavery? How did these writers demonstrate changes in their behaviors or the behaviors of others as a result of being exposed to certain spaces?

Knowingly or unbeknownst to these authors, they began the foundational work of assessing social structures for larger ideological and socio-political implications. For the purposes of this work, their interventions and analyses help to demonstrate how social structures can, in fact, buttress the hegemonic influences of the institution of slavery as well as other oppressive institutions and systems. Consider the implications of living in a world where, as the former slave John Parker remembered: "everything was organized against the slaves' getaways...the woods were patrolled...the whole countryside turned out to stop the fugitives" (Griffler 120). Apply structural consideration to the employment of this legalized fear tactic, and it is clear to appreciate how necessary it becomes to the success of a system of oppression that space(s) is imbued with first-hand, personal memories and/or second-hand, generationally-transferred memories that carry lingering, traumatic, and historical meta-physical impacts. 
In order to further explore the notable theoretical contributions in the slave narratives of Harriet Jacobs, Frederick Douglass, and Solomon Northup, we must better understand how space can indeed be a product and/or mechanism used to influence and manipulate. To bridge this gap between theory and application, one that often impedes a clearer perception of the social implications of space, we must turn to the important work of spatial theorist and sociologist, Henri Lefebvre. In The Production of Space, Lefebvre offers epistemological challenges to the concept of space and compels a re-evaluation of the abstract, geometrical designation often given to various spaces, social and otherwise.

\section{The Production of Space}

How is space more than a matter of geometry? The work of Henri Lefebvre in The Production of Space offers a bridge that connects it to a theoretical realm and moves space beyond a mere practical one (4). It offers a challenge to the epistemological understanding of space as a concept, and he suggests that space actually has an identity that is in flux. Lefebvre compares this state to mental space, which exists as a concept with properties that possess specific orientations and symmetries. However, mental space does not actualize into physical space where the concept of space is typically

oriented (5). In this sense, mental space is ideological, and it also "becomes the locus of a theoretical practice" (6). It is this specific kind of perspective on space that Lefebvre applies to social space, or space that incorporates things, actions, and interrelationships that are produced in a relatively ordered and/or disordered state (73). There is a kinship here, he argues, between mental and social space, and this kinship should be appreciated and retained when evaluating social space so that one might be able to grasp how social 
or public space(s) can be "constituted or constructed" and also used to "represent the political and neo-capitalist [code] of knowledge" (8-9).

For the purposes of this research, it is especially important that we explore and acknowledge what Lefebvre refers to as "the truth of space" so that we can understand how "capital and capitalism [can] influence practical matters relating to space", comparable to Lance Selfa's argument detailing how capital/capitalism influenced a unique form of racism in America during the era of enslavement and beyond (9). ${ }^{8}$ This perspective of space as a commodity or product is critical because in this role it is possible to perceive how space can be weaponized and/or imbued with sentiments/emotions of varying sorts (trauma is pertinent here) in order to be utilized in various capacities, economic and otherwise. It is with this tactical approach to space that many ruling classes and institutions have activated it. Lefebvre suggests that hegemony is maintained by "all available means" and the control of knowledge has been one of its most useful instruments (10-11). Space does not function outside of this system of control; to the contrary, Lefebvre says: "space is operational or instrumental", and "hegemony makes use of it in the establishment of...a system" (11). It is the operational employment of space or the control of knowledge as it pertains to space that is being considered in this research.

Lefebvre explains that "physical space has no reality without the energy that is deployed within it", so "real space" becomes a "space of social practice" (13-14). Signification is a process through which extrinsic meaning is formulated and assigned,

\footnotetext{
${ }^{8}$ In "Slavery and the Origins of Racism", Lance Selfa makes the case that capitalism influenced a unique form of racism to develop in America. I argue that capitalism had a similar influence on American spatial arrangements and spatial production. It is responsible for the development of a complex system of ideologies, practices, and institutions in this country.
} 
and it is through this process that spaces are to be decoded, read, or interpreted (17). Thus, spaces can send messages via their various name assignments and/or the many experiences associated with them. These spatial codes and the practices that occur in response to them can become inherent to a space and inherited reactions to a space transferable from one generation to the next by means of socialization and socio-cultural practices and traditions. For all of the messages that spaces can communicate, Lefebvre establishes the case for a "methodical deduction of the codes relating to space" because, he suggests, space has taken on a reality of its own and operates like other commodities, such as goods, services, and money (26). Although, natural space still exists waiting to be destroyed or commodified, it is this functionality as an actual commodity that makes social space different (30-31).

Consequently, social space can become a tool of domination, action, and power. It is an extension of those who make use of it; this is why Lefebvre's earlier parallel between mental and social space is so profoundly effective. Their employments are nearly indistinguishable because they are both products of invention and realization (28). Additionally, Lefebvre explains that each society or producer offers its own unique space through its own distinctive process of production related to a particular space (31). This is the process by which social space subsumes social action. Analyzing and appreciating this process or the production of space helps elucidate the complex approaches related to space utilized by hegemonic forces engaged in class and/or land domination.

Lefebvre calls it a "theoretical error to see a space without conceiving of it", and says "the rectification of this error would likely lead to the dissolution of a few major ideological illusions" (94). I argue that slave narratives engage in this very specific 
practice of unmasking ideological illusions about the enslaved, their lived experiences, and the spaces that they occupied. From their perspectives, through their lenses of experience, the enslaved and formerly enslaved confront the liquidation of American history, especially as it pertains to their social spaces. In addition, they help to reveal how space can contribute to the deployment of oppressive strategies with undeniable clarity. As Lefebvre highlights, "repressive space wreaks repression and terror" (144). These narratives, especially to those blind to the realities of the enslaved experience, demonstrate a level of galvanizing transparency, and with their analysis "provide a code and a method of deciphering what at first may seem impenetrable, [cloaked, and invisible]" (147).

Often, space is validated by human occupation and named in order to affirm this purpose; otherwise, the space is viewed as empty, void, or utilitarian only in the relation it serves to other objects or physical boundaries. We will contradict this kind of social practice somewhat, for we, along with Lefebvre, suggest that space, specifically social space, can be occupied or imbued with energy and memory, and a component of our analysis will explore how this energy, memory, or feeling actually generates a form that also reflects the space's identity or character.

Additionally, in traditional architecture, structure refers to an object or a building's proportion, dimension, and/or level; structure addresses the framework that reinforces it. Structure is something that a building can express, and a building or object's structure can have little or great prominence (Conway and Roenisch 158-9). For the purposes of this analysis, this explanation of structure is useful, but it will be applied 
to the structures that occupy a social space and how these structures help to contribute to the messages or codes that space generates.

Moreover, an object's structure is often shaped by its function, or the particular purpose of the construction. Objects are constructed for many reasons, including to express emotions and symbolize concepts (Lefebvre 55). For this reason, function is most useful in our analysis of social space. Lefebvre refers to this approach within the theoretical framework of function as spatial-strategic analysis. Spatial-strategic analysis allows for the examination of space as an oppositional force, an object of symbolism, and/or an entity with function with or without human occupation. Furthermore, it is this specific analytical approach that will allow us to observe how foreign entities or structures introduced into an established social and economic structure can be used to establish a political base (151-3). For example, one might not consider the locality of a plantation or the location of a slave owner's home as a strategic action, but Lefebvre observes these places as "superstructures" used to establish a base of influence (151). Thus, the presence of these structures helps to demonstrate the organizing principles of a space. Spatial-strategic analysis aids in exposing the underlying grid that generally establishes the nature of a space, especially as it pertains to power (157). These arrangements can represent an interplay between opposing forces.

Dissecting the messages at the center of this interplay is central to this research. For this reason, the concept of signification, which allows for the interpretation, identification, and enumeration of these codes, is an important methodological approach because it is less technical and rigid and concentrates on the subconscious codes and messages that the spaces are delivering (160). 
Lefebvre argues that greater advancements in the field of "semanticosemiological" research, which signification is a component of, have provided more astute considerations to the relationship between the signifier (the space and what it represents) and the signified (the reactions of those who encounter the space through first-hand experience or second-hand delivery), for this relationship is what has been "susceptible to disjunction, distortion, instability, disparity, and substitutions" (160-1). Accordingly, the research evolved to adopt more flexible, pluralistic readings of what spaces can signify, ones that move beyond limited connotative and denotative decoding methods. Furthermore, Lefebvre states: “There's a proper role for decoding space: it helps us to understand the transition from representational spaces to representations of space, showing up correspondences, analogies, and a certain unity in spatial practice and in the theory of space" (163).

In addition, Lefebvre explains that many social spaces exist, and they are all "susceptible to multiple decodings" (163). We acknowledge this truth, but this work attempts to use spatial theory in order to move beyond the classical field of architecture to explore the context of trauma. Analyzing the context of space will allow us to consider questions to explain how a space can affect or constrain the actions of the enslaved. Where are structures located? Why are these structures positioned in certain locations? This is a qualitative assessment that uses a narrowed scope of analysis of the private and/or public knowledge related to spaces and how they are utilized to produce trauma and promote hegemony. Ultimately, we use slave narratives to demonstrate how "space's hegemony" moves beyond micro and macro levels of consideration, small or larger scale social operations (412). Lefebvre explains "its effects may be observed on all planes and 
in all interconnections between them... [and, it is a] theoretical error [to] restrict the import of space to a single discipline" (412). The authors of the slave narratives assessed in this research engage in and activate spatial analysis, which serves as further validation of this claim.

\section{The Implications of Space in the Narrative of the Life of Frederick Douglass}

The publication of the Narrative of the Life of Frederick Douglass in 1845 has been regarded as one of the most pioneering acts of Douglass' career as a social reformer. His memoir gives a vivid account of his and others' experiences as enslaved people in the antebellum era. As an unwavering member of the anti-slavery movement, Douglass highlights the devastation and cruelty of this American system of bondage. As he dissects the various components of its cruelty, he constructs a spatial analysis that identifies many of the structural features in these societal spaces in which enslavement was enabled to effectively occur. He demonstrates how enslavement as a concept translates to an experience in social space. In the process, he reveals how it takes on a form and a function that manifest as space(s) of hegemonic occupation, the form of this hegemony being racism. Thus, bondage negates freedom, and the social spaces of those in bondage could often work to create a terrorizing context of entrapment. The Narrative of the Life of Frederick Douglass is very much an impassioned work for the cause of abolitionism, but it also works to expose how social spaces were used to fortify the enterprise of slavery in the United States of America by unmistakably signifying that repression and terror begets repressive and terrorizing spaces. 
From the onset of the narrative, Douglass participates in a study of spatial observations. He implores his readers to prepare to enter into a different kind of space, one that "struck [him] with awful force... [for he passes through] the blood-stained gate...to the hell of slavery" (120). In the same way that he shows the indoctrination that his first-time slave owner, Mistress Auld, must embrace so that she successfully transitions on the "downward course" that slave ownership requires, the reader is compelled to appreciate a similar kind of realization regarding the various social spaces of the enslaved (139). A transition happens in these spaces as they are converted into spaces of desperation and isolation in which the enslaved who inhabit them feel as though they have been "cast away upon a desolate island" (125). These were the kinds of spaces, tools of the institution of slavery, which suspended "the [nostalgic, loving] ties that ordinarily bind children to their homes" (133).

Consequently, Douglass makes the intentionally vague boundaries that are severely enforced a main focus to underscore the lack of refuge in his spaces of occupancy. He includes the very senseless and horrifying murders of an enslaved man who "happened to get beyond the limits of" his owner's property while fishing for oysters, and of Demby, another enslaved man, who ran outside of what his overseer perceived as the established boundaries, in order to escape a whipping (131). These two murders demonstrate how trespassing was subjectively adjudicated but strictly enforced to eviscerate the sense of freedom for the enslaved. There were no legal protections for them, and their white murderers routinely escaped punishment. This lawlessness formed an atmosphere of terror, for the enslaved "never knew when they were safe from 
punishment"; often in the presence of an owner or overseer, their only recourse was to "stand, listen, and tremble" (126-7).

Douglass was acutely conscious of the structural layout of his plantation space and how this spatial arrangement was coded in very affecting signifiers. He explains how the home of Captain Lloyd, the patriarch of the plantation, was "the seat of government for the whole twenty farms [that comprised the entire Lloyd estate]" (122). Also, aptly called the "Great House Farm" by the enslaved, it functioned as what Lefebvre refers to as a "superstructure", for it was positioned at a central point on the plantation estate and was the base of business and influence (Lefebvre 151; Douglass 122-3). Overseer dispute settlements, slave-related determinations, enslaved clothing/food allowance distributions, and trades were all conducted at the Great House Farm (Douglass 122). Douglass suggests that the presence of the home was "imposing", so it served as a signifier, which the enslaved frequently associated with the master (128). The enslaved were convinced, Douglass explains, that the "greatness of their master [and his Great House Farm] were transferable to themselves" or signified their own humanity or importance; furthermore, it was considered a disgrace to be a poor man's slave (128). The enslaved delighted in being selected to run errands or chores for the Great House Farm. In this esteemed position they enjoyed vicarious wealth and worth. Consequently, these errands provided them with a sense of pride because it put them in closer proximity to the farm that signified greatness. This increased access also signified privilege and prestige because the enslaved were afforded the opportunity to associate with whiteness via the white elites who occupied this home and determined the fate of their circumstances (123- 
4). As a signifier, this great house worked to strengthen the enslaved mentality among them by limiting their senses of identity and self-worth.

In contrast to the Great House Farm, Douglass makes clear how spaces designated specifically for the enslaved signaled a very different cultural message. Robert Levine asserts that with this focus "Douglass presents himself [in his] account as stultified by the arbitrary authority of a culture that attempts to keep him in his 'proper' place" (105). He is drawing parallels to expose the constructed degradation in the spaces reserved for the enslaved. The "home" facilities for them displayed the absence of prestige and basic comfort; there were no beds, blankets, or adequate spaces to complete simple acts of selfcare. These quarters functioned and were designed to signify a short pause or pit-stop from labor in the fields or elsewhere. As Douglass states, the enslaved were always in the "want of sleep" because the periods of rest were never intended to outlast the hours of toil (Douglas 122). The slave quarters reflected the context of their reality. The enslaved were extensions of the fields, sources of labor and production, so their spaces characterized this pigeonhole. To the sound of the driver's horn and/or the rise and fall of the sun, they responded, and their habitation was fixed accordingly to literally and symbolically prioritize their unyielding proximity to the fields or other designated work spaces. As such, they were bound to these working spaces, where Douglass says they witnessed great cruelty and horror, a constant theme of their lives (123).

To further underscore how the space of the plantation took on a form of repression and terror, Douglass offers Colonel Lloyd's garden, "the greatest attraction of the place" for consideration (125). It was one of his prized possessions and was kept under constant employment and care. This garden contained an ample supply of "fruits 
of almost every description" but was safeguarded from the severely malnourished members of his enslaved community by a tar-covered fence, which made it easy to identify any suspected intruders (125). Ultimately, what it functioned as was a barrier that separated the enslaved from achieving yet another form of fulfillment, sustenance, and more importantly, it stood as a reminder and holder of figurative fruit, the right to life and liberty, constantly positioned as a temptation just outside of the space of their reach.

Douglass is carefully aligning this unfortunate circumstance with the strategically positioned structures in his environment. To underscore this point, he acknowledges how changes in his surroundings among other advantages allow him greater prosperity in Baltimore, where he is eventually sent to live with Mr. and Mrs. Auld. He calls this event "a special interposition of divine Providence in [his] favor" (135). Where he compares his first foray into the enslavement as entering hell, he says his time with the Aulds "opened the gateway to all of [his] subsequent prosperity" (135). Douglass' reference to a gateway is apropos, for he continues to emphasize how for better or worse social space contributes to the quality of lived experiences of the enslaved.

In his new space with the Aulds, the absence of strict physical borders and barriers affords him a much improved quality of life or, in his words, greater "vestige[s] of decency" (137). What was immediately striking in terms of these changes, those of them that he chooses strategically to detail, are the diversity in useful spaces that are made available to him. He is given access to the city streets, which means that he can engage with poor white children, whom he works to convert into unwilling educators (139). Later, he is able to frequent the ship yard and wharf, where he learns the names of letters and how to write some of them too (141-2). Additionally in the Auld home, he 
finds limited access to educational materials. Mr. and Mrs. Auld do not maintain the most intimidating space of terror, so Douglass is left unsupervised occasionally (143).

With this freedom, he ventures to read and utilize the blank writing spaces in Master Thomas's copy books from school. He wills himself to learn to read and write, and with his new education he develops the consciousness that would later inspire his abolitionism (140-3). The physical expansion of his social space allows for a healthier mental space yielding benefits to his cognitive development and ideation. His physical space became less repressive and permits him to exhibit the behaviors of a human being. As a result, he begins to claim and activate his revived sense of humanity, which remains remarkable in spite of slavery's attempts to suppress it. Thus at twelve years old, he elects to read the book, The Columbian Orator, and is awakened to the perspective that enslavement is truly a state of mind that is most effective when it garners the willing participation of those subjected to it (140). He is steadfast is his determination to no longer be a willing participant. True - the Aulds were not the most cruel slave owners, but they were still slave owners. Thus, increased appreciation for their small acts of gentility and kindness is not the key significance of their inclusion in this narrative. Remember, they were actively trying to grow their mentalities as slave owners, which required the adoption of corrupt, inverted senses of humanity (136-9). However, what is at focus is Douglass' determination, ingenuity, and the "interposition of divine Providence" to bestow small spaces of refuge on him (135). The attainment of his future prosperity, which would include a seat at his own table in his own home free from "confine [-ment] in the galling chains of slavery", required both his good fortune and his spirit of hope (135). 
No situation was a greater test to this spirit of hope than Douglass' time with the slave breaker, Edward Covey. He had come to live with Covey as a short-term lease laborer. Douglass had been returned to the family of Captain Anthony, his original owner, after the later died. Following a series of additional deaths in the Anthony family, Douglass found himself in the custody of his former master's son-in-law, Master Thomas, who sent him to work for Edward Covey. Douglass includes the intricacies of these slave transactions to stress the absence of place, home, and permanence in the lives of the enslaved. They were property who could be shipped at a whim for evaluation and/or resale. Douglass explains, "horses, men, cattle, women, pigs, and children all [held] the same rank in the scale of being and were all subjected to the same narrow examination [and treatment]" (143).

Based on his experiences with Covey, one might argue that the animals were given greater favor. Covey had a reputation for his cruelty and, according to Douglass, "it was of immense value to him (Covey)" (151). His most effective weapon in his arsenal of terror was his employment of space. He weaponizes space by positioning himself as an omnipresent authority on his farm. Unlike Douglass' environment in Baltimore, his tenure with Mr. Covey was defined by continuous restriction. There was no room for hiding; Covey's looming presence engulfed the entirety of his locale. This is precisely why work would continue without fail in Covey's absence to the level of his satisfaction (153). Covey had created his own panopticon $^{9}$, and similarly to this

\footnotetext{
${ }^{9}$ Jeremy Bentham's Panopticon (1791) is an architectural plan for institutions, especially prisons, where a large number of individuals could be monitored by a small number of guards. In prisons, in particular, this design could help prevent unwarranted behavior by restricting the prisoners' views of the guard, who were positioned in the center of the circular structural building design in a room with privacy shields. These obstructions allowed the guards, like Covey, an invisible omniscience (Haase 72; Gentry 353-375).
} 
institutional design of control by the social theorist, Jeremy Bentham, his tactical usage of his space provided a means by which his plantation workers internalized his authority and demonstrated obedience as form of Pavlovian conditioning. He had watched his workers from hidden spaces and demonstrated his snake-like approach enough times for them to fear the idea of him. Surprise inspections and his cunning invisibility were central to his method of control. Douglass contends that "[his] forte consisted in his power to deceive" (154).

Douglass explains that his time with Covey "broke him" and "transformed him into a brute" (154). I argue that it was his confinement in a space that Covey had constructed to resemble a prison or a cage that sent him into "a sort of beast-like stupor" (154-5). The constant awareness of the rigidity of his confinement is maddening and would force the most steadfast optimist to discard his faith. There were no beacons of hope in Douglass' immediate space, so reaching the nearby Chesapeake Bay became a symbol of realized freedom. Although the bay was not far from the Covey home, it felt as if that distance was unreachable. He reveals that "[its] beautiful vessels [functioned as] shrouded ghosts [sent to] terrify and torment [him] with thoughts of [his] wretched condition" (155). Douglass uses this imagery to again highlight the indelible connection between physical and mental space. The limitations in his social space led to his mental digression and degradation; he began to internalize the terror permeating the police state in which he lived. Ultimately, it was his perpetual hope and desire for freedom that persists and compels him to resist Covey and reclaim his "manhood" once again (160).

Douglass does not reveal the specific details of his escape when his autobiography was first published in 1845 in order to preserve the safety of those involved, but he does 
expose the framework of social space that functioned as an extension of various plantations, farms, and work spaces that subsisted on slave labor. These additional physical barriers were built to obstruct the path to freedom for the runaway slave; they included but were not limited to gates that restricted unauthorized passage, watchmen, guards at ferry docks, sentinels on bridges, and patrols in woods (167). Douglass makes unquestionably evident that the institution of slavery was a system fortified by spatial boundaries constructed to entrap. Those responsible for designing the Underground Railroad, a system that aided Frederick Douglass and other enslaved persons in their escape efforts, understood the spatial dynamics at play in their society. They understood that social space was indeed a mechanism of oppression, and to thrive the Underground Railroad had to function, according to Douglass as an "invisible agency", in hidden spaces and channels that were loopholes within this system of control (177-8). The societal structure in the antebellum era, compiled in a public compendium of spatial codes, communicated that freedom was a form of trespassing, an illegal activity for the enslaved in the United States of America. Thus, when Douglass lived in what was deemed a free state, he realized that his "freedom" was really a convoluted process of hiding. His sojourn in New York involved this illusion of freedom, for as a fugitive slave he could trust no one and lived in constant fear of slave catchers (181-2).

\section{Exposing Spatial Networks in the American Institution of Slavery in Twelve Years a Slave: Narrative of Solomon Northup}

Where Douglass exposes existing structural boundaries within the system of slavery that serve to further ensnare those in bondage, Solomon Northup with the publication of his narrative demonstrates the fluidity of the demarcation lines between 
slave and free states. Once Douglass achieves his freedom, he seems to attribute his insecurity and fear to his status as a fugitive slave and treats his persecutors as rogue members operating outside of an otherwise democratic space of opportunity (181). With Twelve Years a Slave: Narrative of Solomon Northup (1855), an as-told-to account, Northup substantiates Douglass' feelings of instability as characteristic of the Black experience in the antebellum era in general, for the illusion of freedom that Douglass endures as a fugitive is an organized product of societal construction (XV-XVI). I contend that what Douglass classifies as illegal and unjust loopholes at work in the North are not simply the autonomous entrepreneurial efforts of "money-loving kidnappers" (181). These kidnappers are actually laborers in an extensive network that represents a calculated display of the complex spatial design of the American institution of slavery. Northup's narrative reveals a visible web of exploitation and disorder in the conscience of his society, and he proves that the true illusion is the contention that his homeland could simultaneously support the system of slavery and the cause of black liberation. Solomon Northup's collapse as a successful free man into bondage shows some indication of the Black man's true value to American life and culture.

Notwithstanding, Twelve Years a Slave: Narrative of Solomon Northup (1855) is a unique historical record that effectively contributes to the slave narrative tradition by offering experiences from the perspectives of those who were born into slavery and those who were kidnapped into the institution. Similar to Douglass, Northup speaks to the cruel systemic features of slavery (Foster 36). He also explores the ironies in his society and offers a critical perspective on the institution. The details of his unique journey from capture to escape are not the most meaningful features of this narrative, for he was freed 
while many others remained trapped in bondage. Ultimately, his story is about the structures within the American landscape that enabled his forced descent from a position of relative contentment into one of depravity. His twelve years of servitude is a story of displacement, and as a result, Sam Worley argues, his narrative challenges the assumption that "the principles of justice are available anywhere to the rational mind" (246).

In order to appreciate the gravity of his future entrapment in a space of terror and suffering, Worley suggests that Northup begins his narrative by "[situating] his own life in an unbroken network of family and society" (245). As a freeman, Northup benefits from much familial continuity. He maintains a pleasant relationship with Henry Northup, a white man who descended from the family who once owned Solomon's ancestors, and later Henry Northup would be the principal participant in his rescue. Northup describes his father as a man whose "whole life was passed in the peaceful pursuits of agriculture... [who] acquired by his diligence and economy a sufficient property qualification to entitle him to the right of suffrage" (Northup 19). Under his father's provision, he lives a childhood of amusement, which included violin and academic studies. Additionally, he learns valuable lessons from his father about humility, morality, and kindness as well (20).

He marries his wife, Anne, in a ceremony on Christmas Day in 1829. Mr. and Mrs. Northup are able to commence in the business of homemaking. He pursues a career in rafting and works as a hired hand, and she becomes a cook in high demand (22-24). When not actively engaged in labor, he spends time with his children in the community of Saratoga where he resides. He says that "he had nothing but the common hopes, and 
loves, and labors of an obscure colored man, making his humble progress in the world" (27). What Northup describes is a simple, but beautiful life, one that showcases a clear safe space of both a physical and emotional nature where he is free to pursue his passions and ambitions. Before he is kidnapped and plunged into the American structural network that comprises its internal slave trade and then into bondage as a slave, it is clearly evident that Northup is relishing in the space of home.

By intricately detailing his sense of home as a space of refuge, the reader can make clear distinctions in the context of his new, more hostile environment after his kidnapping. Northup's narrative follows this catastrophic journey, and it illuminates the structural components of his new environment by juxtaposing it against his former one. He outlines the boundaries and the intersections of the spatial context of his oppression for as long as he remains in that condition. In defiance to what he describes as being "hidden from the eyes of all my kindred, and shut out from the sweet light of liberty, for many a weary year", he unshrouds the space of his terror so that it could ultimately lead to its obliteration (27).

His journey begins innocently enough while out searching for employment on the streets of his village in Saratoga Springs. He meets two men, Merrill Brown and Abram Hamilton, who present themselves as two respectable employees of a traveling circus company. He would soon discover that Brown and Hamilton are slave catchers or agents in an underground network that funnels kidnapped free persons into the slave trading market. They offer to pay him to perform at their various engagements in different cities. He agrees and travels with them as far as Washington D.C., after procuring his free papers per their suggestion as a necessary safeguard before leaving the free state of New 
York. Obviously, they know that this suggestion will endear them to him making Northup more susceptible to their deception.

In the Capitol, Northup receives payment for his services and takes in a few social activities, including observing the public funeral of President William Henry Harrison and visiting a saloon. After indulging in some drinks one evening with Brown and Hamilton, Northup finds himself in, he says, "the most excruciating agony" (37). He has been poisoned, and as he drifts in and out of consciousness over the next several hours, he is instructed to visit a local physician's office by voices coming from faces that he is too delirious to recognize. These strangers to him were actually secret agents operating on the peripheries of the internal slave trading network. He follows them and observes, "[that] whether Brown and Hamilton were among them [was] a mere matter of conjecture" (37). What he is unaware of in his state of disillusionment, for he loses his ability to perceive of physical space, is that he has completed the transfer from a space of freedom to one of confinement. His regression from man to property has been concluded, for tragically he is in the hands of slave traders.

Afterward, he says "[he] followed a long passage-way or alley into the open street [that] ran out at the right angles from Pennsylvania Avenue" (37). Here, he is delineating some of the first identifiable structural spaces of this network. The next day, he awakens in a room to find that he has been chained and robbed of his money, free papers, and liberty (38). He once again encounters his slave traders, James E. Burch and Ebenezer Radburn, who would soon begin the initial work of branding him with a slave's mentality. Continuing in his role as archivist, Northup catalogues the space of his confinement by conveying important structural details of his room and the building. $\mathrm{He}$ 
observes that it was "like a farmer's barnyard [but] was constructed so that the outside world could never see the human cattle that herded there" (42). He notes that the building took on the appearance of a quiet residence, and the irony was not lost on him that this slave pen was situated in "plain sight" of the Capitol where he lamented "voices of patriotic representatives [boast] of freedom and equality" (42).

Later, he realizes that he is in an underground structure. With this retelling, Worley explains that Northup continues to emphasize structures in this network because this kidnapping network "defies the understanding of both geographic and ideological space" (Worley 251). His system of mapping makes this space visible to outsiders and/or believers in a singular version of America, the land of opportunity, rationality, and democracy. For some, even while an active system of slavery flourished in the South, it would be hard to conceptualize and acknowledge the reality and expanse of this space of terror, corruption, and hypocrisy. Northup would remain in what he would later discover to be the Williams' Slave Pen for an additional two weeks and would encounter many others in a similar state of misery on his journey through secret pathways, slave pens, and steamboats from Washington, D.C. to his final destination in New Orleans, Louisiana. In continuing his architectural mapping, Northup begins to compile a validating collection of census data. He crosses paths with members of the enslaved community who had been cast away by their owners and others who were sold into bondage as a form of punishment. In naming them, he reclaims a fragment of their humanity, and by detailing their histories he further uncloaks the extensive channels of this underground structural network. Identifying them in such as public fashion could also bring a measure of closure to some of the grieving family members from whom they were severed and in 
some cases never returned. For example, he met a freeman named Robert in a slave pen in Richmond, Virginia. Robert was from Cincinnati, Ohio, but had traveled south with two men who had "hired him" (61). Later, he was kidnapped and confined in Fredericksburg, Virginia (Northup 61). He would get stricken with small-pox and die on the brig en route to New Orleans. Another acquaintance was a freeman named Arthur. Arthur was from Norfolk, Virginia, but was attacked on a street one night and beaten until he was unconscious. He was held in a slave pen there and then transferred to the brig Orleans, while it was anchored in Norfolk (66). Arthur would experience the rare fortune of being rescued by some friends upon his arrival in New Orleans. Through his many conversations, Northup learns that slave pens were very common establishments in the major cities of the south, making clear the wide-ranging nature of this industry and its corresponding shadow of terror (66). Northup's transfer is completed in New Orleans, Louisiana, where he meets his first master, William Ford, and begins his new existence as a slave named "Platt."

Master Ford proves to be a reasonable man, but Northup would have encounters with others during his twelve years of enslavement that formed the fortress of oppressive space to which he was confined. To this end, he highlights methods of mental and physical torture as well as irrational working expectations during his time of enslavement. For instance, he is subjected to a slave breaker named Tibeats, who was just as villainous as Douglass' Covey and also utilizes invisible omniscience as approach of control. Under Tibeats' command, Northup lives in a constant state of fear and the vengeful wrath of this man whom he describes as a "cowardly and malignant tyrant" (120). Additionally, Northup reveals various tools of torture employed to suppress the 
sense of freedom among the enslaved. He details how three men, Warner, Will, and Major, are relegated to the "stocks", a device that restricted movement by securing its victim between two planks by either the neck/wrists or ankles (129). In this trapped position, the enslaved are whipped. Also, he discusses the vicious blood hounds that were often used for tracking potential runaways; these brutal beasts were capable of lacerating the flesh of their victims to the point of death (136-7). On the subject of brutality, it would be difficult to ignore his account of Pasty's plight, a slave woman who had the poor misfortune of suffering both the wrath of her mistress as well as her master, for she was frequently the victim of his sexual advances (197-200). She is a wretched example of the unique brutality that enslaved women in her position endured.

Identifying the institution's various tools of brutality was not Northup's only focus once enslaved; he maintains his attention on spatial arrangements as well. He notes how the swamps in this region with their deep waters, poisonous snakes, and alligators serve as clear, restrictive boundaries. Additionally, he discusses the network of operatives who worked within the slave states to help reinforce its permanence. He is frequently requested to play his violin at festivals in various locations throughout the region. As a result, he is subjected to constant scrutiny and learns, he says, that "catching runaways is sometimes a money-making business" (158). He details the menacing organization of patrollers who are paid by the planters to travel throughout the bayou in large companies inflicting trauma on the wandering slave (137). Also, spies, both Black and white, acted as guards within social spaces on the planter's farms, fields, and working areas. They lurked ready to expose the slightest indiscretion or act of resistance $(233-5 ; 251-2)$. 
Ultimately, Northup discloses a wide social network of hegemonic spaces operating both within and outside of slave states. As opposed to the introspective and interpretative prose of other slave narratives, Northup offers what he describes as a mostly objective historical record (321). This record includes a thorough study of the emotional and psychological impacts of these spaces on those existing in them. For the enslaved, he shows how these environments suppressed their will power and senses of determination and how frequently they were as defeated by the limitations of their circumstances as they were by the mighty whip. For the slave owners in these spaces, he underscores their absence of human decency and respectability and complete adoption of white superiority and moral blindness. This network that Northup is thrust into is essentially an underground railroad of torture that eventually would deliver its victims to the greatest depths of despair. The utmost example of this is the fact of Northup's own fate. Less than ten years after regaining his freedom, he disappears with much speculation surrounding his whereabouts. In the end, he seems to subscribe to the notion that hiding was the only means by which he could truly experience some measure of freedom. His extensive work as antebellum spatial analyst offers the greatest substantiation of this claim.

\section{Traumatic Space and Loopholes in Incidents in the Life of a Slave Girl}

Of the three narratives featured in this chapter, none more directly addresses the subject of traumatic space in the antebellum era than Incidents in the Life of a Slave Girl by Harriet Jacobs. Jacobs names a central chapter in this book, "The Loophole of Retreat", in which she recalls hiding in her grandmother's attic space for seven years to 
elude her captors; ultimately this space and the time in which she occupies allow for her life-altering mental transformation. Harriet Jacobs, or Linda as she calls herself in the narrative, flees to this space after years of resisting the advances of her slave owner, Dr. Flint. She pursues a consensual relationship with a white neighbor, Mr. Sands, in hopes of garnering additional protection. Although she conceives two children with Mr. Sands out of wedlock, Dr. Flint remains unwilling to sell her to him. Instead he intends to bring her children "to the plantation to be broke in", and as a result Jacobs makes a plan to escape (Jacobs 77). Understandably, motherhood changes the nature of this plan. Jacobs explains: "I could have made my escape alone; but it was more for my helpless children than for myself that I longed for freedom. Though the boon would have been more precious to me, above all price, I would not have taken it at the expense of leaving then in slavery" (74).

Thus, she settles for hiding in plain sight, where she can watch her children, but remains invisible to them and the rest of the world until she is ready to escape via other methods. This attic space, her refuge, is constructed for concealment, but most importantly it offers liminality or a spatial position in the border between the space of liberty and the space of enslavement. The space, as she describes:

[Was located in] a small shed [that] had been added to my grandmother's house years ago. It was a pent roof, covered with nothing but shingles, according to the southern custom for such buildings. The garret was only nine feet long and seven wide. The highest part was only three feet high and sloped down abruptly to the loose board floor. [Within it] there was no admission for either light or air (91-2).

In this attic space, according to literary critic, Michelle Burnham, Jacobs finds and occupies a loop hole that functions as a blind spot or a liminal space in the margins of her society (289). Since this space operates between restriction and liberation, as a 
getaway it is both mental and physical. It provides relief from the kind of brutality associated with enslavement, but replaces it with more tolerable pains that serve as a reminder that her freedom had not actually been secured:

It seemed horrible to sit or lie in a cramped position day after day, without one gleam of light. Yet I would have chosen this rather than my lot as a slave, though white people considered it an easy one; and it was so compared with the fate of others... God pity the woman who is compelled to lead such a life (92)!

Literary scholars Nellie McKay and Frances Foster argue that Jacob's decision to conceal herself in this manner affords her a measure of personal freedom through the technique of camouflage and also provides her agency, which she uses to protest against slavery and patriarchy (XIX). According to the literary scholar, Dr. Cynthia Wallace, this approach allows for a synthesized literary critique of oppressive ideologies and institutions as well, and Jacobs' message of resistance addresses the specific web of exploitation that enslaved women suffered (467-9). Thus, the attic space enables a "tactical operation of the loophole" (Burnham 279). Jacobs details her occupancy of a marginal space, which in effect converts it into a site of Black feminist agency, in order to challenge the hegemony and oppression of her society. Jacobs confronts her own life experiences by engaging the motif of space in her work as a means of effecting change in her actual socio-cultural space.

In "The Framework of Culture", Robert St. Clair and Ana Williams argue that "culture functions in the spatial contexts of colonialism and structuration" (1). They suggest that culture is dynamic and is in a constant redefining process triggered by "social and cultural forces within a cultural space" (4). Language (literature for our purposes) can be used to "represent the social construction of reality" (4). As Jacobs is attempting to demonstrate, challenging old structures of colonial or patriarchal space can 
help to craft more desirable social spaces and experiences, for what an analysis of space does more successfully than a more generalized critique of colonialism is that it projects very clear phenomena into the present (2). Challenging spatial arrangements can help to promote the construction of new ones along with new, more effective social systems and social experiences.

Relatedly, in her description of this attic space or space of retreat, Jacobs highlights the access and privilege that it affords her, experiences that were not available to her in the physical space of the socio-cultural realm of her enslavement. She could watch passersby and listen in on "conversations not intended to meet [her] ears" and not suffer any immediate repercussions (94). She could hear the intentions of slave hunters as they plotted their next devious acts (94). Jacobs thus affirms for her readership that the enslaved understand and appreciate the space of freedom. She emphasizes for them that paramount to achieving this reality and/or this feeling is security. As an enslaved woman, she is now "secure" in her retreat, which is essentially a casket, and observes "[that] there was no place, where slavery existed, that could have afforded [her] so good a place of concealment" $(94,98)$. The comparison that she is making here between her space of enslavement and this tomb that she has willingly chosen should communicate a message that is undeniably jarring and incontestable. This is clearly her objective. She unquestionably opens her readers' eyes to the brutal reality of the enslaved, and she, from her own mouth, refers to her experience as better than most (92). As a result, one can absolutely imagine the horrors that exist for others, who remain entrapped in the system, in the spaces that they occupy. 
Jacobs is asserting that her break away in this liminal space is a way out of the closed system of slavery, for she disobeys the oppressor's rules of law with regard to the enslaved in order to one day be able to abide by the rules of law that apply to recognized members of the human community (Burnham 289). Thus, the loophole which Jacobs occupies is inclusive of both the spatial and textual meaning of the term; it is both physical space as well as a legal escape (284-5). In vocalizing from within this dualpurposed loophole, Jacobs affords herself a position as a singularly, utilitarian spectator of slavery, so that she, via her unique perspective, can offer a more direct critique of the institution. This omniscience makes her case almost impenetrable.

Typically, the enslaved, in terms of their personal narratives and history, were relegated to silent spaces or the margins of memory. Frederick Douglass and Solomon Northup's narratives both reflect the limited opportunities for empowerment within the established slave structure; additionally, both argue that their social spaces, much like those that surround Jacobs' loophole, offered limited hope and opportunity. However, Jacobs was able to break through this kind of concealment while enslaved by occupying a space of hiding, which is essentially a space where her humanity was reclaimed in terms of its perceptibility and value. Although Jacobs' narrative was very much shaped by the help of abolitionists, such as Lydia Maria Child, the reader can appreciate a clear sense of her voice and her profoundly determined sense of agency. As Valerie Smith notes, Jacobs is able to inscribe "a subversive plot of empowerment beneath the more orthodox, public plot of weakness, and vulnerability", which was the conventional pattern of rhetorical form for the popular sentimental novel of the time (226). 
Notwithstanding, in the Incidents of the Life of a Slave Girl, Jacobs is able to demonstrate many, important truths about the life of the enslaved, specifically about the spaces that enslaved women occupy. She showcases the hypocrisy of some Christians, like the Flints, who turn a blind eye to its brutality, and exposes their "religion" as a device of the institution. She formulates connections between the institution of slavery and Christianity throughout the book because she is compelled to establish how religious hypocrites have contributed to her oppression and submission. In the chapter, "Church and Slavery", she states:

There is a great difference between Christianity and religion [in] the south. If a man goes to the communion table, and pays money into the treasury of the church, no matter if it be the price of blood, he is called religious. If a pastor has offspring by a woman not his wife, the church [will] dismiss him, if she is a white woman; but if she is colored, it does not hinder his continuing to be their good shepherd (62-3).

Also, she uses the shame of being a sex tool in order to garner sympathy from her readership. Jacobs engages in the taboo subject of sexual relations between the enslaved and slave holders as an attack on these Christian men and women, who in her opinion, arrogantly disobey God's law. She also validates her own self-worth and that of other enslaved men and women when she recounts how she pleads with her sympathetic employer, Mrs. Bruce, to resist buying her freedom. She explains, "I [object] to having my freedom bought", for her freedom only rightfully belonged to her (155). After existing in a loophole for years, she had internalized it, and she finds the fortitude to claim her seat at the table. No longer would she accept a position of submission as "piteous", "virtuous" women of the nineteenth century were expected.

In her role as witness and author, Jacobs's confessional rhetoric, while reflecting on her experience in her secret hiding place, is employed to unveil the darkness of her 
experience. Her narrative is very much concerned with a subject of secrecy and exposure. She addresses the social context of her space without the limitation of great caution; she has freed herself from this degrading social practice. While in her loophole of retreat, she demonstrates that hidden spaces have the potential to empower; she observes a measure of freedom from the bondage of slavery while hiding in the space of her grandmother's attic. She affords herself a form of liberation of the spirit and the mind, and the body would soon follow. For many members of the enslaved community, the toughest battle was breaking its mental bonds. For Jacobs, her loophole of retreat facilitates a new resolve and a new sense of consciousness, much like the new perspective that Frederick Douglass gains after he defends himself against his slave master Covey and refuses his abuse and domination any further. Both Douglass and Jacobs achieve symbolic forms of freedom, for both are technically, when they realize freedom as concept, still located within the closed institution of slavery.

Although Harriet Jacobs had to slightly temper and filter her "truth" to satisfy her mostly white female audience, with this narrative, she triggers a very specific kind of agency: one that is inclusive of African American culture and one that strategically recognizes the failure of traditional feminism to address equality and justice issues for Black women. Her contributions to the development of Black feminism are not a focus of this current research, but it is important to note, beyond its analysis of the space of enslavement, the many categories in which this narrative is groundbreaking. Notwithstanding, Jacobs' influential slave narrative utilizes subversive methods of empowerment and operates as a witness to the misrepresentation, discrimination, and oppression of Black people in order to directly participate in a call for the construction of 
safe spaces for them of both a physical and emotional nature---a demonstration of the most admirable form selflessness and activism.

Definitively, antebellum slave narratives are written quests for freedom; they are all united on this front. They defy the racist mythology of their antebellum societies with the most reliable sense of authority. Frederick Douglass, Solomon Northup, and Harriet Jacobs assert their truths about the institution of slavery, brazenly confronting the dominant narrative. Mining their lived spaces with great focus and attention, these authors signaled an alarm, most importantly, for their descendants and others. Their personal and detailed testimonies of their encounters with enslavement pioneered later movements for human equality in this country by producing the first public calls for selfhood. With the Civil War and Reconstruction on the horizon, these narrators underscored the necessity of safe spaces for African Americans, locales where they could engage in economic and social independence and self-sufficiency. These authors compelled the world to see how the social spaces aligned with the institution of slavery, the ones that they knew first-hand, were more convoluted than most imagined. Enslavement involved an expansive, organizational structure of trauma, one that could be replicated, reinvented, and/or reincorporated anywhere at any course of time. Considerhow much different was the experience of the free person of color from that of the enslaved in the antebellum period? Solomon Northup provides a testimony that would suggest that their worlds, with slave catchers lurking at every corner, were not so different. Their accounts teach us to be careful; history can and does repeat itself, and unfortunately, with regard to the traumatic social spaces that they worked to expose, their steadfastness was impenetrable. 


\section{CHAPTER III}

\section{PASSING THROUGH TRAUMATIC SPACES OF BLACKNESS AND THE BLACK BODY IN LITERATURE OF THE NEW NEGRO ERA AND HARLEM RENAISSANCE MOVEMENT}

"This is the mountain standing in the way of any true Negro art in America-this urge within the race toward whiteness, the desire to pour racial individuality into the mold of American standardization, and to be as little Negro and as much American as possible." -Langston Hughes, "The Negro Artist and the Racial Mountain"

In the Introduction to Black Bodies, White Gazes: The Continuing Significance of Race in America, Dr. George Yancy contemplates the ontological processes and epistemological influence of the white gaze in relation to black bodies. He examines the destructive power of this gaze in its ability to inflict "pain and suffering [on] black bodies that have been stereotyped, criminalized, and rendered invisible by [it]" (XXIX). This gaze, a multifaceted weapon that has commanded the attention of Black Americans in order to preserve their precarious mote of security in this country, has perdured as an unarguable danger. There are no greater exemplars of this tragic truth than those revealed in the horrific circumstances involving the kidnapping and murder of Emmett Till. It is unfathomable to reconcile the innocence and illumination of his baby face so clearly visible in his childhood photographs with what his murderers, Roy Bryant and JW Milam, perceived as they tortured him for hours while ignoring his cries for his mother's and/or God's deliverance. These particular cries were clear indications of his undeniable humanity in their display of godly reverence and the uniquely human feelings of love and sorrow. How inhumane to ignore any cries but those especially? The treachery and 
malevolence of their white gazes allowed a childish wolf whistle to resonate as an act of terrorism.

In actuality, that whistle was an objection to terrorism or the hegemonic system of white spatial order and social boundaries, and this violation of de jure segregation and racism ${ }^{10}$ triggered the actual terrorists to stereotype a fourteen-year-old boy as a villainous, black brute and a virulent societal danger. Emmett's crime was elevating the visibility of his blackness when the rule of law for black bodies, especially in the Jim Crow era, was to maintain an appropriate societal space in the crowd of other nameless, Black anonymities.

This sinister white gaze has the shifting perception configurations of a kaleidoscope, a viewing tool that uses physics to reflect new images of fixed objects. In one instance the black body is received as a threat and in the next it is synthesized as a meaningless entity, indistinct from the landscape. Historically, this social space correlating with the black body, inclusive of and between incriminating "hypervisibility and invisibility", has functioned as the appropriated social parameters of blackness or the operative black space in the public sphere (Yancy XXX); tragically, the white gaze often defines what is possible for Black people both in terms of social mobility and social accessibility. Franz Fanon illustrates this black social restriction and confinement in Black Skin, White Masks:

The white world, the only honorable one, barred me from all participation. A man was expected to behave like a man. I was expected to behave like a

\footnotetext{
${ }^{10}$ Much research exists that attests to the strategic design of racial segregation in America via explicit government policies and practices, e.g. redlining, racial housing covenants, and FHA loan restrictions. See The Color of Law: A Forgotten History of How Our Government Segregated America by Richard Rothstein and others. Furthermore, this work is charged with the responsibility of acknowledging as well as substantiating the myth of natural order with regard to constructed social space where it exists, especially when it has contributed to hegemonic persistence and traumatic experience.
} 
black man or at least like a nigger...I was told to stay within bounds, go back where I belonged (114).

After the Civil War, there was great potential for more inclusive societal and structural change, but the white gaze persisted in reestablishing the intentions of the slave holder's consciousness. As a phenomenological observation of the white gaze, the black body remained in a restrictive binary condition as either a symbol of labor capital or a potential threat that necessitated policing. The boundaries of the antebellum spaces such as plantations and slave-catching networks shifted during and after Reconstruction, but not to the extent that this "barring" to which Fanon refers did not function as an accurate description of the postbellum Black experience. The central focus of this chapter is to contextualize this experience and consider how the epidemiological transfer of inferiority to the black body advanced and created uniquely new activist purposes for Black authors during these formative African American literary periods.

Informed by the lingering traumas of enslavement, many Black writers in the postbellum U.S. scrutinized the evolving social spaces of their society. In the face of a budding economic structural evolution, they outlined new repressive spaces and systems of negotiation related to them. Additionally, my research is concerned with the role that postcolonial literature played in exposing these reinventions of racist social structure and how these spaces materialized while simultaneously maintaining slave-era forms of trauma and oppression. This chapter will endeavor to understand their design and traumatic nature; additionally, it will examine how the black body functions as a symbolic designation of spatial boundaries, social oppression, and social exclusion. We consider the cultural practice of passing as a means of contextualizing black space and the implications of this practice as it pertains to the trauma wed to the black body, a space 
that was frequently appreciated as both invalidating and criminalizing. The literature of this era will demonstrate the yearnings of Black Americans to thwart their social exclusion and to claim greater participation in their society in confrontation with the stark reality that some American traditions are difficult to extinguish.

\section{New Racialized Spatial Arrangements in the Postbellum Period}

The calls for safe spaces that characterized the intentionality behind antebellum slave narratives were the initial movements in the birthing of the African American literary tradition. They began as a confrontation with a racist society, and the battle persisted for much was unresolved in the state of the nation following the Civil War. Especially for the majority of African Americans, a societal place had yet to be determined for them (Frankel 254-263). In March of 1867, The Reconstruction Act was passed, and many of the codes that restricted Black life were dismantled. Key Reconstruction era legislation included The Thirteenth Amendment, which was passed in 1865 to finally outlaw slavery. The Fourteenth Amendment provided citizenship and equal protection of the laws to African Americans and was passed in 1868, and The Fifteenth Amendment, which granted voting rights to Black men, was passed in 1870 . As a result, some African Americans were allowed to vote, participate in elected office, and have influence in their local politics, while other African Americans experienced very few changes to their lives. By 1877, many state and federal courts had reversed the social and economic gains that a small segment of the African American community had achieved during Reconstruction. By 1896, with the Supreme Court affirming the legality 
of separate but equal with its determination in the case of Plessy v. Ferguson, a new era of racial conflict was spreading across the nation.

Economist, Robert Higgs, characterized this era as the "the rise of urban manufacturing, trade, and service industries, [also] described as the [American] industrial revolution" (VII). He argues that the establishment of sound institutions and property rights were key components in the potential for economic growth during this phase. Emancipation dismantled property rights for many whites when the enslaved were freed, which in theory provided the slaves with status as citizens following the passage of the aforementioned amendments (Higgs 113). This economic and spatial restructuring created a great sense of disequilibrium for many social elites (114). Unfortunately for the newly freed men and women, the pursuit of a new societal equilibrium would not proceed on a solid moral high ground. The inequalities that existed prior to emancipation would continue into the postbellum era, and freedom came with many restrictions that were still closely aligned with their physical bodies as Plessy v. Ferguson exemplified.

Relatedly, Higgs explains that although data pertaining to income and earning statistics for Black people during this time period are limited, undeniably this data would demonstrate how a persistent occurrence of discrimination curbed economic opportunities for Blacks (120). Generally, Blacks earned less and were concentrated in more lower-paying industries. Those who did not migrate elsewhere "found themselves with few skills, without physical property and [clustered] in the devastated South" (121). Across the nation, lynch mobs, race riots, the resurgence of the Ku Klux Klan, disenfranchisement campaigns, legal oppression mandated by white-dominated court 
systems that delivered unequal justice, and limited access to educational opportunities wrought the Black experience and restricted Black mobility and advancement.

These tools of intolerance were refashioned, post-emancipation deployments of racism. The greatest among them was the system of spatial segregation known as Jim Crow. Jim Crow was a designation of white social space in the south and a public coding process of restricting black bodies. Following Plessy v. Ferguson, southern states passed laws that codified racism at state and local levels, demarcating public space with value or insignificance. What was a unique and often ignored feature of Jim Crow was not just its function as an acknowledgment of the nation's recommitment to racist ideologies in this time period, but this systemic practice also validated that whiteness, in this phase of postbellum industrial restructuring, was essentially a form of property as well (Harris 1757-8). Space was being defined in terms of access and privilege. Segregation merely identified in clearer terms who was privileged or entitled to inhabit the spaces that black codes and segregation would deem as white. Additionally, these restrictive designations were as prevalent but less visible (or less publicly acknowledged) in the North.

In Bourgeois Nightmares: Suburbia, 1870-1930, Robert M. Fogelson explores less overt systems of racial oppression across the nation with the birth of racial housing covenants, which were agreements among early real estate developers that led to the segregation-influenced spatial mapping of American communities. In the south, public facilities were marked with very visible signs that indicated who had permission to access or utilize a specific space or service, but with racial housing covenants the exclusionary tactics were less observable because they occurred in the underwriting of contractual agreements. However, the impact was no less devastating and just as limiting. Fogelson 
explains that these legal devices banned owners from "selling and leasing to nonCaucasians" and created strict rules pertaining to how property owners could use their property (4). These restrictive covenants, he argues, were a "nationwide phenomenon" and could be found in city and suburban developments in California, Maryland, New York, Massachusetts, Texas, Kansas, Georgia, etc. (22-3). They were designed to "protect" affluent and working class white families in residential establishments, including subdivisions and cooperative apartment houses. Fogelson suggests that these contracts reveal what suburbanites feared and that was not only the presence of dangerous classes of people; they were terrified of a change in the market and social structure where they could potentially lose their status as "the chief beneficiaries" of American prosperity (24). Across the nation, the American antebellum ethos was reaffirmed: some white men were created equal and some white men deserved the right to life, liberty, and the pursuit of happiness.

With the uncertainty that the Civil War caused to the social structure, these covenants were clear examples of whites attempting to consolidate their dominance in the new order. It was a reaffirmation of their stability and permanence at the top of the social and racial hierarchy. As early as the 1860 s, according to Fogelson, these land developers promoted "well designed suburbs" as the "most refined and the most soundly wholesome forms of domestic life" (27). He continues, with restrictions in place developers could "prevent unwanted change by keeping undesirable people and activities, commonly referred to as undesirable encroachments, out of the community" (122). These covenants were not foolproof because they relied on race and class as the basis for which to exclude. Race was easier to determine, still not an exact science; there were examples of 
real estate agents and others who passed to get around the restrictions (131). However, determining what qualified someone as a lower-class citizen would prove to be more problematic, and thus more loopholes opened for prospective tenants and homeowners with class not being as clearly delineated in the absence of income verification measures and requirements (131-2).

Regardless, when the Federal Housing Administration (FHA) was founded as an initiative of the National Housing Act of 1934, legislation aimed at improving the process of regulating mortgage terms after the banking crisis of the 1930s, it relied heavily on racial covenants and restrictions (207). Later these adopted policies would contribute to the twentieth century practice of redlining, which involved more extensive discriminatory practices aimed at limiting investment opportunities in communities on the basis of their demographics (Jan 2019). Racial housing covenants established these demographics through exclusionary practices, which made the redlining of specific communities achievable.

\section{Hegemonic Persistence in the Coding of Blackness and the Black Body}

Housing covenants, Jim Crow policies, and later redlining are old traditional practices disguised in new terminology and operational methods. In the United States, the mapping of space has always been intentional and institutionally managed to represent the values of the privileged. Again, social space is not abstract; according to Henri Lefebvre, it has status and is "the principal stake of goal-directed actions and struggles" in a socio-political setting (410). Thus, space is dominated as well, and when the institution of slavery was ended, space was reconstituted to enforce the pre-existing social hierarchy, and the black body was the clearest point of demarcation. Lefebvre 
argues that space represents logical relationship negotiations of exclusion and inclusion and implication and explication (293-4). He suggests that "[humans] know they have a space and that they are in this space" (294). Hence, space is not only dominated, but it is also possessed. Social space in America has often been conceptualized in terms of oppositions - who does and does not have possession, and this production, Lefebvre states, "is carried out with the state's intervention, and the state naturally acts in accordance with the aims of capital... [which is] an invasive force serving dominant economic interests" (375).

Again, the dominant economic interests in the postbellum era remained unchanged; what evolved were the demarcation sites of exclusion. External signifiers, such as property boundaries enforced by patrollers, dogs, and travel pass requirements, were transferred directly onto the black body. Blackness became the more uniform signifier of exclusion. Blacks were "overdetermined from without" and fixed into lower/working class positions (Fanon 116). Thus, black bodies became coded in meaning, and the spaces that these bodies occupied became racialized as well. The black body essentially became an instrument of social commentary. In "Crossed Lines in the Racialization Process", professor Robert Bernasconi suggests that acknowledging this change in tactical, operational approach is essential. He argues that "the past controls the present and understanding how past racisms have operated and reinvented themselves in response to attempts to challenge them prepares us to fight against current racisms" (207).

Furthermore, Bernasconi explains that dominant classes recognized that racemixing could change the racial landscape in the Reconstruction era (216). He notes how 
important it was for politicians like Thomas Jefferson in the antebellum era to explain the laws as they pertained to racial classifications, which he attempted to extensively in a letter he wrote to Francis C. Gray, a fellow politician from Massachusetts (216). Jefferson knew, especially in consideration to his own personal habits ${ }^{11}$, that these conversations were essential, for they could define the future in terms of American racial identity. These clarifications were especially of concern after the Civil War. Bodies were policed even more strictly and rules related to racial identification better clarified to maintain social order. Thus, Bernasconi suggests "to control sex across the color line...many of the other restrictions that are known collectively under the title of 'segregation' were introduced" (216). New attention was paid to clarifying ambiguity related to boundaries. The Civil Rights Act of 1875 was introduced by Republicans with the intention of achieving symmetrical equality by removing restrictions between the races. Opponents feared "that the Republicans sought [disingenuously] to legislate 'social' equality between the races" in order to increase their voting base (Bank 304, 312-13). In response, the Democrats argued that the racial divide existed as a divine plan to avoid amalgamation and degradation (310-11).

Essentially, the racial coding of bodies was about the maintenance of privilege. If race lost its salience, then how would the American caste system be maintained? In the United States, the institution of slavery began the practice of inscribing racism on the black body. The intensity and necessity of this body signification has fluctuated with time, but it has strong colonial roots that were inherited by the later generations. Moreover, in Black Skin White Masks, Frantz Fanon also acknowledges and explores

\footnotetext{
${ }^{11}$ Thomas Jefferson fathered at least six children with Sally Hemings, an enslaved woman on his Monticello plantation.
} 
these historical, existential notions related to blackness and their resulting traumas; he affirms that as a result of colonial conflict a specific frame of reference was placed on the Black person (110). These designations were "inferior" and "other". Fanon suggests that the black body produces a "racial epidermal schema" in the "spatial and temporal world", and it triggers an imprisonment to inferiority born of "legends, stories, history, and above all historicity" (111-2). According to Fanon, the result is a barring of Black people from participation in the "white world, [which they believe represents] the only honorable one" (114). This barring involves an assignment to a space within established boundaries.

To further clarify, Fanon uses the example of members of the Jewish community, who have often experienced similar forms of cultural stigmas and exclusion, to emphasize the significance of color. He explains that Jews were familiar with the pain of being stereotyped, but they also had the protection of their complexions, which enabled them to often go unnoticed, if desired (115). Robert Higgs substantiates these similar points in his analysis of the postbellum American economy between 1865 and 1914 . He states that during this same period: "Blacks experienced greater discrimination than white immigrants in the non-market sector, especially in obtaining education and equal treatment under the law, and ethnic prejudice against blacks in the labor market was more intense and widespread [as compared to] what other immigrants experienced" (123). Race was the only distinguishing element here. Thus, Fanon's notions of blackness are validated when he suggests that Blacks "are slaves not to the idea that others have of [them] but of [their] own appearance" (116). Blackness is coded in symbolism as notions are fixed to it. 
In Dark Matters: On the Surveillance of Blackness, Simone Browne explores the historical foundations of this coding practice. She suggests, as Fanon had also concluded, that slavery and the branding of black bodies by slave owners made Black people objects and their blackness a visible commodity (Browne 94). She argues that this commodification of their bodies was useful because it made them "ontologically insecure" (109-10). This insecurity, George Yancy asserts, is a product of being "weighed by the white imaginary", the most unfortunate prison (Yancy XXX, 81). The institution of slavery required the possession of black bodies, literally and ontologically. Yancy explains this ontological transformation:

Whiteness is deemed the transcendental norm, the good, the innocent, and the pure, while Blackness is the diametrical opposite. This is the twisted fate of the Black body vis- à- vis white forms of disciplinary control, processes of white racist embodied habituation, and epistemic white world- making (XXX).

The violation of the black body begins in the white imagination through what Yancy calls "felt invisibility [or] a form of ontological and epistemic violence... initiated through white spectatorship, a generative gazing that attempts to violate the integrity of the Black body" (73). Whiteness is also constructed in the negation and/or reconfiguration of blackness (71). The space of the black body is a traumatic one in this scenario because it is held responsible for qualifying the alleged purity and perfection of white bodies. Black people become entrapped in a reactionary battle over their own images. In Embodying Black Experience: Stillness, Critical Memory, and the Black Body, Harvey Young explains how this loss of control over one's public perception drives conflict: 
The experience of racial (mis)recognition plays a determining role within the formation of phenomenal blackness. The black body, whether on the auction block, the American plantation, hanged from a light pole as part of a lynching ritual, attacked by police dogs within the Civil Rights era, or staged as a "criminal body" by contemporary law enforcement and judicial systems, is a body that has been forced into the public spotlight and given a compulsory visibility. It has been made to be given to be seen. This awareness of one's status as the seen/scene structures behavior (12).

According to professor and architect, Mario Gooden, the stereotyping and constructing of otherness that was involved in coding black bodies were "strategies of symbolic containment... used to control the ambivalent and to create boundaries...[to] preserve an illusion of control and order" (102). As a resulting form of resistance, he continues, "[Blacks would have to] move through space, negotiate spatial relationships, and create alternative spaces for creative expression and daily affirmation of life in American society" (15).

With grit and determination, Blacks in the postbellum era seized the opportunities that were presented to affirm their lives and humanity. In Playing in the Dark, Toni Morrison discusses the participation and potential of creative expression in the mode of resistance. She explains how national identities are molded and refined by national literature, and she dissects how this process affects America's Black population, which became a "surrogate for mediation on problems of human freedom" (37-9). She suggests that early Americans suffered from many human fears that pertained to the prospect of being powerless, borderless, poor, outcasts and/or failures in the evolving new world, which lacked "so-called civilization" (37). Fortunately for them, these fears, which felt like an uncontrollable darkness, could be transferred to the country's Black population. She suggests that "nothing highlighted freedom, if it did not create it, like slavery", and 
an objectification of darkness became a clear, identifiable facet of American literature as "black slavery enriched the country's creative possibilities...for in the construction of blackness and enslavement could be found not only the not-free but also, with the dramatic polarity created by skin color, the projection of the not-me" (38).

The black body and slavery made freedom more palatable. Through the construction of blackness, whites could appreciate the value of freedom and their whiteness. New white immigrants, many of Irish and Jewish descent, could also consolidate their whiteness within the mainstream through the projection of blackness (Kibler, 21-50). Later in chapter 5, we will explore black caricatures and the tradition of minstrel shows. Blackface, minstrel performances, and black caricatures demonstrate white Americans' fascination with validating their superiority. There is an admiration of Black culture involved in these performances, but for whites, in their position of privilege, blackness and the black body offer positive reinforcement. Superiority so greatly depends on the presence of inferiority. Morrison asserts that American writers are shaped by their racial other, and the literature often became an "invisible mediating force" (46). For Black authors, many are compelled to explore what is often informed by the distortion and exploitation of their blackness.

\section{Black Identity and the Exploration of Passing as a Mediating Force in the Literature of the New Negro Era and Harlem Renaissance Movement}

In the postbellum era, authors were diligently working to progress the literary achievements of their antebellum, activist predecessors by remaking the African American experience through a literary exploration of the range of problems pertaining to race and the color line (Franklin 31-36). They understood, as Toni Morrison asserts in 
Playing in the Dark, "the objective value and meaning to color" (49). This was the emergence of the New Negro era from 1865-1917. According to Daphne Lamothe:

These writers and artists adopted and adapted anthropology, folklore, and sociological discourses to name and create a cohesive, collective, and modern Black identity... they produced as "sites of culture" in order... to create counter narratives to American society's racist discourse on blackness by mapping African American culture across particular geographical spaces, while viewing it from their socially mediated "sights," or perspectives (1).

Unlike their white literary counterparts, the biographer, Sally Ann Ferguson, suggests that these African American authors adopted the burdens and joys of their literary forefathers, such as Frederick Douglass, Solomon Northup, and Harriett Jacobs (1). Exploring the communal ties that bound members of the Black community together was a key characteristic of the Harlem Renaissance.

Following the paths of authors like Charles Chesnutt, James Weldon Johnson, Paul Lawrence Dunbar, and others in the New Negro era, writers and artists of this period from 1917-1940 brought agency to their imaginings in order to promote better understanding of the Black experience in America. David Levering Lewis says "The Harlem Renaissance was a somewhat forced phenomenon, a cultural nationalism of the parlor, institutionally encouraged and directed by leaders of the national civil rights establishment [such as W.E.B. Du Bois, Charles S. Johnson, Marcus Garvey, Philip Randolph, etc.] on the paramount purpose of improving race relations" (XIII). Artists and writers such as Jean Toomer, Zora Neale Hurston, Langston Hughes, Nella Larsen, Countee Cullen, Gwendolyn Bennett, Alain Locke, George Schuyler, and others worked to bring their culture to the mainstream. They hoped to successfully use the medium of art to change society in order to have a more comfortable space in it (XXI). This Golden 
Age of Harlem was a period of extraordinary achievement in the arts for Black Americans. These artists were inspired by a new purpose, one that not only highlighted the serious concerns related to social conditions, but as Daphne Lamothe explains, "confront[ed] the classist, racist, and cultural biases of the dominant society and challenge[d] their readers to imagine a different set of relations between the powerful and the oppressed" (20).

Following the Civil War, the coding of the black body triggered new impositions and spatial designations; as discussed earlier, spaces of blackness were reconstructed in this time period, and black bodies continued to signal social exclusion. The transition from slave labor to machine and free-labor systems did not change capitalism's influence on spatial arrangements; a fixed, lower working class was still required, which is why many landowners in the south quickly moved to reestablish their labor force by locking the newly-freed into exploitative sharecropping contracts. One cultural practice discussed by many authors of this time period that challenged these social spaces and class arrangements was racial passing, which occurred when Blacks and people of other ethnicities pretended to be of exclusively European descent for the purpose of gaining certain legal protections and social privileges. Passing was a means of circumventing traumas and social stigmas.

Correspondingly, passing is most often examined through a psychological lens as a practice adopted to escape persecution and oppression; it also demonstrates the fragility and burden of race; here, via the authors who depict this real-life phenomenon, it will be investigated additionally as a means of identifying the Reconstruction and postReconstruction parameters of blackness or the range of access that the black body was 
minimally afforded. Thus, the passer in this role will allow us the opportunity to gauge the socio-spatial limitations of blackness. By rejecting these limitations that the black body signaled, many passers were willing and able to cross the color line. According to Gayle Wald in Crossing the line: Racial Passing in Twentieth Century Literature and Culture, "racial passing reveals, boundaries, as entities that must continually be produced, safeguarded, and maintained, [that] are also active sites of negotiation, contestation, and struggle" (80). Participants transcended the physical boundaries of their black bodies, defying their utility as tools of the racial order.

Whiteness was a form of social capital, and Wald suggests that for Blacks, in this case, crossing the color line was "a strategic appropriation of [the white] race's power" (IX). After the end of The Civil War, white supremacy required new guidelines for its implementation, and Wald explains that the color line provided "territorializing functions through its ability to impose and regulate social inequality" (5). These guidelines were implemented in all domains of public and private spatial arrangements. Although many did not for various reasons, members of the Black community who projected an ambiguous racial identity could pass rather than be subjected to the control of white supremacy and racial definition of blackness.

In "Whiteness as Property", law professor Cheryl Harris details how true this was for her grandmother, who passed for white in the 1930s to pursue better economic opportunities. Harris explains how her grandmother bravely entered the white world or "a place where white supremacy and economic domination met-[navigating] the worlds within the world that existed" (1711). In her estimation, her grandmother was “transgressing boundaries, crossing borders, spinning on margins, traveling between 
dualities of Manichean space rigidly bifurcated into light/dark, good/bad, and white/black" (1711). Harris compares her grandmother's process of spatial negotiations to trespassing by means of a false passport (1711). She asserts that this practice was necessary because "becoming white meant gaining access to a whole set of public and private privileges that materially and permanently guaranteed basic subsistence needs and therefore survival" (1713). That is why she argues that "passing is well-known among Black people in the United States and is a feature of race subordination in all societies structured on white supremacy" (1712-3). She suggests that passing elucidates how in various phases of time and in various cultural experiences whiteness has "signified and [been] deployed as identity, status, and property, sometimes singularly, sometimes in tandem" (1725). Thus, whiteness is a valuable asset that marries a range of benefits including, property interests, legal protection, and the right to exclude (1713-4). The latter is of interest to this research. Exclusion meant an influence on spatial changes of varying formulations built on the fear and perception of blackness; what transferred from the slave-era into this new space of time was the significance of being white and its correlating benefits of access to and possession of the properties of whiteness.

In conclusion, Harris states that there was a "presumption of freedom attached to whiteness that functioned as "a shield from slavery, a highly volatile and unstable form of property; the color line became a [new] line of protection and demarcation from the potential threat of commodification, and it determined the allocation of the benefits and burdens of this form of property" (1720-1). Though the construction of racial identities, white privilege, and racial subordination were all important mechanisms essential to the success of the institution of slavery, Frederick Douglass and Solomon Northup helped to 
demonstrate how the demarcations or socio-structural spatial arrangements were equally and conjunctively vital as well. In alliance with these authors, authors of the New Negro era and Harlem Renaissance movement offered insights into the newly reconstructed and traumatizing spaces of their societies; their bodies were the most contested spaces, and they highlighted the effects of being designated as Black by the ideologies and practices of white supremacy in their postbellum world.

\section{Transcending Black Spatial Boundaries in Chesnutt's The House behind the Cedars}

One of these prolific writers in the postbellum era was Charles Chesnutt; he offered his readership a lens through which to gauge the Black American experience. Through his extensive journaling, Chesnutt made his writing aspirations very clear early in his career (Ferguson 1). SallyAnn Ferguson explains that he was "a mentalist determined to write for a high holy purpose and...he would pursue this goal clandestinely by literary means...by what might be called genetic theorizing" (1). This literary ambition may have been more of a consequence of his own physicality, for although he was extensively connected to a Black community and publically acknowledged his African American roots, he wore the appearance of a white man (3). Thus, he could be selective about his racial identity with those unfamiliar to him, and according to Ferguson, Chesnutt often "passed across racial lines to seek stenographic business and intellectual diversity from white bigots" (2-3). His lived experience equipped him with the ability to perceive blackness and the black body as an abstract space that he could adorn or discard. As a result, his writing demonstrated an awareness of many racial dilemmas including the restrictive coding of black bodies and the intricacies- the traumas and challenges - of racial identity in America. Although Black writers of the 
New Negro era did not have the same collective ambitions as those who followed them in the Harlem Renaissance, they began the early labor of cultivating the Black identity into greater recognition. Chesnutt and others took baby steps so that their predecessors could run.

In The House behind the Cedars (1900), Chesnutt explores the vague definitions that are often used to validate racial identity. Through the novel's main characters, Rena and John Walden, who grapple with the realities and consequences associated with the cultural practice of passing, Chesnutt demonstrates how amorphous racial status can be, yet how definitively the presence of blackness or a black body can create specific experiences and spaces within social practice, often ones of a traumatic and restrictive nature. As Donald Gibson, explains, The House behind the Cedars is a story about the "implications regarding the likely conflict between passing and domesticity" of which Chesnutt was intimately aware (XIII). What this fictional story reflects is an awareness of coding on the black body. Blackness offers a strong communal tie, but as Chesnutt demonstrates this tie is also connected to a very specific space of "liability" in the racially-defined American caste system (Gibson VIII; Chesnutt 122).

It is this caste system that is on display at the beginning of The House behind the Cedars, for the reader is immediately confronted with the geographic reality of the postCivil War American landscape. John Warwick, formerly John Walden of the Walden family as noted earlier, is strolling — the action of which is itself a privilege of his newly acquired white identity — through the North Carolina town of Patesville, which he observes is trapped in a state of timelessness: "There are places where Time seems to linger lovingly long after youth has departed, and to which he seems loath to bring the 
evil day" (Chesnutt 1). Most importantly, what is timeless about Patesville is its preCivil war social hierarchy, which he has committed his life to flouting, albeit through the discreetly deceptive act of passing. John, who has been living in South Carolina as a white man, has returned to his hometown of Patesville in his racially disguised body to bestow a life of expanded opportunities on his sister, Rena. His wife has died, and he is seeking a familial female presence in his home for his young son and himself (16). In his estimation, this occasion provides the perfect opportunity for Rena to now pass into his world.

In his reencounter with his hometown, John moves through this space free of any racially-imposed spatial limitations as were present for him during his childhood, which he endured as a Black person. Now, he is only limited by boundaries that are associated with him being a stranger. As a white man, John is able to travel on a steamboat and in a public carriage, which are necessary to make his return to Patesville. Also, he has sought lodging at the Patesville Hotel, a segregated facility. He is able to make his way through the public square and through various "respectable" quarters of Patesville (5). His whiteness has afforded him a new level of access and privilege in his former community, for he has successfully managed to uncloak the black veil of invisibility.

Chesnutt makes us keenly aware of the new reality of this spatial access in his presentation, which is a panoramic view of Patesville through John's lenses. John, as a white man, can appreciate and engage all that the world and currently Patesville have to offer. In addition to opening the novel with a wide-ranging spatial analysis of Patesville from John's now privileged gaze, he juxtapositions it against the limited, veiled geographic reality of the Black experience provided through the spectator's view of his 
sister, Rena. In her blackness, she has been relegated to the social peripheries via the white gaze. In the very same space of time and movement, John observes her from a distance although he does not recognize her: "few people who met [her] greeted her, others...gave her no sign of recognition; from which he inferred that she was a visitor [or] not well acquainted" (5). She was not a visitor or stranger from a distant community, but unlike her brother, she was dressed in black invisibility, which meant even in her hometown there were only certain places where her humanity would be recognized. She, in her black body, is limited in the scope of the white gaze. Rena could only be visible or validated in the appropriate spaces given her racial identity, so John has observed his sister from a distance that is both a reflection of her linear and social position. Thus, Chesnutt has given his readers a foreshadowing of the trauma of her reality from which she needs to be rescued.

As John continues his trek to his mother, Molly Walden's home on the side of town where members of the Black community were located, Chesnutt provides a description of the spaces that were reserved for Rena and those of her ilk:

The houses they passed now grew scattering, and the quarter of the town more neglected. Warwick felt himself wondering where the girl might be going in a neighborhood so uninviting. When she stopped to pull a half-naked Negro child out of a mud hole and set him upon his feet, he thought she might be some young lady from the upper part of town, bound on some errand of mercy, or going, perhaps, to visit an old servant or look for a new one. (6)

It is John's awareness of the limiting and oppressive nature of spaces of blackness, ones reserved for Black people, that drives his restraint and cautiousness regarding his movement in, near, and through them. He is careful to avoid the loss of the public acceptance of his whiteness. He engages his mother's home with much secrecy. 
He moves "toward evening", "in the gathering of dusk", and "by the time night had spread its mantle over the earth" (10). He is cautious, quiet, and stealth-like as to avoid too much attention (10). The risk of losing his access and privilege is too great; he has delivered himself from the pain of this existence and is reluctant to be returned. Upon his arrival at his mother's home, Rena and she observe his selected distance and its associated benefits after reconnecting with him in the family home: "he represent[s] to them the world from which circumstances had shut them out; they [feel] nearer to this far off world because of the glory which Warwick reflect[s] from it" (13-14). It is this exposure to his glory, a gift of passing between worlds, which compels Molly to allow a "wider door" in life to be opened for Rena with her brother's help (19). Passing allows John to experience new, once restricted spaces. He is able to marry into a family of prestige and is admitted into the South Carolina bar association; spaces to which his social status as a Black man would have prevented his acquaintance. The reality of this new, more satisfactory world is too much for his mother to deny Rena:

The life her son had described had been to her always the ideal but unattainable life. Circumstances, some beyond her control, and others for which she was herself in a measure responsible, had put it forever and inconceivably beyond her reach. It had been conquered by her son. It beckoned to her daughter. The comparison of this free and noble life with the sordid existence of those around her broke down the last barrier of opposition. (18-19)

Thus, Rena is permitted to transition from one space of hiding to another. Molly's home "hid discreetly behind a cedar screen" because "she did not [want to] flaunt her prosperity" in the face of the Black community members, whom she lived near but was socio-economically stationed above (105). Rena's transition into the white world is uniquely similar in strategic positioning to the house behind the cedars, her former home; 
she embodies its hidden and veiled space in her racial transformation. Passing involved removing one's Black racial barrier in the shadows of public awareness and view. On the steamboat that would provide transport to her brother's home, Rena remained hidden in her estate room (28). When she finally makes her appearance towards the conclusion of the voyage, she is shielded as "a veiled lady passenger" (29).

These safeguards are constructed in order to initially create the portal between worlds through which one could pass. These portals existed along the peripheries of society, where race could be cleverly discarded in the shadows of public view. After which, these safeguards prompted a constant state of awareness that the passer adopted in order to avoid discovery. Even though John achieved much freedom in his life as a white man, he takes refuge in his plantation home that is conveniently "situated in the outskirts of town" (943). He too fears being overly conspicuous and "his fine social position [collapsing] like a house of cards" (45). His adopted white identity provides him and his sister the perspective and position of "naturalized foreigners... in an adopted country" (45).

With this new-fangled citizenship, Rena is elevated to a more privileged social space and position. Before she makes her permanent home as the new mistress of the Warwick estate, John sends her away to a boarding school for a year. This short tenure at boarding school is dual-purposed. It "improved her mind and manners", but it also functioned as a smokescreen to make her reemergence in his adopted community of Clarence, South Carolina, as Rowena Warwick, John's younger white sister, more ordinary (38). 
Now that the cloak of Black identity had been removed, Rena's value could be fully appreciated, which for a woman of this time meant unfortunately her beauty. Ironically, she has remained unchanged in her physical appearance, but her advancement in social status makes it appear as if she has. At the Clarence Social Club's annual celebration of the "renaissance of chivalry", Rena is crowned the "Queen of Love and Beauty" $(32,37)$. She gains the attention and interest of an attractive young bachelor named, Sir George Tyron, who has shown no previous interest in the institution of marriage. However, he is immediately awe-struck by Rena's beauty upon making her acquaintance at the celebration. Conveniently, he is performing in the event as a knight in shining armor and adds another element to her social rescue. The fairytale comparisons are not lost on Rena, for she likens her new world to a dream and her new experience to that of "Cinderella before the clock has struck" (42).

Conversely, in Rena's fairytale, John Warwick lovingly plays the role of the fairy godmother. Instead of employing magical powers, he uses the illusion of racial passing to liberate her physically and psychologically from socio-spatial isolation. He removes the barrier of her blackness that had served to disconnect her from opportunities and restrict her to a space of vulnerability and insecurity. With this comparison, Chesnutt, like many period authors, represents the southern fixation with Sir Walter Scott's fiction and the influence of chivalric romance, but he also demonstrates the almost fantastical nature of race. Again, unlike Cinderella, Rena has made no remarkable physical transformations. She has merely shed a socially-constructed, racial identifier. The tragedy of Rena's racial designation is that she had been deeply stigmatized by a label that was barely identifiable. 
Her new social reality was short-lived because she is immediately confronted with the fear, loneliness, and persistent social isolation that generally accompanies the continued action of passing. Unable to overcome the traumatizing fear of the unknown and its impact on her future, she demonstrates a reluctance to move her relationship forward with Tryon. The exposure of her secret could send their worlds into complete disarray, and her fear of his reaction to the possible discovery of her betrayal was stagnating. She realizes that her social status as a white woman was tenuous at best. Additionally, she, as the practice requires, willingly severs all ties to her former community, and as a result finds herself surrounded by strangers with whom she could never seek comfort. Speaking to her brother, even privately, comes with a huge amount of risks for worries of being overheard. Consequently, homesickness and concern for her mother's health motivate her to take a short respite in Patesville. Regrettably, Tryon would also be making an unexpected business trip to Patesville as well and encounters his betrothed on the town streets as Rena Walden, a Black woman. Tyron is horrified and flees the city in shame. Their marriage could never happen after this devastating realization:

A negro girl had been foisted upon him for a white woman, and he had almost committed the unpardonable sin against his race of marrying her. Such a step, he felt, would have been criminal at any time. No Southerner who loved his poor, downtrodden country, or his race, the proud Anglo-Saxon race which traced the clear stream of its blood to the cavaliers of England, could tolerate the idea that even in distant generations that unsullied current could be polluted by the blood of slaves (96).

Rena is forced to return to the limitations of the caste of her birth. Even after she learns that Tyron would not reveal her family's secret to the world, she chooses to "pine away in the shade" (120). The fact of her blackness, even vaguely adorned, for she still 
bore the appearance of a white woman, invalidates her American citizenship; she is again "an alien element incapable of absorption into the body politic of [the white world]" (169). Rena attempts to recover her life by taking on philanthropic work with a teaching assignment at a school for colored children. She acknowledges the inequality that has returned to her life in a letter to Tyron:

You are white, and you have given me to understand that I am black. I accept the classification, however unfair, and the consequences, however unjust, one of which is that we cannot meet in the same parlor, in the same church, at the same table, or anywhere, in social intercourse; upon a steamboat we would not sit at the same table; we could not walk together on the street, or meet publicly anywhere and converse, without unkind remark. As a white man, this might not mean a great deal to you; as a woman, shut out already by my color from much that is desirable, my good name remains my most valuable possession (172-3).

Ultimately, Rena's recovery from her social regression never ensues. She can find no satisfaction in a world that is again so restrictive. The connection between her reestablished Black identity and her social exclusion is evident; publically and socially, she is once again isolated. Her black body has become her tomb, and in the end she dies of disillusionment and heartache (192-5). She had been overdetermined from without, and the sacrifice was much too great for her to bear.

\section{Negotiating Racialized Space in Nella Larsen's Passing}

Nella Larson was a notable author of the Harlem Renaissance who examined racial identity and Black discontentment in her work as a means of affirming the humanity in the Black experience. Her writing often highlights individuals' struggles against society, and she showcases Black female characters who resist traditional norms with the aim of identifying more comfortable spaces for themselves. Specifically in her 
novel, Passing, Larsen conveys the story of a search for home, which is ultimately a space of security. The search for home is not exclusively about locating an external safe space, which African Americans are actively pursuing in the aftermath of the Civil War; but there is also a search for self-representation occurring after an ego death or the death of a personal identity. As scholar Cheryl Wall asserts, Passing, the text and the "sociological phenomenon" is "a metaphor of death and desperation" because this practice involves a loss of self or an extensive foray into self-denial (Wall 105).

Passing features two fair-skinned childhood friends, Irene and Clare- the later has spent her adult life passing for white. With Irene, Larsen is translating the psychological space of blackness, a space that has been so determined from without. Irene's narrative perspective anchors our attention in the vexatious space of the black body, and her absence of self brings an awareness to the reader regarding the situation or state of her Black reality. In her narration, she moves racial oppression beyond a conceptual mode into an established and measurable plight. Irene allows us access to a position on the border of the color line so that we can inspect the fluidity of race as a demarcation, but also clearly delineate white space from the distinctly black spaces. With Clare, Larsen underscores the bleakness and isolation involved in the cultural practice of passing among many other themes, but it also qualifies the ways that this practice or any form of racially-influenced escapism affects the Black community as a whole or those individuals who remain and continue to survive in the space of their black bodies. By contrast, it details the nature of the space and/or the qualities that make the black space or body undesirable. Thus, Clare and Irene both function as living qualifiers of blackness and comparatively whiteness as well. 
Although Passing is not drawn from Larsen's own personal experiences, it showcases characters in a similar dilemma with, as her biographer Charles Larson states "[their] mixed heritage and [in a similar struggle with] the subsequent loneliness that follows [Larsen] all her life" (XIV). Whether she saw herself in these characters is immaterial, for they are reflections of true to life Black experiences. Most importantly, her investigative, personal style of writing provides a critical exploration, the kind of focus needed to incite various causes of social justice and reforms of concern to Black people.

With "her depth of characterization", Larson argues that Nella Larsen aligns herself with "the plight of the tragic mulatto" but achieves a more "fully realized" and "convincing" depiction than Chesnutt's The House behind the Cedars (XIV).

Understandably, Larsen was a product of the Harlem Renaissance, which was essentially an explosion of talented Black artists who were pushing themselves and each other to expose more of the wide-ranging complexities involved in the conditions of Black people than was characteristic of the writing in Chesnutt's New Negro era. Larsen targets the roots of their issues: the traumas, psychological and otherwise, that can be associated with Black identity. Her characters are metaphorical representations of real people at the turn of the century who are surviving in and combating the traumatic space of blackness. As Larson so eloquently states “[Larsen's novels should be] regarded as... strong indictments of American life; people are driven to such drastic measures because of American racism and the need for economic survival" (XV).

Passing is a tale inspired by the world in which Nella Larsen existed. It is a confrontation with race; those like Larsen who live on the border of the color line suffer a 
specific kind of racial trauma because of their unique encounter with racialization. When racial identity is fluid, one can observe the very subjective and inconsistent process that others use to qualify race. It becomes an everyday dilemma to willingly assist others ascribe the appropriate racial category and historical context to one's body. If that racial category is Black, then that categorical space is limited in terms of social access and privilege. Irene Redfield, a central character in the novel, negotiates this dilemma during her daily encounters in public space.

She can pass for white, but she proudly takes up the mantle of modeling Black excellence to the masses. Her cause is to resolve the Negro problem through her guiding example as a cultural leader. Irene exemplifies the ethos of the talented tenth, or members of the Black community whom W.E.B. DuBois called to action with the publication of his provocative book, The Souls of Black Folk, in $1903^{12}$. The talented tenth were charged with providing inspiration to the less fortunate members of the Black community who ideally would follow their lead as they navigated the world in their blackness. At Irene's home, she hosts parties for members of the Black social elite, and they engage in intellectual discussions about the most pertinent themes and concerns in the Black community, such as the military occupation of Haiti, the entertainment and activism of Josephine Baker, and the stirring blues performances of Ethel Waters (Larsen 251-2). She does occasionally pass for white, but it is an act of defiance when some stranger mistakenly assumes that she is white and allows her the access that whiteness affords,

\footnotetext{
${ }^{12}$ The New Negro: An Interpretation by Alain Locke, originally published in 1925, helped to usher in the new cultural movement called The Harlem Renaissance; as a result, it is regarded by many scholars as the definitive text of the movement. This text articulates African Americans' desires for equal rights and full citizenship, so it would have been a source of inspiration for Irene and other members of the Black social elite. Locke, Alain LeRoy. The New Negro. Martino Fine Books, 2015.
} 
e.g. entrance into segregated hotel, restaurants, and clubs (Larsen 178). In these moments, she views this as a resistance mode as she refuses to allow her freedoms to be restricted, but in occasionally passing she recognizes and harnesses the privilege of whiteness.

Otherwise, Irene appears ostensively to be at peace as Black influencer and member of the social elite until she is forced to engage her childhood friend, Clare Kendry, who has been passing for white for many years. Their contact with one another had been severed, as is a customary requirement of passing, eliminating all public ties to one's former community, but they unintentionally cross each other's paths while at the Drayton hotel in Chicago. Clare and Irene are both lunching at the hotel while disguised as white women (178). Although Irene finds it acceptable to occasionally tempt danger for temporary excursions, she considers Clare's permanence in her adopted white body as "a life of no allegiance beyond [one's] own immediate desire and [a life that is] selfish, cold, and hard" (172). In the space of passing, Irene suggests that Clare is always stepping "on the edge of danger. Always aware, but not drawing back or turning aside" (172). The danger is the risk of exposing her blackness, which would result in potentially serious ramifications in addition to the immediate loss of her white privileges. Passing, even with the isolation from the Black community, was viewed as a daring but necessary escape, for the real trauma was Black life.

When Clare invites herself to join Irene at her table, it is this danger that Irene resists on Clare's behalf, but she is also curious; she "wished to find out about passing, this breaking away from all that is familiar and friendly... what one did about background... and how one felt when one came into contact with other Negroes" (186-7). She entertains Clare in this moment at the Drayton hotel, and she learns that it was 
Clare's white aunts, who adopted her after her single-parent father died, and their perceptions of blackness and the visceral presence of their white gazes, that drove her to pass (188). Blacks, the aunts believed, had been cursed by Noah for eternity as the sons and daughters of Ham (188). The aunts reflect these mainstream, damning misconceptions of blackness that were often aided by exclusive truth claims, harmful religious doctrine, and/or pseudoscientific principles.

As a self-identifying Black woman, Clare's life with her aunts had been hard; she was expected to "earn her keep (and remain in her Black social position) by doing all the housework and most of the washing" before she decides to escape by passing for white, which she describes as "worth the price" so that she could have "everything [she] wants" (188-90). Informed by their beliefs in the natural order of white supremacy, they had assigned Clare utilitarian tasks, so even in what appears to be a welcoming familial home an appropriate space had to be designated for the Black child (188). There could be no confusion as it pertained to social order, and Blacks occupied the lowest tier.

Even though Irene found Clare's choice of an indefinite state of passing to be abhorrent, something about it made her linger, remaining in Clare's presence longer than she had anticipated (190). The mesmerizing attraction that Irene was slow to recognize was the power, satisfaction, and opportunity that Clare now possesses as a white woman. She describes Clare's new posture of whiteness as one with an "air of indifferent assurance" and the "polite insolence [that] some acquire with the coming of riches or importance" (190). Simultaneously, Irene suffers from resentment, for Clare now has access that, in the space of her own black body, Irene is not afforded (174). Irene's frustration with adhering to her racial identity was intensified in the face of someone who 
has crossed the color line to forego the trauma of her own blackness. Clare, the daughter of a janitor, once envied Irene because of her affluence and privilege.

Clare's passing and its alluring privileges slightly interrupt Irene's perceived contentment within her black body and in her chosen racial identity. In this space, Irene is on the inside observing a freedom that excludes her. These are the parameters of the Black experience that the passers help to expose to those who are entrapped in their blackness as Irene is. Although she occasionally allows others to assume that she is white, Irene identifies as a Black woman. As her association with Clare continues, her resentment, or Black rage, grows as well. She knows that surviving the everyday Black experience involves the emotionally taxing work of negotiating race, and it is a psychological marathon that one must undergo. The passer forces the person operating in the space of blackness to confront a clear indictment against the non-passer's blackness and its value. How does one appreciate and regard an experience that others have determined to be undesirable? At the minimum, it makes you question, and in this case possibly begin to reevaluate the black body in which you live. The evidence can become overwhelmingly traumatic as one confronts the truth and unrelenting predicament of Black life. Irene demonstrates this slow deadly awakening of Black sorrow.

In her mind, these questions and their debilitating mental effects are so easily avoided with distance from Clare; without it, the psychological burden of Clare's rejection would persist and permeate all of Irene's interactions with her. Justifiably, Irene plans to avoid Clare at all costs. She activates strategic distance to defend the Black community that Clare has rejected and to prevent the occurrence of a "sharp remembrance in which humiliation, resentment, and rage were mingled" (174). 
Unfortunately, as is often the case with the privileged, Clare had become driven by a very firm sense of entitlement and wants to use Irene to reestablish her access to the ethnic side of the color line. Not only does Clare impose friendship on Irene, but she unknowingly forces Irene to constantly defend and affirm her loyalty to her Black identity to an extent that as a member of the Black elite she was not accustomed. Her example had usually set the standard. Here, Irene attempts to use the tactical approaches of self-sufficiency and/or self-isolation to resolve her mounting dilemmas, but Clare's intrusion nonetheless represents the repressive environment in which they live. Safe spaces, Black Wall streets for example, violated the social order; Black people were forced to live in confrontation with their society otherwise it could be valued as a homeland. The endless trigger that is the black body maintains the traumatic state. Additionally, as a member of this Black social elite, Irene embraces a very public role where she happily glorifies the strengths of her community and avoids engaging the aspects of it that are unsightly. Strategic denial is a constant feature in her social life. When her husband, Brian, tries to explain why colored people are lynched in America to one of their sons, Irene becomes angry, and she scolds her husband. She says after the boys exit the room: "It was inexcusable for you to bring up a thing like that at dinner. There'll be time enough for them to learn about such horrible things when they're older" (263). As the intensity of the discussion escalates, Irene demands her husband's obedience in shielding the boys: "You're not to talk to them about the race problem. I won't have it" (263). Brian is angered by Irene's naivety. He reasons that the boys have to be prepared for the racism that they will undoubtedly suffer as Black men in America, but Irene's denial is her coping mechanism, her means of survival. She blocks the 
problems of her race, so that she remains lucid. In actuality, she has passed-created her own version of the practice; there's no lucidity in this death. Brian offers a clear indictment of race and validates the insufferable space that it creates. Clairvoyantly, he is questioning this notion of America as a homeland for Black people. Contradictorily, in the presence of Clare, Irene is forced to engage her otherness, for she has to exit her space of denial and have confrontational encounters with the reality of her race. Her husband simply lacked the white privilege to compel her to do so. Again this denial that Irene adopts is a less drastic form of passing, for she has also constructed an alternative reality, but it is whiteness that induces her to accept the character of her blackness as it seems through the white gaze.

Furthermore, Irene Redfield is the best demonstration of the state of anxiety that defines black claustrophobia. It is this common trauma-induced, protective reclusion of both a spatial and psychological nature that Blacks in postcolonial spaces must undergo as their bodies are marginalized in the process of the constant, unending evaluation against white ones. When this process infects the Black psyche, which is the ultimate result of racism, the marginalization is often permanently internalized. A racist society demands that Blacks accept certain messages about their bodies and themselves. Irene cannot avoid the mirror that Clare presents before her. Her elitism and social position cannot trump her blackness. Without the serenity and security of her denial, she begins to slip into the abyss of hopelessness. It begins as soon as Clare finds a crack in what had been Irene's fortress of protection: her system of avoidance.

Later in the text, Irene decides to stop avoiding Clare and attends a tea at Clare's home, which as she fears does "rouse in her a defensive and resentful feeling for which 
she had no explanation" (195). Here, she has caused herself another self-inflicted injury. Clare invites another old, mutual friend of theirs named, Gertrude, who is a Black woman but is married to a white man. Gertrude's husband is aware of her ethnic identity, so she is not technically passing although she makes it clear that her race is a cause of concern for her (197). During the course of this meeting, Irene unsuccessfully attempts to suppress her frustration, which she later describes as "a feeling of being outnumbered, a sense of aloneness, in her adherence to her own class and kind" (195). She, alone, must uphold the dignity of her community in the face an onslaught of attacks. As Clare and Gertrude discuss their children, they openly confide in one another about their fears of having dark offspring (197). Gertrude explains, "It is awful the way it skips generations and then pops out...nobody wants a dark child" (197). When Irene shares that one of her sons is dark, Gertrude reacts as if she has been shot (198). Clare attempts to comfort Gertrude by suggesting that only women like her, who are passing, should have to worry about having "a freak of nature" (198). Irene is left with lingering resentment; she is the mother to two of these "freaks of nature." This characterization is a double entendre in that it speaks to the capriciousness of genetic anomalies and the well-adopted social notions of Blacks as primitives. This is the reality of blackness, previewed through the white gaze, which Clare has been reluctant to engage because she has been conditioned to believe these truths as well. This is the antithesis of her performance as a member of the talented tenth.

John Bellew, Clare's husband, enters the room to greet her guests, and he assumes that he is in the presence of three white women. Without hesitation, he puts his racism on full display. He greets his wife by calling her "Nig", a derivative of the more derogatory 
term and his new nickname for since she has become tanner. He explains: "when we were first married, she was as white as a lily. But I declare she's getting darker and darker" (200). He believes that this is such a hilarious joke because obviously, he states, that there are "no niggers in [his] family. Never have been and never will be" (201). Irene trembles in reaction to this declaration, but she is forced to remain silent, for she explains that she "was held by some dam of caution and allegiance to Clare" (203). She is protecting Clare as a member (regardless of her current choice of racial identity) of the Black community that she left behind. Irene sees this as an act of racial duty and pride (213).

In addition, Mr. Bellew confirms the nature of the white gaze that he fully employs, and in the process showcases the depths of the odds that are stacked against people of color. He admits that he and his wife "hate" Black people, and later says Blacks, whom he calls "scrimy devils", "give [him] the creeps" (202). He believes that they are "always robbing and killing people [or] worse" (202). Ironically, he is unknowingly speaking to three Black women. From his perspective, he illustrates the reality of the battle that Black people are fighting with regard to racism; it is one with false characterizations that have been phenomenologically assigned to their blackness. Irene is left "seething with anger, mortification, and shame", but she chooses to repress her "rage and rebellion" (204). Afterward, she fumes over Clare's "right to expose her [and Gertrude] to such humiliation, [which she considers to be] such a downright insult" and calls Clare's reaction to it all "mocking" and "menacing" (206). What Irene is experiencing is Clare, in the space of her white body and privilege, racializing her through close proximity. Clare and her whiteness require Irene to recognize the dilemma 
and burden of her black body as an act of submission; otherwise, the intrinsic superiority that she (and other bigots) assume would be compromised.

Not surprisingly, with all her deceptively-acquired white privilege, Clare is still unhappy with her level of access, and so she hopes that Irene will ignore the angst that her presence causes her, of which Clare is seemingly unaware, and rescue her (Clare) from the dissatisfaction of her life. Clare alludes to her growing frustrations in a 'thank you' letter she forwards to Irene the day after their visit in her home; she concludes, "Rene dear, it may just be, that, after all, your way may be the wiser and infinitely happier one" (208). Two years after the uncomfortable tea in Clare's sitting room, she writes Irene again and complains:

I am lonely, so lonely...cannot help longing to be with you again, as I have never longed for anything before...You can't know how in this pale life of mine I am all the time seeing the bright pictures of that other that I once thought I was glad to be free of...I wouldn't now, perhaps, have this terrible, this wild desire if I hadn't seen you that time in Chicago (174).

She tries to guilt Irene into providing a means by which she can regain her access to the Black side of the color line (212). Clare refers to it as a yearning for "[her] own people", but Irene believes that Clare feels entitled to enjoy the best of both worlds and has very little concern for the race of people she claims to be so desperate to see (212-3). Clare is truly yearning for the emotional ecstasy that she revels in when she in the whiteness of her body while in close proximity to the blackness of black bodies. Again, it is the juxtaposition coupled with the perspective of the white gaze that affirms her (and other whites') notions of superiority. Her privilege necessitates this constant reaffirmation that is given in the form of Black submission and perceived envy. 
A few days after this appeal, Clare makes a surprise visit to Irene's home where she rejects any fears related to, as Irene refers to it as, "the risk of knowing Negroes" (225). During this visit, Clare learns that Irene is planning the annual Negro Welfare League dance, and invites herself to "see Negroes, to be with them again, to talk with them, to hear them laugh" (231). Clare, while in her mode of white womanhood, performs one of the greatest acts of insult and mockery: cultural appropriation. For a night of revelry, Clare wants to co-opt cultural experiences from the race of people that she was so eager to desert. She has delightedly erased all ties to black suffering and the stigma of her black body, but now as a costume to be worn temporarily and then discarded, she attributes to it a bit of satisfaction.

Unfortunately for Irene, this culturally alluring event sparks the beginning of many and frequent visits from Clare Kendry to the Redfield household. She becomes a regular unannounced guest and attends events, parties, and dinners with them when her husband is out of town or preoccupied (238-9). Clare is addicted to the validating admiration she is given at these various events: "The blond beauty out of a fairy tale" captivates all members of Irene's social group (235).

Not only does Irene have to struggle with an overwhelming sense of dread as a result of Clare's encroachment, but Brian, her husband, has grown "unhappy, restless, and withdrawn" (246). He feels trapped in his black body, "in his profession, and in his country", and he desperately wants to flee (218). Brian seems to admire Clare's escape act and characterizes passing as the "instinct of the race to survive and expand" (216). He had a similar instinct-driven ambition to survive earlier in his marriage to Irene; he wanted to pursue a life in Brazil, where he believed racism to be less of an obstacle (217). 
Since a sense of security was so hard to achieve as a Black American living in the 1920s, he "ached to go somewhere else" (256). Irene rebuffs his plans for her own, for she desires to remain in a space of familiarity (221). She affirms "[I am] an American [grown] of this soil, and [I will] not be uprooted (267). Again, Brian articulates the reality of Black America by rejecting his wife's claim of America as a home. For this to be true, they would have been afforded the privilege of citizenship. He grasps that as a Black person autonomy, self-fulfillment, and safety will never characterize the general state of his occupation in this country; his blackness renders him an illegal alien.

This conflict with Brian, Irene's resentment, and her repressed anger trigger a terrorizing suspicion to rouse in her, which quickly evolves into bewilderment. Influenced by her irrepressible insecurities, she determines that Brian and Clare are secretly having an affair. After learning that Brian invites Clare to an event from which Irene had purposefully excluded her, she proclaims, "Clare Kendry! So that was it! Impossible. It couldn't be" (247-9). Sharp panic compels her to conclude that her husband admires more than just the grit that Clare demonstrates in passing. Her life, she realizes, has been changed drastically for the worse by this "white" temptress (251).

Clare and her white privilege had now become the villains in her life. Her white-masked identity represents both the necessity of and the opportunity for an escape from the Black experience; she concludes that she needs to be free of Clare for her own and her husband's sanity and protection (257-8). It is irrefutably clear to her that Clare ignites her discontent in her Black life, for she makes Irene appreciate her blackness in unprecedented ways: 
[Irene] was caught between two allegiances, different, yet the same. Herself. Her race. Race! The thing that bound and suffocated her. Whatever steps she took, or if she took none at all, something would be crushed. A person or the race. Clare herself, or the race. Or, it might be, all three. Nothing, she imagined, was ever more completely sardonic. Sitting alone in the quiet living room in the pleasant firelight, Irene Redfield wished, for the first time in her life that she had not been born a Negro. For the first time she suffered and rebelled because she was unable to disregard the burden of race. It was, she cried, silently, enough to suffer as a woman, an individual, on one's own account, without having to suffer for the race as well. It was a brutality, and undeserved. Surely no other people so cursed as Ham's dark children (258).

Here, Irene vividly qualifies the burden of her race. It is not something unknowable or ignorable any longer; she contemplates the pain and the dilemma that defines every space of her existence. She is Black! All of the traumatic reality of this term applies to her as well. Even with her affluence and lighter complexion, Irene is cognizant of the fact that passing or some form of escapism is an option for her; she has a strong "instinctive loyalty to [her] race", which she feels shackled to and unable to gain emancipation (260).

Although Irene recognizes the dangers associated with passing and its dubious sense of security - for it involves occupancy in a liminal space, she is still overwhelmed by the menace of doubt that the presence of Clare, the passer, induces. Security is an important bedrock of Irene's coping process, and her sense of security has always been buttressed in denial, an understandable response of the Black psyche. Hence, she is slow to conclude that Clare is not really an enemy or the nucleus of her distress; it has always been her race, and the corresponding racism that undoubtedly complicates the space of her existence.

In the end, Clare falls from a window and dies while attending a party with the Redfields. It is unclear if she faints, as a result of an impending confrontation with her 
husband at this party (he has learned of her true racial identity and storms into the party), or if she is pushed from the window by Irene or said husband. Irene, who had fantasized about Clare's death shortly before it happens, believes that Clare must die so that she may live (261). Otherwise, life in the space of her black body becomes increasingly more difficult. Clare symbolizes the self-hate that racism can trigger as it does in Irene as she despairs increasingly that she too "could not change herself in this respect" (260).

Ultimately, Irene exposes the struggle of black claustrophobia, which is a villain that these Black women are combating in the space of their own bodies. Clare's death is not the end to Irene's misery; Clare's existence is hidden, for passing decreases the literal and figurative presence she maintained in the lives of others. As George Hutchinson expounds:

When the woman on the boundary is done away with, thereby securing the boundary, no one will be at fault. There will be no conscious memory of the crime, only a vacant space where the life of the black white women passed through (310).

Clare's most significant occupancy was in Irene's psyche. Otherwise, as a passer, Irene aspired to be nonexistent.

Thus, there is no real redemption for Irene in Clare's untimely demise as a Black American woman living in the early twentieth century. Her Black identity will continue to define her existence. It seems that this was a similar unending trauma for the novel's author as well, for after the demise of the Harlem Renaissance, Larsen is accused of passing in the latter half of her life (Larson XXI). Her biographer, Charles Larson, describes it as "totally inconsistent with her sense of pride and justice" (XXI). After Larsen's husband leaves her for a white co-worker of his, maybe the menace of doubt drove her to transmute her ethnic identity as well (XVII). Regardless, Passing is a 
distressing testimony about the traumatic space of the black body (especially the psyche) coupled with a clear, indictment against the oppressive, systemic/structural racism that restricts Black humanity. As Larson surmises, "tragedy and disappointment [may have been] constants in [Larsen's] life", but "she knew, even if she was not rewarded in kind, the pain of her inner soul [represented through her introspective writing] [could] be mitigated by others and that invisibility [an escape from her besieged body] is often one's only guarantee of survival" (XXI).

\section{Transcending the Space of the Black Body in George Schuyler's Black No More}

For Larsen invisibility may have provided an adequate escape, but for George Schuyler, a popular author, journalist, and cultural critic of Harlem Renaissance, contradiction, doubt, and denial seemed to be his treatment for the race problem (Ferguson 28-9). As he endeavored to negate the concept of race as a natural, biological consideration, few strove to accentuate the besieged state of the black body more than this proclaimed foe of the movement. Schuyler asserted in his 1926 essay, "The NegroArt Hokum" that "Negro art there has been, is, and will be among the numerous Black nations of Africa, but to suggest the possibility of any such development among the ten million colored people in this republic is self-evident foolishness" (662). Dana Carluccio suggests that in 'The Negro-Art Hokum' [Schuyler] berates his audience for committing itself to incoherent notions of racial identity" (525). Throughout his career, a perception of colorblindness and the belief in possible social inclusion for Blacks in the U.S. was present in his work. Schuyler wrote for the Pittsburg Courier in various roles from 1924 to 1966, and he propelled his cause of assimilationism. According to Jeffrey Ferguson, Schuyler, 
demonstrate[d] [a clear] talent for making enemies. From his controversial column "Shafts and Darts" to his interracial marriage to the archconservatism of his later years, Schuyler fashioned himself as a useful irritant. Although he sometimes stated his opinions on issues in seductive terms, he never expected his audience to follow him. Instead, he flung himself into the cultural fray, always attempting to inspire the reexamination of important beliefs. His use of provocation, invective, name-calling, and other forms of rhetorical violence flowed directly from this ideal. So did his constant embrace of contradiction, both in his thinking and in his politics. Schuyler brought uncompromising skepticism to the race debate of his day. This remains his greatest achievement (28-9).

His family had been free persons of color for many generations, and he spent most of his life in Northern states and public spaces as a member of a Black aristocratic class (Rayson 103). Schuyler's perspectives as a Black man who appeared to have avoided socialization into a white conceptual framework shaped the nature of his activism. According to Dr. Ann Rayson, he often downplayed "the importance of race in his life and work" (102). Schuyler could observe the ontological structure of race, and a result he could consider it conceptually because his life had offered him safe spaces or loopholes within the larger institutional American framework of racism.

Schuyler earned some disfavor in the Black community due to his unwillingness to acknowledge many social realities, including that his socialization and perspectives were uniquely cultivated (Ferguson 29). His upbringing was atypical compared with the average Black American in his generation, and he ignorantly suggested that racial differences and their adverse consequences were "sheer nonsense," as if he could not observe the definitive evidence of which in the United States (Schuyler 662). Schuyler was a supporter of socialism in the 1920 s, so he had some appreciation for inequality at least at the economic level, but he moved towards social conservatism in the 1930s as his alienation from the Black community continued, a result of his increasingly provocative 
and harsh critiques of Black leadership. Later, he became a very vocal critic of the Civil Rights movement and Martin Luther King, Jr., whom he referred to as a "sable Typhoid Mary" and a "pious fraud" (Ferguson 3).

Notwithstanding, his satirical novel, Black No More, is one of the most direct assessments of the racialized body produced during the Harlem Renaissance. Schuyler uses this text to explore various sentiments about blackness and discusses the black body as a cultural signifier by design of the dominant culture, promoted through the socialization of racial inferiority and superiority norms during this time period. Additionally, this text speaks directly to race as a commodity. It asserts that blackness and Black spaces, which include the black body, are produced commodities of both political and capital value. Whiteness and blackness are both artificial, but they possess real significance as conceptions of dominance and power.

Black No More investigates the cultural ramifications of a society in which African Americans are given the ability to purchase whiteness, racializing themselves anew. Schuyler's science fictional exploration of race as a device of bestowing privilege and oppression helps to underscore how race is both a nebulous concept and very much a product of social construction. Although Schuyler is frequently excluded in canonical discussions pertaining to the significant literary contributions of the Harlem Renaissance, his prolific, race-based critique in Black No More makes him a fitting addition to this research because it presents a range of racially-influenced, social tensions and challenges the many social ideologies that contribute to racial divides in America. As the scholar, Sonnet Retman, states:

Black No More is a narrative of passing, part of a genre that subverts basic epistemological assumptions about race and identity. Passing unmasks the 
juridical, economic, and social structures of race. In particular, it reveals the function of whiteness as a kind of property... the pass is always predicated on some kind of trespass, a fact that underscores the inherent mobility involved in the transaction. Specifically, the passer's reliance on bodily performance in the production of visual narratives of identity (1452).

In order to trespass, one has to embrace exclusion. Schuyler evaluates race as a performance of class status and contests that the assumptions that he refused to personally accept about himself and his own cultural experience as a Black man. Most importantly, he, Larsen, and Chesnutt join the legion of postcolonial writers who expose how American socio-cultural spaces are so definitively constructed and preserved around the illusion of race.

Black No More follows the consequences of a surface-level, metamorphosis on Matthew Fisher (formerly Max Disher). Fisher is a young Black man of the 1930s, who is so defeated by his reality as a Black American that he undergoes a racial-identity transforming procedure with the help of Dr. Junius Crookman. By means of his BlackNo-More treatments provided at his numerous Crookman sanitariums, he aspires to cure Black adults and children of their racially-signifying and oppressive blackness. He believes that the race problem can be resolved through this tactical approach of eliminating the skin complexion distinctions in society (Schuyler 8). Whiteness is established as a commodity to be sold as black bodies were commodified at the auction block.

With this literary focus, Black No More conveys how Black trauma and collective memory are wedded in and on the black body. The blackness of the body is the antagonist in this novel and in the lives of many Black Americans in this society who have allowed it, demonstrated in the text, to progress into an inferiority complex; it is 
important to remember that Schuyler was not really a Black sympathizer. However, the text assumes that the readers have received the standard cultural conditioning of the era and are aware of this universal, collective memory inscribed to blackness and the black body. Thus, it acknowledges the wide-spread white supremacy of the day by assuming that the readers would easily appreciate the normalization of rampant Negrophobia present in this fictional society, which is obviously intended to be a very realistic representation. To achieve this study of race, the social coding of the black body, and its interrelated traumas, Black No More asserts many theoretical claims through the novel's characters and circumstances about race as a universal phenomenon and the black body as a signifier of these norms as well as other social distinctions.

In the beginning of the novel, we meet Max Disher, prior to his life-altering transformation into a white man, struggling to overcome the heartbreak of a relationshipending quarrel with his "high yallah flapper" girlfriend on the evening before New Year's Eve (1). He describes her as "uppity" and attributes her constant state of displeasure to her fair complexion; she regards her color, he believes, as her most valuable asset (1). Nonetheless, he perseveres and decides to still celebrate the holiday at the Honky Tonk Club and is joined by his good friend, Bunny Brown. At the club, he is rejected again sadly by a "fair [white] beauty (from Atlanta) [who] had hypnotized him"; however, she proclaims that "[she] never dances with niggers" (5).

Following this second color-based rejection, the next morning at breakfast he takes comfort in a newspaper report of a surgical procedure that could relieve him of the traumas he so frequently faces in the space of his black body (5). This news reignites his passion for life, for racial tension had prompted in him an incessant desire for a new 
beginning. Becoming white could mean in his own words "no discrimination [and] no more obstacles in his path" (14). Here, whiteness is presented through his perspective as access to privilege and social mobility, not a characteristic of biology. Passing, including this fictional form that Max considers, is ultimately about achieving an escape from the social and economic bondage of blackness. He concludes:

Why not be the first Negro to try [the surgery] out? Sure, it was taking a chance, but think of getting white in three days! No more Jim Crow. No more insults. As a white man he could go anywhere, be anything he wanted to be, do most anything he wanted to do, be a free man at last... and probably be able to meet the girl from Atlanta. What a vision (7)!

During Max's transformation procedure, the reader is given greater access to Dr.

Crookman, his colleagues, and financial backers. There are interesting conversations and discussions that take place among them as they establish and protect the industry of Black-No-More, Inc., especially in the space of the white superiority-driven American landscape. The readers are privy to their intimate processes and considerations. We witness Dr. Crookman challenge some of his associates' very misguided notions of blackness; these moments, via the readership, publically confront these popular stereotypes that work so aggressively to determine and regulate the black body. Dr. Crookman refutes his realtor, Charlie "Chuck" Foster's, acceptance of the mythical "darky dialect" by saying:

There is no such thing as a Negro dialect, except in literature and drama. It is a well-known fact among informed persons that a Negro from a given section speaks the same dialect as his white neighbors...There are no racial or color dialects; only sectional dialects (11).

He also educates his banker, Henry "Hank" Johnson, who believes in the existence of a unique set of Black features, e.g. wider noses and fuller lips. Crookman 
explains, "as a matter of fact there has been considerable exaggeration about the contrast between Caucasian and Negro features...many so called-Caucasians...show almost Negroid lips and noses" (11). In this moment, the text is very directly addressing and acknowledging the continued universalization of slave-era notions of blackness, so that a clear distinction can be made between the actual nature of a Black person and the caricatures that have been constructed to provide bigotry with agency.

Post-surgery, Max changes his name to Matthew Fisher, a new name to accompany his new white identity and spatial access. He is thrilled to be a member of the "great majority" (15). Biologically he has not changed, but he is now activating a performance of whiteness. He is essentially a Black man in white face. He leaves the sanitarium behind and jumps into a taxi cab without any hesitation in pursuit of "the great world of whiteness"; in stark contrast, his Black world had been limited and restricted (15). Now, he enjoys the perks associated with white privilege. Immediately perceived as a reliable source, he is given a thousand dollars for selling his story to a newspaper as one of the first African Americans to complete the Black-No-More procedure, which he uses a portion of to finance Bunny's surgery. He exclaims his whiteness to be "a glorious new adventure... he could go anywhere, associate with anybody, and be anything he wanted to be" (22). He endeavors to attempt many firsts in his new white body, including "riding into Atlanta in a Pullman car, not as a Pullman porter" (22). His plans for Atlanta include staying at a fine hotel, the kind that would have been unavailable to him as a Black man, and mingling "with white people in places where as a youth he had never dared to enter" (23). Only now with his purchased whiteness does he enjoy the freedom of American citizenship, a peace he had never previously known (23). Expectedly, he had always 
abided by the social rules aligned with his racial group. His racial identification was authenticated through a performance of stereotypes and submission; it functioned as his navigational guide within his system of social order and procedure. Whites feared a performance of race that did not reinforce the fabricated notions of the white gaze.

To further emphasize the social construction of race, Matthew Fisher, who is a Black man masquerading as a white one, moves into the American south, where racial lines of demarcation are more demonstratively presented. There, Matthew recognizes that in order for him to truly capitalize on and maintain his newly-acquired social access and privilege, he must make regular endorsements of white superiority a condition of his social routine. He remarks: "It has always seemed to me that there was no question in American life more important than that of preserving the integrity of the white race" (38). His white performance is validated in his white supremacism.

He adopts this understanding into his immediate existence and offers his services as a social anthropologist to The Knights of Nordica (the fictional version of the Ku Klux Klan) and its Imperial Grand Wizard, Rev. Henry Givens. Matthew's whiteness and his authority as a scholar are immediately accepted without reservation on the basis of him presenting the vague social qualifiers of the appropriate complexion and an educatedsounding vocabulary, which he borrows from a newspaper supplement that he had read once (38). Here, Black No More affirms how unstable and tenuous racial classifications are, for they are often based on artificial characteristics. With very little effort, Matthew's white privilege affords him access to this organization and all of his immediate dreams are activated. He soon learns that Rev. Givens' daughter is the white woman who shunned him at the Honky Tonk Club. It was his hope in relocating to the south, that his 
whiteness would bestow on him a second chance to make her acquaintance. In his white body, there are no clear limitations or restrictions in terms of his career choices, earning potential, or relationships.

Black No More underscores the existence and prevalence of white privileges in society by juxtaposing them against the disadvantages of blackness, his examples of which firmly emphasize how they serve as an antithesis to one another in terms of social hierarchy. Importantly, these conversations are taking places in the space of a fictional tale that effectively questions the validity of race. If whiteness can be sold and purchased, how real is it? Even though Schuyler minimized the significance of it in his own life, Black No More emphasizes the real character of its conflict and trauma. The narrator notes that many African Americans had rushed to have the Black-No-More procedure done, "leaving behind insult, ostracism, segregation, and discrimination" (31). He highlights how often these traumas of blackness were applied to Black living spaces as well. To elucidate this assessment, the text applies it to real-life locations and circumstances by referencing actual American locations and foregoes the option of creating fictional counterparts for them:

The mechanics of race prejudice had forced [black people] into the congested Harlem area where, at the mercy of white and black real estate sharks, they had been compelled to pay exorbitant rentals because the demand for housing far exceeded the supply. As a general rule the Negroes were paying one hundred percent more than white tenants in other parts of the city for a smaller number of rooms and worse service (31).

Black No More demonstrates how frequently Black spaces are often racialized much like the black body. It suggests that poor whites were able to tolerate their own economic depravity because of the presence of the Black man; though poor, their white spaces were better by comparison (86). Race as a political tool is employed to undermine 
class struggles. Here the effects of the Black-No-More-triggered, ethnic migration on former racialized spaces are also showcased. As a result of Blacks being absorbed into the white majority, spaces once reserved for them had to be renovated and improved:

Hundreds of wooden railroad coaches, long since condemned as death traps in all other parts of the country, had to be scrapped by the railroads when there were no longer any Negroes to Jim Crow. Thousands of railroad waiting rooms remained unused because, having been set aside for the use of Negroes, they were generally too dingy and unattractive for white folk or were no longer necessary. Thousands of miles of streets located in the former Black belts, and thus without sewers or pavement, were having to be improved at the insistent behest of the rapidly increased white population, real and imitation. Real estate owners who had never dreamed of making repairs on their tumbledown property when it was occupied by the docile Negroes were having to tear down, rebuild, and alter to suit white tenants. Shacks and dry goods boxes that had once sufficed as schools for Negro children, had now to be condemned and abandoned as unsuitable for occupation by white youth. Whereas thousands of school teachers had received thirty to forty dollars a month because of their Negro ancestry, the various cities and counties of the Southland were now forced to pay the standard salaries prevailing elsewhere (86).

Black No More explores how blackness challenges the lives of those who are

coded in it. As equally damning and as difficult to circumvent as their racialized spatial arrangements are the restrictions Blacks had to endure in terms of their economic opportunities. Again, these realities are exposed as a result of the Black-No-More procedure making them a notion of the past in this fictional realm:

Politicians and business men shuddered at the thought of such a tragedy and saw horrible visions of old-age pensions, eight-hour laws, unemployment insurance, workingmen's compensation, minimum-wage legislation, abolition of child labor, dissemination of birth-control information, monthly vacations for female workers, two-month vacations for prospective mothers, both with pay, and the probable killing of individual initiative and incentive by taking the ownership of national capital out of the hands of two million people and putting it into the hands of one hundred and twenty million (87). 
As Matthew continues to thrive in his white body, the text explores the larger implications of the Black-No-More treatments, especially how they revolutionize this pseudo-American social landscape to the extent that racial lines become even more indistinct. Interestingly, characters, who blur color lines prior to the invention of BlackNo-More, are strategically incorporated in this story to emphasize the actual invention of race in general. For example, Mrs. Crookman could pass for white with her very "remote Negro ancestry", and we meet Mr. Walter Williams and Rev. Herbert Gronne $(29,57)$. They are two racially-ambiguous leaders in the Black organization, the National Social Equity League, who are equally as alarmed as their white counterparts by the social restructuring that Black-No-More has caused. Their livelihoods as "Black" leaders rest on them bearing a small, mostly unidentifiable amount of blackness, the presence of which others often failed to recognize (57).

These characters demonstrate the ambiguity of racial identity, which is conveyed in Chuck Foster's words: "everything that looks white ain't white in this man's country" (30). Black-No-More treatment only exacerbates this pre-existing phenomenon, and it magnifies the scope on this hegemonic tradition by making whiteness and blackness impossible to distinguish, which again speaks to the existing complex negotiation of this social construction. Determining how to discern Black-No-More whiteness from nontreated whiteness necessitates an explanation for the conundrum that is whiteness as a qualifier in general. Thus, race in Black No More fictional world illustrates a truth about race in any realm; it is a confusing concept because it is a fallacy.

Although race can have this nebulous quality, it has real significance in both a literal and figurative space. Relatedly, this text explores how it can function as a 
commodity of the social elite in order to generate wealth. Less than two years after joining the organization, Matthew has become the Grand Exalted Giraw, the second in command after Rev. Givens in the Knights of Nordica. He has married Helen, a circumstance made possible via his white performance, and is actively working to grow the organization's permanence and prominence. The Knights of Nordica function as the shield of white supremacy, which is being threatened by the Black-No-More treatment procedures.

In this capacity, Matthew is called to rescue workers, who are also members of the Knights of Nordica, at a German-owned mill in Paradise, South Carolina. The owners, Blickdoff and Hortzenboff, have increased working hours without increasing pay. These workers are considering both unionizing and striking; however, the Grand Exalted Giraw intercedes on the owners' behalf, for a large fee of course, and squelches their efforts by stoking fears that among them were Black-No-More-generated whites, who could not be trusted (76-9). Matthew's rumors and secret operatives extinguish the strike and the possibility of a workers' union, for the "erstwhile class conscious workers become terror-stricken by the specter of black blood" (81). The Grand Exalted Giraw exploits their unflinching beliefs in white supremacy, a toxic ignorance that causes these poor people to work against their own best interests. In this space, Matthew has activated, a new blackness - the white Negro, a truly invisible threat, as tool of hate and exploitation. He observes:

The working people were far more interested in what they considered, or were told was, the larger issue of race. It did not matter that they had to send their children into the mills to augment the family wage; that they were always sickly and that their death rate was high. What mattered such little things when the very foundation of civilization, white supremacy, was threatened? (83-4) 
Blackness as a commodity of capital value is affirmed in this conflict. What could potentially happen in a society if race were to be eliminated or removed? The text indicates race will not be allowed to evaporate in a society that requires it to sustain a domination system such as capitalism. A new blackness or racialization practice will be implemented or adopted.

We follow the societal upheaval that Black-No-More treatments cause through a presidential election campaign cycle. Rev. Givens is campaigning to become the presidential candidate on the democratic ticket with the help and support of his son-inlaw, Matthew, and his extensive Knights of Nordica base of members. Also vying for this same nomination is Mr. Arthur Snobbcraft, president of the Anglo-Saxon Association of America. His life had been devoted to "white racial integrity and AngloSaxon supremacy" (101). As a tactical component of his election campaign, Snobbcraft solicits the help of Dr. Samuel Buggerie, a "professional Anglo-Saxon”, statistician, and authenticator of white racial purity (103). Buggerie works secretly on Snobbcraft's behalf to unearth proof of non-white ancestry among his competitors, most importantly the Republican presidential nominee and members of the Republican executive committee (110-111).

This plan backfires illustrating the argument that race as a social delineator is flawed by design. Buggerie learns the reality about American heritage, truth that race was hegemonically constructed to mask:

These statistics we've gathered prove that most of our social leaders, especially of Anglo-Saxon lineage, are descendants of colonial stock that came here in bondage. They associated with slaves, in many cases worked and slept with them. They intermixed with the blacks and the women were sexually exploited by their masters. Then, even more than today, the illegitimate birth rate was very high in America... There was so much of this mixing between whites and blacks of 
various classes that very early the colonies took steps to put a halt to it. They managed to prevent intermarriage, but they couldn't stop intermixture (119).

Unfortunately for members of the Democratic Party, this information is stolen and a report regarding their non-white ancestral heritage is published on the eve of the presidential election by operatives of the Republican Party. Dr. Buggerie and Snobbcraft barely escape a lynch mob in a small, under-fueled plane leaving from the Snobbcraft country estate. Their plane runs out of fuel in Happy Hill, Mississippi. This emergency stop would be a fatal one.

Unbeknownst to Snobbcraft and Buggerie, they landed in a Fundamentalist Christian community, which had made torturing and killing Black people an "established custom" (138). With the most graphic and violent action present in this text, a most meaningful assertion about blackness and the black body is affirmed. Often, the black body is objectified as a carrier of generalized white anxiety, fear, and hysteria that has been transferred onto it, resulting in a form of Negrophobia. Snobbcraft and Buggerie are discovered in the distance by this group during their Election Day revival service, where they had assembled hoping to receive a sign from the Lord (141-143). Snobbcraft and Buggerie have coated themselves in shoe polish, believing that the disguise as Black men would offer protection from them being discovered as themselves, members of the Democratic Party who were masquerading as white men. These men, once sociallyperceived as white, in the present space of passing as Black, appeal to the members of this Christian community for Jesus-like protection; they expose the pale skins under their clothes and plead to have their whiteness recognized (145). However, the terms of qualifying race at this juncture are as vague as they have ever been; thus, this small religious sect, a microcosm of their racist American society, has the power to determine 
the codes of racial identification, which supersede any religious moral codes. In this cultural melee, whites and Blacks can both suffer the victimization of race, which is precipitated by the confusion of racial classification.

What follows is the very grotesque lynching of these two men by these Christfollowers. Their ears and genitals are removed before they are bound to stakes and charred into two unrecognizable hunks of meat before a gleeful and celebratory crowd of "white" onlookers (146-7). Thus, the reader is confronted with the ultimate truth about blackness, it is determined from without by unqualifiable means in the space of the white man's gaze and imagination. For a Black person during the era of the Harlem Renaissance, this was a tragic circumstance. According to the Equal Justice Campaign, lynching of Black people became a tool of power and control most intensely between the years of 1915 and 1940 in order "to suppress African Americans who individually and in organized groups, were demanding the economic and civil rights to which they were entitled" (EJI 14). The demand for rights and recognition were defining characteristics of the Harlem Renaissance and the literature it bore.

\section{The Danger of the White Gaze and Social Perception}

In the early spring of 2018 , one of the sweetest joys of me being a refugee advocate occurred. I had the pleasure of escorting two Congolese refugees, Consolé, 11, and Baraka, 9, to Memphis, Tennessee, on their first out-of-state soccer tournament. The brothers were excited to see more of the country that they had beheld so little of since arriving three years earlier with their family. Often we assume the worst of the circumstances that warranted their relocation and transition to the United States, and so 
we rarely ask them to share any details. We offer the soccer pitch as a safe space of solace and/or remembrance. It offers a common characteristic of the refugee camp communities they left behind; soccer can be played with almost any makeshift ball on almost any surface, and quite frequently around the globe, that is how it is played.

To make the experience all the more pleasurable for children in our care like Consolé and Baraka, we try to accommodate all of their wishes on these first trips with us. The reward for us is simply to watch the wonder of it all as they experience it. During one of our many car conversations and there were many, I asked the boys to tell me about school life. They were elementary school students at the time, and generally the younger boys make the best adjustments in these American school environments. But, we still worry about bullying and the alienation that one often feels as the newcomer. Console and Baraka had been in school for three years and had acquired the English language beautifully ${ }^{13}$. They appeared to be well adjusted, exceptionally loved by their singleparent mother, but significantly limited in resources. Almost all of their personal belongings were secondhand or visibly worn; we replaced many of these items as frequently as we could and as stealthily as we could as to not cause them any embarrassment. What was undeniably apparent about Consolé and Baraka (and any thoughtful person could immediately ascertain this) was the power of their intellects and the intensity of their perception. Honestly, I could see myself in Consolé in his determination specifically. He did most of the talking for his brother and him, but he was respectful and loving enough to leave room for his brother's voice. And to my delight,

\footnotetext{
${ }^{13}$ Consolé and Baraka's mother's country of origin is Congo, a French-speaking country, but they were born on a refugee camp in Uganda or Tanzania, where they awaited a resettlement assignment. Before arriving in the U.S., they spoke Swahili, French, and Lingala.
} 
they loved school and their teachers and told me all about it. They just seemed to really enjoy learning and the opportunity and possibility of a good education.

After the close of a beautiful weekend of soccer, we packed up the car and headed back on the road to Kentucky. I watched them closely in the backseat because returning the boys to their families is usually the difficult part for me-it is hard to end the dream. As the sun set around us, I watched Consolé fight off sleep. He still wanted to enjoy it all. I noticed a sadness in his face, which he seemed to pull in from the darkness beyond the horizon. Even if he didn't have the words to convey them, he was a young man of big ideas. A terrifying curiosity nudged at me to cross a colonial-constructed, cultural barrier and connect with him about what seemed to be a pain that felt so familiar. I drew his eyes into mine through the rearview mirror, and I asked him, "Consolé, is there anything that you don't like about school or your life here in America?"

He said and I will never forget the precision and sentiment of his words, "Yes, sometimes they act as if they don't see me." The sorrow in his eyes was ageless. Yes, a very familiar Black pain — he felt invisible. I didn't have the strength to ask who; I knew the answer was unquantifiable. I followed his revelation with words of affirmation. He was beautiful, smart, and kind-I told him; that's all I could give, but I worried then as I worry today. Will he survive the space of his black body? There were many triggers that could render him invisible in social space; this is true. However, I could not be convinced then or now that he wasn't speaking to the trauma of his blackness. And I thought of Emmett Till.

Consolé and Baraka and those who feel trapped in the space of their blackness now and in the past inform this research. As race continues to be a problematic construct 
so does the trauma that is often associated with black space, the body included. In 1925, Alain Locke conveyed the aims of the Harlem Renaissance in his essay titled "Enter the New Negro", which he contributed to Survey Magazine. He declared "the revaluation by white and black alike of the Negro in terms of his artistic endowments and cultural contributions, past and prospective" to be a major goal of the movement (6). He also considered the movement to be "the consciousness of acting as the advance-guard of the African peoples in their contact with Twentieth Century civilization" and "a mission of rehabilitating the race in world esteem from that loss of prestige for which the fate and conditions of slavery have so largely been responsible" (5).

Accordingly, these Harlem Renaissance writers, expanding on the burgeoning aspirations of the New Negro era, strived to emphasize the value and significance of Black art and most importantly Black humanity, a tradition that many of their postcolonial successors would progress. Black spaces reflect a historical battle for the ontological and epistemological control of the notion of blackness. These authors hoped to clear the air in these spaces by regaining control of this social narrative. They theorized that by revealing truths through literature and art, they could pull African Americans closer to what Locke described as "full initiation into American democracy" (6). The literary works of the New Negro era and Harlem Renaissance movement authors, Charles Chesnutt, Nella Larson, and George Schuyler recognize the significance in articulating sources of trauma; as they were in their era, Blacks are still aspiring for greater social inclusion. Black bodies and spaces continue to be determined by the social perception of an artificial concept—race. It is my duty to continue as these authors endeavored to speak truth to power and persist in cultivating healing spaces. 


\section{CHAPTER IV}

\section{"REMEMORY" AND THE GHOSTS OF THE PAST: THE SIGNIFICATION OF ENSLAVEMENT IN POSTBELLUM SOCIAL SPACES AND INHERITED TRAUMA IN THE NEO-SLAVE NARRATIVE}

"Where I was before I came here, that place is real. It's never going away. Even if the whole farm - every tree and grass blade of it dies. The picture is still there and what's more, if you go there-you who never was there - if you go there and stand in the place where it was, it will happen again; it will be there for you, waiting for you."

-Sethe, from Toni Morrison's Beloved

This chapter of my dissertation explores neo-slave narratives written by the descendants of the enslaved: Toni Morrison's Beloved, Octavia Butler's Kindred, and Ernest Gaines' A Lesson before Dying. Neo-slave narrative refers to contemporary texts that are consumed with the depiction of slavery in its historical context and/or by the institution's legacy, including its immediate and lingering ramifications in postbellum spatial contexts. Kindred and Beloved both feature characters who have first-hand knowledge of this brutal institution, but A Lesson before Dying does not. However, what connects these narratives is the shared spatial/historical context of slavery; slavery is a character of enormous presence, in all of these stories, to which the human characters are responding as a critique of its traditional depictions. Essentially, these narratives are imbued with a determination to acknowledge and legitimate the impact of American slavery on the present-day experience. Thus, these narratives are postcolonial in that they expose lingering manifestations of slavery and other colonial institutions, but more significantly for the purposes of my research they investigate and substantiate the effects of inherited slave-era traumas in contemporary spaces. These spaces - the symbolic 
representations of them in neo-slave narratives - and what they signify are at focus in this chapter. Though these testimonies are fictional, neo-slave narratives exhibit the power of literature to excavate actual sites of conflict by forcing new perspectives of spaces into the public imagination or into our collective memories. Paramount to this research is their analysis of the literal and figurative ghosts of slavery that persist as forms of vicarious traumatization to the extent that they haunt the realities of those with second/third-hand and/or little to no personal experience of the institution other than their corporal or ancestral ties.

Much like the traditional slave narratives of Douglass, Jacobs, and Northup, these neo-slave narratives recast the slave experience and affirm its continued legacy in the social/spatial present. Neo-slave narratives are invested in the cultural condition; in ReForming the Past: History, the Fantastic, and the Postmodern Slave Narrative, Timothy Spaulding asserts that neo-slave narratives are "not merely a metafictional enterprise, but [they offer] a way of revitalizing the historiography of slavery" (4). Yes, these are fictional stories, so they offer their own form of historiography too. However, one could argue that most colonial approaches in historical writing involve elements of historiography. For instance, Jan Carew posits in Columbus and the Origins of Racism in the Americas that Columbus' personal journals were accepted as historical fact because "neo-creationist theology of history [made] it easier to sustain racist fantasies about 'superior' Europeans and 'inferior Indians and Africans'.” This practice also demonstrates the power of the social narrative's conceptual strategies to inform and authorize (11). Reactively, these neo-slave narratives are leaning into postmodernist theoretical inspirations by offering a treatment of the historical record of slavery that 
serves to reclaim the past (Spaulding 3). According to Spaulding, authors of neo-slave narratives "set out to reform our conception of American slavery by depicting a more complex, nuanced view of Black identity in the context of [the system]" (4). In addition, I argue that the trauma analysis that has often accompanied our understanding of the context of American slavery is usually oversimplified and void of a strong spatialhistorical analytical focus, so the neo-slave narrative also exposes greater dimensions, specifically in the spatial-context of slavery, by expanding public knowledge regarding the scale of its affliction on the enslaved and their descendants.

In addition, neo-slave narratives highlight a continued history of contested space in the Black experience; freedom, the ideal and the inspiration behind the original slave narrative, is similarly exposed in its literary successors as an unrealized reality. As barriers shifted from the external landscape to the black body in the transitional period following the Civil War, these narratives suggest that the boundaries of time and space are irrelevant for trauma to the black body and psyche are preserved in varying forms and transfigurations in the postbellum world.

\section{"Rememory" and Spatial Disruption in Toni Morrison's Beloved}

The slave experience as a subject continues to find a presence in African American literature because the scope of its permanence in the lives of Black people has continued to be devalued. It is with us, and its traumas and/or our responses to them have often defined us. The freedom that Black people experience in America is "haunted" by this legacy, and their literature gives voice to this reality. Like the main character in Beloved, a ghost who takes on a human form strategically interrupting the other characters' lives, slavery is a psychological intrusion or a constant, residual occupying 
force in the lives of Black folk. Beloved, along with other postcolonial slave narratives, exposes slavery’s cross-generational, psychological impact. As Timothy Spaulding suggests "postmodern slave narratives blur the lines between historical subject and contemporary author, between the past history of slavery and its current legacy in contemporary culture, and between historical and fictional reconstructions of the past" (18). In this role, Beloved - the ghost, functions as a contemporary explanation of current phenomena in the Black experience. With Beloved, we are given the opportunity to make psychological connections between the past and the present. For example, Beloved occupies as well as personifies the space of slave-era and continued trauma in the lives of Black Americans. Her presence is an exploration and acknowledgement of the psychological manifestations of slavery, which are often triggered by external influences, and the instability that this enduring portal causes in the space of one's lived reality. Beloved embodies the memories of the ancestors lost in the entrapment of the slave trade on the continent through the middle passage and into the thriving American institution; she is the reincarnation of their first-hand experiences and memory provides them an indelible space to occupy.

Morrison uses this tool of "rememory" (a term that she coins for this text), or the element of memory that functions as a form of vicarious traumatization, to mirror the space of black consciousness and demonstrate how movement through the world in black bodies is often complicated by physical and/or psychological constraints, which are indicative of confrontations with trauma of the past and/or ideologies conceived of the traumatic past. In Beloved, Toni Morrison forces readers to reconceptualize the space of enslavement; by witnessing its expansion into the contemporary landscape and its 
imposition within the Black experience. The haunting of the house on 124 Bluestone Road and later the appearance of Beloved in human form represent the various ways that American slavery is grounded in the present. According to Timothy Spaulding, "Beloved remains elusive to those who would contain her; the concept of rememory suggests that we have access to the past through its physical re-emergence in the present. Beloved is also an omnipresent symbol of many social and political realities related to the lingering traumas of slavery" (66).

It is hard to imagine how Beloved, perceivably a memory projected as a ghost, could occupy physical space outside of her existence as an illusion or rememory within Sethe's psyche, but the depth and the nature of the psychological trauma that was sanctioned in the United States in order to brand a people with a deeply impenetrable mentality of inferiority utilizing the social construct of racial identity is equally unimaginable in terms of its form. Old wounds can often be difficult to heal especially when one has to remain in close contact with one's assailant; often the newly freed were forced to live on or close to the plantations on which they had been enslaved. This kind of close proximity can activate fear and unconventional reactions as the mind is forced to return to upsetting events. The physical space can trigger these memories to the extent that the space and the memory become one and the same.

In Slavery Remembered: A Record of Twentieth-Century Slave Narratives, historian Paul Escott presents data compiled from interviews conducted with former slaves for the Federal Writers' Project Slave Narratives and collections of narratives produced by research scholars at Fisk University (3). These interviews were conducted between 1927 and 1938, and Escott suggests that through the voices of the formerly 
enslaved, presented in these interviews speaking for themselves, a new interpretation of American slavery emerges (xiv). He argues that the Black participants in these interviews reveal "a deeply ingrained awareness of themselves as an oppressed racial group and that this awareness reinforced their community while it guided them in their relationships with whites during slavery and Reconstruction" (xiv). According to Escott's analysis of the interviews, what seemed to guide them most consistently was a "sense of foreboding around white people...recalling their days in bondage, a number of the former slaves described the fear and reticence that they had felt around whites" (99). Escott describes their postbellum adjustment as a "pulling back from unnecessary encounters with whites" and a strengthening of cultural ties forged in survival (99-100).

In spite of these attempts to create new physical spaces free of racial hostility for themselves, the emancipated appear to have had a more difficult time creating the same kind of psychological space. In his assessment of slave narrative data, Escott determined that $78.3 \%$ of the former slaves interviewed demonstrated a belief in and/or saw haunts (also referred to as haints) or ghosts. Furthermore, he suggests that this percentage would have been higher, in his opinion, had the participants "had complete confidence [in the process - many of the interviewers were white] and had candor prevailed in each interview" (103). Nonetheless, this large number of participants reporting encounters with ghosts is informative, and Escott provides us with vivid aspects of their testimonials. He includes a summary of their recollections:

Spirits appeared in various forms; nevertheless, there was a substantial amount of consistency among the numerous reports... [The spirits] sometimes looked like a dog or cat or goat or like a man. Many slaves sighted headless cows whose odd appearance and eerie silence was disturbing. The bodies of the spirits could be either solid or vaporous and insubstantial. Haunts appeared in two colors, either white or black (possibly a metaphorical reflection of the American racial 
dichotomy), and, if black, their darkness cloaked them in a striking, impenetrable manner. These apparitions also produced characteristic nonvisual effects such as noises, winds, and changes in temperature. The narratives refer at times to wellknown individuals, such as the master, who came back after death, but frequently haunts were anonymous or rather, had their own identity. They could become quite familiar to human beings. To keep the spirits from being frightening [there was a shared belief among the interview participants that] one had to stand up to them and put them in their place (103-4).

This slave narrative data intimates that Beloved is not far removed from the reality of many Black Americans post emancipation, but my work does not endeavor to quantify literal ghost encounters. Whether these ghosts are literal or figurative is irrelevant to the assumption of this work, which is that these ghosts are the transferrable consequences of the haunting that enslavement produced. The data demonstrates a collective spiritual encounter for those who only share the collective experience of enslavement and of Black identity. Beloved, even as a fictional text, works to identify the cross-generational transference of trauma in the form of various ghosts or the haunting of the Black experience via vicarious traumatization, e.g. there is very little distinction in Sethe and, her daughter, Denver's spiritual encounters. We are given the opportunity in this text to excavate the physical spaces of blackness and the sites of conflict within it in order to better understand the uniquely traumatizing nature of this experience. In postbellum social spaces, Black men and women are confronted with triggers in their physical landscape that work to perpetuate the trauma of enslavement. For my grandmother, the trigger was a sacred, historical site of the Ku Klux Klan: Stone Mountain Park. For Sethe, the house on 124 Bluestone Road was one of many spaces of traumatic "rememory" that opened a gateway into the horrors of the past.

However, before we can appreciate the various demonstrations of rememory in space as a revelation of Black experience in Beloved, we must put this literary approach 
into a theoretical context. What I am attempting to do with this text and the other neoslave narratives that will follow is to recognize the complex nature of trauma by employing postcolonial, culturally-specific modes of interpretation, which will involve looking at the ways that texts and language draw insights into traumatic events and the unconscious, remembering, and identity (for our purposes, Black identity); this approach engages trauma studies but expands it so that non-western perspectives and experiences of trauma are considered (Mambrol, "Trauma Studies"; Visser 252-4). Early trauma studies were influenced by Dr. Sigmund Freud, who provided the guide to appreciating the assimilation of trauma into narrative, and how they reflect the inner workings of the mind. However, Freud's theorizations related to trauma have been challenged in recent years by scholars, who have rejected his usage of Western frameworks of trauma analysis exclusively (Visser 252-4) ${ }^{14}$. Later, more pluralistic models of trauma were adopted that avoided essentializing it and embrace trauma's variability. According to Nasrullah Mambrol, these newer trajectories in trauma studies scholarship allow greater understanding of the "social significance of trauma" and "uncovered new relationships between experience, language, and knowledge", especially of those of a collective or cultural nature (Mambrol, "Pluralistic Trauma Theory: A New Model").

With Beloved, Morrison is drawing a link between the violence of slavery and the many enduring psychological traumas present in the Black experience during slavery and post emancipation. Sethe, the protagonist, and the other Black characters in this story are surrounded by physical signifiers of a gothic past that trigger the trauma of rememory,

\footnotetext{
${ }^{14}$ Visser references the extensive work of scholars who recognized the need to decolonize trauma studies, including Michael Rothberg and his work in sparking this paradigm shift: Rothberg, Michael.

"Decolonizing Trauma Studies: A Response." Studies in the Novel, vol. 40, no. 1-2, 2008, pp. 224-234.
} 
which Beloved, the ghost, ultimately represents. Sethe tells Denver: "Places, places are still there. If a house burns down, it's gone, but the place — the picture of it—stays, and not just in rememory, but out there, in the world" (Morrison 43).

Sethe believes that traumatic events lie in the places where they occurred like a picture, and that places have a visual history. The Black experience is haunted in this way with historical images tied to enslavement that have created an overlapping physical/psychological mode that characterizes this identity. Qualifying this mode of Black experience becomes a challenge to both language and meaning. Sethe reveals a window into this mode through her personal experience after Denver attempts to understand the presence of a white dress holding onto her mother as she prayed; Sethe rationalizes this apparition, and Denver internalizes her mother's explanation (42). It becomes her story as well. Every room in Sethe's home and almost every other space in her life is possessed by the memory of a singular traumatic event or traumatic events of enslavement in general. Denver becomes a captive of this possession as well even though she does not have first-hand knowledge of enslavement, but she occupies the house with her mother and other family members; as a result, she is consumed by her mother's rememories, which through the routine of living (or coping) Sethe has worked to normalize. Here, the text is exposing a pathology in this family or what Freud described in his research as a reproduced thought that causes physical symptoms and ascribes value to a previous repressed experience in the unconscious or "pathogenic reminiscences" (Breuer and Freud 253-306).

These simultaneous physical/spatial hauntings are not accurately or widely acknowledged, but they exist, often repressed in the unconscious, as an unresolved 
characteristic of a Black cultural pathology, which is an important distinction from Freud's psychoanalytical models. According to James Dicenso, “Freud's analyses of cultural formation posit mechanisms, forces, dynamics, and pathologies parallel to those manifested in individual psychology... Freud appears to undertake a reductive conquest, replacing the mystery and complexity of ideal cultural structures with a closed-system explanation governed by instinctual conflicts" (19). Freud's psychoanalysis approaches were dominated by "an awareness of individual psychology being located within the variable systems of culture" (19). This research endeavors to recognize, substantiate, and utilize a cultural (group) trauma that has extensive societal and historical significance.

Furthermore, acknowledging these cultural hauntings can offer some form of healing, which is the ambition of Beloved; as noted earlier, Morrison offers the text as healing space, a "bench by the road." Coming to terms with slavery requires this kind of healing acknowledgment. Later, with this text, we observe how Morrison emphasizes the importance of this public acknowledgement through a form of community atonement, when the neighbors who once rejected Sethe unite to reclaim her from the ghost of Beloved. Ultimately, physical spaces will continue to carry the traces of historical traumas, but Beloved is a story about healing because it acknowledges that these wounds can never be removed. It is important to underscore that this approach strategically and intentionally emphasizes acknowledgment over erasure; it promotes balancing the social narrative. Although the attempt is understandable, the pain does not go away if you remove the physical marker of it. Ignoring history is just as ineffective and/or damning as telling the story of history from a singular perspective. We, as a society, are in need of a means of coping, and Morrison's Sethe understood this well: "The future was a matter of 
keeping the past at bay" (Morrison 51). It is a hope that we might achieve this by

unearthing painful truths about our lived experience, much like allowing a wound to

breathe can aid the healing process. Sethe and her extended family are opening cultural

crypts and exploring ways of surviving. As Timothy Spaulding observes:

As Sethe conceptualizes it, rememory is the aspect of the past that exists apart from her own internal consciousness and exerts itself in the material present. Although connected to her individual memories (in the form of thought pictures), rememories have their own agency in the real world, converting abstract and formless thought into material reality. Sethe asserts that places (Sweet Home plantation), people (Beloved and her ghost), and even nature itself (the trees and grass) contain the text of slavery on its surfaces as readable markers of the past. Within the context of the novel, rememory evokes both the supernatural in the suggestion that the past can haunt the present in physical form and traditional historicism in its conception of past as an accessible and knowable reality (73).

Sethe's memories of trauma have a kind of agency that moves beyond the context of the novel. Sethe's mental process is a demonstration of the Black psyche, and through her Morrison is essentially demonstrating how traumatic memory becomes a family heirloom of the generational curse variety. Morrison also demonstrates through Sethe and other characters in Beloved how physical space can signify trauma and trigger the recollection of these memories. Therapeutically, Beloved endeavors to help understand the plight of those whose traumas are so heavy that they feel as though they navigate hallowed ground in the spaces that they occupy.

\section{Beloved and the Hallowed Spaces of the Postbellum South}

In the same way in 1855 that "Sweet Home", the plantation where Sethe once "lived" in servitude could never actually be a home to her, as a space of protection or comfort much like a mother's womb, in 1873 the house on 124 Bluestone Road could 
never be either, save for twenty-eight days when she saw it through her mother-in-law, Baby Suggs' eyes, as a space of refuge:

Sethe had had twenty-eight days - the travel of one whole moon - of unslaved life. From the clear stream of spit that the little girl dribbled into her face to her oily blood was twenty-eight days. Days of healing, ease and real talk. Days of company: knowing the names of forty, fifty other Negroes, their views, habits; where they had been and what done; of feeling their fun and sorrow along with her own, which made it better. One taught her the alphabet; another a stitch. All taught her how it felt to wake up at dawn and decide what to do with the day (111).

On the twenty-eighth day of her exodus, her captors, four white men who could expand the "terror-tory" of the plantation South at their will by entering into a free state in order to reclaim their property, found it — Sethe and her children, and the safety of 124 went missing. On that day, her grief and trauma returned to center stage, for she was again fully possessed by memories that she had been suppressing. She could not bear the thought of her children enduring the looming torment of re-enslavement, so she attempts to kill them. Her premeditated reaction of motherly instinct to the inevitable arrival of her former slave masters was to slaughter her children; she thought death was the better option to the plantation, which could never offer them any form of humanity. She was only successful in killing one, whom she later buries in a grave with a tombstone that read "Beloved" (5).

Before this incident, "124 had been a cheerful, buzzing house where Baby Suggs, holy, loved, cautioned, fed, chastised and soothed" (102). It was a welcoming space in the community: "Where not one but two pots simmered on the stove; where the lamp burned all night long. Strangers rested there while children tried on their shoes. Messages were left there, for whoever needed them was sure to stop in one day soon" (102). After the incident, the space is consumed by the traumas of blackness, an energy 
so voluminous that it occupies and affects the senses. Baby Suggs recognizes the unique ethos of this energy and responds to it accordingly when it makes its presence known along with the arrival of the white men; she feels the energy before she has eye-sight confirmation of them: "Now she stood in the garden smelling disapproval, feeling a dark and coming thing” (173). This was a form of the energy that idles in private and social spaces when they are imbued with the traumatic memories of enslavement. Beloved's ghost and later what seems to be her human manifestation returned from the dead is another realization of this energy.

Beloved is a daughter, but she is more than a child of Sethe. She is the repressed trauma of slavery or the psychical embodiment of enslavement: the memory of its family separations, abuse, beatings, degradation, sexual violations, mutilations, exploitation, and death - the traumas of blackness. In her voiced rememory, a staccato soliloquy that she offers near the end of her return in human form, she details the wretchedness of her occupation on a slave ship, one of the many communal Black experiences:

All of it is now it is always now there will never be a time when I am not crouching and watching others who are crouching too I am always crouching the man on my face is dead his face is not mine his mouth smells sweet but his eyes are locked...some who eat nasty themselves I do not eat the men without skin bring us their morning water to drink we have none the men without skin are making loud noises I am not dead...the bread is sea-colored I am too hungry to eat it the sun closes my eyes those able to die are in a pile I cannot find my man...if I had the teeth of the man who died on my face I would bite the circle around her neck bite it away...storms rock us and mix the men into the women and the women into the men (248-50).

Beloved is recalling the slave ship — the truest entry port into slavery as it signals the official termination of homeland access. It provides the clearest messages to the enslaved regarding their fate. The inadequate space, food, air, and basic consideration 
establishes the atmosphere of inhumanity that would ultimately accompany them into bondage. When Beloved returns to Sethe's life, she is embodying these kinds of historical memories for her mother and those who have access to her; she conveys and her mother affirms her spirit of being "Rebuked. Lonely and Rebuked" (16). That was the essence of a captive's feelings aboard one of those miserable ships. Of course, "124 was spiteful" and "palsied by the [Beloved's] fury", for she had never really known love (3, 6). In naming her, Sethe attempts to transmit the sentiment beyond the grave, but it did not reach.

Although Sethe and other characters live in confrontation with Beloved and her "outrageous behavior" at 124 Bluestone Road-in the uncomfortable space of it, she is only an extension of the true source of her rage: the racism that rationalized her bondage and inspired her mother's choice of infanticide. For Baby Suggs, Sethe, and her lover, Paul D, Sweet Home and the other plantation spaces like it that they may have encountered were more adversarial. Sweet Home was where they had been placed, but as Paul D concludes “it wasn't sweet and it sure wasn't home” (16). It was the primal scene and trigger of their most frequent traumatic memories. Sethe walks with her haunting memories of Sweet Home, even though "she work[s] hard to remember as close to nothing" (6).

In 124, she battles "turned-over slop jars, smacks on the behind, and gusts of sour air", but the real haunt crept into her mind in a devious way and was activated through ordinary spatial encounters, such as a walk through a field, the sight of items in a path, or the sound of a dog drinking from a puddle (4). Then, her greatest brutalities come roaring back, as she acknowledges, "whether [she] want[s] [them] to or not" (16): 
Unfortunately her brain was devious. She might be hurrying across a field, running practically, to get to the pump quickly and rinse the chamomile sap from her legs. Nothing else would be in her mind. The picture of the men coming to nurse her was as lifeless as the nerves in her back where the skin buckled like a washboard. Nor was there the faintest scent of ink or the cherry gum and oak bark from which it was made. Nothing. Just the breeze cooling her face as she rushed toward water. And then sopping the chamomile away with pump water and rags, her mind fixed on getting every last bit of sap off- on her carelessness in taking a short-cut across the field just to save a half mile, and not noticing how high the weeds had grown until the itching was all the way to her knees. Then something. The plash of water, the sight of her shoes and stockings awry on the path where she had flung them; or Here Boy lapping in the puddle near her feet, and suddenly there was Sweet Home rolling, rolling, rolling out before her eyes, and although there was not a leaf on that farm that did not make her want to scream, it rolled itself out before her in shameless beauty. It never looked as terrible as it was and it made her wonder if hell was a pretty place too. Fire and brimstone all right, but hidden in lacy groves. Boys hanging from the most beautiful sycamores in the world. It shamed her-remembering the wonderful soughing trees rather than the boys (6-7).

Wedded to those idyllic scenes of rolling hills, welcoming oaks, and seemingly, innocent boys at play was her unfortunate and oppressive circumstances of servitude. Not all memories of Sweet Home were undeniably traumatic, but even though the plantation's original owners, the Garners, did attempt to show their enslaved men and women a modicum of respect, as much as one could afford to offer his or her chattel, their unwavering racism, a societal tradition, was the ineffaceable feature of her traumatic experience as a slave woman. This characteristic was what made slavery in America its own unique breed. Though subtle in terms of how rampant it flowed at Sweet Home with the Garners, especially in comparison to other plantations, undeniably, it was there in the atmosphere from the beginning. When Mr. Garner brags to his friends that "[his] niggers is men every one of 'em", it was there (13). When Mrs. Garner, the only other woman on the plantation, laughs at the notion of Sethe wanting to plan an actual wedding with 
Halle, it was there. Mrs. Garner dismisses Sethe's idea of a wedding by telling her that she is "one sweet child" (31). In this response, she is disguising her own lack of civility with gentility and conveys to Sethe that that kind of ceremony — one layered in significance and sentimentalism - is reserved for the humans (31). Mrs. Garner perceives Sethe to be both charming and innately stupid.

Still, Sethe found love and gave birth to her babies at Sweet Home, so she tries to make it feel as though it were a reflection of its name:

She [would] bring a fistful of salsify into Mrs. Garner's kitchen every day just to be able to work in it, feel like some part of it was hers, because she wanted to love the work she did, to take the ugly out of it, and the only way she could feel at home on Sweet Home was if she picked some pretty growing thing and took it with her. The day she forgot was the day butter wouldn't come or brine in the barrel blistered her arms (27).

Unfortunately, Sweet Home was steadfast behind the illusion of Sethe's psychological smokescreens; Baby Suggs' words became undeniably clear: "There is no bad luck in the world but whitefolks" (105). Space between traumatic memories can occur as things interrupt them: work, happiness, other problems, the day to day malaise, etc. Suddenly, spontaneously, painfully, they return. The feelings that make one human are deadened by constant torment and torture, the kind that characterized enslavement. As the little indentured servant girl Amy Denver, who offers Sethe life-saving assistance while they were both on the run, observes, "anything dead coming back to life hurts" (42).

A rise from the dead can be phoenix-like but often for the enslaved and their descendants, it was not so easy. Trauma can linger in and occupy hidden spaces-literal and psychological. Beloved is a story of how painful racism is and the depths of its afflictions. Like Sethe, enslaved mothers were not allowed to be mothers; as female 
hands and producers, they were forced to ignore the instinctive calls to nurture and protect their children, a compulsion honored even in farm animals. As Sethe recalls of her own mother, slaves were simply "ma'ams" to their offspring who observed them from a distance with their "backs turned away, stooping in a watery field" (37). Now, as a mother who never had a mother, how can Sethe forget that kind of memory? The pain of Amy rubbing Sethe's swollen and blistered feet is similar in nature to these traumatic memories - below the surface, inflamed, and triggered by touch. Sethe's past was an unspeakable hurt "like a tender place in the corner of her mouth that the bit left" (69). Sethe simply needed to touch a blade of grass in a field, any field anywhere, to recall any varieties of pain and loss suffered at Sweet Home or on her previous plantations. After being brutally raped and whipped at Sweet Home, she appreciates it as the catalyst of her pain and decides to flee it for her family's sake:

Sethe had the amazing luck of six whole years of marriage to that "somebody" son who had fathered every one of her children. A blessing she was reckless enough to take for granted, lean on, as though Sweet Home really was one. As though a handful of myrtle stuck in the handle of a pressing iron propped against the door in a whitewoman's kitchen could make it hers. As though mint sprig in the mouth changed the breath as well as its odor. A bigger fool never lived (28).

She runs, but the memories of Sweet Home follow her: "Sethe blamed herself for Baby Suggs' collapse...[she] knew the grief at 124 started when she jumped off that wagon, a new born tied to her chest in the underwear of a whitegirl looking for Boston" (105). Eventually, she concedes that her "effort was best directed not on avoiding the pain but on getting through it as quickly as possible" (46). In a shallow psychological grave, she buries the pain. She stops looking outside hoping to see her boys who had run away from home return and "be [comes] oblivious to the loss of anything at all" (47). In 
this state, "the house crowded in on her" and "there was no room for any other thing or body until Paul D arrived and broke up the place, making room, shifting it, moving it over to someplace else, then standing in the place he had made" (47).

For Paul D, who had spent years in the solitary confinement of a cage as a chaingang prisoner, space is an absolute requirement; it represents his freedom. The absence of it or a place, as he describes, "where [he] could love anything [he] chose—not to need permission for desire", is what so acutely and persistently traumatizes him. At Sweet Home, Paul D was one of five enslaved men on the plantation; he and the other men, Paul F, Paul A, Sixo, and Halle Suggs—-Sethe's future husband, were taught to believe that they were men by Mr. Garner:

Allowed, encouraged to correct Garner, even defy him. To invent ways of doing things; to see what was needed and attack it without permission. To buy a mother, choose a horse or a wife, handle guns, even learn reading if they wanted to - but they didn't want to since nothing important to them could be put down on paper (147).

After Mr. Garner's death, their new owner, Schoolteacher, forces them by means of cruel tyranny and harsh mechanisms of control to understand that only in Mr. Garner's imagination could they be perceived as men in America. As Paul D would come to realize, they were "trespassers among the human race. Watchdogs without teeth; steer bulls without horns; gelded workhorses whose neigh and whinny could not be translated into a language responsible humans spoke" (148). When he attempts to run away and is caught, Paul D is bound and subjected to bit torture. In this state, he observes, in a haunting comparison to a rooster named Mister, the reality of his position as a Black man in the antebellum South. He had been restrained and silenced for wanting liberation while Mister, freely occupying space near him, is "allowed to be and stay what he was" (86). 
There was no safety and comfort in his existence. Paul D is sold to a chain gang after attempting to kill his next owner. In the chain gang where he is raped, forced to live in a cage underground, and work endless hours in the worst conditions in Alfred, Georgia, he suffers his greatest defeat: an altered mentality through the psychological acceptance of his inhumanity. He concedes that the white men with guns were the possessors and gatekeepers of the manhood that he, an enslaved person, so valued:

Listening to the doves in Alfred, Georgia and having neither the right nor the permission to enjoy it because in that place mist, doves, sunlight, copper dirt, moon - everything belonged to the men who had guns. Little men, some of them, big men too, each of whom he could snap like a twig if he wanted to. Men who knew their manhood lay in their guns and were not even embarrassed by the knowledge that without gunshot fox would laugh at them (191).

In the space of 124 Bluestone road, Beloved, the ghost of a murdered child and of enslavement, demonstrates that Paul D and Sethe are not as dissimilar as women and men can be, for they are both trapped and fragmented by their blackness, which signifies the cultural practice of knowing a unique kind of human cruelty while simultaneously laboring to overcome it. As a result, the feeling of a fully-realized human experience had eluded them both. As Lori Askeland asserts, Paul D realizes:

[Mr. Garner's] death, however, reveals the fragility of the male slaves' "domain" on Sweet Home, and indeed that of all such domains-especially those dependent upon the benevolence of a master... The limits of their domain and the degree to which they had been isolated in Mr. Garner's "wonderful lie" become clear [to] Paul D...They were, under Mr. Garner as under schoolteacher, simply "the defined" as men, and never the definers of themselves (792).

For Sethe, only a realized experience of motherhood could affirm her sense of completeness, and for Paul D it was manhood that stood just outside of his reach. 
After finally breaking free of the chain gang in Georgia, Paul D embraces the ironic stability of a nomad and walks to the free state of Delaware; he believes "if a Negro got legs he ought to use them. Sit down too long, somebody will figure out a way to tie them up" (Morrison 11). Aimless, detached, and guarded, these were the characteristics he trusted most. Also, he adopts the protective mode of loving small, and he hides his heart away in a "tobacco tin" $(113,191)$. Although he feels contented by pausing these survival techniques after finding refuge with Sethe in her home, especially after he valiantly reclaims it, so he believes, from the ghost that he exorcises from it, what he realizes as Sethe does is that Sweet Home and the consequences of his time there are traumatic memories that are not so easy to forget. They have become a part of his legacy and have taken up psychological space. Beloved's return in human form triggers these rememories as vividly as when in ghost form she made the floor boards tremble and the house pitch propelling him back psychologically into the eighty-three days he spent "locked up and chained down" in Alfred, Georgia (21).

Beloved is a history that refuses to be eliminated; moreover, when he discovers she is "moving [him] out of 124", he wonders if Schoolteacher was right about him (134, 148-51). Can he actually be a man? She and the history that she represents are reclaiming the stability and security that he believes he has found with Sethe. His movement was "involuntary", and he was being "prevented" from maintaining the freedom that he was enjoying in occupying what he identifies as a safe space (136). In his opinion, a man should be able to control this - to stop it. However, he is moved from Sethe's bed to a rocker downstairs to Baby Suggs' room to the store room to the cold house to ending his relationship with Sethe; he realizes that his claim to manhood is 
imaginary, for he had fortified it in a space and a societal circumstance that were as dubious as the notion of committing to the headless bride who once haunted the woods of Sweet Home (16). Beloved had taken hold of him and replaced the lived experience of enslavement with the traumatic rememory of it, an exchange of equal measure.

For Sethe and Paul D, the spaces in and around 124 Bluestone Road signify the pain and the suffering that they associated with Sweet Home. Naively, Sethe believes that love is enough to protect her family from her former space of enslavement. When Paul D. essentially calls her an animal for murdering her child, she rejects his assessment. He calls her love "too thick"; she says "love is or it ain't. Thin love ain't no love at all" (193-4). What she had not anticipated with her determination to rid her children and herself of Sweet Home was that eliminating the close proximity of it did little to nothing to erase the memory of it from within. The memory of Sweet Home was a legacy that she would pass on to her children. Her boys, Buglar and Howard, ran from 124-the location, but what they were fleeing actually was the vicarious traumatization of Sweet Home actualized in the spaces of 124 . Similarly to her brothers, Denver experiences the trauma of Sweet Home as well by way of the permeating influence of Sethe's suffocatingly thick love, buttressed in thick remembrances engulfing 124; this trauma, the permanent scar of human suffering and indignity, is the most substantial, heritable gift from her mother and seemingly all Black American mothers.

When we first encounter Denver, she is filled with grief, loss, and want for company, and she is so desperate for kinship at 124 Bluestone Road that even the presence of her rambunctious, ghost sister is welcomed:

Denver was lonely. All that leaving: first her brothers, then her grandmother-serious losses since there were no children willing to circle 
her in a game or hang by their knees from her porch railing. None of that had mattered as long as her mother did not look away as she was doing now, making Denver long, downright long, for a sign of spite from the baby ghost (14-15).

Additionally, a much known threat has limited her options for company (17). Her small societal space is defined and restricted by whiteness. She believes that her mother's actions years ago were horrific and terrifying, but she understands and appreciates the greatness of this terroristic authority or "the white people who [come] in your yard"; she is aware of their dominion, so strong that it could force a mother, including her own, to commit murder (247). She observes:

I love my mother but I know she killed one of her own daughters, and tender as she is with me, I'm scared of her because of it...All the time, I'm afraid the thing that happened that made it all right for my mother to kill my sister could happen again. I don't know what it is, I don't know who it is, but maybe there is something else terrible enough to make her do it again. I need to know what that thing might be, but I don't want to. Whatever it is, it comes from outside this house, outside the yard, and it can come right on in the yard if it wants to. So I never leave this house and I watch over the yard, so it can't happen again and my mother won't have to kill me too (242).

Denver's home is not a safe space for her, for it causes her great shame, psychological trauma, and alienation; no one visits 124 (17). But, she is keenly aware that it is a safer space than being outside, where she would be fully-exposed in the white world. She knows that world is no less terrifying than her mother's past rememories of Sweet Home. It is her mother's persistent state of traumatic distress that has helped to develop an inherited variation of similar behaviors and/or a similar complex in her. Denver has no direct memories of enslavement, nor can she recall any first-hand details of her sister's death. Through the means of very affecting second-hand accounts, e.g. retold stories and/or interactions with returned configurations of Beloved, she becomes a 
witness and adopts the rememories of enslavement, that terrifying event that so drastically shaped so many of her family members' lives. This is a process of traumatic inheritance. She knows the villains in that institution of terrorism were white people, and yards and open spaces are feeding grounds for them and their sneak attacks. As unprotected spaces, they signal vulnerability; and thus, hidden ones are more of a comfort to her:

Back beyond 124 was a narrow field that stopped itself at a wood. On the yonder side of these woods, a stream. In these woods, between the field and the stream, hidden by post oaks, five boxwood bushes, planted in a ring, had started stretching toward each other four feet off the ground to form a round, empty room seven feet high, its walls fifty inches of murmuring leaves. Bent low, Denver could crawl into this room, and once there she could stand all the way up in emerald light...First a playroom (where the silence was softer), then a refuge (from her brothers' fright), soon the place became the point. In that bower, closed off from the hurt of the hurt world, Denver's imagination produced its own hunger and its own food, which she badly needed because loneliness wore her out. Wore her out. Veiled and protected by the live green walls, she felt ripe and clear, and salvation was as easy as a wish (35).

The reality of Denver's fear is clear and visceral. Her anxiety and avoidance tactics are indicative of someone who has frequent reminders of past traumatic events, so she pursues hidden spaces internally and externally as coping mechanisms. Early in the text, she cries out 'I can't live here. I don't know where to go or what to do, but I can't live here" (17). Denver understands the threat of white people, but she also affords them a duality in their representation. Much like Christian followers in the enslaved community who prayed to a white god, who resembled their slave masters, Denver also associates goodness and safety with whiteness, which is why she loves to hear her birth story. It offers another form of escapism and features details about the kind white girl, Amy Denver, who is also her namesake. Amy represents a rarity in the world for Sethe's 
Denver - a loving, white person. Without these small escapes, Denver is filled with an unending sense of claustrophobia, for she is a young woman living in a haunted house in a societal space tormented by white ghosts with nowhere to run. These white ghosts do not offer Amy's knowledge of "carmine velvet", restorative foot messages, and words of motherly wisdom (41-2). Her whiteness offered sanctuary, and in contrast these white ghosts were reminders of a traumatic heritage of enslavement.

Denver's psychological trauma is this unique product of the socio-political cultural legacy of slavery-inherited, genetic memories. For this reason, she can process and engage Beloved as well. As has been indicated, Denver has no first-hand experience of enslavement, but children of the enslaved and their descendants have continued to suffer the emotional trauma of it. This is a result of the absence of freedom to disentangle from these cultural spaces, which possess the emotional legacy of enslavement. Beloved is as much as adversary in Denver's life as she is in Sethe's. Denver and other descendants of slaves have been shaped by trauma in heritable respects. These psychological byproducts are anxiety, fear, and hopelessness; these are deep-rooted scars, but environmental enrichment can support their healing.

Thus when Arnold Weinstein argues, in Nobody's Home: Speech, Self, and Place in American Fiction from Hawthorne to DeLillo, that Sethe's murder of Beloved "is the primal scene, the ordinary event that has maimed or arrested every life connected with it", he has misidentified the original site of conflict. The scene involving crucial antecedents to Sethe's murder, which triggers the unique sense of black claustrophobia that swarms in on Sethe compelling her to protectively kill must start on the plantation (274). Sadly, if Beloved's death were truly "the primal scene" then this family and the 
Black American families whom they symbolically represent would live less complicated lives. For Black Americans, the primal scene will always pull from some physical space of enslavement or the reconstructed spaces of white power in the postbellum world. This is true for all of these characters as well. What they and Denver are constantly reacting to is the reality of their society—-the lived space of it, as described by Stamp Paid, the Underground Railroad conductor, in undeniably enlightening terms:

Eighteen seventy-four and whitefolks were still on the loose. Whole towns wiped clean of Negroes; eighty-seven lynchings in one year alone in Kentucky; four colored schools burned to the ground; grown men whipped like children; children whipped like adults; black women raped by the crew; property taken, necks broken. He smelled skin, skin and hot blood. The skin was one thing, but human blood cooked in a lynch fire was a whole other thing. The stench stank (Morrison 212).

\section{Beloved's Theme of Community Recognition and Healing}

What Denver learns is a lesson for us all. These traumatic spaces existed and still exist in our minds and in reality, present and otherwise, but as her Grandmother Baby Suggs reminds her from a place beyond, there is no defense to this truth. We have to embrace the past: "know it, and...go on" (288). Truth is what can promote resiliency and strengthen communities, especially broken ones. It does for Denver's community, a symbol of the burgeoning Black society striving to survive in the torment of the postbellum world. At the end of Beloved, the same Black community that had once turned its back on Sethe and her family, offering her only meanness and disapproval shortly after her arrival, comes to her rescue. As an act of atonement, they confront the history of enslavement that Beloved represents by conducting a public exorcism.

Beloved disappears. 
Here, Toni Morrison's message is very clear with regard to traumatic memory. Acts of acknowledgement and gestures of atonement are important steps, but she ends the novel with the word "Beloved" to suggest that there is more involved in this business of healing (324). Specific memories must be passed on, or they blister back up to the surface, especially with regard to the traumatic history of which Beloved was a ghostly reflection. Sethe's community thought it was unwise to remember, but remembering is necessary, especially with regard to national traumas (324). They must find traction in the collective memory of a nation, not merely a segment of it. Morrison provides a clear directive with this text - unbury the memories of the past in order to move on. History is doomed to repeat itself and haunt when it is forgotten. Morrison is reclaiming a space for the "sixty million and more...disremembered and unaccounted for" and marks it with a bench in memoriam (xvii, 324).

\section{Kindred and the Tenuous Space of Blackness in an Amerikkkan Homeland}

Morrison's reclamation of space for the sixty million and more is a postcolonial campaign about identity, belonging, and home. Studies of spatial conceptualizations with regard to the displaced, which applies to African Americans as members of the African diaspora, are conversations about living, specifically about operational agency, freedom as a realized concept, and activating citizenship within this reality. As we have witnessed, space, especially social space, is charged with meaning, and a home is generally a space that signifies comfort, safety, and protection. It stands in sharp contrast to public, less protected space. Thus, the absence of a home or a space that actuates these variations of sanctuary can be traumatizing; one can survive without a home, but can he or she thrive or achieve a life well-lived? The postcolonial theorist, Homi Bhabha says this type of 
alienation or "displacement [where] the border between home and the world becomes confused" can cause division and disorientation (141). A homeland is merely an extension of this home space in that it is a locale that represents a reprieve from cultural instability, for it is a space where cultural identity is affirmed and validated. According to Farid Parvaneh, "in nations and cultures that are experiencing oppression, home is linked to positive versions of the past. It means a life before oppression... 'home' is tied to freedom" (157).

In Kindred, Octavia Butler explores the spatial disruption of homelessness and/or [homeland]-lessness by engaging in a symbolic conversation about the trauma and fluidity of space interrupted by a persistent regeneration of ancestral/historical memory. Furthermore, Kindred is Octavia Butler's version of the neo-slave narrative where science-fantasy and realism marry while simultaneously reverencing a kinship with other narratives in its community that explore the theme of spatial disruption as a trauma in the postbellum Black cultural experience. Again, human characters within the text are responding to slavery in order to challenge its public narrative outside of the text as regards to its lingering ramifications on the black body, the notion of freedom, and the scope of its traumatic effects. Ultimately, Kindred is a story about a community (the kindred) with a lasting, intractable history of cultural displacement and alienation in search of home.

With Dana Franklin, the time-traveling protagonist in Kindred, Octavia Butler queries the notion of America as homeland by erasing boundaries between the contested spaces and limited freedoms associated with the slave-era and those of the present. Through Dana, the reader is forced to resurrect first-hand memories of enslavement and 
acknowledge bonds between the past and the present in a very visceral mode. As Timothy Spaulding asserts, "By displacing time across the physical and psychological planes of Dana's identity, Butler creates a narrative in which the conflation of time has damaging and lasting effects" (43). Sethe's intentional closeting of memories in Beloved is equivalent to Dana' unintentional ignorance about her history in Kindred, for both trigger violent physical encounters with the past. Dana is well-educated but ignorant of specific and incalculable cultural legacies and histories; as she divulges in the text: "People don't learn everything about the times that came before them" (Butler 63). With no explanations from Butler, these memories return, and readers have to grapple with questions about how and why the past could and would intrude so substantially in the life of this young, Black woman; as a result they must consider their own limited conceptualizations of enslavement and freedom. Where does the past really delineate from the present, if it does?

What is revealed in Dana's involuntary travels between 1976 and 1831 is how deeply an inadequate amount of knowledge and concern for one's cultural history can scar and destabilize. As a consequence, Dana has to confront the cultural roots of current phenomenon and legacies (spatial and otherwise) in her modern society. She gathers an affecting, first-hand account of the past and contemplates how different, if at all, people and the spaces that they occupy are from their predecessors-a shackle is a shackle; Dana concludes "We were both failures, she (Alice, her great-grandmother) and I... Nothing in my education or knowledge of the future had helped me to escape" (177). She endures slavery at times as both an observer and a defenseless member of the enslaved, and she gains the ability to realize its lasting physical manifestations in her life (98). The time 
travel device allows for this contrast; additionally, in the absence of safe space, Dana (by proxy, the reader as well) is unable to ignore the inclination to assess the influence of American slavery on the African American consciousness (Richard 119).

Through the blurred boundaries of space and time, she appreciates how forcefully slavery still acts as a determining factor in evaluating blackness in the twentieth century. She makes connections in her personal life, to her work space arrangements, to current systems of oppression, etc. A comparison of her husband, Kevin, and her own experiences in the antebellum period illuminates how limited Black (and female) bodies are by the white male gaze and how this coding also transfers to their respective social spaces as well. Ultimately, Dana is trapped, unable to occupy a position of permanence in either realms of her existence, and has to interpret her brand of freedom as a perpetual illusion: "I felt almost as strange as I had after my first trip back to Rufus—caught between his home and mine" (115). Here, the symbolic implications about freedom and social space are resolute, for we are returned to the question of how much of our experiences as Black people are reflective of Dana's journey, or to coin the scholar, Suchismita Dutta, a "trans-historical reimagining of racial trauma" (100)? Then, we must ask what does the absence of a definitive answer do to challenge the notion of America as homeland for Black people?

These are some of the compelling critiques of this text. Kindred demands our consideration with regard to the depth of social construction at work in the spaces of our realities, and it forces us to examine how much protection and freedom is available to specific cultural groups within these socially constructed spaces. To what extent are we walking through the racial constructs and historical traumas of the eighteenth century? 
Dana learns the dangers of denial and obliviousness as she unearths the history of her black body and all the revelations that are associated with this new experience of knowing. The truth does not set her free per se, but it offers her clarity with regard to the limitations on her person, her identity, her consciousness, and her freedom. In exploring Octavia Butler's Kindred, we embark on a journey to find new courage and direction; these are symbolic lessons about notions of social space, homeland, home, and belonging offered in a fictional text with implications for real people in real postbellum realities.

\section{Kindred and Safe Passage in the Sweet Land of Liberty}

Kindred begins with a deliberate focus on what will be revealed as one of the most pressing themes - the lingering manifestations of the past in the present. In the prologue, we find Dana Franklin recovering in a hospital bed. Through some tragic circumstances, she has lost her left arm and "about a year of [her] life and much of the comfort and security [she] had not valued" (Butler 9). With no specific details, the reader is as equally dazed and confused as she; regardless, she has to be subjected to interrogations by police authorities who undoubtedly assume the worst after analyzing her physical predicament. They represent an unwarranted invasion of her space. She has to reassure them with her truth "over and over until the vague police shapes let [her] alone" (10). This opening is a foreshadowing of a burgeoning awareness that Dana will develop as she better appreciates the cultural kinship between the past and the present and observes the transformed (not changed) racialized constructions in her current circumstance; in this case, we are drawn briefly to consider the efficacy and intentionality of policing practices. 
As readers, we have yet to discover at this juncture that Dana is Black, but her position as defenseless, helpless, and vulnerable is clear-she has been hospitalized. Here, there is a distinct contrast between her state of disarray and the overpowering, oppressive, and authoritative energy that these shadows in blue exude. Irrespective of her racial identity, she is racially profiled to some degree in this instance, for her clear position of inferiority is a secondary concern to her status as suspicious in their estimation. What about her allows them to rationalize invading the healing space of her hospital room? How does she lose her status so quickly, so effortlessly, as a victim, whose vulnerability deserves consideration? She is interrogated as if she is the perpetrator, why? The nature of this kind of approach to policing conjures images of fugitive slave law enforcement, which gave rise to the enduring practice of racial profiling. These interactions represent the kinds of modern racialized disruptions in spaces that we will ultimately, along with Dana, begin to evaluate differently. After digesting some of the societal dynamics of her antebellum circumstances, Dana reflectively observes: "you don't have to beat people to treat them brutally" (100). Her subsistence in both 1976 and the 1800's requires a "putting up with small humiliations so that [she could] survive" later (83). In hindsight, she senses that there had been the presence of a destabilizing force working to negate her humanity long before she "became aware of it" in 1976 (12).

Alas, the events of Dana's awakening do begin in 1976 on June $9^{\text {th }}$, her twentysixth birthday. She is enjoying the occasion by organizing her extensive book collection in her new home in Altadena, California. Without warning or rationale, she is thrust into 1809 in some unfamiliar wooded setting near a river where a child is drowning. She 
assumes a sense of authority, empowered by an academic privilege that she possesses and can still galvanize, and attempts to save the child. Dana succeeds in rescuing the boy, whom she will later discover to be her ancestor, Rufus Weylin. Her reward for saving his life is a direct, terrorizing confrontation with the barrel of his father, Tom Weylin's, rifle. Her fear in that moment triggers her return to the comforts of her living room in 1976. She explains "seeing the rifle again leveled at my head. I had never in my life panicked that way-never felt so close to death" (15). The protective energy of her home is altered instantly as it shifts into a portal projecting her into a past, traumatic dimension; she asserts: “I don't feel secure here... Maybe I'm just like a victim who survives, but who doesn't feel safe anymore" (17). She has been changed emotionally as she faces the threat of constant, enduring sense of fear.

Not only does she manifest a new sense of vulnerability, but she and Kevin also question if what has happened to her is real. He encourages her to do "the best thing [she] can do, whether it was real or not [and] let go of it" (17). In heeding this advice, Dana is attempting to separate the pain from the memory of the event; she hopes to suppress her trauma as a coping mechanism. As her husband, Kevin is offering a form of relief, but as a white man, he also embodies the mainstream perspective, which encourages the denial of traumatic slave memory. She notes: “As real as I know it was, it's beginning to recede from me somehow. It's becoming like something I saw on television or read about—like something I got second hand" (17). Eventually, the value of these slave memories will be made clear to her; she can let them go or deny them, but they still have presence in the spaces around her. Thus, forgetting or denying them is especially dangerous and counterproductive when she is confronted with the lingering trauma of these memories 
and cannot appreciate the cause or historical significance of the affliction.

Unsuccessfully, Dana tries, but her history is unwilling to set her free. She remains unsettled and insecure under the weight of these memories, for "they stayed with [her], shadowy and threatening" (18). Here, she has had a consciousness shift because it now more distinctly includes the socio-historical context of a Black experience.

Later that evening while still in the space of her home, Dana is teleported back to Rufus, who is a few years older; he's in his bedroom, and she has to save him from a fire ravaging his window draperies. She does, but is shocked when she is not immediately transported back home to the future. In this instance, the nature of her vulnerability takes on a specific shape - that of Black subservience and utilitarianism. Dana realizes that "Rufus's fear of death calls [her] to him, but [her] own fear of death sends her home" (50). Rufus, this young white boy, has control of her life. She reflects:

The fear that had followed me from home flared now. What would happen to me if I didn't go back automatically this time? What if I was stranded here-wherever here was? I had no money, no idea how to get home (20).

Furthermore, Dana presents no fear to Rufus, even as a small boy because he is aware of his white male agency and her Black female powerlessness; it is coded on her black body (21-25). The indoctrination or white supremacism required to perceive his position has already materialized in him, even in his limited number of years. To him, she was "some strange n-" whom he had never seen before (24). In the antebellum South, the responsibility assigned to a Black person of keeping any particular white person, including Rufus, "safe" and calm was a corporally designated expectation (20). However, Dana is her only protector - the lone person in this spatial dimension concerned with her safety even though she represents the most vulnerable branch of 
society; thus she is far from home in a literal sense, but more importantly, she is equally as far from home in the figurative sense of home as a space of security.

These references in Kindred of home and space are continuous, so that the reader does not neglect their significance; the historical memories critique the validity of these notions. Dana has found herself in her ancestral home on the Weylin plantation, but as a Black woman in slave-holding Maryland in 1815, she is an illegal alien marked with a death sentence: "Blacks here were assumed to be slaves unless they could prove they were free- unless they had free papers. Paperless blacks were fair game for any white" (34). Dana's quest to reclaim home - a space of security, which she naively assumes can exist for her in the antebellum South, provides one of the narrative's main conflicts; she remarks: "these people were my relatives, my ancestors. And this place could be my refuge" (37). Here is a conspicuous instance of the danger in having a limited base of historical knowledge, especially as a woman of color. Ancestry in this period is limited to racial heritage - demonstrated by the absence or presence of certain physical characteristics; these particular ancestors were as powerless and socially alienated as she, even more so. Regardless of her metaphysical locale, Dana's cultural naivety is a multidimensional constant that remains with her through time travel.

Fortunately, these ancestral memories are revived and returned to her-ripe and anew. Slowly, she comprehends that the ordeals of her ancestors, the prescience of them, have been with her, and now without proper address, they will aggravatingly persist comparable to the bruises that she continues to collect on these Rufus-instigated rescue missions. The descendants of the enslaved did what they could to survive and advance, so exercising the defense mechanism of suppressing traumatic memory is a logical course of 
action. Otherwise, one has to confront the psychologically-taxing contradictions of Black identity. However, collective memories work to shape cultural experience, and they offer unique lessons about the past and its implications for the present. As a symbolic representation of her community, this is Dana's revelation and ours. The readers must challenge the notion of freedom in this country and question, as she does, the extent to which it has been realized by Black people. Yes, these collective notions of identity can be regarded arguably as essentialist, counterproductive, and reductionist practices in absolutism, but when another Black body in our postmodern landscape is fatally harmed during an encounter with the police, adding to a long, unremitting history of similar victimizations, one has to recognize some merit in it. In addition, Kindred is participating in this analysis by assessing the extent to which antebellum power dynamics are still in effect thus filtering the concept of America as land of liberty with a rightful measure of dubiety.

\section{Antebellum Racialized Power Dynamics and Psychophysical Entrapment}

I felt sweat on my face mingling with silent tears of frustration and anger. My back had already begun to ache dully, and I felt dully ashamed. Slavery was a long slow process of dulling (Butler 182).

Kindred examines these modern-day societal amalgamations of enslavement by pinpointing the methods of antebellum social conditioning practices or the methods of "dulling", which fortified its institutional structure. What it reveals within this structure is the tactical nature of the slave-era violence, and how it was employed to affirm the antebellum power dynamics, or the stratagem to cement the unmitigated authority of whiteness and the restrictive inferiority of blackness. As Dana conveys in the above 
quote, the constant barrage of antagonistic forces of varying sorts debilitated the resolve and esteem of the enslaved. These practices, which underscore the simultaneous physical and psychological entrapments of enslavement, are its most enduring legacies. In a flashback, Dana recalls the various forms of racism directed at Kevin and her for merely choosing to be an interracial couple in 1976. His sister refuses to accept Dana's blackness, and Dana's adopted parents struggle with Kevin's whiteness. These respective family members' reactions substantiate the inheritable quality of American racism, akin to Dana's other relative Rufus, whom she asserts "learned [his racism] from his mother and his father" (61).

As I hurried up the steps into the house, I thought of Rufus and his father, of Rufus becoming his father. It would happen some day in at least one way. Someday Rufus would own the plantation. Someday he would be the slaveholder, responsible in his own right for what happened to the people who lived in those half-hidden cabins. The boy was literally growing up as I watched - growing up because I watched and because I helped to keep him safe. I was the worst possible guardian for him-a black to watch over him in a society that considered blacks subhuman, a woman to watch over him in a society that considered women perennial children. I would have all I could do to look after myself. But I would help him as best I could. And I would try to keep friendship with him, maybe plant a few ideas in his mind that would help both me and the people who would be his slaves in the years to come (Butler 68).

With Kindred, racist modern corollaries are contextualized by delving into their naissances, and it illuminates why Dana's twentieth-century America needed not to resurrect the scale of brutality in the institution of slavery in order to attain and activate its psychological outcomes. Dana emerges from her wormhole in the midst of the American regime of white supremacism, which controlled the social narrative and regulated its repressive social structure. After surviving two solo trips to the 1800s without Kevin, he protectively clings to Dana as she teleports back for a third rescue 
mission. In her voice as first-person narrator, she acknowledges "in this place, he was probably better protection for me than free papers would have been" (59). Kevin's male whiteness affords him similar levels of power, privilege, and access to Tom and Rufus Weylin; as his property, Dana occupies a small space in the shadow of his protection. However, she is still obligated to perform her blackness or subservience: "I looked away, remembering that I was supposed to be a slave. Slaves lowered their eyes respectfully. To stare back was insolent. Or at least, that was what my book said" (66).

The idea of a Black woman, even a seemingly magical one, and a white man having an equitable and/or cooperative relationship violated the repressive social order. Blackness had to serve as the antithesis of whiteness; otherwise, slave culture would not have been as prosperous. The enslaved by design served as qualifiers of the privilege and prestige of whiteness; Blacks not only had to reflect this in terms of circumstance, but they had to internalize these notions as well so that they manifested themselves as a presentation of appropriate submission. Essentially, this system of racial accommodation was maintained by obligating Blacks to walk through both a literal and psychological back door. The hallmarks of this system of oppression were violence and inhumane treatment. For example, the enslaved were kept undereducated: “[Marse Tom] don't want no $\mathrm{n}$ - 'round her talking better than him, putting freedom ideas in our heads. Like we so dumb we need some stranger to make us think about freedom" (74). Likewise, their humanity was frequently invalidated, for they possessed no rights. Slave marriages were not legally binding, nor were their family ties respected: "I looked away from her...she seemed almost ready to cry—-to anger. Quiet almost frightening anger. Her husband dead, three children sold, the fourth defective" (76). Finally, in the contest of slave-making, the 
most reliable weapons in arsenals of slave holders were the random acts of merciless violence to which the enslaved were routinely subjected, including rapes and other sexual violations. The resulting trauma convinced them in the name of self-preservation that slavery was the safest course of action (145).

I'm lying. I can't run again. I can't. You be hungry and cold and sick out there, and so tired you can't walk. Then they find you and set dogs on you...My Lord, the dogs...I'm going to him. He knew I would sooner or later. But he don't know how I wish I had the nerve to just kill him! (168).

Fear of the brutality solidified the submission. This rationale illustrates why the practice of public slave whippings and other displays of punishment became so commonplace. As Dana observes: "The whipping served its purpose as far as I was concerned. It scared me, made me wonder how long it would be before I made the mistake that would give someone reason to whip me" (92). During the antebellum period, the social conditioning practices that engineered and preserved white supremacy and Black subjugation were so absolute and intrinsic to American culture that it required a miraculous intervention and/or transformative experience to overcome them, for all were susceptible. This comprehensive cultural indoctrination was on exhibit when Dana observed enslaved children, who were still too young to work, pretending to be slaves in an auction and also parodying field work. At the earliest stages of development, the enslaved were conditioned to accept the limitations of their blackness. After reflecting on the encumbrance of her own ordeal, Dana discerns, "even the games they play are preparing them for their future" (99). Consequently, there is no debate; the trauma of enslavement was and remains deep, inheritable, and persistent. 


\section{A Homeland of Slave Relics and Inherited Traumas}

In a pivotal scene that occurs before one of Dana's final returns to the Weylin farm, she and Kevin argue about the dangers that a now adult Rufus Weylin represents. Dana believes that she can activate some level of control over him as his protector. Kevin asks Dana: "Do you remember what he said just before he tried to shoot you... [he said] you're not going to leave me" (244-5). She responds:

I'm not property, Kevin. I'm not a horse or a sack of wheat. If I have to seem to be property, I have to accept limits on my freedom for Rufus's sake, then he also has to accept limits - on his behavior toward me. He has to leave me enough control of my own life to make living look better to me than killing and dying (246).

What Dana is describing is not control or freedom; it is the illusion of it. Her ancestors had adopted comparable survivalist perspectives, but the slave owners were manipulating the circumstances so that members of their enslaved communities could be persuaded to rationalize their persistence in bondage similarly. Depending on the alternative, enslavement could be a little better than pursuing Dana's morbid choice of "killing and dying"; anyone could be conditioned to disregard the hostility of a space. Dana and her ancestors simply applied different qualifications for "living." The power still remained with the Rufuses or the white men of the world; this is evident to Kevin, and why he feels compelled to issue a warning to Dana. His whiteness allows him the privilege of this perspective. Slavery was a closed stratification system that offered no allowances and/or deviations in its power structure. The slave environment or the macrocosm of the slave institution was not any less restrictive for Dana or any other Black person; this is especially evident when the power structure is challenged, for example slave revolts and runaways were deviations that had to be quickly resolved in 
order to preserve the continuity of the system. There were ebbs and flows in the levels of enforcement within the system, but nonetheless the system was stoic by design.

On the contrary, Dana's perspective of her enslavement had simply adjusted, and that is a component of the danger to which Kevin was alluding. She is making the mistake of allowing the space of her ancestors, where some of them were held in bondage, to function as a home or homeland, and from Kevin's viewpoint this is a costly miscalculation. Even her white ancestor was beholden to certain standards of behaviors deemed appropriate for whites. The framework of this institution could bend, but ultimately it would adjust to reestablish the status quo of the social structure.

Dana makes a similar mistake earlier in the text regarding the cookhouse. When she first encounters it, she says:

The cookhouse looked like the friendliest place I'd seen since I arrived. Luke and Nigel were inside eating from wooden bowls with what looked like wooden spoons. And there were two younger children, a girl and boy, sitting on the floor eating with their fingers. I was glad to see them there because I'd read about kids their age being rounded up and fed from troughs like pigs. Not everywhere, apparently. At least, not here (72).

She allows herself to revere the cookhouse as a refuge even though it still functioned within the space of the plantation. There was a semblance of community that existed there; it was a place where she could have conversations with others and receive advice about coping with trauma (96). It appeared briefly to be a loophole, one that was reserved for the enslaved. However, when she tests the social structure by committing the crime of reading from books that she had "stolen", she recognizes that the cookhouse was no exception to the rule (106):

I turned to go back to the table where Nigel was waiting. In the moment, Tom Weylin opened the door and stepped in. It wasn't supposed to happen. For as long as I had been on the plantation, it had not happened- 
no white had come into the cookhouse. Not even Kevin. Nigel had just agreed with me that it didn't happen. But there stood Tom Weylin staring at me. He lowered his gaze a little and frowned. I realized that I was still holding the old speller...I withdrew my finger and let the book close. I was in for a beating now (106).

Dana is corrected by the system, and she receives a status reminder in the form of a beating so brutal that it transports her through time and space back to her home in California. She awakens bloodied and bruised on the floor of her bathroom. This incident exemplifies how social conditioning works destructively (as it was intended) to convince the traumatized that they have achieved some measure of social mobility, which in this case is represented by her momentary sense of security in the cookhouse, when they have not; the perpetuation of this confusion or delusional condition is a traumatic, involuntary inheritance of slavery. Fortunately, Dana is awakened from this state of delusion and develops a sense of African consciousness or the realization of her place in the world as she gains a more comprehensive historical perspective of her society. Her trials on the Weylin plantation confirm for her that as long as the institutional structure of enslavement endures in America there could be no spaces of convalescence for Black people and freedom, for them, would remain elusive. America was not a home, homeland, retreat, or a refuge; for her and most African Americans, it is simply the place of their ancestors' enslavement. Dana will have to reevaluate her modern society through this new lens. It may even alter her marriage; she and Kevin will have to grapple with and navigate distinct cultural legacies, which can have varying effects on her awakening depending on how they appreciate and cope with Dana's traumatic inheritance.

In Dana's final encounter with Rufus, she has to kill him in order to save herself, but she loses part of her arm in the process: 
I was back at home-in my own house, in my own time. But I was still caught somehow, joined to the wall as though my arm were growing out of it - or growing into it. From the elbow to the ends of the fingers, my left arm had become a part of the wall. I looked at the spot where flesh joined with plaster, stared at it uncomprehending. It was the exact spot Rufus's fingers had grasped. I pulled my arm toward me, pulled hard. And suddenly, there was an avalanche of pain, red impossible agony! And I screamed and screamed (216).

Rufus's interference in her life ends with his death, so Dana believes. Her severed arm symbolically indicates that there are lingering implications for his involvement in her present circumstances. Rufus was a product of an era that was defined by an incredibly resilient slave industry. Dana's injured arm is an undeniable symbol of its brand of trauma on her cultural heritage; Rufus' body is destroyed, but he lives on through his participation in Dana's psychological torment. She is educated via her own first-hand encounters with enslavement and witnesses "how easily people could be trained to accept slavery" (101). Her eyes had been opened; Dana's burden, which is also the reader's obligation as well, is to remain perceptive so that she may process the variations of remnants of this institution in her modern society. She would be adopting willful ignorance to assume that a system that so frequently recalibrated in response to other instances of upheaval and resistance would not make similar adjustments to the disruption, not interruption, of the Civil War.

Throughout the text, subtle references are made to modern-day ideologies, conflicts, and institutions that arguably have roots in the antebellum period. Dana discusses the presence of bigotry and colorism in Kevin's family and her own (111). Additionally, she acknowledges concerns about racial profiling, abusive policing practices, and segregated communities (111). Finally, when reminiscing about her history with Kevin, she recalls her time working at a "casual labor agency", which she 
refers to as a "slave market"; her discussion of this agency delves into issues related to working-class poverty and other forms of social inequality (52-55). The relics of the slave-era are conspicuous; they are not hiding in plain sight. Undeniably, this system of oppression has readjusted. As long as any form of it, modern variations and manifestations etc., exists the space of blackness will continue to be perplexing along with the notion of America as a homeland for Black people, for these modern spaces hold the potential to trigger ghosts of the past or inherited memories of a slave-era trauma.

\section{A Lesson before Dying and the Black Prisoners of their Environments}

These perplexing modern variations and manifestations are exactly what is being emphasized in Ernest Gaines' A Lesson before Dying, which is a fictional portrayal of young Black men who suffer the simultaneous traumas of possessing stigmatizing black bodies and of dwelling in the haunting space of enslavement $-a$ former plantation community in 1940's Louisiana. A Lesson before Dying is a story about these men's efforts to overcome the limitations of their circumstances; in the process, they demonstrate the danger and devastation of what Dr. Joy DeGruy defines as the post traumatic slave syndrome and how it emanates from the American construction of traumatic space. I argue that the circumstances and the syndrome are related by design, and the protagonists in A Lesson before Dying, Jefferson and Grant Wiggins, men who are headed in entirely different directions in terms of social and life trajectories, demonstrate this strategic interconnectedness through their shared traumatic sufferings that they have both obtained as cultural inheritance.

Grant is a Black school teacher in the segregated South. He finds his work unfulfilling and limiting. He is frequently defeated by the lack of progress he can actually 
effect in the lives of his poor Black students. Nonetheless, he is educated and employed, but neither of these social achievements can reverse the limitations of his blackness. Conversely, Jefferson is a poorly educated field hand who is sentenced to death for a murder that he witnesses but does not commit. He and Grant occupy the same social designation as Black men and the same locale or physical space of a former plantation; in this time, the land and the black bodies, both signify a historical memory of inferiority. The body as a trigger is an easier concept to understand, especially with it being a visible qualifier of blackness, but the space is an equally significant component in the production of the traumatic experience.

A Lesson before Dying establishes this spatial characterization through the use of juxtaposition and contrast that results from the physical relocations of both Jefferson and Grant. Grant temporarily relocates to California where he is properly educated, and Jefferson is imprisoned, a relocation where ironically he perceives his first sense of humanity. In these situational parallels, their shared former space of occupancy is properly vilified. We, the readers, can begin to imagine how this environment is a central contributor to the racial trauma imposed on these men once they are removed from it. These lived spaces expose the legacy of a nation built on the backs of slaves, for the bigotry that fortified the institutional power of enslavement remains as an unmitigated contagion in the realities of the descendants of the enslaved. This infection or condition of post-traumatic stress is undeniably linked to triggers, or objects and/or events which recur in the surroundings as signifiers of enslavement. For the Black person in America, there is no more traumatizing historical signifier that manifests more substantially in the spaces of this nation than those aligned with the trauma of slavery. Manifestations of 
trauma that trigger memories of enslavement work to keep the terror of this institution or the ghosts of this past horror agonizingly operative. This distinctively Black cultural trauma and its inherited forms, as coined by Dr. Joy DeGruy, a social researcher, create a condition called post-traumatic slave syndrome (PTSS):

[It is] a condition that exists when a population has experienced multigenerational trauma resulting from centuries of slavery and continues to experience oppression and institutionalized racism today. Added to this condition is a belief (real or imagined) that the benefits of the society in which they live are not accessible to them (DeGruy 105).

Furthermore, Dr. DeGruy explains that post-traumatic slave syndrome is an unwarranted inheritance:

The individuals and families that survived the slave experience reared their children while simultaneously struggling with their own psychological injuries, and they often exhibited the typical symptoms associated with Post Traumatic Stress Disorder. The children lived and learned the behaviors and attitudes of their often injured and struggling parents. Today, we are those children. The legacy of trauma is also passed down through extended family, and community. During slavery, the black community was a suppressed and marginalized group. Today the African American community is made up of individuals and families who collectively share differential anxiety and adaptive survival behaviors passed down from prior generations of African Americans, many of whom likely suffered from PTSD. The community serves to reinforce both the positive and negative behaviors through the process of socialization (1034).

Constructively, A Lesson before Dying offers some healing guidance or positive behavioral reinforcement for the Black psyche by highlighting faith, constructive racial socialization modes, and consciousness-building educational approaches as a means of facilitating psychological restoration. Of equal significance, it demonstrates traumainducing features of the community establishment that serve to enforce oppressive and regressive forms of socialization onto the Black psyche. Before we examine these unique 
socio-spatial constructions, it is necessary to recognize the presentation of PTSS in the main characters of this text and identify the resulting cultural pattern of behaviors.

\section{Indicators of Post-Traumatic Slave Syndrome in Jefferson and Grant}

According to Dr. DeGruy's research, “There's not a single pattern of behavior

[that would characterize someone who is suffering from post-traumatic slave syndrome].

There are many. [She] identified three categories [of these behaviors]: vacant esteem, ever-present anger, and racist socialization" (105). These categories of behavior are the result of the persistent circumstances of "multigenerational trauma and continued oppression, plus a real or imagined lack of access" (105). She argues that PTSS is sustained in the Black psyche through the power of belief:

Our beliefs color everything with which we come in contact. They determine what we perceive and how we evaluate. They determine what we consider unlikely and what we consider possible. They shape our memories as our expectations. They strongly influence how we think and feel (105)

A fragmented sense of identity is the consequence of a problematic belief system and the persistent negative impact of enslavement on one's personal circumstances. The categories of behaviors that can present individually or collectively as a vacant sense of self-esteem are a manifestation of one who possesses this kind of fragmented identity. Dr. DeGruy describes a healthy self-esteem as "the result of an accurate and honest assessment of one's worth, worth being the degree to which one contributes" (107). On the contrary, when a person's worth is undervalued, or he or she undervalues his or her own self-worth, the result is an unhealthy or vacant sense of self-esteem. Dr. DeGruy 
suggests that this problematic psychological state is "exacerbated by pronouncements of inferiority from the personal sphere and larger society" (108).

The important factor in this assessment is the belief system that generates the worth designation. If someone has an unhealthy process of measuring self-worth then the evaluation will not result in an accurate measure of one's worth regardless of the outcome (109). Within the African American community, Dr. DeGruy suggests that vacant esteem is a uniquely American product of traditional design:

[In the African American community] society contributes to the formation of PTSS and vacant esteem in a number of ways; through its laws, institutions, and policies, as well as through the media. African Americans have and continue to be disproportionately represented in our penal institutions. African Americans often live in neighborhoods where schools are functionally segregated and lack adequate revenue to sustain them. In African American communities, banks charge higher interest rates on home and auto loans, as well as make it more difficult for African Americans to get small business loans. The media contributes to vacant esteem's formation by frequently displaying African Americans as criminals, disadvantaged, academically deficient, and sexually irresponsible. All these and more serve to influence how African Americans perceive themselves and so impact their assessment of their own self-worth (109-110).

With Grant and Jefferson, the main characters in A Lesson before Dying, we can observe different versions of these fragmented senses of identity. In the segregated South, a Black person was expected to deliver a public performance of vacant esteem. Jim Crow laws demanded these acts of subservience from them. These conditioned responses and behaviors worked to reestablish the indoctrination of second-class citizenship in the Black community as public defiance of Reconstruction-era efforts. However, Grant's education had afforded him a measure of escape; he had lived in California, a more liberated society during this time, while attending university. Still, the parish plantation 
was his home, and it is where he returned when he finished school. He had changed, but the circumstances of his environment had not. As a school teacher, he was forced to rediscover feelings of vacant self-esteem resulting from the ineffectiveness of his work: "Yes, I'm a teacher. And I teach what the white folks around here tell me to teachreading, writing, and "rithmetic" (Gaines 13). The trauma that he suffers from his inability to help many of his students and former classmates like Jefferson overcome the mental bondage of their blackness is psychologically disturbing. For most of his tenure in his own community as the plantation church teacher, he has felt useless and believes his only resolve is to flee the place he considers home. Again, he has changed, but the home that he loves is compelling him to embrace its mental shackles, an inheritance of enslavement. As a result, Grant nearly loses his complete ambition and purpose:

I was not happy. I had heard the same carols all my life, seen the same little play, with the same mistakes in grammar. The minister had offered the same prayer as always, Christmas or Sunday. The same people wore the same old clothes and sat in the same places. Next year it would be the same, and the year after that, the same again. Vivian said things were changing. But where were they changing? I looked back at the people around the tables, talking, eating, drinking, their coffee and lemonade. But I was not with them. I stood alone (151).

Correspondingly, Jefferson's vacant esteem was the unsurprising result of his endless state of depravity. He says to Grant while awaiting his execution date: "I never got nothing I wanted in my whole life" (170). From the very beginning, his life was measured by its utilitarian value alone; his station in life appeared to offer no real worth. In his own assessment of it, he reveals "it look like the lord just work for wite folks cause ever sens i wasn nothing but a boy i been on my on haulin water to the fiel" (227). Furthermore, after he witnesses the murder of a store owner and is later convicted of this crime, he can easily absorb and personify the words of his defense attorney who argues 
that he neither has the intellect nor the humanity capable of committing such a crime. He says of Jefferson: "What justice would there be to take this life? Justice, gentlemen? Why, I would just as soon put a hog in the electric chair as this" (8).

When Grant later visits Jefferson in his jail cell, Jefferson has become the living embodiment of an actual hog. He refuses to eat foods "that [are] for youmans" or concern himself with behaviors that hogs do not possess (82-84, 138-140). He has completely adopted a hog's identity, a change that was almost instinctively triggered by a white stranger's evaluation of him. His vacant esteem and the conviction of his blackness make this transition possible. As a Black man, he was born into his guilt. It is why Grant could remark of Jefferson's trial: “I was not there, yet I was there. No, I did not go to the trial, I did not hear the verdict, because I knew all the time what it would be" (3).

These injustices pertaining to race, as they existed then and exist today against members of the Black community, help to substantiate ever-present anger, or the second category of behaviors that usually typify PTSS. Dr. DeGruy describes anger, or "the normal emotional response to a blocked goal", that African Americans experience as a "reaction to [their] hopes and dreams being continuously undermined by the institutions which govern [them], and the racism that permeates American society" (113-115).

Jefferson and Grant both exhibit visible signs of anger and rage as they endeavor to survive in the face of indignities and injustices that plague their oppressive society. Jefferson's rage is understandable. As Grant observes "I could see in those big reddened eyes that he was not going to scream. He was full of anger-who could blame him?" (130). He was a man wrongly convicted of a crime. He was a victim of inconvenience, but there was no chance of that sufficing as a defense. A Black man is rarely given the 
benefit of the doubt now in the twenty-first century, but they definitely were not afforded that luxury during the Jim Crow era. Jefferson's life is framed by injustice: criminalized by the blackness of his body at birth and criminalized by a justice system managed by his white oppressors who unfairly sentence him to death. These are the exact circumstances that generate an ever-present anger or rage.

Relatedly, although Grant had more opportunities as an educated man with a solid network of family support, he still suffers the pains and disappointments of members of his community along with his own. However, initially when his aunt demands that he provide counsel to Jefferson while he awaits his execution, the inequity that he would be forced to confront in the circumstance enrages him. He says "I wanted to scream at my aunt; I was screaming inside. I had told her many, many times how much I hated this place and all I wanted to do was get away" (14-15). Instead, of offering him an escape exit, she is asking him to become more ensnared in the system. She is obligating him to withstand the emotional blows that would accompany any attempts to help a Black man synthesize the degradation of his place. This place, the plantation home of his ancestors, where they had worked until they died, was a place where faith never seemed to reach. His old school teacher, Mr. Antoine, once said of their quarter of the parish: "there's no life here. There's nothing but ignorance here...Just go on and be the nigger you were born to be, but forget about life" (65).

Living with the constant frustrations of this place incited anger and rage in him, which are the characteristic responses of survivors' of trauma. Of the people he knew in his community from his childhood and beyond, he reveals "there was always news coming back to the quarter about someone who had been killed or sent to prison for 
killing someone else" (62). Unfortunately, Jefferson was not the first and would not be the last Black person he would witness suffer this fate. There was always a reason to feel the anger boiling to the surface, but he remains in Bayonne because he is reminded that he loves the people more than he hates the place (94). He determines to be a part of the solution by choosing to teach, which allows him to confront the place and its racist socialization of his people, which is the third category of behaviors that usually typify PTSS, according to Dr. DeGruy.

Racist socialization is essentially the process by which the Black community is conditioned to adopt the slave master's value system. Dr. DeGruy explains:

African Americans have a unique socialization experience due to centuries of systematic and traumatic programming of inferiority, covering all aspects of one's being. In other words, from the beginning Africans were taught they were inferior physically, emotionally, intellectually, and spiritually, thus rendering them completely ineffectual in their own eyes and in the eyes of the society around them. At the end of slavery, little changed to dispel these notions. In fact, since the abolition of slavery, such notions have continued to infiltrate all aspects of American life (118).

In terms of this research, we are concerned with the ways by which these racist socialization tactics infiltrated social structure. Using the lens that Gaines creates through which to observe this fictional representation of his childhood home, we can consider the structural mechanisms enacted to reestablish plantation discipline throughout the South. In order to contradict the surface-level ambitions to redress the inequities of slavery during and after the Civil War and Reconstruction periods, the American power structure reestablished social spaces and environments that adequately conveyed the popular, contemptuous notions of blackness. 


\section{Black Person versus Environment in A Lesson before Dying}

Originally, Ernest Gaines says he intended to make A Lesson before Dying a novel about a death row prisoner set in contemporary space of the 1980s (Gaines 770). Then, a colleague shared a case of a seventeen-year-old boy sentenced to the electric chair for murdering a white man in Louisiana in the 1940s. This case had taken place in close proximity to University of Louisiana at Lafayette, where Gaines was teaching, and his hometown of Pointe Coupe Parish. Although he recognized that many of the particulars surrounding the case of the fictional character he was envisioning and the young boy involved in the real-life case he was reviewing were different in many regards, they were sentimentally and traumatically linked. Both were "black, nearly illiterate, and involved in the murders of white men (in the South during the pre-Civil Rights era)" (771). Thus, there is symmetry in the nature of the justice that both of these men would inevitably receive. For the subject of his case study, the character whom he would feature in his novel, and the contemporary prisoners he initially desired to investigate, the roots of their criminal conflicts were formed long before their births. The familiarity impels Gaines to place his story in the 1940s; he explains:

I asked myself. Why not bring my story back to the forties? If I set the story in that decade, there was so much that I already had, I could use the plantation as home for my characters, I knew life on the plantation because I had written about it in several other books-The Autobiography of Miss Jane Pittman, Of Love and Dust, and the stories in Bloodline. I could use the church school for background, the church where generations of my folks had worshiped and where I had attended school my first six years, I could use the crop as background - when it was planted, when it was harvested. I knew the food the people ate, knew the kind of clothes they wore, knew the kind of songs they sang in the fields and in the church. The best thing to do was to bring my story back to this familiar period where I was most comfortable (771). 
A Lesson before Dying is a fictional tale, but Bayonne, the community in which it takes place, embodies many of the characteristics of Gaines' childhood parish in Louisiana; these added details imbue the text with a measure of historical value. There is a testimonial import and validating utility in the autobiographical context that Gaines creates with Bayonne. On the surface, the story details the journey of two Black men trying to realize their manhood and dignity, but the place, the physical locale, is an underrated adversary. By featuring the community as Gaines does with such deftness of hand and closeness in proximity, the reader can begin to deconstruct its villainy and as a result better classify and appreciate the facility of racism.

Often, racism is excluded in some scenarios as the central perpetrator; in its micro-aggressive form, it can function so stealthily in its attack that both perpetrator and victim go unrecognized and other divisive forces bear the blame. This is the unsung space it is given, hidden behind a cloak of abstractness. However, A Lesson before Dying explores the community that constructs the framework through which the racism becomes institutionalized and offers us a lens through which to demystify the often nonrepresentational expanse of this ideology. This foe and the conflict that it creates in the lives of the members of the Black people depicted in this community are extremely significant to my research in traumatic spatial analysis because this is the quintessential tale of person versus environment. The environment is a participant in the progression of trauma as a cultural inheritance.

With the character Grant Wiggins, Gaines constructs a teacher who provides a trustworthy testimonial about his community, and he seems more knowledgeable of the micro aggressions that habitually go unnoticed in the segregated spaces of his society. 
With segregation, the analysis of its underlying principles is usually oversimplified as the codification of the "separate but equal" decision of the U.S. Supreme Court in Plessy V. Ferguson (1896), or it is evaluated as a practice of separating Blacks and whites. The overt images of "white only" signs prohibiting persons of color from entering various public facilities throughout the South cloud out many other public memories of the Jim Crow era. What is often lost, as a result, are the micro aggressions, some as seemingly insignificant as the absence of paved roads or street lights in the Black area of town when the public funds are readily available, that signal/trigger various other traumas in addition to social exclusion from access to white spaces. These indignities reinforced the slaveera indoctrination of Black insignificance. Grant draws our attention away from the social spaces from which Blacks had been barred to better gauge the nature and purpose of the spaces that were being constructed in the shadows for Black people. Most importantly, through Grant's first person account, we observe the subtle, racialized codification systems designed for these spaces. Black spaces were demarcated by the restrictive boundaries of segregation and usually existed in the societal backwaters. These lands were not selected by Black people; they were merely designed to appear to be their choices. Black spaces were constructed by the white power establishment to substantiate a neglectful characterization of Black people.

With the activation of Jim Crow legislation, the power structure was working to convey ambitions greater than segregation, but as Grant consciously observes of his white contemporaries: "they play by the rules their forefathers created hundreds of years ago. Their forefathers said that we're only three-fifths human — and they believe it to this day" (192). Whiteness was qualified by separation and the notion of inferiority that they 
associated with blackness. Blacks had to not only remain hyper vigilant about being accused of trespassing outside of their communities, but within their communities they had to be subjected to racist socialization practices that invalidated their humanity. In Grant's description of his town of Bayonne, everything reserved for Blacks in the Black section of town on the other side of the railroad tracks, a nationally-observed demarcation of a privileged section from one not so, reflected second-class citizenship (25). Grant explains the myth that underscored the establishment's tolerance of black ghettos, as redlining and racial housing covenants in chapter three illustrated, and its spite for Rosewoods and Black Wall Streets:

A myth is an old lie that people believe in. White people believe that they're better than anyone else on earth - and that's a myth. The last thing they ever want is to see a black man stand, and think, and show that common humanity that is in us all. It would destroy their myth. They would no longer have justification for having made us slaves and keeping us in the condition we are in. As long as none of us stand, they're safe (192).

This condition that Grant references is mental enslavement represented in the widespread presence of post-traumatic slave syndrome among members of his community, and the coding of black spaces, which were constructed by the establishment to signal inferiority and insignificance, work as allies with this condition; again, these signals are the traumatizing micro aggressions that often go unrecognized. Although Grant tries his best to overcome its many limitations, his plantation school is an example of this strategically-constructed, oppressive black space. A school should symbolize knowledge, intellectualism, achievement, and personal development. On the contrary, the school where Grant teaches characterizes education as superfluous for its pupils. His students use church benches for desks, which meant they had to get "down on their knees 
and use the benches as desks to write upon, or use the backs of their books upon their laps to write out their assignments" (34). Grant is forced to teach using hand-me-down books from the white schools, and he is expected to thrive as he labors to provide his students a satisfactory education with an insufficient amount of supplies (57).

During the school's annual inspection, Dr. Joseph, the white superintendent, is most concerned with the students' exercise regimen and hygiene. He checks their hands and teeth and refers to them as "an excellent crop of students" (56). Their availability as field hands is what he prioritizes, but he represents the desires of the school board leadership and district, which are further indicated by this Black school calendar's allegiance to the crop production schedule or "start[-ing] a month later and [finishing] two months earlier than the whites" (255).

As he explains to Jefferson and the readers, this signification of neglect is of institutional design:

I have always done what they wanted me to do, teach reading, writing, and arithmetic. Nothing else — nothing about dignity, nothing about identity, nothing about loving or caring. They never thought we were capable of learning these things. 'Teach those niggers how to print their names and how to figure on their fingers.' And I went along, but hating myself all the time for doing so (192).

As Grant alludes, Blacks of this particular era were not afforded the right or assumption of dignity; this is why they were restricted so extensively from white public and private spaces or given minimal access, which was often girdled in humiliation. For example, when Grant is coerced by his aunt, Tante Lou, into returning to the Pinchot plantation home, where his ancestors were enslaved and she served as the help, to request special visitation privileges to see Jefferson, the current landowner, Henri Pinchot, anticipates an array of subservient acts as if a history of them had not already taken place 
(107). He presumes this trespasser will oblige the long-standing traditional protocols of vacant esteem, such as entering his antebellum home through the backdoor, waiting in the kitchen area or other spaces designated for the Black servants, lowering his eyes to appear less educated, and translating his signals that will cue Grant when to speak (16-23, 49).

These are the behavioral expectations that Blacks observed within many white people's homes in the Jim Crow South, but additionally Grant allows us to bear witness to the covert expanse of these calculated indignities. They extended outside of the home as well and in this case were activated by merely entering into close proximity of a white person's home:

I stopped at the side gate to Henri Pichot's large white and gray antebellum house. When my aunt started to get out of the car to open the gate for me, I told her to keep her seat because I had nothing to do all that day but serve. I felt her eyes on the back of my neck again, then on the side of my face as I pushed open the gate, and on me directly as I came back to the car. After driving into the yard, I had to get out again to shut the gate. Since the side entrance led from the quarter to the house, Henri never used this gate. Only tractors, wagons, and trucks used this entrance, and over the many years, they had cut just as many ruts across the yard. I must have hit every one of them, driving up to the house. My aunt never said a thing, but I could feel her eyes on the back of my neck. I was not aiming for the ruts, but I wasn't avoiding them either. I could hear them bouncing on the backseat, but they never said a word (17).

On the surface this appears to be a quarrel between Grant and the aunt who raised him. He is frustrated that he is being asked to go pander to a white man in return for favors. This is not necessarily untrue, but what is also contributing to the family conflict are the racist micro aggressions to which they are all being subjected. Before entering the home, they, as Black people, must drive through a gate that is intended to complicate entry for those coming from the direction of the Black-inhabited section of the quarter 
where the sharecroppers live. If you are entering that side of the property, the expectation is that you would be traveling on foot or in a service capacity in a service vehicle, so if you should happen to come by car as Grant or the minister would, you risk damaging the suspension-related faculties of your car or worse. Furthermore, the expectation is that you, as a person of color, would not be able to afford the luxury of an automobile. Finally, after entering an unnecessarily tedious gate into the property, which was constructed to exclude your ilk, you are then expected to perform subservience as a reward for your entry.

This is entrapment; in this society there has been a cognitive dissonance in detecting and decrying this fact. For Black people, choices are recurrently limited to a space of inferiority on one hand or on the other a mimicry of liberty, which essentially represents minimal access with a restitution of humiliation. Both result in the same brand of psychological damage or PTSS. Tragically, the onus falls on people of color to unmask the context of their reality, which involves such an extensive network of manifestations of racism. For example, this situation occurs on Pinchot property, so it appears that Grant and his associates are choosing to be victimized. Thus, no victimhood can be claimed. However, Black people are contending with spatialized Catch-22 situations; when your societies have been structured so that you must "choose" to interact with those who willingly and/or instinctively systematize your oppression, that's a traumatic form of entrapment or plainly, the Black experience in America. Racist socialization is most effective in its ambiguity, for it covertly activates in the form of racial microagressions in social and public settings. This formless, shapeless Belovedtype of energy lingers in these spaces, and it often goes unnamed but is culturally 
anticipated. Grant senses trauma before he enters the Pinchot plantation space, and Mr. Henri delivers this American tradition, where blackness triggers relentless indignities.

The scale and scope of American racism is beautifully constructed in Bayonne, but we have to grasp it. As the literary scholar Dr. Karen Carmean illustrates "having created a myth of racial superiority and perpetuated its 'truth' by rigging the educational and legal systems, whites sustain the illusion of their right to power...Bayonne's power is all white and all male" (135). Gaines locates overt symbols of this power when his Black characters enter the parish jail and courthouse and have to confront the confederate flag and statue of a confederate soldier (176). The "truth" in this imagery is that the state and public service institutions are complicit; moreover, white supremacy and hate are fully operational in these spaces. Jefferson's fate as a Black man accused of murdering a white man is sealed for this reason. How could justice be colorblind in that building where he was tried by a white jury not of his peers and defended by a white attorney who subscribed to notions of eugenics? Notwithstanding, he was going to be subjected to one form of public lynching or another.

Historical records have documented the public assemblies of lynch mobs that terrorized Black communities mostly in the South following Reconstruction through the Civil rights era, but what is less documented are the similarities between the state sanctioned electric chair executions and those conducted by mobs of racist vigilantes. During his research process for A Lesson before Dying, Gaines reveals in "Writing a Lesson before Dying" the public nature of executions in Louisiana between 1941 and 1957:

In 1986, a young female attorney in my class asked me if I would like to meet the lawyer who had defended the young man whose case Paul Nolan 
had spoken about. I told her I certainly would. She brought the old man to my house - a Cajun fellow, probably in his seventies, bent, frail. My student and I made coffee, and she had brought cookies, and we three sat on the porch. It was this man who told me about the traveling electric chair. I had heard about it, read about it, but I had not spoken to anybody who knew about it firsthand. He told me about the generator that accompanied the chair because sometimes our Louisiana weather causes the electricity to be erratic. To avoid that problem, the state prison sent its own generator. We don't use the electric chair in Louisiana now, but some type of lethal injection is given instead for execution. But let's go back to the late forties, when Gruesome Gerty [what the electric chair was called] did travel from one parish to another. At that time the execution was administered in the parish where the crime was committed, not necessarily at the state prison, as it is today. This attorney told me about how the chair with the generator was delivered in a truck, a special truck that delivered it the morning of or the night before the execution. He told me that the time of execution in that particular parish was between noon and 3:00 on Friday. He told me the generator had to be tested beforehand in order to be sure it was working in time. He told me you could hear the generator at least two city blocks away from the jail. He had witnessed the execution of a young man who had been sent to the chair a year earlier...Suddenly the attorney became silent and brought his hands up to his face. My student moved closer to him and held him. He lay his head on her shoulder and wept. Forty years later he could still remember that generator, that chair (774-5).

Not all executions in Louisiana involved Black men, but consider the kind of injustice that has been meted out to them specifically. How different then are these electric chair executions as described by the attorney in the above passage than lynching? Undoubtedly, these were both community events intended to show whites' authority to subvert the judicial process. As mirrored in Jefferson's case, in these parishes, people watched the electric chair arrive into town and "felt a cold chill" at it passed (Gaines 235). People crowded around the courthouses to partake in the spectacle of it (236). Imagine that day for the family members of the wrongly accused; they watched over and held onto one another. Black children were asked to kneel in their classrooms and pray. Then there was the noise of the electric chair as the executioners "warm [-ed] up the 
thing, test [-ed] [its] instrument to make sure that everything was in working order" (242). How different is this lynching from the public slave whippings, which also functioned as symbolic rites of intimidation? Sadly, not very. Ultimately, they all help to unmask a legacy of historical, inheritable trauma preserved in a system of micro and macroaggressions present in many American social environments.

\section{Traumatic Space, Loopholes, and New Pathways}

Neo-slave narratives open a lens to serious cultural dilemmas in need of reconciliation, and for this reason they allow us to reimagine who we can be as a society. Slavery's traumas resonate in our communities, in the streets, businesses, neighborhoods, parks, schools, churches, and homes; they have evolved with us because Reconstruction failed to provide the promise of equality for African Americans. In Kindred, we observe through Dana how easily the unreconciled past can manifest and wreak havoc in one's contemporary circumstances. With Sethe in Beloved, we witness the significant obstacles that often interrupt healing historical wounds. However, as Jefferson and Grant discover, healing can occur in the creation of safe spaces. Ironically, Jefferson found a sense of community, a purpose, and a positive racial identity while in jail. He gains a greater understanding of his humanity and worth because he sheds his traumatic cloak of black invisibility and is embraced as a community hero. His home, the place of his birth, had been his prison. As when Grant flees Louisiana for California and is afforded the space to discard his own slave mentality, his education becomes a second loophole of escape from his Jim Crow confinement. When Grant returns to Louisiana, he activates his education 
and teaches Jefferson to embrace his manhood and become that hero to those in his beleaguered Black community.

These characters model the nascent stages of soul reconciliation and healing, and it begins, as it did for them, with historical truth. By acknowledging the racist constructions in our modern spaces, we, through Sethe, Paul D, Denver, Dana, Jefferson, Grant, and other characters in these narratives, come to appreciate that history has to be embraced, but a richer, more nuanced, and complex form of it. White supremacism has cultivated a legacy of violence and apathy in this country. The Civil War was not the demise of this campaign of hate because its power was maintained and consolidated; additionally, it won the battle of the social narrative. That is the historical truth, this continuing legacy, which must be aggrandized; for consequently, the enslaved and their descendants have borne the brand of trespassers. We are coded and entrapped in our blackness, and the criminalization of it is as deadly as it ever has been. For Jacob Blake, George Floyd, Breonna Taylor, Ahmaud Arbery, Trayvon Martin, Emmett Till, George Stinney, Philando Castille, and countless other souls whose Black bodies cost them their lives, we must expose the roots of this nation's pathogenic institutional and societal structures. Only then can a new present be envisioned and claimed, and claiming and/or creating safe spaces must be the next phase is this process!

Relatedly, it is not a coincidence that at the end of A Lesson before Dying Jefferson walks to the electric chair epitomizing his spiritual paragon, Jesus and that the only member of his community brave enough to witness his final hour was the reverend. When hope is frail, there is always solace and safety in faith, a necessary ally in the pursuit of safe space. 


\section{CHAPTER V}

\section{REIMAGINING CONTESTED SPACE, ARTICULATING LIBERATION, AND PROJECTING HEALING IN AFRO-FUTURISTIC LITERATURE}

"Treat your people well, Shori. Let them see that you trust them and let them solve their own problems, make their own decisions. Do that and they will willingly commit their lives to you. Bully them, control them out of fear or malice or just for your own convenience, and after a while, you'll have to spend all your time thinking for them, controlling them, and stifling their resentment. Do you understand?"

\section{-Iosif Petrescu, from Octavia Butler's Fledgling}

Chapter four ends with a recognition of faith's integral place as a balm in the struggle for equality. Faith relies on the imagination to conceive of the wondrous possibility of what is unforeseen. Imagination creates a vision or manifestation of a world that could one day be a reality. This vision, specifically its potential in terms of its influence on human agency, is a bridge to healing. In Afrofuturism: the World of Black Sci-fi and Fantasy Culture, Ytasha Womack details how the renowned Civil Rights activist and scholar, W.E.B. Du Bois, utilized his own imagination to perceivably escape the maddening reality of the early twentieth century by momentarily convalescing in a fictional upgrade of it. In 1920, he penned a short story, called "The Comet", about a young Black man named Jim, who briefly evades racial oppression after a comet destroys his former home of New York City (Womack 119-20). Jim’s Promised Land disappears, for the comet has only destroyed New York City. The rest of the United States and its systems of inequality have been spared. However, the idea of freedom for both Jim and Du Bois, who achieves it vicariously through his fictional character, does not vanish; this idea and the quest for it, although realized only in the imagination, could not be lost. Its 
birth in the psyche represents the frail but indestructible hope that is the minimum requirement of faith; this same kind of hope is what is activated by The Columbian Orator and sustains Frederick Douglass until he actually seizes his own freedom. As Douglass' course to emancipation demonstrates, it is often the imagination that fires the inspiration, which drives the dream into fruition. Correspondingly, Womack asserts that Du Bois' endeavor into the world of science fiction was essentially this same process of realizing the prosperity that was absent in his reality by way of imagination:

As a man who devised strategies for eradicating race imbalances for much of his life and who staunchly believed that intellectual achievement could bring political parity, sci-fi was both a great release and the ideal tool to ponder the what-ifs in climbing through a rigid race-based social structure. He placed a thoughtful black man at the heart of his story and displayed the frailties and dilemmas of hope in a world resistant to change. As a fervent activist, Du Bois pushed for many social changes, most of which blossomed after his lifetime. With the tug and pull of a transitioning landscape at the turn of the century - the hope of the end of slavery, the horror at the institution of Jim Crow and mob lynchings, the progression of a small upper class, and the undermining of the larger masses-I wonder if Du Bois, too, felt like he was seesawing between progress and devolution. However, Du Bois was one of many activists who, beginning in the nineteenth century, used speculative fiction and sci-fi to hash out ideas about race, re-create futures with black societies, and make poignant commentary about the times (120).

Likewise, many African American writers before and following Du Bois, including Martin Delany, Edward A. Johnson, Frances E. Harper, and his contemporary, George Schuyler, activated the speculative literary world to seemingly expand the scope of their own realities as well (120-4). Although their purposes varied, these African American authors employed art in order to imagine societal change, demonstrating that art is not only inevitably political, even if it simultaneously demonstrates "multiple, conflicting allegiances" (Hai 7). Each author's cultural journey is uniquely his or her own. 
Even though this societal change would not be actualized or given some real-life application in their social spaces, these authors' writings offered readers and themselves an escape to some semblance of a home or safe, less confrontational space. These depictions of freedom, reconciliation, and/or safety were not only critiques of systems of power and dominance, but they were progressive visions of the future that, although limited to the imaginary realm, could rouse hope, especially for communities of color. These authors were speaking to their desires for a homeland of their own in the U.S., for the realization of this space would offer a measure of healing, a resolution in the aftermath of their slave-trade initiated exile.

Undeniably, in their societal experience race was frequently activated to reproduce the wounding of this exile. Thus, as Womack explains, "[these] black visionaries of the past sought to alleviate debilitating system[s] and end the racial divide [by using speculative fiction] to articulate their issues and visions" (124). Consequently, speculative fiction or writing that conceptualizes that which does not exist in the real world gave birth to the cultural aesthetic and/or artistic genre known as Afrofuturism. The term, coined by cultural critic, Mark Dery, in 1994, refers to "speculative fiction [or art] that treats African American themes and addresses African American concerns in the context of twentieth-century technoculture—and, more generally, African American signification that appropriates images of technology and a prosthetically enhanced future" (180).

As Womack explains:

[Afrofuturists] analyze dynamics of race and culture specific to the experiences of black people through sci-fi and fantasy works. They use it as a platform to assess humanity issues - including war, apartheid, and genocide - while also exploring class issues, spirituality, philosophy, and history. Others reevaluate the use of technology, its use in society, and its 
role in the creation of art as a process. Still others look to these analyses as methodologies to free people from mental blocks and societal limitations. But each, from the artist to the professor to the fan, prioritizes the reenvisioning of people of color in a shared harmonious future free of race-based power issues. At the very least, they create a future with people of color integrally involved (123-4).

Of interest to this research is Afrofuturism's place within the literary canon where it assumes a platform that confronts humanity's lingering societal issues and helps Black communities negotiate futures that offer more balance and promise. I. Bennet Capers asserts that Afrofuturism is a movement of reclamation and disruption. He asserts:

[A] mainstay of Afrofuturism is a commitment to the disruption of hierarchies based on race, gender, sexuality, and class... [and another] recurring theme in Afrofuturism is reclaiming the identities and perspectives that were lost as a result of the slave trade and colonialism. In this sense, Afrofuturism is both future looking and backward looking, committed to reclaiming approaches, methodologies, and ways of thinking that predate slavery and colonization. Afrofuturism asks: What would we be without? What would we be if? Most importantly, by engaging in reclamation, by valorizing a range of cultural traditions, it offers a vision of what could be in the future (14-17).

Additionally, Afrofuturism and postcolonial criticism share a similar ambition in highlighting new and diverse productions and readings of literature; they both draw attention to the destruction of cultural images and construction of cultural myths that have been employed to justify Western domination, oppression, and exploitation of other cultural groups. As discussed in the introductory chapter, postcolonial literature is written in a "context of embattled power relations... situated between various cultural borders, [postcolonial authors] focus self-reflectively in their writing on the unstable capacity of words to be used and abused, to tell (or make) truth and to be censored" (Hai 6). Postcolonial literature endeavors to give some power and authority to the colonized subject; these narratives are told from the perspective and gaze of the postcolonial author. 
They are counter discourses that "write back" to the empire. According to Ashcroft et al.:

[In order to reclaim] "self-assertion and the ability to reconstruct the world as an unfolding historical process, [these authors write.]...the imperial conquest has always destroyed the land and often regarded the human occupants as disposable, almost as if they were a species of exotic fauna. But the conquerors themselves, the present controllers of the means of communication, those who have subjugated or annihilated the original occupants could not feel at home in the place colonized. Out of this sense of displacement emerges the discourse of place which informs the postcolonial condition (81).

Relatedly, this research has been consumed with this "discourse of place" or themes of space, spatial constructions, and configurations that contribute to a traumatizing social experience for marginalized groups in this country, which fuses both postcolonial literature and Afrofuturism. In this particular chapter, we will continue to delve into the works of Octavia Butler, a foremother of Afrofuturism. Often with her novels, she reached into her imagination to fashion the equanimity that her societal space lacked. With the neo-slave novel Kindred, Butler observes and critiques existing power structures, and the institution of enslavement is a central focus in its discussion, as the novel takes inspiration from real slave accounts. In the Butler's Afro-futuristic works, Fledgling and Parable of the Sower, we will observe a move from emphasizing remembrance and historical significance to locating societal spaces of repression and restriction as well as envisioning spatial models of reconciliation and resolution. The projections that these texts offer for the future are what compel them into the genre of Afrofuturism. Butler constructs African American and other oppressed characters who respond to homeland exile and cultural loss by restoring their agency through their own volition so that they can create new home spaces and cultural identities. 
In Parable of the Sower, Butler creates an Afro-futuristic dystopia that demonstrates a future world that feels far from fictional. She affirms what authors of slave narratives and African American writers in postbellum America could attest: fiction and real-life can often feel indistinguishable. With Parable of the Sower, Butler offers warnings of societal collapse reminiscent of antebellum slave plantation culture. She illustrates how capitalistic greed can expansively rot society and supersede the interests of the people to the extent that civilization disintegrates into an authoritarian regime. Butler's twenty-first century California in its depiction of societal collapse is a microcosm of the larger United States and global society. In this fictional space, the illusion of safety only exists in privatized cities, debt slavery is legal, and all functioning democratic institutions have been dismantled. The United States in the 2020s is a collection of transnational plantations, outside of which only lawlessness exists. The story's protagonist, Lauren Olamina, is simply trying to survive; she is a Black woman, but her race is not the primary cause of her trauma, which should resonate as progress. Unfortunately, her society manufactures a social trauma that is no longer raciallytriggered or fixed. Black claustrophobia in this societal sphere is a cross-cultural, poor, working, and middle class reality. In Lauren's society only the disproportionately wealthy can locate spaces of safety or exemption from the devastation of this millennial capitalism. In the absence of safety, she remains hopeful that she and others can plant a new civilization away from her dying one (69).

Butler creates this cultural war zone by resurrecting plantation spatial restrictions and extending them throughout the contiguous United States. Cultural norms of twohundred years earlier return, signifying a clear missive in this Afro-futuristic dystopia: 
Black trauma can become anyone's trauma. Thus, its existence in our current society should be a concern for all. The rationalization process that cultivates racism and bigotry can be applied to any cultural group or ecosystem; racialization is a mutable adversary. Parable of the Sower is the story of one young woman's journey to find an escape from the oppression and restriction of her society, and she is all of us, potentially, for apathy is always a catalyst for cultural destruction and societal collapse. In one of her Earthseed books, Lauren proclaims that "In order to rise from its own ashes a phoenix first must burn" (137). From her society, we see the spatial expanse of this burn, and we consider all of the structural elements of her trauma. Besieged and surrounded by flames, Lauren remains resolute in her own perseverance; she finds solace in her newly adopted theology of Earthseed and through it she finds her desired freedom.

With Fledgling, we turn to find a model of how a society can rise from the ashes. In its epilogue, we find, Shori, the protagonist, determined to move forward after surviving multiple attempts on her life, the complete loss of both her maternal and paternal family lines, and post-traumatic amnesia. She says:

What about my mothers and sisters, my father and brothers? What about my memory? They were all gone. The person I had been was gone. I couldn't bring anyone back, not even myself. I could only learn what I could about the Ina (her cultural heritage), about my families. I would restore what could be restored...begin again (310).

Even though Shori is of another species, an Ina vampire to be specific, her firstperson perspective begs the reader to consider what it would require to recover from the traumatic, irreversible cultural displacement that she suffers. How does one make the space in which the trauma occurs more humane or at least livable? How does one decrease the impact of the trauma and promote healing? Shori's dilemma is undeniably a 
Black dilemma. Although this narrative presents useful applications for various groups of marginalized people, the cultural loss that Shori endures is undeniably a Black cultural narrative, for it contemplates the process of healing emanating from a very specific type of cultural wounding; a trauma similar in nature to the indelible, cultural legacies or wounds of the transatlantic slave trade and plantation slavery. Essentially, Shori is on a quest for home, which she must construct after suffering a catastrophic loss of her cultural identity as a result of her amnesia. The slave trade and plantation slavery impelled African Americans to confront a similar circumstance: homeland exile.

As a melanin-enhanced Ina vampire, Shori is the most powerful being on earth, not in spite of her black skin but because of it. Shori presents to the world as a Black female child; and as a result, she faces bigotry, xenophobia, and racial violence. Thus, she carries both the African American stigmas of cultural alienation and of the Black female body; unlike, her human counterparts, she has the access and means to recover her culture and overcome racism within her Ina society. Shori becomes an agent of change not an object of subjugation; she is a model of redemption. She responds to the trauma of her amnesia, as a result of which she only possesses sensory memories, by reestablishing her own agency; she asserts her self-determination and reconstructs her home and her identity by accumulating new concrete memories of her Ina culture. Here, Butler's use of the first-person is an important element of this process. Correspondingly, Florian Bast asserts:

Authors of slave narratives very consciously used the first-person to write themselves into existence, [Butler uses] the first person [in Fledgling] to combine [the] rewriting of the slave narrative with postmodern complications of subjectivity and authorship. In a narrative construction that has deep roots in the African American literary tradition, this victim of racially motivated violence narrates her own search for the truth about 
the past, about the trauma that she suffered, and about her attackers' identity as the central quest for her identity and self-awareness, explicit sources of agency. What is significant in terms of the text's investigation of the multifaceted nature of agency is the fact that, in the end, Shori overcomes both xenophobia and her own ignorance. By way of her own physical and emotional strength and with the help of both her human symbionts and her Ina friends and relatives, Shori soundly defeats her speciesist enemies and her own ignorance. She possesses the monetary resources, the legal and physical security, and the social networks necessary to continue her growth into a productive and powerful member of Ina society (Bast).

Additionally, through Shori's journey, Fledgling sets forth to construct a vision of the United States of America as a homeland for Black people. The homeland that Shori reclaims for herself and her loved ones embraces mutualism, freedom of choice, a high code of morality, and cultural representations that resist distortion or the popularization of caricatures of dominated groups.

In order to conceptualize America as a homeland, Fledgling uses a fictional model of this nation and returns to its economic and sociological roots on the plantation. Butler erects this reimagined homeland by repurposing plantation space. In the process, the reader is implored to consider what American society could have been or could resemble in the future, if past economic decisions had embraced mutualism as opposed to individualistic, capitalistic plantation-based economic schemes. There is a rejuvenating contemplation occurring at the center of this text about the possibility and potential of open and cooperative social space, for all members of Shori's plantation network in Fledgling are valued and considered. These fictional representations challenge the traumatic, spatial design of the slave plantation and all historical iterations of plantation space that have existed and/or exist currently in the American social landscape. Thus, repurposing the plantation provides a map for transforming all spaces of trauma. In 
addition, Fledgling places a transformative lens on the Black female body, American cultural structures within the established social framework, and the normative white male social structure as an entire entity. Although imaginary, this text considers the relevancy of the safety that it is constructing in its homeland comprehensively, and I argue that the various spatial models present in Fledgling and Parable of the Sower demonstrate the power of literature to improve societies and people through the potential of projection. Against our previous studies of contested space, these literary models project the healing and liberation that our current societies desperately need. These speculative narratives engage Afro-futuristic visions of the future buttressed by progressive and compassionate individuals and communities formed of egalitarian spaces that offer freedom from confining social structures and systems. By imagining the world anew, they draw us closer to realizing a better version of it.

\section{Societal Collapse, $21^{\text {st }}$ Century Spatial Entrapment, and Reimagining Contested Space in Octavia Butler's Parable of the Sower}

A sower went out to sow his seed: and as he sowed, some fell by the way side; and it was trodden down, and the fowls of the air devoured it. And some fell upon a rock; and as soon as it was sprung up, it withered away, because it lacked moisture. And some fell among thorns; and the thorns sprang up with it, and choked it. And other fell on good ground, and sprang up, and bear fruit an hundred-fold. And when he had said these things, he cried, He that hath ears to hear, let him hear. -The Bible, Authorized King James Version, St. Luke 8: 5-8

Parable of the Sower provides a structural model or replica of Black plight in this country, specifically the feeling of being a desperate refugee with few options for advancement. Correspondingly, this research project has attempted to highlight the various structural limitations that exist in this society and demonstrate how they contribute to this traumatic cultural experience. What Butler's Parable of the Sower, in 
adherence to its Biblical reference, does is espouse the value of fertile soil, and she reveals this through a presentation of the alternative-uninhabitable soil. The United States has always maintained this perception as a land of great fortune and colorblind opportunity even as slavery, the Jim Crow Era, and various phases of injustice have proven otherwise. African Americans have faced numerous conflicts in their struggle to persist, which the various authors featured in this research have documented, in their adoption of this country as a homeland, to the extent that physical spaces have often felt uninhabitable. In the current climate of racial unrest and the unending murders of Black people at the hands of police officers, many have asked, "Where can we go to escape this persecution?" and "Where is our Promised Land?"

Parable of the Sower endeavors to model the characteristics of their problematic existences in this country so that those who suffer in them are validated and others are assisted in comprehending the scale and gravity of this Black trauma. This is a therapeutic and foreshadowing vision of American cultural society that invites consideration, compassion, and activism. Parable of the Sower is a story that demonstrates the spatial arrangement of inescapable degradation. It possesses a straightforward, but evocative plot. Without nourishment, seeds will not grow. Behold the brokenness of our societies to which Black people in black bodies have been subjected to for far too long. In this text, Butler replicates, as argued earlier in the texts discussed thus far, the structural triggers of the unique psychological trauma of blackness; specifically, she demonstrates how enclosed racialized space or spatial restrictions can foster toxic social environments and social anxiety, which has prevented homeland realization for Black people. 
Lauren Olamina, the young, Black protagonist of Parable of the Sower is a

resident in a suburb in twenty-first century California where trauma is tragically ordinary. She and her family are surrounded by constant, senseless death. As an empath, Lauren processes pain collectively, so she feels the sufferings of her community. She is born with the curse of heightened compassion in a world that has lost its spiritual center, if it ever truly possessed one, but she is gifted intellectually and understands that she represents the human weapon necessary to bring down the stronghold that has desecrated her society. Her community represents the status quo; Butler constructs, according to Tom Moylan:

A world in which transnational corporations have prevailed by destroying the social and natural ecology that had sustained capitalism through its many stages...the end result of the economic, political, and environmental matrix produced by the capitalist restructuring and conservative policies that dominated the last twenty-five years of the twentieth century (Moylan 224).

When we encounter Lauren on her fifteenth birthday, she is feeling this loss of her identity and freedom as immense barriers in her life. She is recalling a dream from the previous night. In it, she and her stepmother are observing the stars in the sky, but in her gaze stands the obstructive neighborhood wall that she describes as "a massive, looming presence nearby... as a crouching animal, perhaps about to spring. More threatening than protective" (Butler 5). There is nothing in her society for her to celebrate at her tender age of fifteen. In the community of Robledo, California, where Lauren and her family reside, the "protective" wall around their neighborhood restricts its open flow. The interactions outside of the neighborhood are limited, and the wall has replaced any preexisting boundaries that served as points of demarcation. The wall only provides the illusion of security and safety because it does not protect those enclosed in it from the societal chaos that exists just outside of it. Lauren notes "when people want to come in, 
they come in. The thieves used simple hand tools - crowbars, hydraulic jacks, things anyone can get" (103).

Her "cul-de-sac with a wall around it" is one version of many walls that have been constructed to minimize the encroaching rage outside of the wall (73). Outside of the wall, climate change, economic collapse, drugs, and poverty have decimated peace and good will. The people outside of the wall are American citizens who have become refugees; they are homeless, destitute, and desperate. Survival is their singular ambition. When Lauren and members of her community venture out of the neighborhood armed and in groups, they engage the most tortured members of their community. Lauren observes:

Inside our neighborhood walls I do fine. Our rides today, though, were hell. Going and coming, they were all the worst things I've ever feltshadows and ghosts, twists and jabs of unexpected pain. If I don't look too long at old injuries, they don't hurt me too much. There was a naked little boy whose skin was a mass of big red sores; a man with a huge scab over the stump where his right hand used to be; a little girl, naked, maybe seven years old with blood running down her bare thighs. A woman with a swollen, bloody, beaten face... (11).

There is a larger metaphorical wall that has been erected around her neighborhood and the racially-diverse population of non-elites. Their value is only appreciated as sources of labor for the transnational corporations that are now ruling the country (114). Their access to social services is limited, and there are no places to move freely. When Lauren's family members are killed in a violent arson attack on her community, she is forced into the streets and becomes a refugee too. In her search for a new home and safety, she travels with a diverse group of people, who like her possess no real privileges. They have all been relegated to the shadows of their society. State lines and borders are closed, so there is no escaping this reality, and the only other option is debt slavery. 
Those wanting to find a place of solace could agree to work for corporations, which

represents another form of entrapment:

The workers fell into new hands. Wages were paid, but in company scrip, not in cash. Rent was charged for the workers' shacks. Workers had to pay for food, for clothing - new or used - for everything they needed, and, of course they could only spend their company notes at the company store. Wages-surprise!-were never quite enough to pay the bills. According to new laws that might or might not exist, people were not permitted to leave an employer to whom they owed money. They were obligated to work off the debt either as quasi-indentured people or as convicts. That is, if they refused to work, they could be arrested, jailed, and in the end, handed over to their employers. Either way, such debt slaves could be forced to work longer hours for less pay, could be "disciplined" if they failed to meet their quotas, could be traded and sold with or without their consent, with or without their families, to distant employers who had temporary or permanent need of them. Worse, children could be forced to work off the debt of their parents if the parents died, became disabled, or escaped (2589).

Essentially, this societal collapse is an edifice of capitalist design congruous to slave plantation spatial arrangements, Jim Crow Era segregation laws, convict labor/leasing systems, racial housing covenants, and discriminatory policing practices. These arrangements were orchestrated to maintain social order and white dominance. These are the regressive spatial networks that must be constructed when a regressive regime is in power. Parable of the Sower provides an opportunity to examine the structure of the spatial arrangements that are utilized to form the space of social entrapment. In this text, Black people are joined in their struggle by all cultures of people. In the United States, race has been a fixed signification tool of exploitation and social restriction. In Butler's fictional America, class functions as the demarcation line between the protected and unprotected castes, and thus a wider audience is given the opportunity to identify with the psychological trauma that the text cultivates. Butler is begging the 
reader to look beyond race and realize that the misery of the Black experience is a brutality that can be expanded and shared.

As the great Martin Luther King Jr. said, "Injustice anywhere is a threat to justice everywhere. We are caught in an inescapable network of mutuality, tied to a single garment of destiny. Whatever affects one directly, affects all indirectly" (King, 75). The Black plight could be yours. Do not be blind. Butler designs a societal state that is a mirror. In addition, Jerry Phillips suggests that her fictional society has privileged control over justice, “the state establishes quasi-permanent 'structures and organized systems', which secure interests of the few at the expense of the many...the individual suffers a crushing loss of self-identity: neurosis and psychosis become normal states of being" (Phillips 305). Again, this societal circumstance represents a cross-cultural nightmare.

However, Lauren and her refugee community begin a new way of life, called

Earthseed that empowers their progress:

We do not worship God.

We perceive and attend God.

We learn from God.

With forethought and work, We shape God.

In the end, we yield to God.

We adapt and endure, For we are Earthseed And God is Change.

A victim of God may, Through learning adaption, Become a partner of God, A victim of God may, Through forethought and planning, Become a shaper of God. Or a victim of God may, Through shortsightedness and fear, Remain God's victim, God's plaything, 


\section{God's prey}

\section{-Earthseed: The Books of the Living (Butler 15, 27)}

In fleeing her former community, Lauren was not heading in any particular direction. There were no safe options; ultimately she was merely heading away, but on her journey she claims authority over her life and affirms a safe space through the theology that she develops in Earthseed. As a belief, Earthseed is the representation of a new world, but it initially exists only in psychological space and in the tenets that Lauren establishes. A belief in Earthseed allows Lauren and her followers, current and future, an escape from their apocalyptic world by reimagining a new one through an ecofeminist lens; Earthseed is their Afrofuturism:

Create no images of God.

Accept the images

that God has provided.

They are everywhere, in everything.

God is Change-

Seed to tree, tree to forest; Rain to river, river to sea; Grubs to bees, bees to swarm. From one, many; from many, one;

Forever uniting, growing, dissolvingforever Changing.

The universe is God's self-portrait.

-Earthseed: The Books of the Living (283)

The Earthseed belief system supports psychological well-being and reconciliation. Unlike Robledo and many other communities in the United States of her 
time, the space that Lauren will ultimately establish as a colony, born of her new ideology, is not bound by fear but it is bolstered in the acceptance of the inevitable:

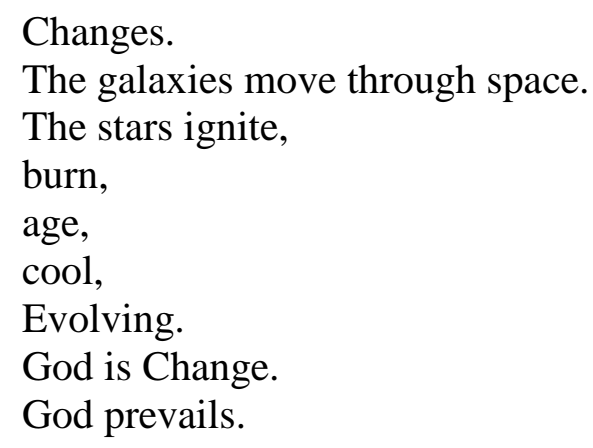

-Earthseed: The Books of the Living (202)

Earthseed asserts that there are no easy relationships with God, but through common acceptance of humanity and loving kinship a community of God can be shaped:

We are all Godseed, but no more or less so than any other aspect of the universe, Godseed is all there is - all that Changes. Earthseed is all that spreads Earth life to new earths. The universe is Godseed. Only we are Earthseed. And the Destiny of Earthseed is to take root among the stars

Kindness eases Change.

-Earthseed: The Books of the Living $(68,149)$

What Earthseed makes clear is that the path to healing is full engagement as human beings, pragmatism, "commitment to social activism rather than passive belief [, and]...hope without the certainties and reassurances of more traditional religious beliefs" (Jos 426-7). Through Earthseed, Lauren understands and coveys the limitations of her current societal space:
All struggles
Are essentially power struggles. Who will rule, Who will lead, Who will define, refine, 
confine,

design,

Who will dominate.

All struggles

Are essentially power struggles,

And most are no more intellectual

than two rams

knocking their heads together.

-Earthseed: The Books of the Living (Butler 83)

The Earthseed worldview is shaped in conflict resolution, which will ultimately

help Lauren's followers heal from the consequences their societal collapse. By moving its

followers towards mutual cooperation and reconciliation, it cultivates in them an

imagined and operative vision of peace:

Embrace diversity.

Unite-

Or be divided,

robbed,

ruled,

killed

By those who see you as prey.

Embrace diversity

Or be destroyed.

-Earthseed: The Books of the Living (Butler 176)

Earthseed celebrates personal agency and expands on a theme presented in the biblical letter of James, one of its more moralistic books: "even so faith, if it hath not works, is dead, being alone" (James 2:17) Lauren's Earthseed affirms a place for all its followers through self-determination even though this place may exist beyond this realm:

The Self must create

Its own reasons for being.

To shape God,

Shape Self.

-Earthseed: The Books of the Living (Butler 176) 
Thus, Lauren believes that "the Destiny of Earthseed is to take root among the stars" with the aid of space travel; they can one day claim a refuge (68). The psychological trauma of the living in spaces that are not safe or inclusive feels endlessly burdensome, but the stars represent an exodus. While limited to the confines of Earth, the Earthseed believers mirror the homelessness that Black Americans face every day in not feeling safe in their places of residence, in church, in classrooms, on the street, or in work spaces. The absence of sanctuary in the United States of America while living in a black body can often feel dystopian. Lauren is a Black woman, but her experience takes on a universal character. Parable of the Sower illustrates the emotional space of harmful environments and circumstances that are often triggered by one's race, but it offers a projection of healing and liberation by reimagining contested space.

\section{Cultural Loss, Black Identity, Black Body as Hero's Shield, and the Repurposing Plantation Space as Homeland in Octavia Butler's Fledgling}

In the opening scene of Fledgling, the narrative lens is immediately fixed on this notion of liberation by emphasizing spatial confinement; we locate a nameless character, whom we will later determine to be our protagonist, Shori, who is being held presumably in some type of enclosure. She states, "I awoke to darkness. I was hungry—starving!and I was in pain. There was nothing in my world but hunger and pain, no other people, no other time, no other feeling" (1). Shori is operating in a primitive state, relying on instincts alone; she is unaware that she has been relegated here by some racist adversaries. One aim of locating Shori in this space and in this specific situational conflict is that it foreshadows the immense danger of the societal conflict, or the actual nature of the darkness, to which she awakens. Another equally important significance of 
her location is that it signals what appears to be a traumatic cultural loss or disconnect.

With respect to evolutionary assumptions, culture is what distinguishes human beings and primitives. Her focus seems so clearly fixed on feeding and survival in this opening scene. Acknowledging this cultural loss places this work unequivocally in the literary canon of Afrofuturism. In "Monster Studies: Liminality, Home Spaces, and Ina Vampires in Octavia Butler's Fledgling", Dr. Lin Knutson describes Shori’s primal wound, established in this opening scene, as "Butler's attempt to narrate a science fictional history of African American historical loss... [reflecting] an aimed recuperation of historical memory of African American slaves and of erased names, lives, and history" (221).

Shori and African Americans, whose ancestors survived the middle passage, share this primal wound of cultural decimation and the consequential crusade for renewed acculturation, which in both cases is complicated by a spatial dislocation and disorientation. Although we will later discover that Shori is in a cave, she could have easily been describing the space of a slave ship hold:

The hunger was a violent twisting inside me. I curled my empty, wounded body tightly, knees against chest, and whimpered in pain. I clutched at whatever I was lying on. After a time, I came to understand, to remember, that what I was lying on should have been a bed. I remembered little by little what a bed was. My hands were grasping not at a mattress, not at pillows, sheets, or blankets, but at things that I didn't recognize, at first. Hardness, powder, something light and brittle. Gradually, I understood that I must be lying on the ground - on stone, earth, and perhaps dry leaves. The worst was, no matter where I looked, there was no hint of light. I couldn't see my own hands as I held them up in front of me. Was it so dark, then? Or was there something wrong with my eyes? Was I blind? I lay in the dark, trembling. What if I were blind? (Butler 1).

It is Shori's occupancy in a cave that initially signals her cultural loss; much like the hold of a slave ship, it replicates the feelings of isolation, separation, and primitive 
survivalism felt by the enslaved ensnared on these vessels. However, it is after the reader, in fact, determines that she has been isolated in a cave but more significantly is suffering from apparent amnesia that her cultural loss is confirmed and magnified:

I climbed to my feet slowly, my knees protesting the movement with individual outbursts of pain. Once I was up, I stood still for a while, trying to get used to balancing on my legs. I held on to the rocks that happened to be next to me and stood looking around, trying to understand where I was... I decided that it was time for me to go. I began to walk down the hill... I stopped once and looked back. I could see then that I had come from a shallow hillside cave... It had kept me safe, that small hidden place. But how had I come to be in it? Where had I come from? How had I been hurt and left alone, starving? And now that I was better, where should I go? I wandered, not aware of going anywhere in particular, except down the hill. I knew no other people, could remember no other people (3-4).

Her amnesia also situates her cultural loss further into the scope of the African American experience, even more so than her isolation. In the process of enslavement, the slave ship hold signals the primal space of disconnection for the enslaved, but through the brutal and violent conditioning tactics involved in plantation society, a cultural amnesia is achieved. The African American is permanently disconnected from his or her African cultural roots in terms of possessing the ability to recognize and fluently interpret preenslavement cultural practices, beliefs, values, and traditions. Even if Shori were to be reconnected with her familial communities, she has suffered a locational and cognitive cultural disconnect that would render them unrecognizable.

Thus, as we follow her journey from the cave, she must engage her surroundings as an illegal alien and perceive every space with trauma and every stranger with caution. She is aware that she is a survivor of some violent attack and that she is in an unfamiliar space. Thus, she carries a similar psychological burden such as post-traumatic slave trauma, which this research has deemed a form of black claustrophobia. Shori says, "I 
didn't know any other people. I knew they existed, but thinking about them, wondering about them scared me almost as much as it interested me" (5). There are many layers to Shori's story, but ultimately at its core it is a story about restoration, reconciliation, and her journey to reclaim what she has lost: her cultural heritage, which symbolically is her home.

What is revealed after she exits the cave and as the story progresses is that Shori is a fifty-three-year-old (a juvenile) Ina vampire who finds herself in this cave, amnesiac and seriously wounded, because her family and their symbionts (blood slaves) were murdered for their participation in a genetic engineering project which resulted in a generation of part-Ina, part-human children (64). Her Ina mothers were able to engineer the improved survival of the Ina vampire species, who are typically pale-skinned and highly susceptible to sunlight. Shori is their most successful experiment, for she bears the melanin-enhanced skin of her human genetic contributor. As her Ina father explains before he too is murdered, her dark skin is her shield and protection:

The sun wouldn't disable her at once. She's a faster runner than most of us, in spite of her small size. And she would have come awake faster when everything started. She's a light sleeper, compared to most of us, and she doesn't absolutely have to sleep during the day... Some of us have tried for centuries to find ways to be less vulnerable during the day. Shori is our latest and most successful effort in that direction. She's also, through genetic engineering, part human (66).

In Octavia Butler's world of the Ina, blackness is transformed and elevated. As participants on Shori's journey of cultural reclamation, we, the readers, are able to partake in escapism to a reality where blackness is a privilege. The first component that Shori is able to recover of her identity is this skin privilege. In the realm, the reader can dismiss the indoctrination of race-based ideologies born of colonialism with this discovery as well. Shori is a black character who is facing social alienation and spatial 
disorientation, which resembles the cultural trauma of black claustrophobia, and it is later revealed that her dark skin complexion has triggered her adversaries. However, in this imagined space her adversaries are in the minority within the Ina community. As an Ina vampire who can withstand the sun, she is the most powerful being on earth; the majority of the Ina would welcome her skin protection. Unlike so many victims of racism, her black body has been given agency; within Ina society, it generates a defense in its visibility and causes concern in its absence or invisibility. This is an example of where, according to Susana Morris, "Afrofuturism [functions as] an epistemology that both examines the current problems faced by blacks and people of color more generally and critiques interpretations of the past and the future" (153). With this attention to skin privilege, Butler is confronting the corporeal and race-based hierarchies that have maintained social inequality and problematized the Black experience in U.S. culture (Knutson 224-5).

With Shori, Butler is cultivating the sentiment and space of a home or homeland for Black (female) bodies in the U.S. This radical reimagining utilizes the plantation system and structure, but Butler transforms it. As in the U.S. plantation framework, there is a master-slave dynamic. As a blood-thirsty Ina, Shori requires human blood for sustenance. The blood is comparable to slave labor; it is what activates the human bondage. In return the humans are "addicted to a substance in Ina saliva—in [their] venom — that floods [their] mouths when [they] feed... [it is like a] powerful hypnotic drug... [that makes the human symbionts] highly suggestible and deeply attached to the [Ina, and the humans] need it" (Butler 73). The human symbionts are bound to and live with their Ina for the duration of their lives. There is no reversing this "mutualistic 
symbiosis" (63). The human symbionts are unbound only by death, which was the case for a large majority of the enslaved.

However, mutualistic symbiosis is vastly different from enslavement in most cases: the symbionts are given a singular choice to be bound to their Ina. This choice occurs in a small window of time, but it is a window nonetheless. Additionally, the Ina are concerned with the well-being of their symbionts, and the Ina respect their symbionts and their personal freedom $(49,53,66)$. Shori declares: "I wanted that - a home in which my symbionts enjoyed being with me and enjoyed one another and raised their children as I raised mine. That felt right, felt good" (127). Now, there are less ethical Ina who misuse their symbionts and resent their need for human blood (270); they are as individual within their species as their human counterparts (148). However, the majority of the Ina work to improve the lives of their symbionts to the extent that their humans "live to be between 170 and 200 years old" (63).

Again, Butler has constructed a new-age societal structure that critiques antebellum plantation society while reconfiguring it. Her plantation society has no restrictive boundaries - the symbionts have no restraints on their mobility, and the prevailing Ina cultural identity is nonviolent and mutualistic. Freedom of choice, ethics, and morality are hallmarks of Shori's social network. As Shori reclaims a space of belonging, Butler not only resurrects the black body, but she empowers the black image as well. Within the confines of what superficially appears to be a colonial agenda, she constructs sympathetic and three-dimensional characters who stand in defiance to the primitive, beastly, and one-dimensional depictions of Blacks created during and following the slave-era to demonize them and legitimize colonization and oppression. 
Although Butler could have constructed alternative configurations of home locations for Shori, who chooses to erect her mutualistic plantation base in accordance with her Ina culture to which she is fiercely loyal, it feels of significance that Butler returns this character to a space of primal wounding for Black Americans as she frequently does with her work. Butler accentuates the birth place of collective Black trauma in this country.

In the process, Butler also draws attention to the reoccurring devastation of stereotypes. As a result, Butler, firmly in charge of her moral authority as author and her postcolonial, Afro-futuristic perspective, identifies a weapon against social, economic oppression: realistic, positive representation. Butler achieves these political feats by manipulating her character agents and the cultural, political context within which she positions them.

\section{Repurposing Plantation Notions with Black Caricatures in Fledgling}

The trauma of being Black in America or this sense of black claustrophobia to which Butler is responding in the construction of this fictional realm was born of the slave industry and solidified on the plantation. Butler utilizes to the plantation imagery to confront this nascent space of barbarism in the Black American saga. To further elucidate her reconceptualization of the American plantation, Butler employs black caricature imagery, including the black brute, pickaninny, mammy, and the Uncle Tom. These caricatures were popularized during and following the Civil War on minstrel show stages and later in motion pictures, including the widely-acclaimed film The Birth of a Nation (1915), and in television. These popularized notions of blackness have been commonly accepted in entertainment and have evolved as they have persisted, for their utility is still 
valued and commonly galvanized. As Jennifer Bloomquist explains in "The Minstrel Legacy: African American English and the Historical Construction of 'Black' Identities in Entertainment", these images were intended to justify slavery and as a result rationalize the oppression of Black Americans:

While the practice is common in other postcolonial empires, America, in particular, has had a protracted history of Whites creating Black caricatures. Although Blacks served as amusement for White audiences on plantations throughout the enslavement period, the national White fascination with African American life as popular entertainment began with the proliferation of minstrel shows in the late 1820s. These traveling variety shows (mostly featuring music and comedy) dominated American entertainment until well into the 1880s and featured so-called "Ethiopian delineators" who were all-White, all-male casts in blackface. Their comedy hinged on gross misrepresentations of what the actors determined to be (southern) Black culture, including singing, dancing, and delivering comedic speeches. In the early days of minstrelsy, more often than not, the actors had little or no real contact with African Americans, so their version of Black culture was almost entirely grounded in racist stereotypes (411).

Octavia Butler confronts this legacy of minstrelsy and the black caricature tropes that this tradition popularized. By manipulating these caricatures into new, less limited and binary social positions, she reverses power relations thereupon extending agency to the American citizens that these black caricatures have intended to demonize since their inception in the early nineteenth century (Bast). She is catalyzing her postcolonial theorist intentions and "writing back" to the empire.

One of the first caricatures that is reconceptualized in this text is the "black brute". The images from the following scene from the widely-acclaimed, racistpropaganda masterpiece, The Birth of a Nation, quintessentially capture the nature of the "black brute" caricature, which portrays Black men as innately savage, animalistic, destructive, and criminal; deserving punishment and even death (Bogle 13-4). The black 
brute could also be depicted as a fiend, a sociopath, an anti-social menace, and as a

pedophile who craved innocent (most often young) white woman:

Flora, (Lil' Sis), the delicate young Cameron daughter, cheerfully ventures alone to the spring to fetch water in a bucket. By a fence, an emancipated former house servant/slave - the inflamed, lusty Negro "renegade" Gus (Walter Long) notices her. At the spring, Flora dips her bucket in the water as he follows her path in the forest. From his hiding place in the underbrush, he watches her sitting on a log, where she gestures and plays with a squirrel (in close-up). A close-up of his face displays an ominous look. However, he approaches (with hope) and confronts her with the news that he is now a distinguished military officer and ready for marriage:

Gus: (touching his uniform hat) "You see, I'm a Captain now - and I want to marry."

When he takes her hand as a gesture, she slaps him, jumps over a log, and runs off. He pursues her after the rejection and chases her through a sun-splattered pine-forested area (with dramatic, natural contrasts of light and shadow). In the meantime, to heighten tension, there are cross-cuts to scenes of Ben being notified of Flora's errand at the house, and his efforts to reach her in the forest (he retraces their steps through familiar settings).

As he chases after her, Gus reassures Flora: Gus: "Wait, missie, I won't hurt yeh."

After a long and exciting pursuit sequence (involving all three characters: Ben, Flora, and Gus), Flora scrambles higher and higher up a rocky cliff. As Gus approaches closer toward her and gestures for her to come down, she turns and repeatedly threatens him: "Stay away or I'll jump."

With arms outstretched, Flora appears to lose her balance and she falls off the cliff - seen from a long shot. [It could be interpreted that she committed suicide by jumping or leaping off the cliff to her tragic death, to avoid being raped and suffer dishonor, but it is more likely that her death is merely an accident. However, it could be interpreted that her threatened rape symbolizes the emasculation and 'rape' of whites in the South by a rampant black population suddenly emancipated - and destructive of the racial order.] At the scene of the fall, a fearful Gus is made an innocent victim - he will undoubtedly be held accountable and punished for her demise (Dirks "Birth of Nation").

In Fledgling, Butler creates a brute [or it could also be suggested that she acknowledges who more frequently played this role in slave-era societies] in the character of Wright, Shori's white symbiont. His name is even a recognition of the 
position of power and privilege that often has been assigned to his racial class. White men have possessed the privilege of the assumption of innocence; he is born with the presumption of righteousness hence the name, Wright. The character Wright encounters Shori after she stumbles from the cave bruised and amnesiac. Butler's brute is not an exact replica in design of the black brute caricature, for as a consequence the brute as a tool of oppression would be resurrected. What Butler does is utilize one of the most charged facets of this caricature's nature: his lust for the innocent white woman.

Historically, this innocence was most often conveyed by making the white women visibly young as in the case of Flora (Bogle 14).

Wright agrees to shelter girlish-looking Shori in his home and has sexual intercourse with her. Shori is small in stature and her memory loss and/or her absence of a developed sense of identity renders her innocent. With the exception of her race, she is Flora. Wright perceives her to be helpless; he says: "You're soaking wet and filthy" (Butler 8). He notices blood on her shirt and asks "Look, is there some place I can take you?" He continues, "You shouldn't be out here in the middle of the night in the rain! You can't be any more than ten or eleven" (8). Butler emphasizes her size in relation to Wright to draw attention to the illusion of power that is destructively attached to the black brute. Shori says, "He shook me, actually lifting me into the air a little" (11). In reality, Shori is a vampire who is capable of subduing any human of any size, but before we are allowed to observe her in this role as a commanding slave master to her venomaddicted human symbiont, she is depicted first as an innocent, helpless victim.

In reality, Wright and the black brute caricature are both powerless in terms of social position, and their physical power is decidedly useless in the greater scheme of 
their societies. For the black brute, this subjection applies to the actual Black men the caricature is intended to represent in their respective societies. Wright could never defeat a vampire who possesses cat-like motor skills and lioness power, and Black men of the plantation-era could hardly retrieve any significant amount of control from the white power establishment. African Americans maintained a nearly immutably low position on the social hierarchy. Though Shori is a vampire, Wright is depicted as an adult who takes advantage of an innocent child: "There he sat down and drew me close so that he could open one of my filthy shirts, then the other. Having reached skin, he stroked my chest. 'No breasts,' he said. 'Pity. I guess you really are a kid”'(18).

The most significant consequence of this depiction of Wright is that it is his first impression and even if he garners some sympathy or earns redemption as the plot matures, this first portrayal is inescapable. It models the devastation of negative stereotypes and destructive misrepresentation. Unfortunately, the Black man and the black brute have been inextricably linked in a similar relationship. The trauma of this mischaracterization has followed the Black man since the caricature's inception, and as this first depiction of Wright follows him in the reader's cognition throughout this text, the Black man has been similarly evaluated and as a result disregarded, vilified, oppressed, profiled, misrepresented, and demonized. The black brute is what is tragically visible in the white gaze. Butler displays this vicious cycle with Wright; when and where racial stereotypes are activated, the potential of this traumatic cycle exists. The black brute and other destructive caricatures born of the plantation can trigger anxiety and hopelessness in those who suffer under the weight of their influence. Butler's 
manipulation of these and other stereotypes underscore their non-existence or falsity in an objective reality; analogous to this narrative, they too are products of science fiction.

Correspondingly, Butler juxtapositions Shori, the protagonist, against other black stock caricatures as she constructs this plantation space with a vivid cognizance of the plantation allusion that she is molding and the history that she is reimagining. As Shori reclaims her identity and separates further from her cave state, she is positioned in contrast to other stock caricatures who validated misguided notions about blackness. Shori claims an elevated position of power in her society via her burgeoning, authoritarian position as the slave master figure. With her identity and status as an Ina vampire on a quest of cultural renewal, it seems superfluous to consider Shori in this campaign to unbound Black agency from the confines of black caricaturizations; however, Butler engages Shori's bodily schema separately to contrast the multitudes of ontological narratives (again, a second narrative or metanarrative example of "writing back") written on and about the black body. In this awareness of what Fanon referred to as the black body's third-person consciousness, Butler seizes the opportunity to settle the "atmosphere of certain uncertainty" that often proceeds, and "certifies [the black body's] existence and threatens its dismemberment" (Bhabha XVI; Fanon 110-11). Shori is one element of this story and her Black female body is another, which carries its own separate messages in the spaces that Shori enters.

We can recall in the earlier chapters of the book, Shori emerges from the cave appearing to be the most oppressed figure imaginable; she is small, young, female, brown-skinned, homeless, and mentally incapacitated due to memory loss. Later, after her father reveals that she is an Ina vampire who has survived an attack that resulted in 
the demise of all of the members of her maternal family, we learn that she is also biracial, bi-species, polyamorous, and a social outcast in the opinions of the Ina who attempt repeatedly to murder her (62-4). These attributes would appear to further stigmatize her in U.S. society. However, as she rebuilds the framework of her community, we observe a figure of good repute emerge.

Symbolically, her community undoubtedly resembles a new-age slave plantation, which allows these caricature references to be viable. The Ina vampires bite their human symbionts and addict them to a lifetime commitment as the blood supply (63). Therefore, the bite or series of bites, from which there is no psychological return, become a brand. The humans discard their old identities and adopt new ones that prioritize their bond to their vampire masters, e.g. Wright is referred to as Wright Sym Shori in Ina society as opposed to Wright followed by his human surname. They are branded like cattle. In addition, the human symbionts do work and contribute to the maintenance of their Ina communities, which is reminiscent of slave labor (203). However, the symbionts are allowed to choose the level to which they contribute financially and the nature of the work they pursue. Also, comparably to the enslaved, symbionts function outside of the Ina legal system, for the case adjudication process necessitates Ina-level intuition capabilities (245-6). A human is bitten and essentially becomes the property of his or her Ina master.

Thus, Shori is a "master" figure, but her position of superiority does not impede her ability to extend compassion to her symbionts. Through her racially-unconscious Ina gaze, of which the readers are given a first-hand perspective, her symbionts are elevated from a historically-accurate depiction as enslaved people, who are often viewed with a 
one-dimensional, utilitarian level of significance, to relatable and complex threedimensional characters who project humanity. Principally, they are visible and their humanity is valued. As Shori's father, Iosif, reminds her, the symbionts are to be helped, reassured, and protected (73).

Specifically, in her capacity as an amorous slave holder, Shori is the antithesis of the asexual, mythic mammy caricature. The mammy caricature portrays a complete devotion to her white family for whom she endlessly toils (Bogle 9, 36). The Birth of a Nation depicts the mammy as a "faithful soul", or a utilitarian character who lives for the sole purpose of preserving her slave master's happy, content family life. She adores the white children she cares for and even reprimands them for playing with the uncivilized slave children. In reality, the mammy of the plantation household, whom the caricature was intended to represent, was as overworked as a field slave. Her work could persist past exhaustion beyond sun up to sun down. An actual house slave's insatiable desire to satisfy her white family was generally an act of survival or a disguised attempt to maintain some favor that could be activated at a later point, including and not limited to preventing the sale of members of her enslaved community. In addition, this mammy mythology would have us believe that house servants were treated as beloved members of the family; however, the mammy was frequently subjected to physical abuse and exploited as her slave master's concubine (Lewis 177). When mammies became too old, they were often abandoned with very little regard for their well-being. Frederick Douglass confirms this as his own grandmother's fate:

My grandmother, who was now very old, having outlived my old master and all his children, having seen the beginning and end of all of them, and her present owners finding she was of but little value, her frame already racked with the pains of old age, and complete helplessness fast stealing 
over her once active limbs, they took her to the woods, built her a little hut, put up a little mud-chimney, and then made her welcome to the privilege of supporting herself there in perfect loneliness; thus virtually turning her out to die! If my poor old grandmother now lives, she lives to suffer in utter loneliness; she lives to remember and mourn over the loss of children, the loss of grandchildren, and the loss of great-grandchildren (Douglass 47-8).

Shori, unlike the mammy character, is young, powerful, sexually-liberated, and a dominant member of her Ina society. She governs her symbionts and as an unspoken agreement in their relationship, they dutifully satisfy her requests. Shori has no need to appeal to anyone for assistance because everyone in her life is essentially under her venom-addicted spell. As is the case with all Ina, she can live for over six-hundred years and appear to be much younger in age by human standards (Butler 233). For this reason, Shori possesses longevity and prominence.

In addition, there is one other character in the text who seems to subtly contradict this mammy caricature. Celia is one of Shori's Black symbionts; we meet Celia for the first time in a kitchen on Iosif's property, so there is an immediate maid/mammy association (75-76). These references to her in a kitchen continue: "Celia was one of the two Black women in the kitchen. She had seemed friendly and interesting” (101). However, Celia is not a docile and submissive type. Initially, she resists being bound to Shori (110). Her frustrations were vocal and ostensible in display: "There was nothing but grief and anger in her expression" (101). She even ceased taking her iron supplements to make her blood supply less appealing to her new mistress, Shori (248-9). In addition, Celia took advantage of her freedom to choose her own sexual partners (247). Finally, Celia becomes a fierce protector of Shori's Ina clan once she determines that Shori is trustworthy. Shori observes, "My concentration was shattered by the sudden, deep, quick 
spitting of Celia's gun. She had shot a man who had come around the house from the front" (116). Celia is the multidimensional human being that the mammy caricature was designed to minimize and/or delegitimize.

Lastly, Shori also stood in contraction to the caricature of the pick-a-ninny. These caricatures were depicted as the wild, unsightly, care-free, whimsical, and animalistic children of the enslaved (Bogle 7). They emphasized the importance or the necessity of boundaries and restrictions, for they were destructive, free roamers who were not quite old enough to have material responsibilities on the slave plantation. They were crafted to castigate the offspring of the enslaved as unkempt, poorly behaved, mischievous, and uneducated. In the mythology often promoted with these caricatures, white children were warned by their mammies against fraternizing with pick-a-ninnies for fear of learning too many of their primitive behaviors. Shori may have shared a similar physical appearance and condition with this caricature early in the narrative, for she presents to Wright as filthy, bloody, and bruised (Butler 8-9). However, Shori is only child-like in size and stature. Her human symbionts determine her to be honest, trustworthy, responsible, articulate, intelligent, and authoritarian. She is also fiercely independent and ethical (162, 286-7). As a leader, she is ardently responsible for her human symbionts, and she cleverly defends her entire clan as their legal counsel.

Another character who challenges black stereotypes through his leadership and autonomy is Martin. As a Black man and symbiont of the Gordon Ina clan, Martin is such a unique character to the Fledgling storyline because he is so consciously aware of the Ina, including their shortcomings. He is very vocal about the aspects of his society that are very much oppressive and/or unjust $(203-4,254)$. He is allowed this authority and the 
power of vocalism and perspective even as a symbiont. Martin is a spokesman, honest, and as independent as any human being in the Ina society or elsewhere could ever aspire to be (245-6). He manages the entire Gordon community $(160,203)$. As a former history teacher, he is also well-educated (203).

Martin stands in stark contrast to the Uncle Tom stock caricature. An Uncle Tom is a pejorative term as well as a trope for a Black person who is perceived by other Blacks as obsequious or servile to white authority figures, or someone who seeks recognition from whites by way of unnecessary accommodation (Bloomquist 411). It is also used to denote an African American whose political views or allegiances are considered by critics to be detrimental to Blacks as a group. The 'Uncle Tom' caricature comes from the title character of Harriet Beecher Stowe's novel Uncle Tom's Cabin. The caricature is depicted as a loyal, faithful friend to both whites and Blacks (411). In contrast, Martin seems to relish his freedom within the Ina community. Even though Martin is still essentially a slave to his Ina masters, it is meaningful that he frequently crosses the line between "faithful soul" who happily manages the Ina community and authority/overseer who warns about inequities in this Ina society (Butler 203-4). He helps Shori realize the distinction in terms of psychological impact on a symbiont who is unwillingly bonded to his or her life versus one who is given the freedom to choose his or her life. He affirms that his life is his choice. He says:

Hayden [his Ina master] let me know what was going to happen if I stayed. He let me know while I could still leave, and I did leave. They didn't stop me. [His son] asked me to stay, but that made me run faster. The whole thing was too weird for me. Worse, I thought it sounded more like slavery than symbiosis. It scared the hell out of me. I stayed away for about ten months. I'd only been bitten three times in all, so I wasn't physically addicted. No pain, no sickness. But psychologically ... Well, I couldn't forget it. I wanted it like crazy. Hell, I thought I was crazy. All of 
a sudden, I lived in a world where vampires were real. I couldn't tell anyone about them. Hayden had seen to that. But I knew they were real. And I wanted to be with them. After a while, I quit my job, packed my things, put what I could in my car, gave the rest away, and drove here. God, it was a relief (204).

Martin is an enslaved character who is confident, well-informed, educated, and amiable. Martin serves his community, but he does not project self-hatred or servility. $\mathrm{He}$ is the antithesis of the Uncle Tom, for he revises the image of the enslaved.

\section{Fledgling's Ina Society as Homeland Model}

In addition to reimagining plantation spaces and notions of blackness in Fledgling, Butler actuates the imaginary and crafts a homeland prototype for African American people within this text. Literally from the ashes, Shori emerges like a phoenix and begins a quest to reclaim her home. Her cultural loss is damaging but not destructive or permanently disabling. She is able to refabricate her cultural identity and reestablish her individual Ina nation state. The danger of extinction drives her determination, revitalization, and reclaimed sense of belonging and community. She settles into an Ina

global network of shared power, and within this global community mutualistic symbiosis is the guiding principle. Shori reclaims and occupies a space that is intentionally unbounded within Ina society; she is powerful as a master Ina but oppressed as a consequence of her willing submission and humble obedience to her symbionts. Here, we observe how women often confront forms of oppression that maintain both structural and cultural elements. Shori, with all of her authority, still obliges a cultural standard and portrays a submissive type. Thus, postcolonial feminist theory engages intersections of analysis to expose the context and impact of domination systems on women. 
Shori is a self-proclaimed, gamete-producing female, who projects gender-fluidity in her refusal to acquiesce to socially-constructed gender norms or archetypes. With her symbionts, she maintains a gender profile that is variations of masculinity, femininity, and androgyny. Shori is loyal to her cluster of symbionts and her chosen Ina mating family, but among them she is polygamous. Her Ina mothers merged melanin-yielding, Human DNA and melanin-deficient, Ina DNA to create her, so she is both a hybrid species and bi-racial. Her territory is free of restrictive internal and external boundaries; freedom of choice is privileged for her symbionts and her. Shori's community embraces all varieties of sexual, occupational, cultural, and religious freedom. Her homeland culture is a practice of passing without hiding, for she, in full adoption of her Ina culture, rebukes destructive categorizations and operates in a space of liminality, a demonstration of her agency in her occupancy of loopholes instead of cultural standardization.

In addition, Ina culture is regulated by a majority who collectively assume an egalitarian social conscience that rejects unnecessary violence and social unrest. The attempted murders of Shori and both her paternal and maternal families trigger an Ina council of judgement, when she and the Gordon family (her mating partners) suspect that another Ina Family, the Silks, is responsible. Shori explains how this council is assembled to protect the interests of both the accuser and the accused:

'The rule of seven' had to be satisfied. Seven families with whom both the Silks and I share a common ancestor within seven generations of the oldest living Silk or Matthews had to agree to send representatives to Punta Nublada for a Council of Judgment that would judge the accusations that I and the Gordon family were making against the Silk family. Once that was done, Preston phoned the Silk family (197).

This vicious attack on Shori is the result of an Ina minority sentiment that resembles human racism, bigotry, and xenophobia combined. The Silk family “[did] not 
care for the genetic engineering experiments" that resulted in Shori's conception (197).

Even with the venomous nature of the crime that is alleged, the Ina justice system

remains steadfast in its allegiance to its reasonable, restorative practices. For example, the

Ina do not endorse prison deterrence or incapacitation as a viable method of punishment

(224). As Daniel Gordon explains, most of the crimes are settled with amputations (from

which they will fully recover) and in extremely rare cases executions (brutal crimes of an unforgivable nature):

Amputations and executions are also recorded. Amputations are punishments of pain, humiliation, and inconvenience. Limbs grow back completely in a few months, maybe a year or two for legs taken off at the hip. Of course, when it's done, people are given nothing for the pain, and the pain is terrible. It hurts for a long time, although once people are returned to their families, the families can help them with the pain. They're permitted to, not required to (224).

Additionally, the councils are formed of members of Ina elders who represent both the defendants and the plaintiffs in cases. Martin reveals to Shori that elders are required for the council because they "are so good at spotting truth and untangling lies.

They use their senses, their intelligence, and their long experience" (245). As Daniel Gordon elucidates, the Ina are vigilant of not replicating the shortcomings of the American justice system:

We can see that our Councils aren't games like the trials humans have. The work of a Council of Judgment is to learn the truth and then decide what to do about it within our law. It isn't about following laws so strictly that the guilty go unpunished or the innocent are made to suffer. It isn't about protecting everyone's rights. It's about finding the truth, period, and then deciding what to do about it... "Human trials are often games to see which lawyer is best able to use the law, the jury's beliefs and prejudices, and his own theatrical ability to win. There's talk about justice, of course, but if a murderer has a good lawyer, he might go unpunished even though his guilt is obvious. If an innocent person has a bad lawyer, he might lose and pay with his life or his freedom even though people can see that he's innocent. Our judges are our elders, people who have lived three, four, 
five centuries. They sense truth more effectively than people my age, although I can sense it, too (220).

The Ina appreciate that an unfair justice system is also a faulty one, and there should be no controversies and/or obstructions in achieving fairness in a system of justice. Furthermore, the Ina construct a homeland that could adequately serve African Americans communities, for it observes unfairness in its justice system as a rare, not systematic failure. In addition, equality, equity, and inclusion serve as its cultural hallmarks. Fledgling, with its Afro-futuristic, epistemological foundations is not conceptualizing a homeland for Black people that is perfect or free of shortcomings. Intrinsic to human nature is the propensity to err.

What Afrofuturism and literature of this genre, such as Parable of the Sower and Fledgling, offer is an imaginary path forward, one that champions pragmatism and restoration, not historical revision. This literature offers an approach to negotiating and realizing safe space for our communities. America as homeland for Black people is a possibility, and Afrofuturism is equipped to articulate the healing vision of this reality. 


\section{CHAPTER VI}

\section{CONCLUSION}

"Oh, the porpoises scream

And the rabbits hop

And the beavers chew trees when they need 'em

But Patty and Mickey and Liza Sue-

Who says they can't handle their freedom?"

-Toni Morrison, The Big Box

My grandmother, who served as an inspiration for this research, graduated from the Hampton Institute in Virginia in 1950. She spent her formative years in Clearwater, Florida but relocated to New York City after college, where she worked as a social worker and elementary school teacher. Outside of the home in Harlem, she was very active in her local community. Later in her life, during her summer visits with us in Georgia, where my parents resettled, I remember her as a woman who was very selective about how she moved outside of our home. She would take us to the museum, theatre, school supply stores, or on excursions to visit family members in Washington, D.C. or New York City, but these trips were infrequent. There were only a few places that were appealing (the word I would use from my limited perspective then) enough to draw her from our house. Progressing the educational opportunities of her grandchildren was worth her time and now I assume the risk. Grandma was most comfortable at home, and she would position herself in a central location, usually at the dining room table, where she could see everything and everyone.

I was too young then to consider the roots of her resistance to interacting with the area in which we lived. She understood our community in Georgia in a respect that I did 
not, and I imagine she considered the possibility of confronting lingering manifestations of a traumatic past in ways that I could not imagine, until recently. I do not know how often or how horrifyingly vivid these considerations were for her, but they happened. If I could join my grandmother at that dining room table today, I would hold her hand and attempt a dialogue about this trauma; although she guarded her pain and shielded us from dark matters, I would still try. We could discuss how commonplace the seemingly routine murders of Black people by policing forces feel from her perspective. I would imagine to her it would all seem very American. Present day, I am left wondering how I could help us both move to a space of healing. How do we follow Baby Suggs' counsel to Sethe? How do we lay down our swords and shields in order to embrace this home, here in the divided states of America?

With regard to the subject of healing and reconciliation, many activists and intellectuals have offered suggestions as to how the United States can atone for its legalized atrocities against Black Americans; they often involve public acknowledgement and/or reparations. To some extent, these solutions may help the redress the racial wealth gap and the egregious injustices associated with American slavery.

In my estimation, the most powerful means of reclaiming our time or getting out of the spatial box of oppression that I have endeavored to constructively highlight in this research is to reclaim space, which combines both. Reclaiming space functions with the knowledge that spatial design is tactical. Space is an accessory in the oppression of others. A central assumption of this research is that spaces can hold trauma, and for African Americans this trauma is tied to the primal wound of slavery. We have considered this trauma's roots, its transformations, and its intransience. This research is 
my own contribution to the Toni Morrison's "bench by the road" campaign. My grandmother and so many others who suffer as she did deserve a public space to grieve as Ngũgĩ asserted in Something Torn and New, "the deaths [that were never properly mourned] that occurred in... slavery and colonization" (59).

This campaign of healing began with an exploration of various theories related to space which offer greater attention to the implications of actual geographical space. We consider the groundbreaking work of Henri Lefebvre in The Production of Space, where he suggests that space is a product of people and can be imbued with meaning. The meaning at focus in this research is that which is coded in trauma; thus, trauma theory has a needed presence in this work. Trauma theory is about adaption and promoting healing in the aftermath of trauma and suffering, and it works to dissect the location of trauma, which is congruent with this research's aims of locating trauma in space.

From there we placed the work of identifying trauma in spaces within the framework of postcolonial theory and considered the historical practice of its theorists in revealing modern traumatic cultural formations and impacts of slavery and colonialism. Also, credit is given to postcolonial authors for affecting the ways that their readers can come to understand spaces and recognize sites of conflict. With respect to postcolonial theory, we state a case for viewing as well as reimagining spaces in the postcolonial world to highlight trauma and tensions that challenge the potential for those who reside in colonized spaces to achieve productive lived experiences. A central consideration of this effort is the socio-cultural ramifications of racialized and gendered space.

For this reason, this investigation goes directly to the site of encounter or where Black trauma begins in this country: slavery. We examine the slave narrative's 
connection to spatial theory; as postcolonial literature, slave narratives convey the hegemonic spatial dynamics at play in their societies. These narratives demonstrate how social space is used as a mechanism of oppression and control. Authors of slave narratives substantiate its terrors and refute denials associated with the role of this institution in shaping the lives of the enslaved and their descendants. For example, in Frederick Douglass' narrative, his remarkable triumph over the psychological indoctrination weaponized by this institution is often highlighted, but Douglass also utilizes spatial analysis in his work to unshroud the physical boundaries and structures associated with the regulatory processes of enslavement. Additionally, Solomon Northup's narrative reveals his unwavering emphasis on the secret, structural network that enabled his kidnapping; this hidden network contributed to a tremendous amount of social anxiety for freemen and women. Northrup openly questions the possibility of the United States as a home for Black people and asserts a clear ambition for one that is safe for members of his community.

Harriett Jacobs' work is also considered in this study, as a foremother in spatial theory, devoted theorist, and critic of gender-induced trauma; her influential slave narrative utilizes subversive methods of empowerment and operates as a witness to the misrepresentation, discrimination, and oppression of Black people, Black women especially, in order to directly participate in a call for the construction of safe spaces for them. Through their collective work, we can see clear connections that link slave patrollers to police officers and stand-your-ground empowered neighborhood watchmen, and slave pens to detainment cages that house immigrant children today. It is the 
American tradition of racialization that has determined so many from without and led to the expanse of traumatic social space.

Expanding on this analysis of the implications of blackness, we consider the postbellum visibility of it, which varies within the white gaze. Additionally, we attempt to contextualize this experience and consider how the epidemiological transfer of inferiority to the black body persisted following the Civil War. In postbellum society, the coding of the black body triggered new impositions and spatial designations; one cultural practice discussed by many authors of this time period was racial passing, for it challenged socially designated space and class arrangements. Passing was a means of circumventing traumas and social stigmas as well. In general, these authors of the New Negro era and Harlem Renaissance movement offered insights into the newly reconstructed and traumatizing spaces of their societies; their bodies were the most contested spaces, and they called attention to the effects of being designated Black by the ideologies and practices of white supremacy.

\section{In The House behind the Cedars, Charles Chesnutt explores vague racial} definitions and exhibits how amorphous racial status can be. This work also examines how definitively the presence of blackness or a black body can create specific experiences and spaces within social practice, often ones of a traumatic and restrictive nature. In Passing, Nella Larsen utilizes Black female characters who resist traditional norms with the aim of identifying more comfortable spaces for them. This is also a story of a search for home, which is ultimately a space of security, something that continued to elude African Americans following Emancipation. In Black No More, George Schuyler creates one of the most direct assessments of the racialized body produced during the 
Harlem Renaissance. Black No More explores various sentiments about blackness and considers the significant burden of the black body as a cultural signifier and design construct of the dominant culture. He also explores the socialization of racial inferiority and superiority norms during this time period. This era was significant in underscoring the cultural traumas that persisted in the Black experience.

The New Negro era and Harlem Renaissance movement authors paved the way for neo-slave narratives, written by the descendants of the enslaved. These narratives depict the peculiar institution's legacy, including its immediate and lingering ramifications in various modern spatial contexts; slavery is a character of enormous presence in all of these stories. These narratives draw inspiration from actual slave narratives and are postcolonial in that they expose lingering manifestations of slavery and other colonial institutions. In the interests of my research, they also probe and substantiate the effects of inherited slave-era traumas in contemporary spaces. Although these are works of fiction, they present an effective investigation of the literal and figurative ghosts of slavery that persist as forms of vicarious traumatization to the extent that they haunt the realities of those with second/third-hand and/or little to no personal experience of the institution other than their corporal or ancestral ties. This is especially true of the neo-slave narratives featured here.

With Toni Morrison's Beloved, we study her use of "rememory", or the element of memory that functions as a form of vicarious traumatization. It mirrors the space of Black consciousness and demonstrates how movement through the world in black bodies is often complicated by physical and/or psychological constraints, which are indicative of confrontations with trauma of the past and/or ideologies conceived of a traumatic past. 
Toni Morrison forces readers to reevaluate the space of enslavement by witnessing its expansion into the contemporary landscape and its continued imposition within the Black experience. With Octavia Butler's Kindred, we explore the spatial disruption of homelessness and/or [homeland]-lessness in the African American community by engaging in a symbolic conversation about the trauma and fluidity of space interrupted by a persistent regeneration of ancestral/historical memory. The characters within the text are responding to slavery in order to challenge its public narrative, and they force us to examine how much protection and freedom is available to specific cultural groups within the socially constructed landscape of the U.S.

Other lingering traumas of enslavement that neo-slave narratives consider are the psychological effects of walking through spatial and historical constructs or remnants of the eighteenth century. In Ernest Gaines' A Lesson before Dying, we deploy Dr. Joy DeGruy definitions of post-traumatic slave syndrome through the main characters of this text. By examining the main characters' lived experiences, we see how this syndrome emanates from the construction of traumatic space in the U.S. Jefferson and Grant Wiggins both share the interconnectedness of post-traumatic slave syndrome through their shared traumatic sufferings obtained as a cultural inheritance. In addition, they suffer the simultaneous traumas of possessing stigmatized black bodies and of dwelling in a haunted space of enslavement — a former plantation community in 1940's Louisiana. These neo-slave narratives expose the roots of this nation's pathogenic institutional and societal structures. Recognizing these truths locates us on the path to healing. The next phase in this process is envisioning new spaces and/or reformulating old ones. 
For direction in this endeavor, we turned to the imaginary and the literary field of Afrofuturism. Conceived of the wondrous possibility of what is unforeseen, the imagination creates a vision or manifestation of a world that could one day be a reality. Afro-futristic literature activates the imaginary for the cause of envisioning Black prosperity. Relatedly, we consider the works of a foremother of Afrofuturism, who crafted visions for the future where Black people could claim freedom, homeland space, and healing. In Fledgling and Parable of the Sower, Octavia Butler presents models of societal space and/or psychological space that offer equanimity and progressive visions of blackness and/or Black identity. She suggests that healing is not a product of historical revision, but it involves learning from the past and fashioning new societal spaces that embrace historical truth and endeavor to improve on past shortcomings.

Afrofuturism allows us the opportunity to consider and imagine infinite future possibilities in which Black people thrive, but I would like to suggest other areas where future critical-theoretical research could help expand the focus of this project to even greater achievements. In this project, I have attempted to excavate manifestations of trauma in social space; my study utilized works of fiction and slave narratives as my vehicle of cultural exploration and excluded other forms of literature and communicative art forms. Additionally, I did not include literature written in the last ten years, for I was most concerned with charting the roots of spatial trauma and explaining the methods and tactics of its entrapment.

Nevertheless, my work here could be expanded to include more recent narratives of fiction, memoirs, autobiographical texts, spoken word poetry, social media posts and podcasts, for there are postcolonial voices that are employing these various mediums to 
articulate the traumatic spaces in which we currently live. More focus can be given to female voices by expanding the current research on how gender complicates and intensifies black claustrophobia.

In addition, an old problem with long historical roots that continues to be addressed in a wide variety of literary spaces is discriminatory racial profiling by law enforcement. These rampant abuses of power are frequently suffered by minorities and within minority communities. Postcolonial authors have contributed a considerable amount of labor compiling the experiences of those who are profiled, and the resulting psychological damages of existing while Black in America. I have added my own work of short fiction that strives to highlight one of these experiences in particular in the appendix section of this project.

Another topic connected to this campaign that has garnered national attention, that could be included in future research projects, is the removal of relics of a traumatic past that exist in public, non-museum exhibit space. These relics include confederate flags, statues of confederate soldiers, and other emblems of hate. In addition to the historical practices of redlining, Jim Crow segregation, and racial housing covenants, these relics have served to demarcate Black and white spaces, which continue to contribute to the persistence of spatial trauma. Furthermore, as I demonstrate in this research, their purpose, which is equally true of the overwhelming trend of murders of Black men and women by police officers, is to reinforce the boundaries of white supremacy in the spatial construction of this nation.

Along these lines of spatial recovery, it might also be useful to consider the work of Afrocentric and Afro-futuristic artists; art installations are popping up all over the 
country with the intention of revealing historical truths and allowing Black people and their voices to take up space. For example, here in Lexington, Kentucky, the I Was Here $^{15}$ public art project was commissioned in 2018. It features portrait installations of African Americans in public spaces that were once connected to enslavement. These pieces help to educate the community, uncloak slave legacies, and memorialize the victims of enslavement in public space. Unlike Confederate monuments, which commemorate white supremacy and celebrate racial division, these installations educate by negating a revisionist history of this country in which Confederate soldiers are somehow cast as patriots. These Confederate statues, emblems, etc. are monumental lies and exhibitions in historical erasure. Additionally, the Equal Justice Initiative, as a component of its community remembrance project ${ }^{16}$, memorializes sites of public lynching throughout the nation to heal and inspire meaningful conversations about justice and racial conflict. These lynching memorials are notable efforts to reclaim space.

Subsequently, future research projects could be useful in other global sites of colonial conflict. I remember studying in South Africa in the summer of 2002, and my student housing was at the Break Water Lodge, which in its history had been a prison during the long years of Apartheid. I was deeply affected by the traumatizing, spiritual energy of that space; I can only imagine what lingers in other spaces connected to the brutal institution of Apartheid. Furthermore, throughout the continent there are useful opportunities to explore the dilemmas of reconstructed postcolonial/post-occupation spaces. Works by authors, such as Ngũgĩ Wa Thiong'o (Grain of Wheat), Chris Abani

\footnotetext{
${ }^{15}$ The I Was Here Website: https://www.codaworx.com/projects/i-was-here-2/

${ }^{16}$ The Equal Justice Initiative Community Remembrance Project: https://eji.org/projects/communityremembrance-project/
} 
(Graceland), Zakes Mda (Ways of Dying), and Peter Abrahams (Mine Boy) provide a fictional landscape for spatial analysis in various African social contexts. In addition, themes of spatiality and globalization are concerns evident in the works of Caribbean authors as well. They face heightened space-related tensions as island communities grow deeply concerned with increased global environmental degradation and climate change. Postcolonial authors in the Caribbean address these issues and concerns as well as effect change by promoting environmental preservation and protection through the lens of spatiality.

When I initially began this research my principal interest was in validating environmental spaces that are often disregarded in the capitalistic drive of globalization, which has helped to expand a new branch of postcolonialism called Ecocriticism. Ecocriticism is the analysis of texts in order to illustrate environmental concerns, and it is also an examination of the ways that literature codes nature. According to Bryon Caminero-Santangelo and Garth A. Myers, ecocriticism merges "a sense of political commitment, interdisciplinary studies, and the interrogation of capitalist development and progress" (3). It forces postcolonial theory to pay more attention to environmental factors through an increased awareness of imperial contexts (4).

Ecocriticism plays an important role in the battle against hegemonic forces and neocolonialism in the postcolonial world. It should be noted that environmentalism, or the concern for and/or action aimed at environmental protection, and postcolonialism have been perceived at odds on occasion because environmentalism often prioritizes habitats over people. This tendency can be accompanied with antipathy for new settlers, immigrants, globalization, and cosmopolitan development. However, ecocriticism would 
yield many research opportunities pertaining to spatial conflict, expansion-related tensions, and trauma analysis; as a result, this study could trigger healthy community dialogues, in which people and the spaces they occupy both maintain value.

Finally, I want to emphasize that this work is not about erasure; we cannot change the past. This is a struggle for expanded recognition, a challenge to the collective memory, and a projection of healing. In Beloved when Denver stands on the porch in the sun and struggles to leave 124, her grandmother, Baby Suggs, speaks to her from the beyond and says:

You mean I never told you nothing about Carolina? About your daddy? You don't remember nothing about how come I walk the way I do and about your mother's feet, not to speak of her back? I never told you all that? Is that why you can't walk down the steps? My Jesus my (Morrison 287-88).

Denver affirms her own fears: "But you said there was no defense" (288). And Baby Suggs says, "There ain't" (288). Then Denver wonders: "Then what do I do?" (288). Her grandmother responds "Know it, and go on out the yard. Go on" (288). Denver goes on and confronts her fear of the white world to save her mother. This project is about figuring out how to go on. Like Denver, I am trying to heed my own grandmother's beacon to go on.

Denver and I are both armed with the knowledge of our experiences and accept how differently we in black bodies must walk through this world. That understanding and recognition is the point. We have to know our history and go on. Arguably, the United States can never be a homeland for Black people. As Chris Rock so brilliantly stated recently "The beauty of being Black is the future is always better. Tomorrow is always better because there are no good old days" (Rock). As Black Americans, our pasts are tied to too much trauma, but there are still ways to make this feel like a home, which is 
essentially a place where one feels welcome. Again, the goal is not to erase the past but to learn how to cope with it; with restorative methods more members of the world community can embrace truth and find healing.

Ultimately, colonial histories will remain, but through literature and an exploration of specific themes, postcolonial theorists help to contest these records. New voices can emerge bringing with them a decentering of colonial norms. Although much of this analysis is forward-looking and forward-thinking, as I am writing I recognize the significance of the written word in the now. These pages and the spaces that they proffer and unveil are healing, validating, and liberating. There is comfort in knowing that the act of writing, the written product, and the reader's space provide provision and a consistent, easily-accessible means to mitigating Black cultural trauma. 


\section{REFERENCES}

Ali Akbar Moghaddasi Rostami, and Farid Parvaneh. "The Notion of Unhomeliness in the Pickup: Homi Bhabha Revisited." Advances in Language and Literary Studies, vol. 7, no. 1, 2016, pp. 157-160.

Andermahr, Sonya, editor. Decolonizing Trauma Studies: Trauma and Postcolonialism. MDPI, 2016.

Anderson, Benedict R. Imagined Communities: Reflections on the Origin and Spread of Nationalism, Paw Prints, 2016.

Andrews, William L, and Henry Louis Gates. The Civitas Anthology of African American Slave Narratives. Civitas/Counterpoint, 2000.

Appadurai, Arjun. "Disjunction and Difference." Post-Colonial Studies Reader, edited by Bill Ashcroft, Gareth Griffiths, and Helen Tiffin. Routledge, 2006, pp. 468-472.

Ashcroft, Bill, et al. The Empire Writes Back: Theory and Practice in Post-Colonial Literatures. 2nd ed., Routledge, 2005.

Ashcroft, Bill, et al. The Post-Colonial Studies Reader. 2nd ed., Routledge, 2006.

Askeland, Lori. "Remodeling the Model Home in Uncle Tom's Cabin and Beloved." American Literature, vol. 64, no. 4, 1992, pp. 785-805.

Baldwin, James. "The Creative Process.” Collected Essays. Library of America, 1998, pp. 669-672.

Bank, Steven A. "Anti-Miscegenation Laws and the Dilemma of Symmetry: The Understanding of Equality in the Civil Rights Act of 1875." The University of Chicago Law School Roundtable, vol. 2, no. 1, 2015.

Barry, Peter. Beginning Theory: An Introduction to Literary and Cultural Theory. 3rd ed., Manchester University Press, 2009.

Barthes, Roland, and Stephen Heath. Image, Music, Text. Harper Collins, 1977.

Bast, Florian. "'I Won't Always Ask': Complicating Agency in Octavia Butler's Fledgling." Current Objectives of Postgraduate American Studies, Vol. 11, 2010, https://copas.uni-regensburg.de/article/view/128/152. Accessed 11 Sept. 2020. 
"BBC Culture Writer Chimamanda Ngozi Adichie discusses her career." YouTube, uploaded by Today News CNN, 24 December 2013, www.youtube.com/watch?v=NHE_CQOAE98

Bentham, Jeremy. The Panopticon Writings, edited by Božovič Miran. 2nd ed., Verso, 2011 .

Bernasconi, Robert. "Crossed Lines in the Racialization Process: Race as a Border Concept." Research in Phenomenology, vol. 42, no. 2, 2012, pp. 206-228.

Bertens, Johannes Willem. Literary Theory: The Basics. Routledge, 2001.

Bhabha, Homi. "The World and the Home." Social Text, vol. 31-32, no. 31-32, 1992, pp. 141-153.

--- . Forward. Black Skin, White Masks. By Fanon, Frantz, and Charles Lam Markmann. Pluto Press, 1986.

Bloomquist, Jennifer. "The Minstrel Legacy: African American English and the Historical Construction of 'Black' Identities in Entertainment." Journal of African American Studies, vol. 19, no. 4, 2015, pp. 410-425., doi:10.1007/s12111-0159313-1.

Bogle, Donald. Toms, Coons, Mulattoes, Mammies, and Bucks: An Interpretive History of Blacks in American Films. 4th ed., Continuum, 2000.

Browne, Simone. Dark Matters: On the Surveillance of Blackness. Duke University Press, 2015.

Burnham, Michelle. "Loopholes of Resistance: Harriet Jacobs' Slave Narrative and the Critique of Agency in Foucault." Incidents in the Life of a Slave Girl: Contexts, Criticism, edited by Nellie Y. McKay and Frances S. Foster. W.W. Norton, 2001, pp. 278-294.

Butler, Octavia E. Parable of the Sower. A Four Walls Eight Windows 1st ed., Four Walls Eight Windows, 1993.

--- Fledgling: Novel. 1st ed., Seven Stories Press, 2005.

--- Butler, Octavia E. Kindred. Beacon Press, 2013.

Caminero-Santangelo, Byron, and Garth A. Myers. "Introduction." Environment at the Margins: Literary and Environmental Studies in Africa, edited by Bryon Caminero-Santangelo and Garth A. Myers. Ohio University Press, 2011.

Capers, I. Bennett. "Afrofuturism, Critical Race Theory, and Policing in the Year 
2044." New York University Law Review, vol. 94, no. 1, 2019.

Carby, Hazel. "Postcolonial Translations." Ethnic and Racial Studies, vol. 30, no. 2, 2007, pp. 213-234., doi:10.1080/01419870601143893.

Carew, Jan R. "Columbus and the Origins of Racism in the Americas." Fulcrums of Change. Africa World Press, 1988.

Carluccio, Dana. "The Evolutionary Invention of Race: W. E. B. Du Bois's 'Conservation' of Race and George Schuyler's Black No More.” Vol. 55, no. 4, 2009, pp. 510-546., doi: 10.1215/0041462X-2009-1004.

Carroll, Robert P, and Stephen Prickett. The Bible: Authorized King James Version. Oxford University Press, 1997.

Chesnutt, Charles W. The House behind the Cedars. Penguin Books, 1993.

Conway, Hazel, and Rowan Roenisch. Understanding Architecture: An Introduction to Architecture and Architectural History. Routledge, 2005.

Crampton, Jeremy W, and Stuart Elden. Space, Knowledge and Power: Foucault and Geography. Farnham, Surrey, Ashgate, 2014, p. 45.

Crisman, Phoebe. "Form." Whole Building Design Guide, https://www.wbdg.org/resources/form. Accessed 8 July 2019.

Culler, Jonathan D. Literary Theory: A Very Short Introduction. 2nd ed., Oxford University Press, 2011.

DeGruy, Joy. Post Traumatic Slave Syndrome: America's Legacy of Enduring Injury and Healing. Amistad, 2017.

Dery, Mark. Flame Wars: The Discourse of Cyberculture. Duke University Press, 1994.

DiCenso, James J. The Other Freud: Religion, Culture and Psychoanalysis. Routledge, 1999.

Dirks, Tim. "The 100 Greatest Films: The Birth of a Nation." AMC Filmsite. AMC Networks, Inc. Accessed June 9, 2020. https://www.filmsite.org/birt3.html

Douglass, Frederick. Autobiographies: Narrative of the Life of Frederick Douglass, an American Slave; My Bondage and My Freedom; Life and Times of Frederick Douglass. Edited by Henry Louis Gates, Literary Classics of the United States, 1994. 
---.Narrative of the Life of Frederick Douglass. The Civitas Anthology of African American Slave Narratives, edited by William L. Andrews and Henry Louis Gates. Civitas/Counterpoint, 2000, pp. 105-193.

Douglass, Frederick, and Benjamin Quarles. Narrative of the Life of Frederick Douglass: An American Slave. Belknap Press, 1960.

Du Bois, W.E.B. “The Talented Tenth.” The Negro Problem: A Series of Articles by Representative American Negroes of To-Day. Arno Press, 1969.

---. The World and Africa. Oxford University Press, 2007.

Durrant, Sam. Postcolonial Narrative and the Work of Mourning: J.M. Coetzee, Wilson Harris, and Toni Morrison. State University of New York Press, 2004.

Dutta, Suchismita. "Indelible Race Memories and Subliminal Epigenetics in Octavia Butler's Kindred." Vol. 21, no. 21, 2018, pp. 86-103.

Escott, Paul D. Slavery Remembered: A Record of Twentieth-Century Slave Narratives. University of North Carolina Press, 1979.

Equal Justice Initiative. Lynching in America: Confronting the Legacy of Racial Terror. Equal Justice Initiative, 2015.

Eyerman, Ron. Cultural Trauma: Slavery and the Formation of African American Identity. Cambridge University Press, 2008.

Fanon, Frantz. Black Skin, White Masks. Grove Press, 1967.

Fanon, Frantz, and Charles Lam Markmann. Black Skin, White Masks. Pluto Press, 1986.

Fabre Geneviève, and Robert G O'Meally. History and Memory in African-American Culture. Oxford University Press, 1994.

Ferguson, Jeffrey B. The Sage of Sugar Hill: George S. Schuyler and the Harlem Renaissance. Yale University Press, 2005.

Ferguson, SallyAnn H., editor. Charles Chesnutt Selected Writing. Houghton Mifflin, 2001.

Fogelson, Robert M. Bourgeois Nightmares: Suburbia, 1870-1930. Yale University Press, 2007.

Frankel, Noralee. "Breaking the Chains: 1860-1880." To Make Our World Anew: A History of African Americans to 1880, edited by Robin D. G. Kelley and Earl Lewis, Oxford University Press, 2000, pp. 227-280. 
Franklin, John Hope. The Color Line : Legacy for the Twenty-First Century. University of Missouri Press, 1993. EBSCOhost, search.ebscohost.com/login.aspx $?$ direct $=$ true $\& d b=$ nlebk $\& A N=49562 \&$ site=ehostlive.

Gaines, Ernest J. A Lesson Before Dying. Alfred A. Knopf, 1993.

---“Writing a Lesson Before Dying.” Southern Review, vol. 41, no. 4, 2005.

Gates, Henry Louis, et al. The Norton Anthology of African American Literature. 2nd ed., W.W. Norton, 2004.

Gentry, James Theodore. "The Panopticon Revisited: The Problem of Monitoring Private Prisons." The Yale Law Journal, vol. 96, no. 2, 1986, pp. 353-375.

Gibson, Daniel B. Introduction. The House behind the Cedars, by Gibson. Penguin Books, 1993, pp. VII-XXIII.

Gikandi, Simon. "Globalization and Claims of Postcoloniality." South Atlantic Quarterly. Duke University Press, vol. 100, no. 3, 2004, pp. 628-658.

Ghansah, Rachel Kaadzi. "A Most American Terrorist: The Making Of Dylann Roof". GQ, 21 Aug. 2017, pp. 11-21.

Gooden, Mario. Dark Space: Architecture, Representation, Black Identity. Columbia Books on Architecture and the City, 2016.

Greenblatt, Stephen. "Resonance and Wonder." Bulletin of the American Academy of Arts and Sciences, vol. 43, no. 4, 1990, pp. 11-34.

Griffith, D. W, et al., directors. The Birth of a Nation. Madacy Entertainment Group, 2001.

Griffler, Keith. "The Runaway.” National Underground Railroad Freedom Center (Cincinnati, Ohio). Unchained Memories: Readings from the Slave Narratives. 1st ed., Bulfinch Press, 2002.

Hai, Ambreen. Making Words Matter: The Agency of Colonial and Postcolonial Literature. Ohio University Press, 2009.

Harlow, Barbara. Resistance Literature. Methuen, 1987.

Haase, Felix. "Within the Circle': Space and Surveillance in Frederick Douglass's 
Narrative of the Life of Frederick Douglass, an American Slave." Aspeers:

Emerging Voices in American Studies, vol. 8, 2015, pp. 71-88, www.aspeers.com/2015/haase. Accessed 20 Nov 2019.

Harris, Cheryl I. "Whiteness as Property." Harvard Law Review, vol. 106, no. 8, 1993, pp. 1707-1791.

Higgs, Robert. The Transformation of the American Economy, 1865-1914: An Essay in Interpretation. Ludwig Von Mises Institute, 2011.

Hutchinson, George. In Search of Nella Larsen: A Biography of the Color Line. Belknap Press of Harvard University Press, 2006.

Hughes, Langston. "The Negro Artist and the Racial Mountain." The Norton Anthology of African American Literature, edited by Henry Louis Gates and Nellie Y. McKay, W.W. Norton, 1996, pp. 1267-1271.

Iggers, Georg G. "A Search for a Post-Postmodern Theory of History." History and Theory, vol. 48, no. 1, 2009, pp. 122-128., doi:10.1111/j.14682303.2009.00491.x.

Jacobs, Harriet A. Incidents in the Life of a Slave Girl. Oxford University Press, 1988.

---. Incidents in the Life of a Slave Girl. Incidents in the Life of a Slave Girl:

Contexts, Criticism, edited by Nellie Y. McKay and Frances S. Foster. W.W. Norton, 2001, pp. 1-158.

Jan, Tracy. "Analysis | Redlining Was Banned 50 Years Ago. It's Still Hurting Minorities Today." The Washington Post, WP Company, 27 Apr. 2019, https://www.washingtonpost.com/news/wonk/wp/2018/03/28/redlining-wasbanned-50-years-ago-its-still-hurting-minorities-today/. Accessed 6 Jul. 2020.

Jos, Philip H. "Fear and the Spiritual Realism of Octavia Butler's Earthseed." Utopian Studies, vol. 23, no. 2, 2012, pp. 408-429.

Kibler, M. Alison. Censoring Racial Ridicule: Irish, Jewish, and African American Struggles Over Race and Representation, 1890-1930. Univ. of North Carolina Press, 2015.

King Jr, Martin Luther. "Letter from Birmingham Jail.” Atlantic, 2018 Mlk Special Edition, P74, 2018.

Knutson L. "Monster Studies: Liminality, Home Spaces, and Ina Vampires in Octavia E. Butler's Fledgling." University of Toronto Quarterly, vol. 87, no. 1, 2018, pp. 214-233., doi:10.3138/utq.87.1.214. 
Lamothe, Daphne Mary. Inventing the New Negro: Narrative, Culture, and Ethnography. University of Pennsylvania Press, 2008.

Larsen, Nella, and Charles R Larson. The Complete Fiction of Nella Larsen. Anchor Books, 2001.

Lee, Dennis. "Writing in Colonial Space." Post-Colonial Studies Reader, edited by Bill Ashcroft, Gareth Griffiths, and Helen Tiffin. Routledge, 2006, pp. 347-350.

Levine, Robert S, et al. The Slave Narrative and the Revolutionary Tradition of American Autobiography, 2007, pp. 99-114.

Lefebvre, Henri, and Donald Nicholson-Smith. The Production of Space. Blackwell, 2009.

Lefebvre, Henri. The Production of Space. Blackwell, 1991.

Lewis, David Levering, editor. The Portable Harlem Renaissance Reader. Penguin Books, 1995.

Lewis, Earl, and Robin D. G Kelley. To Make Our World Anew: A History of African Americans to 1880. Oxford University Press, 2000.

Locke, Alain. "Enter the New Negro" Survey Graphic, Mar. 1925, http://nationalhumanitiescenter.org/pds/maai3/migrations/text8/lockenewnegro.pd f. Accessed 13 Jul 2020.

Madsen, Deborah L. Post-Colonial Literatures: Expanding the Canon. Pluto, 1999.

Mambrol, Nasrullah. "Pluralistic Trauma Studies: A New Model." Literary and Criticism, 19 Dec. 2018, https://literariness.org/2018/12/19/trauma-studies/. Accessed 25 March 2020.

---. "Trauma Studies." Literary and Criticism, 19 Dec. 2018, https://literariness.org/2018/12/19/trauma-studies/. Accessed 25 March 2020.

McKay, Nellie Y, and Frances S. Foster, editors. "Introduction." Incidents in the Life of a Slave Girl: Contexts, Criticism, edited by Nellie Y. McKay and Frances S. Foster. W.W. Norton, 2001, pp. ix-xxiii.

Meskell, Lynn, and Robert W Preucel. "Places.” A Companion to Social Archaeology. Blackwell Pub, 2004.

Miller, Orloff. "Living Conditions." National Underground Railroad Freedom Center (Cincinnati, Ohio). Unchained Memories: Readings from the Slave Narratives. 1st ed., Bulfinch Press, 2002. 
Morris, S.M. "Black Girls Are from the Future: Afrofuturist Feminism in Octavia E. Butler's Fledgling." Women's Studies Quarterly, vol. 40, no. 3/4, 2012, pp. 146166.

Morrison, Toni. Beloved. Vintage, 2004.

---. Playing in the Dark: Whiteness and the Literary Imagination. Harvard University Press, 1992.

Morrison, Toni, and Robert Richardson. "A Bench by the Road." [Unitarian Universalist] World 3.1 (Jan.-Feb. 1989): 4.

Moylan, Tom. Scraps of the Untainted Sky: Science Fiction, Utopia, Dystopia. Westview Press, 2000.

Ngũgĩ Wa Thiong’o. Barrel of a Pen: Resistance to Repression in Neo-Colonial Kenya. Africa World Press, 1983.

---. Something Torn and Something New: An African Renaissance. Basic Civitas Books, 2009.

---. "Writing Against Neo-Colonialism." African Literature: An Anthology of Criticism and Theory, edited by Tejumola Olaniyan and Ato Quayson. Blackwell Publishing, 2007, pp. 157-164.

Nicol, Bran. The Cambridge Introduction to Postmodern Fiction. Cambridge University Press, 2009.

North, Joseph. Literary Criticism: A Concise Political History. Harvard University Press, 2017.

Northup, Solomon. Twelve Years a Slave. Dover Publications, 1970.

Omi, Michael, and Howard Winant. Racial Formation in the United States. 3rd ed., Routledge/Taylor \& Francis Group, 2015.

Patton, Michael Quinn. Qualitative Research \& Evaluation Methods: Integrating Theory And Practice. 4th ed., SAGE Publications, 2015.

Phillips, Jerry. "The Intuition of the Future: Utopia and Catastrophe in Octavia Butler's 'Parable of the Sower.'" Novel: A Forum on Fiction, vol. 35, no. 2-3, 2002, pp. 299-311. 
Pilgrim, David. “Jim Crow Museum Academic Resources.” Academic Resources - Jim Crow Museum - Ferris State University, 2000, www.ferris.edu/HTMLS/news/jimcrow/academics/index.htm.

Pilkington, Ed. "Will justice finally be done for Emmett Till? Family hope a 65-year wait may soon be over." The Guardian, 25 Apr. 2020, https://www.theguardian.com/us-news/2020/apr/25/emmett-till-long-wait-forjustice. Accessed 6 Jul. 2020.

Radstone, Susannah. "Trauma Theory: Contexts, Politics, Ethics.” Paragraph, vol. 30, no. 1, 2007, pp. 9-29.

Rayson, Ann. “George Schuyler: Paradox among 'Assimilationist' Writers.” Black American Literature Forum, vol. 12, no. 3, 1978, pp. 102-106.

Retman, Sonnet H. "Black No More: George Schuyler and Racial Capitalism." PMLA, vol. 123 , no. 5, 2008, pp. 1448-1464.

Richard, Thelma Shinn. "Defining Kindred: Octavia Butler's Postcolonial Perspective." Obsidian III, vol. 6-7, 2005, pp. 118-134.

Riggs, Marlon T, et al. Ethnic Notions. 2004.

Rock, Christopher J. Interview by Charlamagne tha God, Angela Yee, and DJ Envy. The Breakfast Club, 25 Sept. 2020, https://www.youtube.com/watch?v=0OMdMK9y4Ao. Accessed 27 Sept. 2020.

Rothstein, Richard. The Color of Law: A Forgotten History of How Our Government Segregated America. 1st ed., Liveright Publishing Corporation, a Division of W.W. Norton \& Company, 2017.

Said, Edward W. Orientalism. Vintage Books, 1978.

Schuyler, George S. “The Negro-Art Hokum.” Nation, 16 June 1926, pp. 662-63.

---. Black No More: Being an Account of the Strange and Wonderful Workings of Science in the Land of the Free, A.D. 1933 - 1940. Unabridged republ. [d. Aug.] publ. in 1931 by Macaulay, New York ed., Dover Publ, 2011.

Selfa, Lance. "Slavery and the Origins of Racism." International Socialist Review, Vol. 26, 2002, https://isreview.org/issues/26/roots_of_racism.shtml. Accessed 8 July 2019 .

Smith, Valerie. "Form and Ideology in Three Slave Narratives." Incidents in the Life of a Slave Girl: Contexts, Criticism. Ed Nellie Y. McKay and Frances S. Foster. W.W. Norton, 2001, pp. 222-236. 
Soja, Edward W. Thirdspace: Journeys to Los Angeles and Other Real-and-Imagined Places. Blackwell, 2014.

Spaulding, Timothy. Re-Forming the Past: History, the Fantastic, and the Postmodern Slave Narrative. Ohio State University Press, 2005.

St. Clair, Robert N and Ana C.T. Williams. "The Framework of Cultural Space.” Intercultural Communication Studies, vol. 17, no. 1, 2008, pp. 1-14.

Teverson, Andrew and Sara Upstone. Postcolonial Spaces: The Politics of Place in Contemporary Culture. Palgrave Macmillan, 2011.

Thomas, Brook. Plessy V. Ferguson: A Brief History with Documents. Bedford Books, 1997.

Thomas Jefferson Foundation, Inc. "Thomas Jefferson and Sally Hemings: A Brief Account." Monticello, Home of Thomas Jefferson., Thomas Jefferson Foundation, Inc., Feb. 2003, www.monticello.org/thomas-jefferson/jefferson-slavery/thomasjefferson-and-sally-hemings-a-brief-account/. Accessed 6 Jul. 2020.

Tiffin, Chris and Alan Lawson, eds. De-Scribing Empire: Post-colonialism and Textuality. Routledge, 1994.

Veeser, H. Aram. The New Historicism Reader. Routledge, 1994.

Visser, Irene. "Trauma Theory and Postcolonial Literary Studies." Journal of Postcolonial Writing. Vol. 47, 2011, pp. 270-282.

---. "Decolonizing Trauma Theory: Retrospect and Prospects." Humanities, vol. 4, no. 2, 2015, pp. 250-265. Accessed 29 Aug. 2020.

Wald, Gayle Freda. Crossing the Line: Racial Passing in Twentieth-Century U.S. Literature and Culture. Duke Univ. Press, 2000.

Wall, Cheryl A. "Passing for What? Aspects of Identity in Nella Larsen's Novels." Black American Literature Forum, vol. 20, no. 1-2, 1986, pp. 97-111.

Wallace, Cynthia. "Chimamanda Ngozi Adichie's Purple Hibiscus and the Paradoxes of Postcolonial Redemption." Christianity and Literature, vol. 6, no. 3, 2012, pp. 465-83.

Weiner, Melissa F. “Towards a Critical Global Race Theory.” Sociology Compass, vol. 6, no. 4, 2012, pp. 332-350.

Weinstein, Arnold L. Nobody's Home: Speech, Self, and Place in American Fiction from 
Hawthorne to Delillo. Oxford University Press, 1993.

Womack, Ytasha. Afrofuturism: The World of Black Sci-Fi and Fantasy Culture. $1^{\text {st }}$ ed., Lawrence Hill Books, an Imprint of Chicago Review Press, 2013.

Worley, Sam. "Solomon Northup and the Sly Philosophy of the Slave Pen." Callaloo, vol. 20, no. 1, 1997, pp. 243-259.

Yancy, George. Black Bodies, White Gazes: The Continuing Significance of Race in America. 2nd ed., Rowman \& Littlefield, 2017.

Young, Harvey. Embodying Black Experience: Stillness, Critical Memory, and the Black Body. University of Michigan Press, 2010.

Young, Robert J. C. Postcolonialism: A Very Short Introduction. Oxford Univ. Press, 2007. 


\section{APPENDIX}

\section{Black Claustrophobia}

Ahmad had never seriously dated a white girl. He'd been friendly to them. And he was extra aware of them when they came in close proximity. But on this early evening in May, with slight winds whispering through the maple trees nearby, he wondered about the impact of his new, more than friendly relationship. Ahmad was a tall, slim, seventeenyear-old Black boy with serious eyes, calm with a dignified air. He sat on his grandmother's front porch—she was known to all as Ms. Pat—gazing at the elderly passersby, trying to settle the butterflies in his stomach, trying to convince himself that this was just another date with his girl, Katie. That fact that it was the prom should not matter, and her whiteness was still insignificant to him but how others would be affected by it weighed on him. Almost everybody from school would be at the prom. Public dates with her could be nauseating. He pulled in a relaxing deep breath. Not tonight, he thought, this one had to be special. People-gazing kind of helped at the moment. Better to be doing the gazing than to be the gazed upon. He was waiting to go meet up with Katie and taking a break from entertaining his two younger cousins, who were inside taking their own needed quiet break from one another. Too many fights over who got to be first. So, Ahmad was watching, waiting, and anticipating. His grandmother's neighborhood was its usual active self behind closed doors. Few people outside, but lots of light and activity visible through the windows. Ms. Pat's neighborhood was a 
collection of townhomes built to house active senior citizens in suburban Atlanta, and like most communities for miles around, it was predominantly Black.

Ahmad watched Mr. Greene in the townhouse across the street struggling for ten whole minutes to get his large body into his old Buick; Ahmad thought at least three times about going to help. But how would you ask to help someone in that kind of predicament without offending them, he wondered? Mr. Greene seemed so determined that he decided against it. He liked being useful. Better than being stuck in the way, in the middle of pointless arguments. There was always something for his parent to argue about these days.

Right now, his dad was making it a routine of not engaging his mother in her new house, the one he no longer shared with her. When he stopped by speak to Ahmad, he preferred to wait on the doorstep, back turned, staring off in the distance until Ahmad joined him outside. He didn't treat this home, or any place where his mom was living, as a safe space anymore. With his mother in her new house, Ahmad had watched the tension develop its new ubiquitous place in her face; it became even more pronounced if he made the mistake of complimenting his dad in her presence. The face of divorce. Didn't want to see that right now. A break from them is a good thing, he thought. Ms. Pat's house was his stability now.

Ahmad felt the tangerine sun's presence as it made its final salute; at this part of the day, it was shining but not squeezing all of the coolness from the world beneath it. Good to go run, he thought. In about two hours, he would be with Katie. He looked over to see that Mr. Greene had finally managed to pull-off after sitting in his car to warm it 
up for about fifteen more minutes. Good thing he didn't have a garage, Ahmad thought, that'd be a tough way to go out, stuck in your car.

Ahmad smiled to himself, again thinking of Katie; she wasn't the first not-Black girl that he had dated. There was Jeannette Gonzalez back in the $8^{\text {th }}$ grade. They would meet before and after they dressed out for gym class. She was a walking glow stick in her leggings with their blues, purples, pinks and oranges; always bright and vibrant. Her brightness was captivating. When they started talking, it was mostly about their school days, what they had for lunch, and what they were doing after seventh period. Her parents were strict, so she could never come outside when she was at home unless she had a chaperone, which was never because her older brother and sister were always working at their restaurant jobs. He rode his bike to Jeannette's house once after school so they could spend more time together, but she was on restriction so basically trapped in her bedroom again. She waved at him from her window though. From that distance, the window panes almost appeared to be frosted. There was no way that they could see each other clearly. Ever. And so they eventually stopped trying.

That was five years ago. Today, he was going to the prom with Katie Morrison, his girlfriend. They would go to The Optimist on Howell Mill Road after to eat. Best restaurant to take someone you want to impress in Atlanta. Well, that's what a friend had told him. He said it was the quickest way to get a girl "to crush hard and then let you get in." Ahmad was okay with being slow with the getting “in”, but of course he wouldn't tell anyone.

Tonight, he was prepared to spend all of his hard-earned cash from soccer refereeing on their meal. His plan was the "indirect, direct approach" always. He would 
order the spicy charred octopus as the appetizer and suggest the Maine lobster roll to her and order the shrimp burger for himself. Too bad the lobster couldn't come from Savannah, he thought. It'd be a lot cheaper from water just a few hours away.

From the left-corner of his eye, Ahmad could see Ms. Rose across the street opening her door, one hand on her four-wheel rolling walker and another on the leash of her asthmatic terrier, Princess. He looked at his watch and begged the time. "Come on", he said. He still had an hour and a half to go. Princess usually sounded like someone trying to squeeze the last drops of red ketchup out of a bottle. A sad life, he thought. That's the only way she knew how to breathe. They slowly rolled by. Princess gasping for air. Mrs. Rose smiling. She couldn't hear anything anymore, so Ahmad just waved and smiled back. He'd become good at forcing smiles. His phone vibrated in his hand.

[Text Message] Katie: almost done n abt 2 hrs

Ahmad: ok, i'll b there.

The wait was almost over. He guessed it took a while to perfect her "dirt" look. This was the new style-people in dingy clothes and girls wearing brown make-up strategically applied above the eyes and on the cheeks. Ahmad thought it worked for her, made her look she was always coming from some runway. The way he felt, she should could wear anything really. That was her freedom. He just wanted to be with her alone, any place; the cost of the meal and the time he had to wait to pick her up didn't matter. He'd always shown her that he liked her, but wasn't too quick to say it, the indirectdirect, not so visible, approach. Tonight might be different.

Ahmad and Katie had been friends first on the swim team in the tenth grade. The butterfly was her best stroke, and his was the freestyle. She helped out for a while as a 
timer on the team. That's how he knew she was curious about him. He saw her watching him instead of the clock a few times. At summer practices, they'd discuss senior year, her plans, and how ready he was to go off to college. Her parents were allowing her to take a break year abroad before starting college. She wanted to get to know Costa Rica. He had asked his mother what she thought about him taking a break year. She said, "Don't get any ideas. The only breaks you'll know begin with summer and spring."

The freedom with which Katie moved through the world was one of the reasons why he thought his mom wouldn't see Katie or didn't want to see her. She knew how to recognize someone. She said "it's dangerous for you to get ideas about being that free." He asked, "What's wrong with that?"

She said, "It just makes the inevitable fall that much more painful."

She was always seeing limits, Ahmad thought. He saw that as her new postdivorce outlook.

The other reason, he believed, his mom didn't like Katie was because she was white, just like his dad's new wife. In her eyes, his interest in Katie was a failure on her part to teach him how to love himself and his brown skin. She wanted him to be a proud Black man. To that end, she spent years working to get his two younger sisters and him into DeKalb County's gifted and talented program—only a select few were fortunate enough to win the lottery and gain entrance. His school had given him exposure to people from all kinds of cultural backgrounds. That didn't faze her. She spoke to him about the beautiful Black woman just like his sisters and her that he would one day marry. That declaration was always coupled with a redemptive smile. She was seeing his future 
through her own eyes, not his. These were her hopes. Then, the first girl he'd brought home was Katie.

So his mother saw Katie as an interrupter. She was worth his mother's anger though; when he was with Katie, his worries didn't matter. The escapism that she was, was invaluable. And Katie willingly shared her world with him.

That was one of the reasons that she came to his Young and Christian club meetings. She wasn't much into religion. But, she was serious about promoting peace, so she was willing to listen. The club met in the summer to do service projects. They passed out grocery bags of various food items to those in need. She was glad to help with the food drives too. She came once in a t-shirt that read, "1969 peace and love," in goldfaded letters. She handed out bags of groceries, and he heard her tell a few of them, "remember everything will fall into peace." Ahmad loved that she didn't see color. And she could be comfortable anywhere.

"Ahmad, the boys and I are getting ready to make cookies. You wanna help?" Ms. Pat called through the screen door from the kitchen.

"No, grandma. Ima go for a quick run. I need to go pick up my friend soon." "Okay, on your way back in, ask Mrs. Clara, next door if she needs anything. She may want you to run up to the store and get her some eggs. If you don't, she'll be asking for mine or trying to get somebody to bring her a plate at breakfast tomorrow."

“Okay, I will.” Ahmad knew without even looking that Mrs. Clara was sitting near her living room window and could hear everything that Ms. Pat had said. Ms. Pat knew it too. He grinned. Ms. Pat was bold always. 
Stretching his arms and legs, Ahmad checked his watch and looked off in the distance. He enjoyed this quiet break from his cousins too. Tariq and Kenule "Kenny" were three years apart. Kenny was older but with his Asperger's, the age difference didn't really matter. Ms. Pat loved having her grandsons together, her granddaughters— not so much. They were too disgruntled, she would always say now that his sisters were teenagers too. Often, his sisters felt the weight of Ms. Pat's disdain for women. But her grandsons, like all the men in her presence she wanted to make them feel special. “Always make a welcoming space for your future husbands”, she'd tell his sisters.

This was the first time Kenny was in town for a visit without his parents. He could finally negotiate airplane travel as an unaccompanied minor. Two hours of recorded footage of himself playing video games had done the trick. How his parents stumbled on that was a wonder, but they never stopped searching for ways to make him comfortable. He was in his own world by himself, but they thought he was missing out on theirs. And one of them called daily to check on Kenny like he was going to somehow get lost in the woods. My people love to fear getting lost in the woods, Ahmad recalled. That's every Black person's nightmare.

Ahmad could see his cousin's head darting back and forth across the window. Kenny's behavior could be unusual sometimes, even though he was high-functioning; he had few friends as well. Most thought he was a seven or eight-year-old boy instead of an eleven-year-old one because he loved action figures and cartoons. He was out of touch with his peers and had trouble identifying the appropriate tone of voice, making eyecontact, and knowing how to talk to people. His meds kept his weight down, so that helped to convince people that he was younger than he was too. 
With Tariq, Kenny had grown to be more social than he was with most people. They fought, they made up, and they negotiated the world. Most of the time when they were together, it was easy to forget that Kenny had Asperger's. And Tariq appreciated having a friend, someone who would forgive him for occasionally flying into fits of rage like his dad. Tariq's mother had been in and out of love with his hot-tempered father, which is why he basically lived with Ms. Pat. Tariq and Kenny needed each other and loved their big cousin, Ahmad, equally as much.

It's funny, Ahmad thought, as he walked along the track adjacent to Ms. Pat's community. He understood Kenny almost as much as anyone. The way he had explained Kenny to a classmate once was that Kenny could literally see the color of someone's soul. Those with souls void of color, he ignored or gravitated away from. Those with souls like his favorite "blue-morpho" butterfly could drown under his attention. With these rare types, his ability to engage on a social level transformed. These were special moments to witness because for Kenny jokes and things that most people got through making common inferences were in Black and white - mostly everything in his world came in Blacks and whites.

But a balloon was red, bright red. A bubble was purple. A videogame was electric pink and only a few people got the opportunity to be recognized by him in this manner. Ahmad believed he was yellow, and Kenny's mom and dad were probably orange, and Tariq was lilac. You could tell when Kenny saw color in something or someone and when he didn't. He gazed like he was seeing a rainbow for the very first time, like witnessing something magical. That was rare because he was in his own world usually, guarded from the overwhelming numbers of colorless people and events. 
That for whatever reason made a whole lot of sense to Ahmad, and that's how he had come to understand his cousin. He remembered his English teacher, Mrs. Roth, saying that some guy in a story was having some sort of metaphysical dilemma in life. He lived in hiding because he could hear people's thoughts and found it difficult to trust anyone. Kenny was that way with souls.

The track was pretty empty when he arrived for his run. Families usually littered the track. Hmm, guess everyone else was preparing for a busy evening too. He saw a helicopter hovering over a section of trees. They must be looking for someone. It reminded him of the Ka-27 naval helicopter he flew in during his young naval cadet training program last summer. That thing was fast, he remembered. That chopper had been fitted to ferry supplies back and forth to the USS Taylor. He looked at his watch again. It was his habit to end any run with an attempt at a $200 \mathrm{~m}$ sprint, he became a future Olympian in his head anytime he stepped on a track. That was the distance that he wanted to run on the track team in the spring. He liked the idea of bragging to the girls in college that he ran the same distance as Usain Bolt. Of course, that he would offer in passing. He nodded his head. The indirect-direct approach. That appeals to all the ladies. He pulled his air pods over his ears and shuffled to Outkast's "Hey Ya" on his phone, his old school, go-to sprint track.

A few quick laps and he was done, he didn't have much time but he didn't need much. He positioned himself at the beginning of the side walk that faced his grandmother's home. He could feel the anticipation welling up in him. One more challenge for the future Olympian, he said. He looked for a clear passage. No elderly 
people in sight. The thought of having to hurdle an old woman brought him a rush of excitement. He saw a police car up towards the entrance of the neighborhood, normal rounds. An old lady had had her purse stolen in the community two months ago. She left it in her car with the door unlocked, easy money for them.

He closed his eyes briefly, pulled in a few drags of air, and counted to three. 1...He smiled, an hour and a half from now he'd be knocking on Katie's front door 2...He would wear his purple shirt with the crisp collar under his suit $3 \ldots$ she would be wearing something sort-of fitted and brown. He flew. His legs struggled beneath him. They were still recovering. His heart was heavy from the pumping. He could see Ms. Pat's door grow closer and closer. This, he thought, could be my fastest time ever. VrroOOOM! Bam! Car doors slamming. Feet shuffling. And a loud rumble from behind.

From his left side, a violent force of energy thrust into him, throwing him off balance, pulling him into the ground. He was confused and disoriented. Am I being mugged? A dark silence clouded his thoughts. He was frozen. He couldn't recall or see clearly. A second ago, he was running. The door, yes, he'd seen the door. Right there. Then he was thrown into the ground. And no one near to help. Someone yelled, "Stay down! On the ground! Arms out! Arms out!" He couldn't speak or scream, but he heard them clearly. His entire body was pained. The impact of it hitting the ground consumed him. He felt his chest cave inward beyond the threshold of its elasticity.

He could taste the bland, bitterness of blood in mouth, before he could feel words escaping his lips. The words so indistinct, disconnected from his cognitive processing. Sets of knees, he felt, in his back. They projected his noises with more force. He was 
yelling from the pain of the knees, the hands all over his person. Searching. These voices - he knew these voices. He heard this sequence of questions before. Do you have any weapons or drugs? Where's your ID? He knew not to challenge. He thought of the Talk with his parents, and his navy de-escalation tactics: be meek, be respectful, don't use humor, comply, and be calm. Am I being arrested? He asked himself. I am being arrested, he concluded quickly. I had to be, he thought, I was someone else to them.

He was in handcuffs. God, make them stop. He shivered at the thought of what happens to the wrong guy. Right now, he thought I'm Kalief. The pain of his body being forced into the ground. He prayed, "My, my name is... Ahmad Martin", he managed to let escape. I don't live in this neighborhood, but I'm... my grandma does. She lives there," he heard himself say.

[Cop radio] 1022- Suspect apprehended at $30^{\text {th }}$ and Broadway. Over

"Shit," one cop said, then grabbed the radio to respond.

"Message received. 10-4."

He felt the two officers pull him up.

"Why were you running from us?" the female cop asked.

He licked the blood from his lips. "I was running sprints from the track. I didn't see you."

"So you didn't see us up the hill? We saw you look in our direction and take off," the male cop interjected.

"No, sir, I didn't."

“How old are you, Ahmad?" the female cop asked.

"I'm 17, ma'am. I'll be a senior this year at North Druid." 
"Good school," the female cop replied. "I'm Officer Mitchell and this is Officer Jones.

And we've been searching this area for a robbery suspect wearing about the same color blue shirt that you have on."

Ahmad looked down at his green, clearly green shirt and looked up slowly into her eyes. He wanted to say that his shirt was green, but he knew he shouldn't respond. He barely had the breath. I'm Mrs. Rose's dog. He thought. Sad life.

"We're going to let you go. Where does your grandma live, son, so we can watch you walk to your door?” asked Officer Jones.

He lingered on her use of the word son for a moment.

"Over there," he replied. He couldn't point it out to them. They turned him around and released the handcuffs.

"You walk; we'll watch," she said.

He fixed his gaze toward his grandmother's house and he could see Ms. Pat, Tariq, and Kenny running in his direction. Ms. Pat, laboring as she ran. She was screaming his name as loud and as desperately as she could. Tariq and Kenny were not too far behind, hesitant to reach Ahmad before Ms. Pat. Kenny held his ears and cried out "stop hurting, Ahmad!"

Damn, Ahmad thought, what had he seen? Ahmad knew that look on Kenny's face. It was the same one he wore when he accidentally left his favorite bear on the Marta bus on their way to Lenox mall. Mr. Chubb was his best and only friend. Then, he had to watch the bus drive off never to see Mr. Chubb again. Ahmad believed that Kenny saw 
the color of pain that day. He wondered now what that color was; he wished he didn't already know the answer.

[Text Message] Katie: where ru?

Ahmad: sry. somthin came up. 


\section{CURRICULUM VITA}

NAME: $\quad$ Saleema Mustafa Campbell

ADDRESS: 1044 Running Brook Drive

Lawrenceburg, KY 40343

DOB: $\quad$ St. Petersburg, Florida - January, 51981

EDUCATION

\& TRAINING: $\quad$ B.A., African American Studies and Journalism

Emory University

1999-2003

M.A.T, English Education

Agnes Scott College

2005-07

M.A., Special Education, LBD P-12

Kentucky State University

2009-2011

PROFESSIONAL APPOINTMENTS:

Kentucky State University

English and Developmental Education Instructor

2008-Present

TEACHING \& RESEARCH EXPERIENCE:

ESL 085 Fundamentals of English for Foreign Speakers

ENG $088 \quad$ College Reading

ENG 089 Basic Writing I

ENG 099 Basic Writing II

ENG $101 \quad$ English Composition I

ENG 101-R English Composition I/ College Reading

ENG 102 English Composition II

ENG 211 Introduction to Literature

ENG 409 African American Literature

UNV 101 University Orientation

IGS 304 African American Experience

Emory University, Agnes Scott College, and The University of Louisville, Researcher/Research Assistant 
2016-Researched postcolonial literature and environmental issues at the University of the West Indies in St. Augustine, Trinidad and Tobago. This research was a component of my dissertation pre-planning and a project supervised by Dr. Rajack-Talley in the Pan African Studies Department at the University of Louisville. The project was funded by Kentucky State University.

2010 - Researched the history and impact of Grady Memorial Hospital's segregated era. This research was project sponsored by the Transforming Community Project of Emory University and Dr. Leslie Harris.

2007-Worked with Dr. Willie Tolliver at Agnes Scott College on Deconstructing Will Smith: Theorizing Race, Celebrity, and Masculinity. This research explored the connection between Will Smith, the cultural icon, and early $20^{\text {th }}$ century black caricatures.

2003 - Researched student activism which led to the formation of the African American Studies at Emory University. Research was integrated into the University Special Collections Archives

AWARDS: $\quad$ Scholarships for Education and Economic Development (SEED) program Service Award Kentucky State University 2009

5-Year Service Award

Kentucky State University 2013

Outstanding Community Service Award Kentucky State University 2014

10-Year Service Award Kentucky State University 2018

PROFESSIONAL SOCIETIES:

Kentucky Education Association (KEA) 
National Education Association (NEA)

Modern Language Association (MLA)

Alpha Delta Kappa Xi Chapter (Organization of Female Educators)

\section{NATIONAL MEETING PRESENTATIONS}

Mustafa-Campbell, S. R. (2016, November). African Female Authorship and Expanding the

African Literary Canon. Panel Presentation at the $34^{\text {th }}$ Annual Meeting of the Association of Third World Studies (ATWS) Conference, New Albany, IN.

Mustafa-Campbell, S. R. (2012, October). Diversifying Your High School Portfolio: Dual Enrollment, AP Courses, and Foreign Language. Presentation at the $7^{\text {th }}$ Annual HBCU Conference, Louisville, KY.

Mustafa-Campbell, S. R. (2005, March). Guts and Glory: The Formation of the African American Studies Department at Emory University. Paper presented at the Transforming Community Project Conference, Pine Mountain, GA. 